\title{
WestVirginiaUniversity
}

THE RESEARCH REPOSITORY @ WVU

Graduate Theses, Dissertations, and Problem Reports

2013

\section{Mechanisms of cadmium tolerance in Populus}

Brahma Reddy Induri

West Virginia University

Follow this and additional works at: https://researchrepository.wvu.edu/etd

\section{Recommended Citation}

Induri, Brahma Reddy, "Mechanisms of cadmium tolerance in Populus" (2013). Graduate Theses,

Dissertations, and Problem Reports. 404.

https://researchrepository.wvu.edu/etd/404

This Dissertation is protected by copyright and/or related rights. It has been brought to you by the The Research Repository @ WVU with permission from the rights-holder(s). You are free to use this Dissertation in any way that is permitted by the copyright and related rights legislation that applies to your use. For other uses you must obtain permission from the rights-holder(s) directly, unless additional rights are indicated by a Creative Commons license in the record and/ or on the work itself. This Dissertation has been accepted for inclusion in WVU Graduate Theses, Dissertations, and Problem Reports collection by an authorized administrator of The Research Repository @ WVU.

For more information, please contact researchrepository@mail.wvu.edu. 


\title{
MECHANISMS OF CADMIUM TOLERANCE IN POPULUS
}

\author{
Brahma Reddy Induri
}

\author{
Dissertation submitted to the \\ Eberly College of Arts and Sciences \\ at West Virginia University \\ in partial fulfillment of the requirements \\ for the degree of
}
Doctor of Philosophy
in
Biology

\author{
Stephen P. DiFazio, Ph.D., Chair \\ Carina Barth, Ph.D. \\ Dorothy Vesper, Ph.D. \\ James B. McGraw, Ph.D. \\ Jonathan R. Cumming, Ph.D.
}

\section{Department of Biology}

\section{Morgantown, West Virginia}

2013

Keywords: Cadmium, candidate genes, genotype, heritability, homeostasis, phenotype, phytoremediation, Populus, quantitative trait loci

Copyright 2013 Brahma Reddy Induri 


\section{ABSTRACT \\ Mechanisms of Cadmium Tolerance in Populus}

\section{Brahma Reddy Induri}

Cadmium (Cd), a known carcinogen and one of the leading heavy metal pollutants on a global scale, is released to the atmosphere through various industrial processes such as smelting and mining and other applications including manufacture of batteries and phosphate fertilizers. It causes many deleterious effects in plants, and is harmful to humans through its entry into the food chain. Traditional methods of remediating Cd-contaminated soils, such as excavation and land-filling, are expensive and disturb the natural topography. The emerging method of phytoremediation in which plants are employed to remediate contaminated soils has become increasingly popular because of its cost effectiveness and environmentally friendly characteristics. Populus trees have been extensively studied for their effectiveness in phytoremediation due to their size, productivity, and status as a model organism. My dissertation had the following objectives with the ultimate focus on developing transgenic Populus trees for phytoremediation of Cd contaminated soils: 1.) Map QTL (Quantitative Trait Loci) for Cd tolerance and identify candidate genes for Cd tolerance from QTL intervals, microarray studies and comparative genomics in Populus; 2.) Map QTL for growth, biomass and phenology traits in Populus under greenhouse and field conditions; 3 .) Study the influence of Fe on Cd toxicity effects on growth and biomass traits of Cd tolerant and Cd susceptible Populus genotypes. In Chapter 2, I conducted a greenhouse hydroponic study in which 252 genotypes of a pseudobackcross Populus progeny of family 52-124 were grown and treated with Cd. The phenotypic data recorded on these genotypes were used to identify tolerant and susceptible genotypes, and also for identifying QTL for Cd tolerance. The individuals used in the hydroponic experiment were scored for SNP (Single Nucleotide Polymorphism) markers, and statistical associations were detected between the phenotypic and genotypic data, indicating the presence of QTL. Candidate genes were identified from these QTL intervals using microarray studies and comparative genomic approaches. The same pedigree was grown in a field trial at West Virginia University Agronomy Farm and extensive phenotypic data was recorded on growth, biomass and phenology traits during 2008 and 2009 seasons. In Chapter 3, I compared biomass and phenology trait QTLs across the above hydroponic experiment and from the field study. Extensive phenotypic variation was observed among the growth and biomass traits in both the studies and the change in the QTL positions across experiments and across years suggested changing genetic control on the traits. For Chapter 4, a greenhouse hydroponic experiment was carried out in which a $\mathrm{Cd}$ tolerant and a $\mathrm{Cd}$ susceptible Populus genotype were studied. This experiment was a dosage study with two levels $(0 \mu \mathrm{M}$ and $25 \mu \mathrm{M})$ of $\mathrm{Cd}$ and two $(0$ and 100 $\mu \mathrm{M})$ levels of Fe. All of the treated plants were examined for Cd toxicity effects under high $\mathrm{Fe}$ and Fe deficiency conditions on growth and biomass traits. This experiment demonstrated that high $\mathrm{Fe}$ conditions mitigated the toxic effects of $\mathrm{Cd}$, and that this effect was more pronounced in the $\mathrm{Cd}$ susceptible genotype than in the $\mathrm{Cd}$ tolerant genotype. In the future, the candidate genes identified from these studies will be functionally characterized using transgenic approaches and tested for their production and phytoremediation capabilities under greenhouse and field trials. My research has therefore laid the groundwork for the improvement of Populus as a crop for biofuels production and phytoremediation. 


\section{DEDICATED TO}

My Beloved Parents - Yellamanda Reddy and Indira 


\section{ACKNOWLEDGEMENTS}

First, I would like to sincerely thank my advisor, Dr. Stephen DiFazio, for the opportunity to work in his lab as his first graduate student. I also thank him for his mentorship, wisdom, unfaltering support, commitment, time and effort towards my dissertation research. I definitely believe that he made me a competent and independent researcher than usually I am. His unmatchable curiosity towards science stimulated me to become a better researcher. His training on scientific values especially on scientific integrity enabled me to understand the subtle nuances of science. I would also like to thank my committee members Dr. Jonathan Cumming, Dr. James McGraw, Dr. Carina Barth and Dr. Dorothy Vesper for their technical expertise, encouragement, and equipment support throughout the dissertation research process. Their helpful reviews of my research proposals and this dissertation strengthened my research. I would also like to thank my former committee member Dr. Benoit Van Aken for his support and for serving in my committee. I thank all my committee one more time for their timely inputs and guidance at every stage of my degree including qualifying examinations.

I would like to thank Dr. Jonathan Cumming for letting me use the spectrophotometer. I would like thank all the undergraduates from the labs of Dr. DiFazio and Dr. Barth, who helped me in changing the hydroponic solutions and recording phenotypic data in greenhouse hydroponic study and grinding of leaf samples. I would also like to thank Dr. Dorothy Vesper for her generous help in letting me use their microwave digester. I want to thank Dr. Louis McDonald from the Davis College of Agriculture, WVU for his help and guidance regarding cadmium measurements by ICP. I would like to thank Dr. Gancho Slavov for his brotherly affection, suggestions in both personal and professional life, and also for his statistical expertise. I am thankful to Dr. Danielle Ellis and Dr. Hao Ma for their excellent ideas and advice. I would like to thank my labmates - Mindie Funke, Adam Hnatkovich, Hari Chhetri, Rose StricklandConstable, Eli Rodgers-Melnick and Luke Evans for their friendship and support throughout all these years. I also thank Patricia Lutsie and Wendy Sites for their support and advice.

I would like to thank my parents Yellamanda Reddy and Indira for their constant support, encouragement and their motivation which enabled me to focus on my successful completion of dissertation. I would also like to thank my brother, Ramalinga Reddy and his wife, Kauvery for their support and help throughout my career. I thank my sister Nandini for her support and love throughout my studies. My niece Vindhya Reddy made this whole journey an exciting one. I would also like to thank my friends Usha Kiran Reddy, Keerthi Reddy, Veerakishore Reddy, Sreemohana Reddy, Raja Kesari, Vijay Reddy, Jyothsna Reddy, Vasavi Reddy, Brahma Reddy Vemula, Lakshmi Priya, Cherry, Soumit, Dipen, Anitha, Sunitha, Anji Reddy, Malliswari, Malleswari, Kavitha, Vijay Reddy, Ramesh Reddy, Dhiraj, Shalaka, Gnanesh, Mounika, Rachitha, Rajesh, Sunitha, Vivek, Nitin, Prateek, Monica, Rutika Bhapkar, Sravanthi Reddy, Manish, Anji Reddy, Sudha, Srikanth, Sirisha, Naani and Vinod. Being an ardent lover of sports, I would like to thank the Mountaineers for making this whole journey a memorable one with their performances. I thank my villagers for their moral support. I would like to thank the Department of Biology for their continued support and funding through Teaching Assistantships throughout my doctoral studies which enabled me to complete my degree in a timely fashion. Funding for this research was provided by WVU EPSCOR, WVU ARTS, WVU Environmental Center, WVU Research Corporation. Research and Dissertation Scholarships from the Eberly College and Department of Biology were also greatly appreciated. 


\section{TABLE OF CONTENTS}

MECHANISMS OF CADMIUM TOLERANCE IN POPULUS

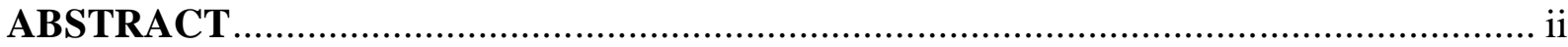

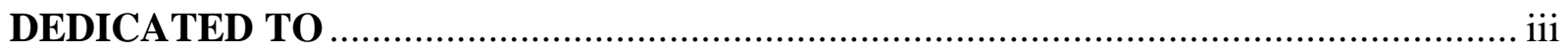

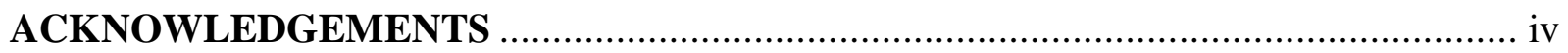

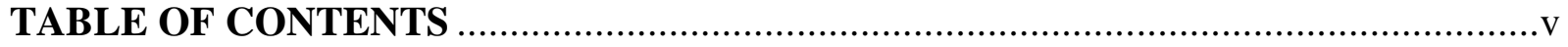

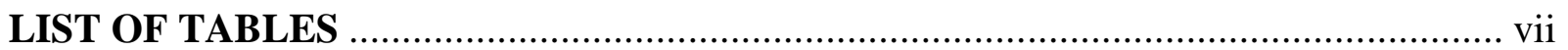

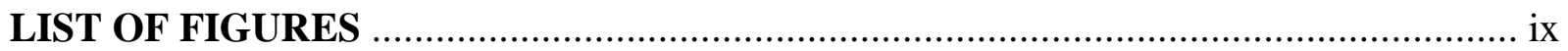

CHAPTER I: GENERAL INTRODUCTION .........................................................

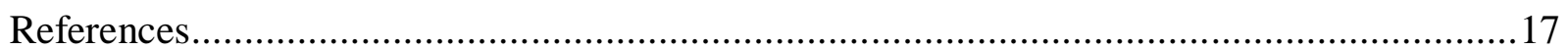

CHAPTER II: IDENTIFICATION OF QUANTITATIVE TRAIT LOCI (QTL) AND CANDIDATE GENES FOR CADMIUM TOLERANCE IN POPULUS.............................35

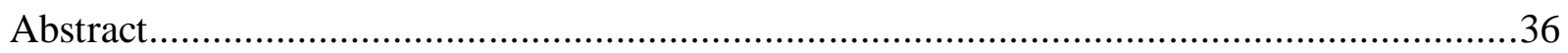

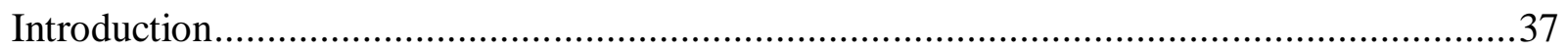

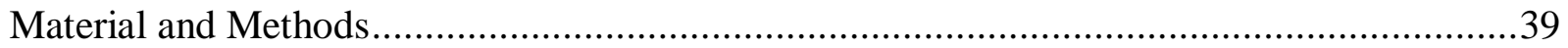

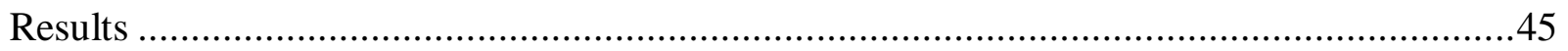

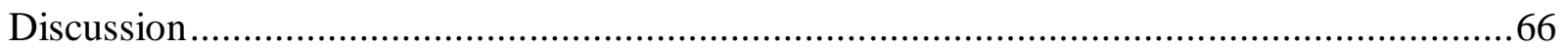

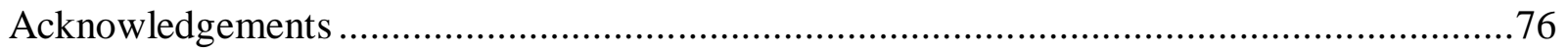

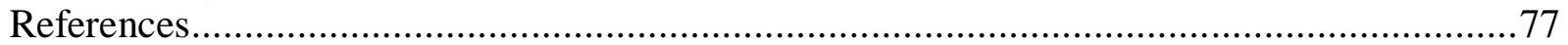

CHAPTER III: QUANTITATIVE TRAIT LOCI FOR GROWTH, BIOMASS AND

PHENOLOGY TRAITS IN POPULUS UNDER GREENHOUSE AND FIELD

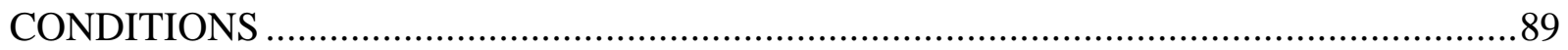

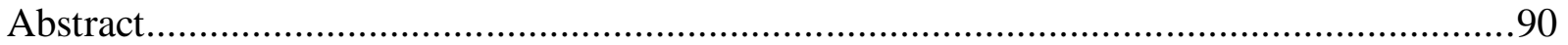

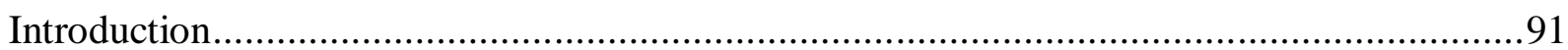

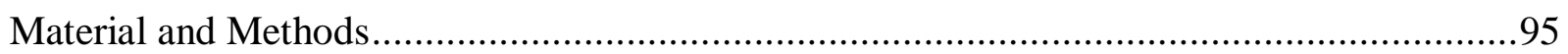

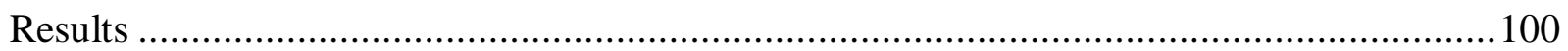

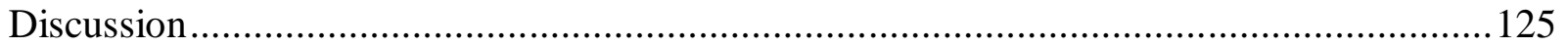

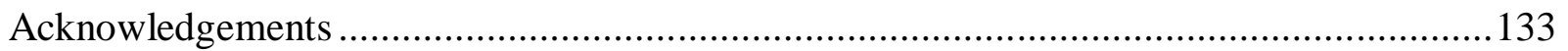

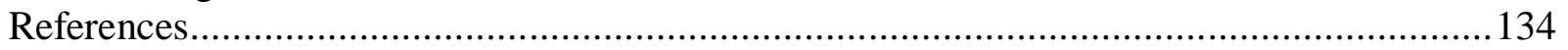

CHAPTER IV: INFLUENCE OF FE ON CD TOXICITY ON GROWTH AND BIOMASS TRAITS OF Cd TOLERANT AND Cd SUSCEPTIBLE GENOTYPES OF POPULUS......140 


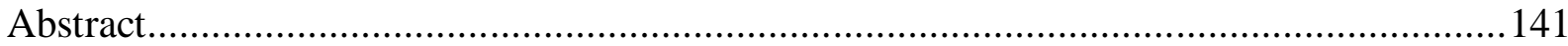

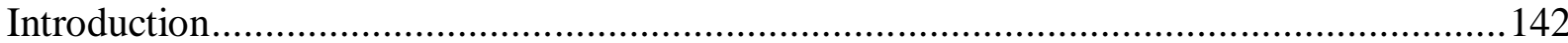

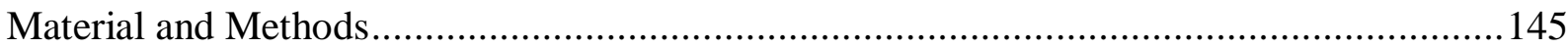

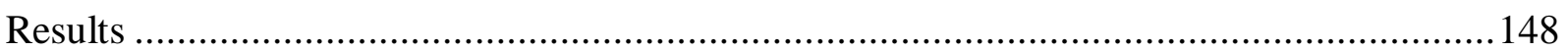

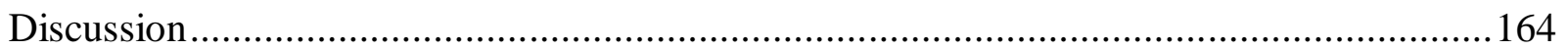

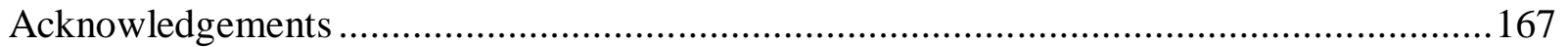

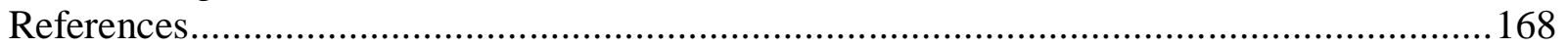

CHAPTER V: GENERAL CONCLUSIONS ....................................................... 174

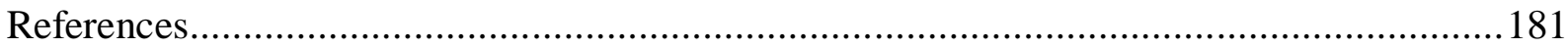

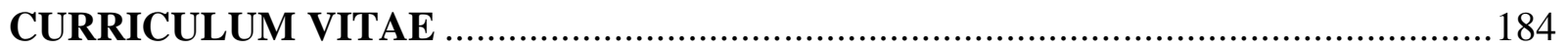




\section{LIST OF TABLES}

Table 2.1. Summary statistics and heritability estimates for total dry weight and other measured traits along with their variance components.

Table 2.2. Results of ANOVA for traits measured in the greenhouse hydroponic study that showed significant differences between $\mathrm{Cd}$ and control conditions.

Table 2.3. Linkage group (LG), QTL positions, Logarithm of Odds ratio (LOD) scores, Percent Variation Explained (PVE), and direction of effect of each QTL are given under the control (C), Cadmium treated $(\mathrm{Cd})$ conditions. .50

Table 2.4. Genetic (above diagonal) and phenotypic correlations among the variables measured.

Table 2.5 Paired correlations and their ' $p$ ' values estimated by the REML method.... .53

Table 2.6. Cd tolerance candidate genes in QTL intervals that also showed altered expression levels in the microarray experiment. Corresponding Arabidopsis genes were identified based on best reciprocal blast hits and the putative functions were derived from the TAIR 9 annotation. Fold Change is the ratio of normalized expression levels under $\mathrm{Cd}$ versus control conditions. ns, Not significant with false discovery rate of 0.05 .

Table 2.7. Candidate genes identified from the QTL intervals with no detected change in expression in response to $\mathrm{Cd}$ treatment.

Table 3.1. List of traits measured in the field trial. .105

Table 3.2. Clonal means, variance components, and heritabilities for all measured traits in the greenhouse hydroponic study. Values in parentheses are Standard Deviations. 106

Table 3.3. Mean and Standard Deviation (SD) estimates for all the measured traits at the end of 2008 and 2009 in the field.

Table 3.4. Heritability estimates for field traits measured in 2008 and 2009 growing seasons. 108

Table 3.5. Phenotypic (below diagonal) and genetic correlations (above diagonal) among greenhouse traits estimated by REML method. All the correlations were significant except with rooting dates.

Table 3.6. Phenotypic (below diagonal) and genetic (above diagonal) correlations among shared genotypes of growing seasons 2008 and 2009 estimated by REML method (Correlations of > $|0.5|$ are in bold).

Table 3.7. Genetic correlations between selected traits measured in the greenhouse and those measured in the field.

Table 3.8. QTL identified for traits measured in the greenhouse study. 
Table 3.9. QTL identified for traits measured in the field study in both growing seasons. .......113

Table 4.1. Lay-out of the Cd-Fe interaction experiment. ............................................ 150

Table 4.2. Treatment effects averaged over ramets. Effects are calculated as the difference in trait values measured before treatments were imposed subtracted from the final trait values.

Numbers in parentheses are standard deviations.

Table 4.3. Leaf dry weight, Shoot dry weight, Root dry weight and Total dry weight averaged over ramets. Numbers in parentheses are standard deviations.

Table 4.4. Summary of results of ANOVA analyses. 'p' values are from the 'F' test.

Corresponding 'p' values for interaction terms are in parentheses. Significant ' $p$ ' values are in bold. 


\section{LIST OF FIGURES}

Figure 2.1. Morphological effects of $\mathrm{Cd}$ treatment in a hydroponic experiment. A) Control roots

B) Cd treated roots C) Control leaf D) Cd treated leaf.

Figure 2.2. A) Genotypic variation in visible effects of $\mathrm{Cd}$ treatment. A) Differences between control (right two plants) and Cd (left two plants) treatments; B) Variation among genotypes under $\mathrm{Cd}$ conditions. Blue bar is $30.5 \mathrm{~cm}$.

Figure 2.3. A) Distributions of the difference in BLUPs of total dry weight between control (C) and Cadmium $(\mathrm{Cd})$ treatments. Genotypes from the left portion of the curve are relatively tolerant of Cd treatment B). Distributions of BLUPs of Cd contents among 240 genotypes and C). BLUPs of Cd contents among 40 genotypes with replication. .58

Figure 2.4 A). Dipiction of variation within the genotypes B). Correlation between independent digestions for the same samples and C) Correlation between $\mathrm{Cd}$ contents and total dry weights among the pedigree.

Figure 2.5. LOD scores from the QTL analysis. A) Total dry weight Control: Linkage Group III, B) Total dry weight Cd: Linkage Group XVI, C) Total dry weight Control-Cd: Linkage group III, and D) Total dry weight Control-Cd: Linkage group XVI........................................60

Supplementary Figure S.2.1. Correlation between ICP-OES and FAAS analyses of leaf Cd...61 Supplementary Figure S.2.2. Matrix of dot plots showing pairwise relationships among all measured traits.

Supplementary Figure S.2.3. Matrix of dot plots showing pairwise relationships among all measured traits with PAR.

Supplementary Figure S.2.4. Venn diagram of number of up-regulated genes from microarray experiment for two genotypes after 24 and 72 hours. Tol, Cd-tolerant genotype (clone 1-183); Susc, Cd-susceptible genotype (clone 182). .64

Supplementary Figure S.2.5. Venn diagram of number of down-regulated genes from microarray experiment for two genotypes after 24 and 72 hours. Codes are as in Fig. S2

Figure 3.1. Overview of A) Greenhouse hydroponic study and B) Field trial on July 28, 2008, one year after establishment.

Figure 3.2. Distributions of BLUPs for A) Shoot length, B) Shoot diameter C) Shoot length/Shoot diameter and D) Total dry weight in the greenhouse study.

Figure 3.3. Transgressive segregation in 52-124 Family demonstrated by the distributions of BLUPs for A) Plant height 2008, B) Plant diameter 2008 C) Plant height 2009, D) Plant diameter 2009 in the field study. 
Figure 3.4. Scatter plots showing correlations among the measured growth traits within the same year in the field study.

Figure 3.5. Scatter plots showing correlations among the measured traits across different years in the field study.

Figure 3.6. Scatter plots showing correlations among the measured phenology traits and relationships to height in the field study.

Figure 3.7. Co-localization of QTLs as demonstrated by superimposition of QTL peaks observed for total dry weight (blue colored) and root dry weight (red colored) at a LOD threshold of 3.0.

Figure S 3.1. Appearance of a terminal vegetative bud in the family 52-124 trial shortly after bud set.

Figure 4.1. Cd-Fe experiment setup. A). Overview of hydroponic experiment prior to $\mathrm{Cd}, \mathrm{Fe}$ treatments. B). Control hydroponic roots before $\mathrm{Cd}$, Fe treatments

Figure 4.2. Effects of $\mathrm{Cd}$ and $\mathrm{Fe}$ on plant height, calculated as the difference in trait values measured before treatments were imposed subtracted from the final trait values. Error bars represent standard error in this and subsequent figures.

Figure 4.3. Effects of $\mathrm{Cd}$ and $\mathrm{Fe}$ on leaf number, calculated as the difference in trait values measured before treatments were imposed subtracted from the final trait values.

Figure 4.4. Average damage rating at different levels of $\mathrm{Cd}$ and $\mathrm{Fe}$.

Figure 4.5. Rooted length observations at different levels of $\mathrm{Cd}$ and $\mathrm{Fe}$. 158

Figure 4.6. Total dry weight of plants at different levels of $\mathrm{Cd}$ and $\mathrm{Fe}$.

Figure 4.7. Leaf dry weight at different levels of $\mathrm{Cd}$ and Fe. .160

Figure 4.8. Shoot dry weight at different levels of $\mathrm{Cd}$ and Fe. 161

Figure 4.9. Root dry weight at different levels of $\mathrm{Cd}$ and $\mathrm{Fe}$. 162

Figure 4.10. Average $\mathrm{Cd}$ content of solutions measured after 3 days for different treatment combinations. 
CHAPTER I

\section{GENERAL INTRODUCTION}




\section{Cd contamination}

Cadmium $(\mathrm{Cd})$ is one of the most widespread pollutants of soil and water in industrialized nations and is one of the major pollution problems on a global scale (Zacchini et al., 2009). Cd was ranked seventh in the top ten priority hazardous substances list of the American Agency for Toxic Substance and Disease Registry (Kamnev and Lelie, 2000). Cd is used in the manufacture of batteries, pigments, plastics, electroplating, and fertilizers and is also released into the atmosphere from mining, smelting and smoke from factories and recycling plants. Cd is being released from coal burning, zinc smelting, application of mineral phosphate fertilizers, vehicular traffic, metal industries, volcanoes, and continental dust released by weathering of bedrock (Pinot et al., 2000; Schützendübel et al., 2002; Zacchini et al., 2009). Application of sewage sludge, $\mathrm{Cd}$ rich phosphate fertilizers and mining are adding $\mathrm{Cd}$ to the soils (McLaughlin et al., 1999, Pinto et al., 2004, Rodriguez-Serrano et al., 2009) which, over time, accumulates in soil and crops risking human health and crop production (Hall, 2002). The cleaning of these contaminated lands by traditional methods such as excavation followed by land filling, soil washing and chemical treatment is ineffective, expensive and not eco-friendly. Because of this, there is a huge demand for eco-friendly and cost effective methods of remediation. Phytoremediation is an emerging cost-effective and environment friendly technology that utilizes plants to remove, transform, or stabilize contaminants including organic pollutants located in water, sediments, or soils (Cherian and Oliveira, 2005). Phytoextraction, i.e., removal of heavy metals from the soil and storing them in the harvestable plant parts (Padmavathiamma and Li, 2007), is an important component of phytoremediation. The contaminant is removed from the site permanently by harvesting and subsequent incineration of these plants (Cherian and Oliveira, 2005). 


\section{Cd toxicity on humans}

$\mathrm{Cd}$ is the leading heavy metal pollutant and its worldwide pollution in food production systems and increased movement in soil-plant systems is posing serious threat to human health (Shao et al., 2008). Cd causes many disorders and diseases in humans, and is reported to affect the endocrine, renal, and reproductive systems and is also reported to cause kidney dysfunction, leukemia, and cancer of the lung and prostate (Henson et al., 2004).

\section{Cd effects on plants}

Cd causes many harmful effects on plants and was reported to be the most toxic heavy metal to plants by causing 50\% reduction in the dry weight in some plants (Almeida et al., 2007). Apart from affecting protein structure and membrane lipid composition (Vanassche et al 1990; Ouariti et al., 1997), Cd was found to be toxic even at minute concentrations by developing symptoms such as leaf roll, chlorosis and root and shoot growth reduction (Milone et al., 2003). Cd decreases the photosynthetic activity of plants by disturbing chloroplast ultrastructure (Sandalio et al., 2001) and altering stomatal closure. Apart from affecting the ion and water balance of plants, $\mathrm{Cd}$ has been shown to affect various physiological processes such as photosynthesis, respiration, nitrate assimilation and metabolite accumulation (Solti et al., 2008), transpiration and various cellular processes such as enzyme activity (Smeets et al., 2005). Cd also interferes with the uptake and distribution of other nutrients (Shao et al., 2007; RodriguezSerrano et al., 2009). Cd disturbs iron (Fe) metabolism (Siedlecka and Krupa, 1999; Fodor et al., 2005; Solti et al., 2008). Cd has also been shown to affect the electron transport system, interact with antioxidative defense systems and induce lipid peroxidation (Smeets et al., 2008; Rodriguez-Serrano et al., 2009). 
Developing plants that can tolerate and accumulate toxic levels of $\mathrm{Cd}$ is of utmost importance, considering the harmful effects $\mathrm{Cd}$ has on humans and plants. Some herbaceous plants accumulate higher levels of metals in their cells naturally, but their slow growth rate, annual habit, small stature, low biomass and/or narrow geographic adaptability make them unsuitable for phytoremediation on an operational scale (Eapen and D'souza, 2005). Higher growth rate, easy propagation by cuttings, suitability for replicated trials, wide range of adaptability, high bulk root volume, very high transpiration rate and large stature make Populus an ideal choice for phytoremediation (Rockwood et al., 2004).

Populus is regarded as a model forest tree (Rae et al., 2007; Taylor, 2002; Wullschleger et al., 2002) because of the availability of many genetic tools including marker saturated genetic linkage maps and whole genome microarrays along with the availability of multiple generation pedigrees (Yin et al., 2004). Along with these genetic tools that are beneficial for genetic studies, most importantly, a whole genome sequence is available for Populus (Tuskan et al., 2006), thereby facilitating the identification and isolation of genes that may be important for $\mathrm{Cd}$ tolerance. Cd tolerance is also reported to segregate in the genus Populus (Robinson et al., 2000). Therefore, Populus provides an excellent system both for exploring the basic mechanisms of Cd tolerance, as well as for developing a viable system for phytoremediation. Apart from having ideal phytoremediation characteristics, Populus is currently being employed to remediate soils polluted by atrazine (Burken and Schnoor, 1998), trichloroethylene (Newman et al., 1997), chloroacetanilide herbicides (Gullner et al., 2001), Cd (Robinson et al., 2000), Se (Pilon-Smits et al., 1998) and zinc (Di Baccio et al., 2003). Phytoremediation is increasingly becoming popular because of the low cost and limited funds available for remediating environmental pollution (Pilon-Smits, 2005). Salt et al., (1995) and Robinson et al., (2000) reported a phytoremediation 
cost of $\$ 60,000$ to $\$ 100,000$ per hectare, substantially lower than the cost of traditional methods. Apart from the low costs, the solution with phytoremediation is permanent, has low risk of pollution by leaching and the soil will be fertile (Robinson et al., 2000).

\section{Mechanisms of Cd tolerance and metabolism in plants}

Plants have many mechanisms to cope with the heavy metal stress. Heavy metal tolerance is defined as the ability to survive soil metal concentrations that are toxic to other plants (Hall, 2002). In general, heavy metal tolerance in plants is by either reduced uptake or elevated plant internal sequestration (Yang et al., 2005b; Macnair et al., 2000; Hall, 2002). Plants developed various mechanisms of heavy metal tolerance including chelation of metals in the cytosol by various ligands, such as phytochelatins, metallothioneins, metal-binding proteins, organic acids and amino acids (Yang et al., 2005b; Hall, 2002), by molecular chaperones and metal trafficking, increased expression of heat-shock-proteins (Yang et al., 2005b), storage of heavy metals in vacuoles, epidermal cells and trichomes and enhanced expression of their enzymatic and nonenzymatic antioxidant defense responses (Milone et al., 2003; Zhao et al., 2005), thereby maintaining homeostasis in plant cells.

Different protein families involved in conferring tolerance to heavy metals including $\mathrm{Cd}$ are metal transporters such as heavy metal (or CPx-type) ATPases, natural resistance associated proteins (Nramp), cation diffusion facilitator (CDF) proteins, zinc-Fe permease (ZIP) proteins, other yet to be identified metal transporters (Yang et al., 2005b), increased expression of ABCtype (ATP-Binding Cassette) transporters, vacuolar transporters like $C A X 1$ and $C A X 2$ (Clemens, 2001), ZRT (zinc transporters)- and IRT (Fe transporters) like proteins and cation antiporters (Cherian and Oliveira, 2005). Membrane transporters play an important role in metal uptake and homeostasis as demonstrated in yeast and Arabidopsis (Clemens, 2001). Some plants called 
hyperaccumulators naturally accumulate very high concentrations of heavy metals in their above ground portions (Robinson et al., 2000). Plants having high heavy metal tolerance and very high accumulation rates are of great use in phytoremediation. In fact, the concept of phytoremediation was inspired by them (Chaney et al., 1997).

\section{Mechanisms of Cd tolerance in Populus}

Populus tolerates Cd either by sequestration of Cd into vacuoles (Zacchini et al., 2009) or by reduced translocation from roots to shoots to protect the photosynthetic machinery of the plants (Dos Santos Utmazian et al., 2007). Overexpression of phytochelatins, metallothioneins and antioxidative enzymes conferred Cd tolerance to Populus as shown below. The biochemical and molecular mechanisms of $\mathrm{Cd}$ accumulation and translocation are unknown and are still being investigated by many researchers (Zacchini et al., 2009).

\section{Biotechnological approaches to enhancing Cd tolerance}

There have been many biotechnological efforts to enhance $\mathrm{Cd}$ tolerance levels, including several studies in Populus. Transferring unique genes from plant hyperaccumulators, bacteria, yeast and animals to fast growing and high biomass producing species has been practiced to improve the phytoremediation capabilities by employing genetic manipulation and plant transformation technologies including overexpressions of chelators like phytochelatins, metallothioneins, glutathione enzymes, and various antioxidative enzymes involved in oxidative stress and different metal transporters to improve the phytoremediation potential of many plants (Cherian and Oliveira, 2005).

Populus has been used in remediating various soils contaminated with atrazine, trichloroethylene and selenium. Transgenic Populus, overexpressing $\gamma$-glutamyl-cysteine synthetase ( $\gamma$-ECS), with increased Cd uptake capacity and increased GSH levels, was used for 
remediating heavy metals and herbicide polluted soils (Gullner et al., 2001). Bacterial gene, gsh1, when transferred to Populus, enhanced the tolerance to (Arisi et al., 1997, 2000) and accumulation of $\mathrm{Cd}$ in roots (Rennenberg and Will, 2000). Simultaneous transfer of many genes into appropriate candidate phytoremediation plants will solve the problem of mixed contamination (organic and inorganic pollutants) of soils (Cherian and Oliveira, 2005).

\section{Importance of QTL mapping}

Some phenotypic characters are governed by single genes (qualitative) and some characters are controlled by many genes with cumulative effects and are called quantitative or polygenic characters. These characters are also called complex traits as many genes are involved and the traits show a continuous range of variation and are influenced more by the environment. This is in contrast to qualitative characters, which show discontinuous variation of the phenotype and are influenced more by the genotype compared to the environment (Kearsy, 1998). The discovery of molecular markers is a milestone development in the quest for unraveling the genetic basis/ dissection of complex traits with which we can develop the linkage maps of the pedigree we study, thus providing the basis for QTL analysis (Doerge, 2002). QTLs are the regions in the genome controlling a phenotypic trait of interest.

QTL mapping is a very powerful tool for elucidating the genetic architecture of complex traits (Rae et al., 2008). Information regarding the number, genomic location and individual effects of genes controlling complex traits can be used to unravel their genetic architecture, and thus help in the breeding programs of forest trees (Zhang et al., 2006). By growing pedigrees segregating for a trait of interest one can test for correlations between the phenotypes and the molecular markers (genotypes) to gain an understanding of the molecular basis of complex traits (Wheeler et al., 2005). Identification of the genes underlying the QTL intervals leads to efficient 
selective breeding, and opens up the possibility of using transgenic technology to alter polygenic traits, facilitating discovery of alleles responsible for the process of evolution (Falconer and Mackay, 1996).

Estimation of heritability is one of the first aims in the genetic dissection of a quantitative character (Falconer and Mackay, 1996). Heritability estimates separate the contributions of genetic and environmental variances to the total proportion of variation. Heritability in general can be defined as the proportion of the phenotypic variation in a population that is explained by the differences in the genotypic values of individuals in that population. Broad-sense heritability determines the degree to which an individual's phenotype is controlled by the genotypes whereas narrow-sense heritability determines the degree to which the individuals' phenotype is determined by the actual genes transmitted from their parents (Falconer and Mackay, 1996). Heritability is the reason for degree of resemblance between relatives and it is the proportion of the total variance due to the variation in breeding values (Falconer and Mackay, 1996) and the prediction of genotypic value by the phenotypic value as the most important function of heritability. Heritability will give the strength of correspondence between these two values, thus helping the breeders in estimating the future performance of the population. Broad-sense heritability is the ratio of genotypic variance, $\operatorname{Var}(\mathrm{G})$ to the phenotypic variance, $\operatorname{Var}(\mathrm{P})$. The trait that is being mapped should be under at least moderate genetic control without which the trait cannot be mapped.

QTL mapping of responses to a wide variety of environmental cues enabled researchers to better understand plant responses to the environment (Rae et al., 2007) including salinity (Koyama et al., 2001), drought (Lanaceras et al., 2004), nitrogen supply (Loudet et al., 2003) and soil aluminum concentration (Hoekenga et al., 2003). QTL methodology will give us some 
of the first data on the genomic response and on the underlying genes responsible for $\mathrm{Cd}$ tolerance in Populus. Here, QTL mapping of Cd tolerance will be carried out using an interspecific pedigree.

\section{QTL mapping in forest trees}

QTL analyses in forest trees are very important in that they help in dissecting the genetic architecture of quantitative traits (Wu and Lin, 2006). The linked markers with the QTLs also provide the basis for designing marker assisted selection methods. QTL mapping in forest trees is difficult because a standard QTL methodology will involve a number of experimental crosses, which is time consuming and often impossible in trees. Another important prerequisite of QTL mapping is the presence of sufficient phenotypic variance and marker polymorphism in the population being mapped (Karp et al., 1997; Lynch and Walsh, 1998; Lexer et al., 2004). QTL analysis in unstructured intra-specific populations of trees is not possible because of the rapid decay in linkage disequilibrium between molecular markers and traits in large outbreeding populations (Lexer et al., 2004; Hedrick, 2000). QTL analysis is generally carried out by employing three-generation families such as F2 and backcross from inbred stocks, but lack of inbred lines in forest trees, the long generation times (Hayashi and Awata, 2004; Tulsieram et al., 1992) and inbreeding depression (Verhaegen et al., 1997) of forest trees makes it virtually impossible to create F2 and backcross pedigrees. QTL analysis is, therefore, difficult in forest trees due to lack of multi-generational pedigrees (Tulsieram et al., 1992).

Because of the higher heterozygosity of forest trees than crop plants due to outcrossing, intra- or inter-specific crossing between the individuals leads to substantial segregation due to gene recombination, thus making QTL analysis possible in the full-sib or half-sib (twogeneration) populations of forest trees (Hayashi and Awata, 2004). The pseudo-test cross 
strategy (backcross model) is generally used for construction of linkage maps in forest trees (Hayashi and Awata, 2004). Although most trees do not have multigeneration pedigrees, they do have parents and full sibs or maternal half sibs. Because of this, in the present study, the pedigree is derived from a pseudo-back cross (Grattapaglia and Sederoff, 1994) between heterozygote female parent and homozygous null male parent. This approach has been employed in many mapping studies successfully, e.g., eucalyptus (Grattapaglia and Sederoff, 1994) and also in potato (Gebhardt et al., 1989).

Populus can undergo interspecific hybridization and first generation intercross $\left(\mathrm{F}_{2}\right)$ and first generation backcross $\left(\mathrm{BC}_{1}\right)$ progeny of interspecific hybrids segregate for a wide range of complex traits (Bradshaw and Stettler, 1995; Taylor, 2002). Separate linkage maps are generally constructed for each of the parents by employing two-way pseudo-backcross configuration of markers heterozygous in one parent and homozygous in the other parent (Hayashi and Awata, 2004) and these two linkage maps are combined with the codominant markers segregating in both the parents (Hayashi and Awata, 2004; Wu et al., 2000).

\section{QTL mapping in Populus}

Although there is considerable difficulty in working with forest trees, the Populus genus is a more convenient system than other trees, owing to its widespread distribution in contrasting environments (Rae et al., 2007) and considerable genetic variation (Wullschleger et al., 2005). There have been many QTL studies in Populus for various characters, including leaf morphology and variation (Wu et al., 1997), bud set and bud flush (Frewen et al., 2000), leaf stomatal and epidermal cell development in response under elevated $\mathrm{CO}_{2}$ (Ferris et al., 2002), dormancy related traits (Chen et al., 2002), leaf level productivity traits (Bunn et al., 2004), growth and biomass distribution (Wullschleger et al., 2005), leaf morphology and spring bud flush (Zhang et 
al., 2005), flavonoid biosynthesis (Morreel et al., 2006), wood chemical properties (Zhang et al., 2006), osmotic potential (Tschaplinski et al., 2006), drought resistance (Street et al., 2006), leaf growth and delayed senescence under elevated $\mathrm{CO}_{2}$ (Rae et al., 2006), biomass under elevated $\mathrm{CO}_{2}$ (Rae et al., 2007), and yield in bioenergy Populus (Rae et al., 2008). The present study of QTL mapping for Cd tolerance will provide some of the first data on the genomic regions responsible for Cd tolerance in Populus.

\section{Microarray analysis}

Microarrays are powerful genomics tools developed to unravel differential gene expression within cells. Most importantly, they can facilitate a global view of a gene expression across an entire genome (Jaluria et al., 2007). Based on this expression pattern of the genes from microarrays, potential defense functions or mechanisms can be identified (Miranda et al. 2007). A microarray is defined as a collection of microscopic spots arranged in an array or grid-like format and attached to a solid surface or membrane (Jaluria et al., 2007). Thus, a DNA microarray consists of arrayed series of thousands of microscopic spots called features, each containing picomoles of a specific DNA sequence from a specific section of a gene or other DNA fragment. These spots are called features or probes and are designed in such a way that each probe binds to a specific nucleic acid sequence in the target gene by a process called hybridization (Li et al., 2002). The target sequence, which is bound to the probe, is generally labeled with some signal emitting molecule or dye such as a fluorophore (Butte, 2002). These probes are used to hybridize to fluorescent or chemiluminiscent target cDNA samples under stringent conditions. The resulting intensity of the fluorescence or labeling dye signal from the probe-target hybridization, after scanning, will provide relative abundance of the expression of the specific gene containing the target sequence (Jaluria et al., 2007; Li et al., 2002). Function of 
unknown genes can be identified from the large collection of the reference data that is generated from different mutants, tissues and treatments (Rensink and Buell, 2005). Accessibility, cost efficiency and amenable protocol standardization have made microarray a preferred choice although there are many modern and comprehensive wide genome gene expression technologies (Jares, 2006).

Spotted cDNA arrays and oligonucleotide arrays are the two major classes of arrays and these two arrays basically differ in the arrayed material with spotted cDNA array probes being oligonucleotides, complementary DNA (cDNA), fragments of Polymerase Chain Reaction (PCR) products, expressed sequence tag clones, or long genome cloned fragments using vector or gene specific primers (Jares, 2006) and the probes in oligonucleotide arrays coming from oligonucleotides.

\section{Microarrays in Populus}

Release of the Populus trichocarpa 'Nisqually-1' genome sequence has led to development of many novel genomic tools, including whole genome microarrays to analyze the transcriptome of Populus, which helps in unraveling molecular mechanisms of variation underlying plant growth, development, environmental response, and eventually in understanding adaptation and evolution (Quesada, Li et al., 2008). Several whole-genome oligonucleotide microarrays have been developed for Populus with Oak Ridge National Laboratory and NimbleGen developing the first whole genome oligonucleotide microarray (Yang et al., 2009 unpublished and Tsai et al., 2009). Populus presently has different whole-genome microarray platforms, including NimbleGen (first and second generation), Affymetrix and Agilent microarrays. 
There have been many gene expression profiling studies (Yang et al., 2009, unpublished) using the first-generation Populus DNA microarray, 13K POP1 array developed by Andersson $e t$ al., (2004) to identify potential regulator genes of cambial stem cell identity across the wood forming meristem (Schrader et al., 2004), to identify the genes involved in change in the carbon flow into various cell wall components during wood formation (Andersson-Gunneras et al., 2006), to identify drought response (Street et al., 2006), to better understand environmental and hormonal regulation during dormancy (Druart et al., 2007) and to study auxin-regulated wood formation process (Nilsson et al., 2008). By employing the second-generation Populus DNA microarray, 25K POP2 array, developed by Moreau et al., (2005), transcript profiling has been accomplished to monitor nocturnal gene expression changes in leaf growth of Populus leaf tissue (Matsubara et al., 2005), to drought response in Populus genotypes of mapping population Family 331 showing extreme sensitivity and insensitivity (Street et al., 2006) and in apical bud formation and dormancy induction (Ruttink et al., 2007). Microarray studies were also carried out to study the gene expression changes in young Populus plants that were exposed to gradually increased water deficit for 4 weeks in a greenhouse (Bogeat-Triboulot et al., 2007) and in Populus hybrid plants infected by leaf rust (Miranda et al., 2007). A whole genome microarray analysis was carried out in the present study to understand the molecular mechanisms of $\mathrm{Cd}$ tolerance in two tolerant and two susceptible genotypes of Populus.

\section{Candidate gene identification}

A candidate gene is defined as any gene that has been identified in one organism that is predicted to influence a similar phenotype in another organism (Fitzpatricket al., 2005; Piertney and Webster, 2008). There are different ways to identify candidate genes including forward genetics approaches in which we create mutant phenotypes by using insertional mutagenesis or 
by disrupting a gene function and then studying the phenotypic variation (Grattapaglia et al., 2009). Reverse genetics approaches, such as QTL analysis and association mapping, will help in identifying functionally important loci. Another refined reverse genetics approach is integration of gene expression data (metabolic and peptide data to a particular stress response) with QTL mapping information - called the genetical genomics approach, thereby facilitating the identification of candidate genes. Consolidated QTL positions and the availability of a genome sequence facilitates the identification of candidate genes and this approach has been successful in many plant species for complex traits (Grattapaglia et al., 2009). QTL positional information will be crucial to identify candidate genes in the context of availability of large mapping pedigrees and high throughput genotyping technologies (Grattapaglia et al., 2009). Microarray, i.e., parallel profiling of all genes in a genome, facilitates identification of expression patterns associated with traits of interest (Street et al., 2008). Generally, researchers use these microarray data sets just to shortlist candidate genes. Thus, QTL positional data along with association mapping studies, genome-wide insertional mutagenesis studies, and whole genome microarray studies is an invaluable tool for identification of candidate genes for various phenotypes.

\section{Cd and interaction with other elements}

$\mathrm{Cd}$ has a similar ionic radius to that of some essential macronutrients and micronutrients, including potassium, calcium, magnesium, iron, manganese, copper, nickel and zinc, and is reported to inhibit their uptake and distribution because of competition for binding sites of common transmembrane transporters (Clemens, 2001; Shukla et al., 2008; Rodriguez-Serrano et al., 2009). In fact, mineral nutrient homeostasis disturbance is one of the most important $\mathrm{Cd}$ toxicity effects in plants (Shao et al., 2007; Liu et al., 2003). One of the primary interactions occurs with Fe. Cd disrupts Fe metabolism (Wallace et al. 1992; Siedlecka and Krupa 1999; 
Fodor et al., 2005; Solti et al., 2008) and decreases the shoot Fe content by affecting its translocation from root to shoot in Populus (Fodor et al., 2005; Solti et al., 2008). Siedlecka and Krupa (1999) reported that Cd affecting Fe translocation from roots to leaves as the prominent aspect of Cd-Fe interaction.

Solti et al. (2008) reported that Cd disturbs the Fe homeostasis in Populus. Fe is essential for photosynthesis and chlorophyll biosynthesis. Furthermore, because of its capacity to donate and accept electrons, it functions as a cofactor for many enzymes with important roles in respiration, nitrogen metabolism and DNA biosynthesis (Jeong and Connolly, 2009). A cellmembrane bound transporter transports both Fe and Cd (Shao et al., 2007, Lombi et al., 2002). $\mathrm{Cd}$ treated and Fe deficient plants look similar in their effects on thylakoid structure changes, suggesting an interaction between $\mathrm{Cd}$ and Fe in Populus (Fodor et al., 2005). High Cd concentration results in chlorosis in plants and is associated with decreased translocation of Fe to leaves, thus inducing Fe deficiency (Sarvari et al., 2001; Shao et al., 2007; Solti et al., 2008). Furthermore, competition between $\mathrm{Fe}$ and $\mathrm{Cd}$ ions for uptake by a membrane bound $\mathrm{Fe}$ transporter caused decreased Fe levels in leaves at increased concentrations of Cd (Shao et al., 2007).

Cd toxic effects were recovered by high Fe concentrations (Siedlecka et al., 1997; Fodor et al., 2005; Meda et al., 2006; Shao et al., 2007), suggesting an interaction between the two elements. Thus, Cd sensitivity depends on the concentration of Fe in the medium (Solti et al., 2008). Cd and Fe interaction may vary among the Cd tolerant and Cd susceptible genotypes of Populus. The level of induction of iron transport systems, based on the external Fe concentration, determines Cd uptake in higher plants (Shao et al., 2008). Under Fe deficiency conditions, induction of Cd uptake is stronger, resulting in increased Cd levels in shoots (Shao et al., 2008). 
In the Cd microarray study conducted by DiFazio and Ellis (personal communication), the expression of Fe transporters including Yellow Stripe-Like 5 and Yellow Stripe-Like 8 were significantly overexpressed in the susceptible genotypes, but not the tolerant genotypes suggesting the $\mathrm{Cd}-\mathrm{Fe}$ interaction plays a significant role in contributing to Cd uptake and sensitivity in Populus. In the same study, the genes that were significantly expressed in $\mathrm{Cd}$ susceptible genotypes compared to the tolerant genotypes are NRAMP3, YSL5, YSL8, HMA6 (PAA1), YSL7, YSL5, FRD3, YSL8, and MTP3.

\section{Main Objectives}

1). Map QTL (Quantitative Trait Loci) for Cd tolerance and identify candidate genes for Cd tolerance from QTL intervals, microarray studies and comparative genomics in Populus.

2). Map QTL for growth, biomass and phenology traits in Populus under greenhouse and field conditions.

3). Study the influence of $\mathrm{Fe}$ on $\mathrm{Cd}$ toxicity effects on growth and biomass traits of $\mathrm{Cd}$ tolerant and Cd susceptible Populus genotypes. 


\section{References}

Almeida, A. A. F., Valle, R. R., Mielke, M. S., and Gomes, F. P. 2007. Tolerance and prospection of phytoremediator woody species of $\mathrm{Cd}, \mathrm{Pb}, \mathrm{Cu}$ and $\mathrm{Cr}$. Brazilian Journal of Plant Physiology. 19:83-98.

Andersson, A., Keskitalo, J., Sjödin, A., Bhalerao, R., Sterky, F., Wissel, K., Tandre, K., Aspeborg, H., Moyle, R., Ohmiya, Y., Bhalerao, R., Brunner, A., Gustafsson, P., Karlsson, J., Lundeberg, J., Nilsson, O., Sandberg, G., Strauss, S., Sundberg, B., Uhlen, M., Jansson, S., Nilsson, P. 2004. A transcriptional timetable of autumn senescence. Genome Biology, 5(4):R24.

Andersson-Gunneras, S., Mellerowicz, E.J., Love, J., Segerman, B., Ohmiya, Y., Coutinho, P.M., Nilsson, P., Henrissat, B., Moritz, T., Sundberg, B . 2006. Biosynthesis of cellulose-enriched tension wood in Populus: global analysis of transcripts and metabolites identifies biochemical and developmental regulators in secondary wall biosynthesis. Plant Journal 452:144-165.

Arisi, A.C.M., Noctor, G., Foyer, C.H., Jouanin, L. 1997. Modification of thiol contents in Populus (Populus tremula x P. alba) overexpressing enzymes involved in glutathione synthesis. Planta 203(3):362-72.

Arisi, A. C., Mocquo, B., Lagriffioul, A., Mench, M., Foyer, C. H., Jouanin, L. 2000. Responses to cadmium in leaves of transformed poplars overexpressing $\gamma$-glutamylcysteine synthetase. Physiologia Plantarum 109:143-149.

Beavis, W. D., Smith, O. S., Grant, D., Fincher, R. 1994. Identification of quantitative trait loci using a small sample of topcrossed and F4 progeny from maize. Crop Science 34:882896. 
Bert, V., Meerts, P., Saumitou-Laprade, P., Salis, P., Gruber, W., Verbruggen, N. 2003. Genetic basis of Cd tolerance and hyperaccumulation in Arabidopsis halleri. Plant and Soil 249:9-18.

Bogeat-Triboulot, M.B., Brosche, M., Renaut, J., Jouve, L., Le Thiec, D., Fayyaz, P., Vinocur, B., Witters, E., Laukens, K., Teichmann, T. 2007. Gradual soil water depletion results in reversible changes of gene expression, protein profiles, ecophysiology, and growth performance in Populus euphratica, a poplar growing in arid regions. Plant Physiology 143(2):876-892.

Bradshaw, H. D. and Stettler, R. F. 1995. Molecular-genetics of growth and development in Populus .4. Mapping QTLs with large effects on growth, form, and phenology traits in a Forest Tree Genetics 139(2):963-973.

Bradshaw, H. D., Otto, K. G., Frewen, B. E., McKay, J. K., Schemske, D. W. 1998. Quantitative trait loci affecting differences in floral morphology between two species of monkeyflower Mimulus. Genetics 149:367-382.

Brunner, A.M., Yakovlev, I.A., Strauss, S.H. 2004. Validating internal controls for quantitative plant gene expression studies. BMC Plant Biology 4:14.

Bunn, S. M., Rae, A. M., Herbert, C. S., Taylor, G. 2004. Leaf-level productivity traits in Populus grown in short rotation coppice for biomass energy. Forestry 77:307-323.

Burken, J. G. and Schnoor, J. L. 1997. Uptake and metabolism of atrazine by Populus trees. Environmental Science and Technology 31 5:1399-1406.

Bustin, S. A. 2000. Absolute quantification of mRNA using real-time reverse transcription polymerase chain reaction assays. Journal of Molecular Endocrinology 252:169-193.

Butte, A. 2002. The use and analysis of microarray data. Nat Rev Drug Discov 1:951-960. 
Chaney, R.L., Malik, M., Li, Y.M., Brown, S.L., Brewer, E.P., Amgle, J.S., Baker, A. J.M. 1997. Phytoremediation of soil metals. Current Opinion in Biotechnology 8:279-284.

Charrier, B., Champion, A., Henry, Y., Kreis, M. 2002. Expression profiling of the whole Arabidopsis shaggy-like kinase multigene family by real-time reverse transcriptasepolymerase chain reaction. Plant Physiology 1302:577-90.

Chen, T. H. H., Howe, G. T., Bradshaw, H. D. 2002. Molecular genetic analysis of dormancyrelated traits in Populus. Weed Science 50:232-240.

Chen, J., Xia, X. and Yin, W. 2009. Expression profiling and functional characterization of a DREB2-type gene from Populus euphratica. Biochemical and Biophysical Research Communications 378:483-487.

Cherian, S., Oliveira, M. M. 2005. Transgenic plants in phytoremediation: recent advances and new possibilities. Environmental Science \& Technology 39:9377-9390.

Clemens, S. 2001. Review: molecular mechanisms of plant metal tolerance and homesostasis. Planta 21:457-486.

Courbot, M., Willems, G., Motte, G., Arvidsson, S., Roosens, N., Saumitou-Laprade, P., and Verbruggen, N. 2007. A major Quantitative Trait Locus for cadmium tolerance in Arabidopsis halleri colocalizes with HMA4, a gene encoding a heavy metal ATPase. Plant Physiology 1442:1052-1065..

Cunningham, S. D. and Ow, D. W. 1996. Promises and prospects of phytoremediation. Plant Physiology $110(3): 715-719$.

DalCorso, G., Farinati, S., Maistri, S., Furini, A. 2008. How plants cope with cadmium: Staking all on metabolism and gene expression. Journal of Integrative Plant Biology 50 (10):1268-1280. 
Di Baccio, D., Tognetti, R., Sebastiani, L., Vitagliano, C. 2003. Responses of Populus deltoides $\mathrm{x}$ Populus nigra (Populus x euramericana) clone I-214 to high zinc concentrations. New Phytologist 159:443-452.

Doerge, R.W. 2002. Mapping and analysis of quantitative trait loci in experimental populations. Nature Reviews Genetics 3:43-52.

Dos Santos Utmazian, M.N., Wieshammer, G., Vega, R., Wenzel, W.W. 2007. Hydroponic screening for metal resistance and accumulation of cadmium and zinc in twenty clones of willows and Populus. Environmental Pollution 148:155-165.

Druart, N., Johansson, A., Baba, K., Schrader, J., Sjodin, A., Bhalerao, R.R., Resman, L., Trygg, J., Moritz, T., Bhalerao, R.P. 2007. Environmental and hormonal regulation of the activity-dormancy cycle in the cambial meristem involves stage-specific modulation of transcriptional and metabolic networks. Plant Journal 504:557-573.

Eapen S. and D'souza S.F. 2005. Prospects of genetic engineering of plants for phytoremediation of toxic metals. Biotechnology advances 23:97-114.

Falconer, D. S., Mackay, T. F. C. 1996. Introduction to Quantitative Genetics. Harlow, Essex: Addison Wesley Longman, 464.

Ferris, R., Long, L., Bunn, S.M., Robinson, K.M., Bradshaw, H.D., Rae, A.M., Taylor, G. 2002. Leaf stomatal and epidermal cell development: identification of putative quantitative trait loci in relation to elevated carbon dioxide concentration in poplar. Tree Physiology 229:633-640.

Fitzpatrick, M.J., Ben-Shahar, Y., Smid, H.J., Vet, L.E.M., Robinson, G., Sokolowski, M.B. 2005. Candidate genes for behavioural ecology. Trends in Ecology \& Evolution 202:96-104. 
Fodor, F., Gaspar, L., Morales, F., Gogorcena, Y., Lucena, J.J., Cseh, E., Kropfl, J., Abadía, K., Sarvari, E. 2005. Effects of two iron sources on iron and cadmium allocation in Populus alba L. plants exposed to cadmium. Tree Physiology 25:1173-1180.

Frewen, B. E., Chen, T. H. H., Howe, G. T., Davis, J., Rohde, A., Boerjan, W. and Bradshaw, H. D. Jr. 2000. Quantitative trait loci and candidate gene mapping of bud set and bud flush in Populus. Genetics 154:837-845.

Furnham, A., Johnson, C., Rawles, R. 1985. The determinants of beliefs in human nature. Personality and Individual Differences 6:675-684.

Gebhardt, C., Ritter, E., Debener, T., Schachtschabel, U., Walkemeier, B., Uhrig, H. et al. 1989. RFLP analysis and linkage mapping in Solanum tuberosum. Theoritcal \& Applied Genetics 78:65-75.

Gibson, G. 2002. Microarrays in ecology and evolution: a preview. Molecular Ecology 11: 1724.

Grant, C. A., W. T. Buckley, L. D. Bailey, and F. Selles. 1998. Cadmium accumulation in crops. Canadian Journal of Plant Science 78:1-17.

Grattapaglia, D. and R.R. Sederoff 1994. Genetic linkage maps of Eucalyptus grandis and E. urophylla using a pseudo-testcross mapping strategy and RAPD markers. Genetics 137: $1121-1137$.

Grattapaglia, D., Plomion, C., Kirst, M., Sederoff, R.R. 2009. Genomics of growth traits in forest trees. Current Opinion in Plant Biology 122:148-156.

Gullner, G., Komives, T., Rennenberg, H. 2001. Enhanced tolerance of transgenic Populus plants overexpressing gamma-glutamylcysteine synthetase towards chloroacetanilide herbicides. Journal of Experimental Botany 52:971-979. 
Hall, J. L. 2002. Cellular mechanisms for heavy metal detoxification and tolerance. Journal of Experimental Botany 53:1-11.

Hassan, M. J., Wang, Z., Zhang, G. 2005c. Sulfur alleviates growth inhibition and oxidative stress caused by cadmium toxicity in rice. Journal of Plant Nutrition 28:1785-1780.

Hayashi, T., and Awata, T. 2004. Efficient method for analysis of QTLs using F1 progenies in an outcrossing species. Genetica: 122:173-183.

Hedrick, P.W. 2000. Genetics of Populations. Jones and Bartlett Publishers, Sudbury, MA.

Henson, M. C., Chedrese, P. J. 2004. Endocrine disruption by cadmium, a common Environmental toxicant with paradoxical effects on reproduction. Experimental Biology and Medicine 229:383-392.

Hoekenga, O. A., Vision, T. J., Shaff, J. E., Monforte, A. J., Lee, G. P., et al. 2003. Identification and characterization of aluminium tolerance loci in Arabidopsis Landsberg erecta $\times$ Columbia by quantitative trait locus mapping. A physiologically simple but genetically complex trait. Plant Physiology 132:936-48.

Jaluria, P., Konstantopoulos, K., Betenbaugh, M., Shiloach, J. 2007. A perspective on microarrays: current applications, pitfalls, and potential uses. Microbial Cell Factories $6: 4$

Jares, P. 2006. DNA microarray applications in functional genomics. Ultrastructural Pathology 303:209-219.

Jeong, J., Connolly, E.L. 2009. Iron uptake mechanisms in plants: Functions of the FRO family of ferric reductases. Plant Science 176 (6): 709-714. 
Kamisugi, Y., von Stackelberg, M., Lang, D., Care, M., Reski, R., Rensing, S.A., Cuming, A. C. 2008. A sequence-anchored genetic linkage map for the moss, Physcomitrella patens. Plant Journal 56:855-866.

Kamnev, A.A., Lelie, Daniel van der. 2000. Chemical and biological parameters as tools to evaluate and improve heavy metal phytoremediation. Bioscience Reports 20(4):239-258.

Karp, A., Edwards, K.J., Bruford, M., Funk, S., Vosman, B., Morgante, M., Seberg, O., Kremer, A., Boursot, P., Arctander, P., Tautz, D., Hewitt, G.M. 1997. Molecular technologies for biodiversity evaluation: opportunities and challenges. Nature Biotechnology 15:625-629.

Kearsey, M. J. 1998. The principles of QTL analysis a minimal mathematics approach. Journal of Experimental Botany 49:1619-1623.

Koyama, M. L., Levesley, A., Koebner, R. M. D., Flowers, T. J., Yeo, A. R. 2001. Quantitative trait loci for component physiological traits determining salt tolerance in rice. Plant Physiology 125:406-422.

Lanaceras, J. C., Pantuwan, G., Jongdee, B., Toojinda, T. 2004. Quantitative trait loci associated with drought tolerance at reproductive stage in rice. Plant Physiology 135:384-399.

Lander, E. S., Botstein, D. 1989. Mapping mendelian factors underlying quantitative traits using RFLP linkage maps. Genetics 1211:185-199.

Lexer, C., Heinze, B., Alia, R., Rieseberg, L. H. 2004. Hybrid zones as a tool for identifying adaptive genetic variation in outbreeding forest trees: lessons from wild annual sunflowers Helianthus spp.. Forest Ecology and Management 197:49-64.

Li, X., Gu, W., Mohan, S., Baylink ,D. J. 2002. DNA microarrays: their use and misuse. Microcirculation 9:13-22 
Liu, J. G., Liang, J. S., Li, K. Q., Zhang, Z. J., Yu, B. Y., Lu, X. L., Yang, J. C., Zhu, Q. S. 2003. Correlations between cadmium and mineral nutrients in absorption and accumulation in various genotypes of rice under cadmium stress. Chemosphere 52:1467-1473.

Liu, X., Ma, L., Zhang, J.F., Lu, Y.T. 2004. Determination of single-cell gene expression in Arabidopsis by capillary electrophoresis with laser induced fluorescence detection. Journal of Chromatography B 8082:241-247.

Lombi, E., Tearall, K. L., Howarth, J. R., Zhao, F. J., Hawkesford, M. J., and McGrath, S. P. 2002. Influence of iron status on cadmium and zinc uptake by different ecotypes of the hyperaccumulator Thlaspi caerulescens. Plant Physiology 128:1359-1367.

Loudet, O., Chaillou, S., Merigout, P., Talbotec, J., Daniel-Vedele, F. 2003. Quantitative trait loci analysis of nitrogen use efficiency in Arabidopsis. Plant Physiology 131:345-358.

Lynch, M., Walsh, J.B. 1998. Genetics and analysis of quantitative traits. Sinauer Associates, Sunderland, MA.

Macnair, M. R., Tilstone, G. H., Smith, S. E. 2000. The genetics of metal tolerance and accumulation in higher plants.. Phytoremediation of Contaminated Soil and Water. CRC Press, LLC, 235-250.

Matsubara, S., Hurry, V., Druart, N., Benedict, C., Janzik ,I., Chavarrı,'a-Krauser, A., Walter, A., Schurr, U. 2005. Nocturnal changes in leaf growth of Populus deltoides are controlled by cytoplasmic growth. Planta 223(6):1315-1328.

McLaughlin, M. J., Parker, D.R., Clarke, J.M. 1999. Metals and micronutrients food safety issues. Field Crops Research 60:143-163. 
Meda, A. R., Scheuermann, E. B., Prechsl, U. E., Erenoglu, B., Schaaf, G., Hayen, H., et al. 2006. Iron acquisition by phytosiderophores contributes to cadmium tolerance. Plant Physiology 143:1761-1773.

Milone, M. T., Sgherri, C., Clijsters, H., Navari-Izzo, F. 2003: Antioxidative responses of wheat treated with realistic concentration of cadmium. Environmental and Experimental Botany 50:265-276.

Miranda, M., Ralph, S.G., Mellway, R., White, R., Heath, M.C., Bohlmann, J, Constabel, C.P. 2007. The transcriptional response of hybrid poplar Populus trichocarpa $\mathrm{x} P$. deltoides to infection by Melampsora medusae leaf rust involves induction of flavonoid pathway genes leading to the accumulation of proanthocyanidins. Molecular Plant-Microbe Interactions 207:816-831.

Monteiro, M., Santos, C., Soares, A.M.V.M., Mann, R.M. 2008. Does subcellular distribution in plants dictate the trophic bioavailability of cadmium to Porcellio dilatatus Crustacea, Isopoda? Environmental Toxicology \& Chemistry 27(12):2548-56.

Moreau, C., Aksenov, N., Lorenzo, M., Segerman, B., Funk, C., Nilsson, P., Jansson, S., Tuominen, H. 2005. A genomic approach to investigate developmental cell death in woody tissues of Populus trees. Genome Biology, 64.

Morreel, K., Goeminne, G., Storme, V., Sterck, L., Ralph, J., Coppieters, W., Breyne, P., Steenackers, M., Georges, M., Messens, E., Boerjan, W. 2006. Genetical metabolomics of flavonoid biosynthesis in Populus: a case study. Plant Journal 47:224-237.

Newman, L. A., S. E. Strand, N. Choe, J. Duffy, G. Ekuan, M. Ruszaj, B. B. Shurtleff, J. Wilmoth, P. Heilman and M. P. Gordon. 1997. Uptake and biotransformation of 
Trichloroethylene by hybrid Populus. Environmental Science and Technology 31:10621067.

Nilsson, J., Karlberg, A., Antti, H., Lopez-Vernaza, M., Mellerowicz, E., Perrot-Rechenmann, C., Sandberg, G., Bhalerao, R.P. 2008. Dissecting the molecular basis of the regulation of wood formation by auxin in hybrid aspen. Plant Cell 204:843-855.

Novaes, E., Osorio, L., Drost, D. R., Miles, B. L., Boaventura-Novaes, C. R. D., Benedict, C., Dervinis, C., Yu, Q., Sykes, R., Davis, M. et al . 2009. Quantitative genetic analysis of biomass and wood chemistry of Populus under different nitrogen levels. New Phytologist 182:878-890.

Ouariti, O., Boussama, N., Zarrouk, M., Cherif, A., Ghorbal, M. H. 1997. Cadmium- and copper-induced changes in tomato membrane lipids. Phytochemistry 45:1343-1350.

Padmavathiamma, P. K., Li, L. Y. 2007. Phytoremediation technology: Hyper-accumulation metals in plants. Water, Air, and Soil Pollution 184:105-126.

Piertney, S. B., Webster, L. M. 2008. Characterising functionally important and ecologically meaningful genetic diversity using a candidate gene approach. Genetica.

Pilon Smits, E., M. Desouza, C. Lytle, C. Shang, T. Lugo and N. Terry. 1998. Selenium volatilization and assimilation by hybrid Populus tremula X P. alba. J. Exp. Bot. 49328:1889-1892.

Pilon Smits, E. A. H. 2005. Phytoremediation. Annual Reviews in Plant Biology 56:15-39.

Pinot, F., Kreps, S., Bachelet, M., Hainaut, P., Bakonyi, M. and Polla, B. 2000. Cadmium in the environment: sources, mechanisms of biotoxicity, and biomarkers. Reviews of Environmental Health 15:299-323. 
Pinto, A. P., Mota, A. M., De Varennes, A., Pinto, F. C. 2004. Influence of organic matter on the uptake of cadmium, zinc, copper and iron by sorghum plants. Science of the Total Environment 326:239-274.

Quesada, T., Li, Z., Dervinis, C., Li, Y., Bocock, P.N., Tuskan, G.A., Casella, G., Davis, J.M., Kirst, M. 2008. Comparative analysis of the transcriptomes of Populus trichocarpa and Arabidopsis thaliana suggests extensive evolution of gene expression regulation in angiosperms. New Phytologist 1802:408-420.

Rae, A. M., Ferris, R., Tallis, M. J., Taylor, G. 2006. Elucidating genomic regions determining enhanced leaf growth and delayed senescence in elevated $\mathrm{CO}_{2}$. Plant, Cell \& Environment 29:1730-1741.

Rae, A. M., Tricker, P. J., Bunn, S. M., Taylor, G. 2007. Adaptation of tree growth to elevated $\mathrm{CO}_{2}$ : quantitative trait loci for biomass in Populus. New Phytologist 175:59-69.

Rae, A. M., Pinel, M. P. C., Bastien, C., Sabatti, M., Street, N. R., Tucker, J., Dixon, C., Marron, N., Dillen, S. Y.,Taylor, G. 2008. QTL for yield in bioenergy Populus: identifying G×E interactions from growth at three contrasting sites. Tree Genetics \& Genomes 4:97-112.

Rennenberg, H., Will, B. 2000. Phytochelatin production and cadmium accumulation in transgenic Populus (Populus tremula X P. alba). Sulfur nutrition and sulfur assimilation in higher plants. Bern Paul Haupt:393-398.

Rensink, W. A., C. R. Buell 2005. Microarray expression profiling resources for plant genomics. Trends in Plant Science 1012:603-609.

Robinson, B.H., Mills, T.M., Petit, D., Fung, L.E., Green, S.R., Clothier, B.E. 2000. Natural and Induced cadmium accumulation in Populus and willow: Implications for phytoremediation. Plant soil 227:301-306. 
Rockwood, D. L., Naidu, C. V., Carter, D. R., Rahmani, M., Spriggs, T. A., Lin, C., Alker, G. R., Isebrands, J. G., Segrest, S. A. 2004. Short-rotation wood crops and phytoremediation: opportunities for agroforestry? Agroforestry Systems 61:51-63.

Rodriguez-Serrano, M., Romero-Puertas, M. C., Pazmino, D. M., Testillano, P. S., Risueno, M.

C., Del Rio, L. A., Sandalio, L. M. 2009. Cellular response of pea plants to cadmium toxicity: cross talk between reactive oxygen species, nitric oxide, and calcium. Plant Physiology 1501:229 -243.

Romero-Puertas, M. C., Rodriguez-Serrano, M., Corpas, F. J., Gomez, M., Del Rio, L. A., Sandalio, L. M. 2004. Cadmium-induced subcellular accumulation of $\mathrm{O}_{2}{ }^{-}$and $\mathrm{H}_{2} \mathrm{O}_{2}$ in pea leaves. Plant Cell Environment 27:1122-1134.

Ruttink, T., Arend, M., Morreel, K., Storme, V., Rombauts, S., Fromm, J., Bhalerao, R., Boerjan, W., Rohde, A. 2007. A molecular timetable for apical bud formation and dormancy induction in poplar. Plant Cell 198:2370-2390.

Salt, D.E., Blaylock, M., Kumar, N., Dushenkov, V., Ensley, B.D., Chet, I., Raskin, I. 1995. Phytoremediation - A novel strategy for the removal of oxic metalsfrom the environment using plants. Bio-Technology 13:468-474.

Sandalio, L.M., Dalurzo, H.C., Gomez, M., Romero-Puertas, M.C., Del Rio, L.A. 2001. Cadmium-induced changes in the growth and oxidative metabolism of pea plants. Journal of Experimental Botany 52:2115-2126.

Sanita di Toppi, S. L., Lambardi, M., Pazzagli, L., Cappugi, G., Durante, M., Gabbrielli, R. 1998. Response to cadmium in carrot in vitro plants and cell suspension cultures. Plant Science 137:119-129. 
Sarvari, E., Szigeti, Z., Fodor, F., Cseh, E., Tussor, K., Záray, G. Y., Veres, S. Z., Mészáros, I. 2001. Relationship of iron deficiency and the altered thylakoid development in $\mathrm{Cd}$ treated poplar plants. In Proc. 12th Congress on Photosynthesis:23-25.

Schrader, J., Nilsson, J., Mellerowicz, E., Berglund, A., Nilsson, P., Hertzberg, M., Sandberg, G. 2004. A high-resolution transcript profile across the wood-forming meristem of poplar identifies potential regulators of cambial stem cell identity. Plant Cell 169:2278-2292.

Schützendübel, A., Nikolova, P., Rudolf, C., Polle, A. 2002: Cadmium and $\mathrm{H}_{2} \mathrm{O}_{2}$-induced oxidative stress in Populus $\times$ canescens roots. Plant Physiology and Biochemistry 40:577-584.

Shao, G., Chen, M., Wang, W., Mou, R., Zhang, G. 2007. Iron nutrition affects cadmium accumulation and toxicity in rice plants. Plant Growth Regulation 53:33-42.

Shao, G., Chen, M., Wang, D., Xu, C., Mou, R., Cao, Z., Zhang, X. 2008. Using iron fertilizer to control Cd accumulation in rice plants: a new promising technology. Science in China Series C Life Sciences. 513:245-53.

Shukla, U. C. Murthy, R. C., Kakkar, P. 2008. Combined effect of ultraviolet-B radiationand cadmium contamination on nutrient uptake and photosynthetic pigments in Brassica campestris L. seedlings Environmental Toxicology 236:712-9.

Siedlecka, A., Krupa, Z. 1996a. Interaction between cadmium and iron: accumulation and distribution of metals and changes in growth parameters of Phaseolus vulgaris $\mathrm{L}$. seedlings. Acta Societatis Botanicorum Poloniae 65:277-282.

Siedlecka, A., Krupa, Z. 1996b. Interaction between cadmium and iron and its effects on photosynthetic capacity of primary leaves of Phaseolus vulgaris. Plant Physiology and Biochemistry 34:833-841. 
Siedlecka, A., Krupa, Z., Samuelsson, G., O“ quist, G., Gardestro, P. 1997. Primary metabolism in Phaseolus vulgaris plants under $\mathrm{Cd} / \mathrm{Fe}$ interaction. Plant Physiology and Biochemistry 35:951-957.

Siedlecka, A., Krupa, Z. 1999. Cd/Fe interaction in higher plants - its consequences for the photosynthethic apparatus. Photosynthetica 36:321-331.

Smeets, K., Cuypers, A., Lambrechts, A., Semane, B., Hoet, P., Van Laere, A., Vangronsveld, J., 2005. Induction of oxidative stress and antioxidative mechanisms in Phaseolus vulgaris after Cd application. Plant Physiology \& Biochemistry 43:437-444.

Smeets, K., Ruytinx, J., Semane, B., Van Belleghem, F., Remans, T., Van Sanden, S., Vangronsveld, J., Cuypers, A. 2008. Cadmium-induced transcriptional and enzymatic alterations related to oxidative stress. Environmental and Experimental Botany 63:18.

Solti, A., Gaspar, L., Meszaros, I., Szigeti, Z., Levai, L., Sarvari, E. 2008. Impact of iron supply on the kinetics of recovery of photosynthesis in Cd-stressed Populus glauca. Annals of Botany 1025:771-782.

Street, N.R., Skogstrom, O., Sjodin, A., Tucker, J., Rodriguez-Acosta, M., Nilsson, P., Jansson, S., Taylor, G. 2006. The genetics and genomics of the drought response in Populus. Plant Journal 483:321-341.

Street, N. R., A. Sjodin, Bylesjö, M., Gustafsson, P., Trygg, J., Jansson, S. 2008. A cross-species transcriptomics approach to identify genes involved in leaf development. BMC Genomics, 9:589.

Taylor, G. 2002. Populus: Arabidopsis for forestry. Do we need a model tree? Annals of Botany 90:677-687.

Thomine, S., Wang, R., Ward, J. M., Crawford, N. M., Schroeder, J. I. 2000. Cadmium and 
iron transport by members of a plant metal transporter family in Arabidopsis with homology to NRAMP genes. Proceedings of National Academy of Sciences, USA 97:4991-4996.

Tsai, C. J., Ranjan, P., DiFazio, S. P., Tuskan, G. A., Johnson, V., Joshi, C. P. 2009. Populus genome microarrays. In Genetics, Genomics and Breeding of Crop Plants: Populus. Science Publishers, Enfield, N.H.

Tschaplinski, T. J., Tuskan, G. A., Sewell, M. M., Gebre, G. M., Donald, E. T. I., Pendleyi, C. 2006. Phenotypic variation and quantitative trait locus identification for osmotic potential in an interspecific hybrid inbred $\mathrm{F}_{2}$ Populus pedigree grown in contrasting environments. Tree Physiology 26:595-604.

Tulsieram, L.K.; Glaubitz, J.C.; Kiss, G. and Carlson, J.E. 1992. Single tree genetic linkage analysis in conifers using haploid DNA from megagametophytes. Biotechnology 10:686690.

Tuskan, G. A., S. DiFazio, S. Jansson, J. Bohlmann, I. Grigoriev, U. Hellsten, N. Putnam, S. Ralph, S. Rombauts, A. Salamov, J. Schein, L. Sterck, A. Aerts, R.R. Bhalerao, R.P. Bhalerao, D. Blaudez, W. Boerjan, A. Brun, A. Brunner, V. Busov, M. Campbell, J. Carlson, M. Chalot, J. Chapman, G. L. Chen, D. Cooper, P.M. Coutinho, J. Couturier, S. Covert, Q. Cronk, R. Cunningham, J. Davis, S. Degroeve, A. Dejardin, C. dePamphilis, J. Detter, B. Dirks, I. Dubchak, S. Duplessis, J. Ehlting, B. Ellis, K. Gendler, D. Goodstein, M. Gribskov, J. Grimwood, A. Groover, L. Gunter, B. Hamberger, B. Heinze, Y. Helariutta, B. Henrissat, D. Holligan, R. Holt, W. Huang, N. Islam-Faridi, S. Jones, M. Jones-Rhoades, R. Jorgensen, C. Joshi, J. Kangasjarvi, J. Karlsson, C. Kelleher, R. Kirkpatrick, M. Kirst, A. Kohler, U. Kalluri, F. Larimer, J. Leebens-Mack, J.C. Leple, P. 
Locascio, Y. Lou, S. Lucas, F. Martin, B. Montanini, C. Napoli, D.R. Nelson, C. Nelson, K. Nieminen, O. Nilsson, V. Pereda, G. Peter, R. Philippe, G. Pilate, A. Poliakov, J. Razumovskaya, P. Richardson, C. Rinaldi, K. Ritland, P. Rouze, D. Ryaboy, J. Schmutz, J. Schrader, B. Segerman, H. Shin, A. Siddiqui, F. Sterky, A. Terry, C. J. Tsai, E. Uberbacher, P. Unneberg, J. Vahala, K. Wall, S. Wessler, G. Yang, T. Yin, C. Douglas, M. Marra, G. Sandberg, Y. Van de Peer, and D. Rokhsar. 2006. The genome of black cottonwood, Populus trichocarpa Torr. \& Gray. Science 313:1596-1604.

Vanassche, F., Clijsters, H. 1990. Effects of metals on enzymes in plants. Plant Cell Environment 13:195-206.

Verhaegen, D., Plomion, C., Gion, J.M., Poitel, M., Costa, P., Kremer, A. 1997. Quantitative trait dissection analysis in Eucalyptus using RAPD markers: 1. Detection of QTL in 182 interspecific hybrid progeny, stability of QTL expression across different ages. Theoritical and Applied Genetics 95:597-608.

Wallace, A., Wallace, G. A., Cha, J. W. 1992. Some modifications in trace metal toxicities and deficiencies in plants resulting from interactions with other elements and chelating agents—-the special case of iron. Journal of Plant Nutrition 15:1589-1598.

Wheeler, N. C., Jermstad, K. D., Krutovsky, K. V., Aitken, S. N., Howe, G. T., Krakowski, J., Neale, D. B. 2005. Mapping of quantitative trait loci controlling adaptive traits in coastal Douglas-fir. IV. Cold-hardiness QTL verification and candidate gene mapping. Molecular Breeding 15:145-156.

Wu, R., Bradshaw, H. D. Jr., Stettler, R. F. 1997. Molecular genetics of growth and development in Populus (Salicaceae). V. Mapping quantitative trait loci affecting leaf variation. American Journal of Botany 84:143-153. 
Wu, P., Liao, C., Hu, B., Yi, K., Jin, W., Ni, J., He, C. 2000. QTLs and epistasis for aluminum tolerance in rice Oryza sativa L. at different seedling stages. Theoritical and Applied Genetics 100:1295-1303.

Wu, R.L., Lin, M. 2006. Opinion - Functional mapping - how to map and study the geneticarchitecture of dynamic complex traits. Nature Reviews Genetics 7:229-237.

Wullschleger, S. D., Jansson, S., Taylor, G. 2002. Genomics and forest biology: Populus emerges as the perennial favorite. Plant Cell 14:2651-2655.

Wullschleger, S., Yin, T. M., DiFazio, S. P., Tschaplinski, T. J., Gunter, L. E., Davis, M. F., Tuskan, G. A. 2005. Phenotypic variation in growth and biomass distribution for two advanced-generation pedigrees of hybrid Populus. Canadian Journal of Forest Research 35:1779-1789.

Yang, X.-E., Jin, X.F., Feng, Y., Islam, E. 2005b. Molecular mechanisms and genetic basis of heavy metal tolerance/hyperaccumulation in plants. Journal of Integrative Plant Biology 47:1025-1035.

Yin, T.M., DiFazio, S.P., Gunter, L.E., Jawdy, S.S., Boerjan, W., Tuskan, G.A. 2004. Genetic and physical mapping of Melampsora rust resistance genes in Populus and characterization of linkage disequilibrium and flanking genomic sequence. New Phytologist 1651:95-105.

Zacchini, M., Pietrini, F., Scarascia, G., Mugnozza, Iori, V., Pietrosanti, L., Massacci, A. 2009. Metal tolerance, accumulation and translocation in Populus and willow clones treated with cadmium in hydroponics. Water, Air, and Soil Pollution 197:23-24. 
Zhang, DeQiang., Zhang, Z.Yi., Yang, Kai., Li, BaiLian. 2005. QTL Analysis of leaf morphology and spring bud flush in Populus tomentosa $\times$ P. bolleana $\times$ P. tomentosa . Chinese Academy of Forestry 411:50-56.

Zhang, D., Zhang, Z., Yang, K. 2006. QTL analysis of growth and wood chemical content traits in an interspecific backcross family of white Populus (Populus tomentosa $\times$ P. bolleana) $\times$ P. tomentosa. Canadian Journal of Forest Research 36:2015-2023.

Zhao, Z., Cai, Y., Zhu., Y, Kneer., R. 2005. Cadmium-induced oxidative stress and protection by L-Galactono-1, 4-lactone in winter wheat Triticum aestivum L. Journal of Plant Nutrition and Soil Science 1686:759-763. 


\section{CHAPTER II}

\section{IDENTIFICATION OF QUANTITATIVE TRAIT LOCI (QTL) AND CANDIDATE GENES FOR CADMIUM TOLERANCE IN POPULUS}

Induri, B.R., Ellis, D.R., Slavov, G.T., Yin, T., Zhang, X., Muchero, W., Tuskan, G.A., DiFazio, S.P. 2012. Identification of quantitative trait loci and candidate genes for cadmium tolerance in Populus. Tree Physiology 32:626-638.

\section{Authors' contribution}

Brahma Reddy Induri wrote the manuscript and performed the greenhouse experiments and $\mathrm{Cd}$ assays. Tongming Yin and XinYe Zhang performed the marker analyses, developed the genetic map, performed QTL mapping and provided text describing those methods. Wellington Muchero and Gerald Tuskan contributed toward QTL mapping. Danielle Ellis performed the microarray experiment, analyzed the microarray data, and contributed text describing this work. Gancho Slavov contributed to the statistical analysis. Stephen DiFazio directed the project and performed microarray analysis and contributed toward the writing. 


\begin{abstract}
Understanding genetic variation for the response of Populus to heavy metals like cadmium (Cd) is an important step in elucidating the underlying mechanisms of tolerance. In this study, a pseudo-backcross pedigree of Populus trichocarpa Torr. \& Gray and P. deltoides Bart. was characterized for growth and performance traits after Cd exposure. A total of 16 Quantitative Trait Loci (QTL) at logarithm of odds (LOD) ratio $\geq 2.5$, were detected for total dry weight, its components, and root volume. Major QTL for Cd responses were mapped to two different linkage groups and the relative allelic effects were in opposing directions on the two chromosomes, suggesting differential mechanisms at these two loci. The phenotypic variance explained by Cd QTL ranged from 5.9\% to $11.6 \%$ and averaged 8.2\% across all QTL. Leaf Cd contents also showed significant variation in the pedigree independent of variation in $\mathrm{Cd}$ tolerance, suggesting that there is potential for improving the phytoextraction potential of Populus genotypes. A whole-genome microarray study led to the identification of nine Cdresponsive genes from these QTL. Promising candidates for Cd tolerance include an NHL repeat membrane-spanning protein, a metal transporter, and a putative transcription factor. Additional candidates in the QTL intervals include a putative homolog of a glutamate cysteine ligase, and a glutathione-s-transferase. Functional characterization of these candidate genes should enhance our understanding of Cd metabolism and transport and phytoremediation capabilities of Populus.
\end{abstract}




\section{Introduction}

One of the challenges posed by phytoremediation of cadmium $(\mathrm{Cd})$ contamination is the development of plants that are tolerant of the deleterious effects of this toxin, which has no known nutritional value in plants. Symptoms of Cd toxicity include leaf roll, chlorosis and reductions in root and shoot growth, even at minute concentrations (Almeida et al., 2007; Milone et al., 2003). Cadmium compromises the structure and function of many proteins by acting on sulphydryl groups (Vanassche and Clijsters, 1990) and affects the permeability of membranes by altering lipid composition (Ouariti et al., 1997).

In addition to disrupting the ion and water balance of plants, $\mathrm{Cd}$ affects various physiological processes such as photosynthesis, respiration, nitrate assimilation, metabolite accumulation, and enzyme activity (Smeets et al., 2005; Solti et al., 2008). Cd decreases the photosynthetic activity of plants by changing chloroplast ultrastructure (Sandalio et al., 2001) and altering stomatal closure. Cd also interferes with the uptake and distribution of other nutrients (Rodriguez-Serrano et al., 2009; Shao et al., 2008), most notably iron (Fe) (Fodor et al., 2005; Siedlecka and Krupa, 1999; Solti et al., 2008). Cd has also been shown to affect the electron transport system, interact with antioxidative defense systems and induce lipid peroxidation (Rodriguez-Serrano et al., 2009; Smeets et al., 2005).

Most phytoremediation research thus far has been carried out on herbaceous plants that accumulate high levels of metals in their cells naturally. However, their slow growth rates, annual habit, small stature, low biomass and/or narrow geographic adaptability make them unsuitable for phytoremediation on an operational scale (Eapen and D'Souza, 2005). Populus, with its rapid growth, makes an ideal plant species for phytoremediation of soils polluted by heavy metals (Cunningham and Ow, 1996). Furthermore, Populus is readily-propagated from 
vegetative cuttings, and has a wide range of adaptability, high bulk root volume, high transpiration rate and large stature, all of which should enhance the efficacy of phytoremediation (Rockwood et al., 2004). Previous studies have assessed the potential of using Populus to remediate soils polluted by atrazine (Burken and Schnoor, 1997), trichloroethylene (Newman et al., 1997), Cd (Robinson et al., 2000), selenium (Pilon-Smits et al., 1998), and zinc (Di Baccio et al., 2009). In addition, some hybrid Populus clones have shown elevated tolerance of Cd in field plantings relative to other tree species (Migeon et al., 2009), and there is considerable natural variation within the genus that could be exploited to enhance Cd tolerance further using biotechnological approaches.

To further characterize Cd tolerance in Populus, we 1) quantified phenotypic and genetic variation for $\mathrm{Cd}$ tolerance and $\mathrm{Cd}$ accumulation in a pseudo-backcross multiple generation Populus pedigree that was grown under greenhouse conditions 2) detected QTL for traits related to Cd tolerance including dry weight components and root volume and 3) identified candidate genes in the QTL intervals based on transcriptional data from a microarray study. 


\section{Material and Methods}

\section{Plant materials}

An interspecific mapping population was developed at the University of Minnesota Natural Resources Research Institute by crossing $P$. trichocarpa clone 93-968 from western Washington to $P$. deltoides clone ILL-101 from southern Illinois. The resulting $\mathrm{F}_{1}$ hybrid, 52-225, was in turn backcrossed to $P$. deltoides clone D-124 from Minnesota. Two-hundred and fifty-two full-sib progeny from the 'pseudobackcross' pedigree (Family 52-124) were used for the current study. Dormant cuttings were collected from a stoolbed in early spring prior to bud break and were stored at $4^{\circ} \mathrm{C}$ for five weeks to meet chilling requirements. This facilitated uniform rooting of the cuttings, and enabled selection of plants with approximately uniform sizes at the initiation of our experiment. Two ramets per clone were used for both control and Cd treatments. A total of 1008 vegetative cuttings ( 252 genotypes $\mathrm{x} 2$ treatments $\mathrm{x} 2$ cuttings per genotype) were examined in this experiment.

Cuttings with approximate lengths of $15 \mathrm{~cm}$ and diameters of $1 \mathrm{~cm}$ were dipped in 1:10 dilution of the commercial liquid rooting hormone solution (Dip N Grow 1\% IBA, 0.5\% NAA) for 15 seconds, surrounded by foam stoppers and plugged into $3 \mathrm{~cm}$ holes at $8 \mathrm{~cm}$ spacing in the lids of polyethylene containers. Approximately $5 \mathrm{~cm}$ of the base of the cuttings was submerged beneath a dilute, continuously aerated nutrient solution $0.1 \mathrm{X}$ Johnson's solution; (Siddique et al., 1990). The nutrient solution was composed of $400 \mu \mathrm{M} \mathrm{NH}_{4} \mathrm{NO}_{3}, 400 \mu \mathrm{M} \mathrm{KNO}_{3}, 200 \mu \mathrm{M}$ $\mathrm{Ca}\left(\mathrm{NO}_{3}\right)_{2} \cdot 4 \mathrm{H}_{2} \mathrm{O}, 100 \mu \mathrm{M} \mathrm{MgSO}_{4} \cdot 7 \mathrm{H}_{2} \mathrm{O}, 50 \mu \mathrm{M} \mathrm{K}_{2} \mathrm{HPO}_{4}, 20 \mu \mathrm{M} \mathrm{KCl}, 25 \mu \mathrm{M} \mathrm{H}_{3} \mathrm{BO}_{3}, 0.5 \mu \mathrm{M}$ $\mathrm{Na}_{2} \mathrm{MoO}_{4} \cdot 2 \mathrm{H}_{2} \mathrm{O}, 2 \mu \mathrm{M} \mathrm{MnSO}{ }_{4} \cdot 4 \mathrm{H}_{2} \mathrm{O}, 0.5 \mu \mathrm{M} \mathrm{CuSO}_{4} \cdot 5 \mathrm{H}_{2} \mathrm{O}, 2 \mu \mathrm{M} \mathrm{ZnSO} \cdot 7 \mathrm{H}_{2} \mathrm{O}, 0.5 \mu \mathrm{M} \mathrm{CoCl}_{2}$ and $20 \mu \mathrm{M}$ Fe-Na EDTA. The $\mathrm{pH}$ was approximately 5.4. One primary shoot was maintained per cutting. 
Once the cuttings developed roots and shoots, they were transplanted into 126 polyethylene containers $(24 \mathrm{~cm} \times 12 \mathrm{~cm}$ x $38 \mathrm{~cm}$ ) following a partially balanced incomplete block design, with two treatments ( $\mathrm{Cd}$ and control), 126 containers as incomplete blocks, and two replicates of each genotype in each treatment. Each container had one ramet from each of eight different genotypes at $9 \mathrm{~cm}$ spacing and contained 7L of the $0.1 \mathrm{X}$ Johnson's solution described above. The solutions were changed every three days throughout the experiment (from 05/19/07 to 07/10/07) to maintain nutrient and oxygen levels and to avoid algal growth.

The experiment was carried out with a target day temperature of $25^{\circ} \mathrm{C}$ and a night temperature of $21^{\circ} \mathrm{C}$ and a photoperiod of $18 \mathrm{~h}$. Artificial lighting was provided by high-density mixed halide lights and photosynthetically active radiation (PAR) was recorded for every container used in the study, at plant height (Average PAR $=224.05 \mu \mathrm{mol} / \mathrm{m}^{2} / \mathrm{s}$ and standard deviation $=55.08)$. Temperature was maintained by an evaporative cooling system.

Cuttings were grown for 40 days and one half of the containers were randomly selected to receive a $25 \mu \mathrm{M} \mathrm{CdCl}_{2}$ treatment for an additional 20 days. The remaining half of the containers were maintained as described above for two weeks and used as controls. The $\mathrm{Cd}$ concentration was selected based on pilot experiments that revealed substantial phenotypic variation in this family without excessive mortality. Fresh $\mathrm{CdCl}_{2}$ was added each time solutions were changed. Before and after 20 days of treatment, measurements were taken on shoot length, cutting diameter, shoot diameter, photosynthetically active radiation (PAR), root collar diameter (the diameter recorded right above the origin point of the uppermost root on a cutting), and rooted length for each cutting (portion of the cutting occupied by roots). Furthermore, root volume was estimated using water displacement in graduated cylinders. After two weeks, roots and shoots were harvested, separated into paper bags and dried in an oven at $60^{\circ} \mathrm{C}$ for 6 days. 
Roots were washed with deionized water and blotted on paper towels before being stored in the bags. Dry weights were recorded for leaves, roots, and shoots separately, and total dry weights were calculated by summing all components.

\section{Cd analysis}

The dried leaf samples with the petioles of all genotypes used in the QTL hydroponic study, were ground to pass through a 20-mesh sieve. Approximately, $0.1 \mathrm{~g}$ of ground leaf tissue per genotype was placed into $75 \mathrm{ml}$ microwave digestion tubes. These samples were acid digested with $5 \mathrm{ml}$ of $70 \%$ nitric acid (NF, technical grade) and $2 \mathrm{ml}$ of $30 \%$ hydrogen peroxide by a closed vessel MARSXpress microwave digester, version 5.0. (CEM Corporation, Matthews, NC, USA). Digestions were completed at $200^{\circ} \mathrm{C}$ for $2 \mathrm{~h}$ (Jones and Case, 1990).

The volumes of the digests were brought to $75 \mathrm{ml}$ with deionized water and all digests were filtered through Whatman No. 44 filter paper to remove any particulate matter. Quality procedures included running blank and control samples in each microwave digestion as well as including a reference genotype in all microwave digestions. Cd contents of the filtrates were determined by using a Varian 220FS flame atomic absorption spectrophotometer, FAAS, (Varian, Inc., Mulgrave, Vic., Australia) and results were verified for a subset of 50 samples using an ICP-OES (Inductively Coupled Plasma - Optical Emission Spectra).

\section{Statistical analysis of phenotypic data}

Phenotypic data were tested for normality using the Shapiro-Wilk test (Shapiro and Wilk, 1965) and logarithmic transformations were performed to mitigate heteroscedasticity of variance versus predicted values. Data were analyzed with mixed linear models using SAS JMP, version 8.0 (SAS Institute Inc, Cary, NC). The general form of the statistical model was:

$\mathrm{Y}_{i j k}=\mu+\mathrm{T}_{i}+\mathrm{B}_{j}+\mathrm{G}_{k}+\varepsilon_{i j k}$ 
where $Y_{\mathrm{ijk}}$ was the measurement of response variable $\mathrm{Y}$ (total dry weight, root dry weight, leaf dry weight, stem dry weight, or root volume) for genotype $k$ in container $j$ under treatment $i, \mu$ was the population mean, $\mathrm{T}_{i}$ was the effect of treatment $i, \mathrm{~B}_{j}$ was the effect of incomplete block (container) $j, \mathrm{G}_{k}$ was the effect of genotype $k$, and $\varepsilon_{i j k}$ was the experimental error. When significant $(P \leq 0.05)$, the rooted length and dry weight of each cutting and PAR for each container were also included as covariates. Genotype and all interactions with Genotype were treated as random effects in the model, whereas all remaining variables were treated as fixed effects.

Broad-sense heritabilities $\left(H^{2}\right)$ were calculated as $H^{2}=\mathrm{V}_{\mathrm{G}} /\left(\mathrm{V}_{\mathrm{G}}+\mathrm{V}_{\varepsilon}\right)$ based on the variance components for Genotype $\left(\mathrm{V}_{\mathrm{G}}\right)$ and Error $\left(\mathrm{V}_{\varepsilon}\right)$ estimated using restricted maximum likelihood (REML) in mixed linear models that were fitted separately for control and Cd treatments. This was done to assess differences in variances and heritabilities under these two conditions; where, $V_{g}$ is the genotypic variance component and $V_{p}$ is the total phenotypic variance, each of which was estimated using estimated using the restricted maximum likelihood (REML) method.

The effect of $\mathrm{Cd}$ on each genotype (hereafter referred to as "Cd effects") was estimated by subtracting its Best Linear Unbiased Predictor (BLUP) under Cd conditions from that under control conditions (Coles et al., 2010) for all biomass traits described above. The genotypes with the largest BLUP differences were identified as Cd sensitive and those with the smallest BLUP differences were identified as Cd tolerant. Genetic correlations among traits were calculated using BLUPs and the REML method in SAS JMP, version 8.0.

\section{Linkage map construction}

To construct a genetic map for Family 52-124, 188 progeny were genotyped using 590 
amplified fragment length polymorphism (AFLP) markers. In addition, 418 progeny were genotyped using 287 simple sequence repeat (SSR) markers (Yin et al., 2009) that were chosen based on their physical locations along chromosomes to achieve an even distribution of markers on each linkage group. Four aneuploid trees were identified by genotyping with fully informative SSR markers and these individuals were later removed from the mapping data set. Marker generation, genotyping and nomenclature were performed as described previously (Tuskan et al., 2004; Yin et al., 2004). Map construction was conducted using JoinMap 3.0 under the CP cross type (Van Ooijen, 2001).

\section{QTL analysis}

QTL were identified using MapQTL version 5.0 (Van Ooijen, 2004). Interval mapping was performed initially to identify markers associated with putative QTL. Markers with significant effects in this analysis were then used as cofactors in restricted Multiple QTL Model (MQM) mapping (Van Ooijen, 2004). LOD scores were calculated at $1.0 \mathrm{cM}$ intervals. Only QTL with LOD score > 2.5 are reported here.

\section{Microarray study}

A whole-genome microarray study was conducted using two genotypes that demonstrated differential Cd effects in the above QTL hydroponic study: a Cd tolerant genotype (1-183), and a Cd susceptible genotype (182). The experiment consisted of 6 polyethylene containers as described above but with only 4 plants per container. Each genotype was represented by two ramets per container with randomly assigned locations. Three containers were treated with 25 $\mu \mathrm{M} \mathrm{CdCl}_{2}$ and the remaining three containers were under control conditions. Three ramets from each genotype $\mathrm{x}$ treatment combination were harvested at $24 \mathrm{~h}$, and three at $72 \mathrm{~h}$ after $\mathrm{Cd}$ 
treatment. Roots from each plant were thoroughly washed in deionized water and blotted dry and all material was quick frozen in liquid nitrogen and stored at $-80^{\circ} \mathrm{C}$.

Plant tissue was ground in liquid nitrogen, RNA was extracted using the Qiagen RNA Mini kit (Qiagen, Germantown, MD), and double stranded DNA was synthesized using the Invitrogen SuperScript ${ }^{\mathrm{TM}}$ double-stranded cDNA Synthesis Kit (Invitrogen, Carlsbad, California). Labeling, hybridization, and scanning were performed by NimbleGen (Roche NimbleGen, Madison, WI). The raw data were normalized using the robust multichip averaging (RMA) procedure, which performs a convolution background correction, quantile normalization, and summarization based on a multi-array model fit robustly using the median polish algorithm (Bolstad et al., 2005). Differentially expressed genes (Cd treated vs control) were determined using rank product analysis (Breitling et al., 2004) using 1000 permutations and a percentage of false positives cutoff of 0.05 . 


\section{Results}

\section{Cadmium effects}

The effect of Cd was evident for all measured traits (Table 2.1). Cd symptoms included necrotic spots on leaves and browning of roots (Figure 2.1). The genotypes under Cd conditions showed poor growth compared to those under control conditions (Table 2.1). The effects of genotype, treatment and their interaction were highly significant $(P<0.001)$ for total dry weight, root dry weight, leaf dry weight, stem dry weight and root volume. The covariate effects of cutting rooted length, cutting dry weight, and PAR were also significant $(P<0.001)$ for all traits except PAR for root volume (Table 2.2).

There was extensive variation in $\mathrm{Cd}$ responses among genotypes (Figures 2.2, 2.3.A). Broad-sense heritabilities of total dry weight and its components were relatively low and comparable between control (range $H^{2}=0.19-0.39$ ) and cadmium conditions (range $H^{2}=0.11$ 0.34, Table 2.1). Root volume showed the lowest heritabilities under either control $\left(H^{2}=0.19\right)$ or $\mathrm{Cd}\left(H^{2}=0.11\right)$ conditions. In contrast, total dry weight had heritabilities of 0.36 and 0.34 in control and Cd conditions respectively (Table 2.1).

\section{Leaf cadmium content}

There was excellent correspondence between the Cd concentrations estimated by FAAS and those estimated by ICP-OES $\left(\mathrm{R}^{2}=0.998\right.$; Supplemental Figure 2.1$)$, indicating the reliability of our analysis method. Genotypes showed significant variation for leaf $\mathrm{Cd}$ content as dipicted in the histograms (Figures 2.3.B and 2.3.C ). However, the broad-sense heritability estimate for leaf Cd content was only 0.12 . There was a poor correlation between leaf $\mathrm{Cd}$ contents of different ramets for the same genotype $(\mathrm{r}=0.014)$ (Figure 2.4.A). However, there was a high correlation between $\mathrm{Cd}$ measurements of two independent digestions and analyses from the same ramet, 
$(\mathrm{r}=0.948)$ (Figure 2.4.B). Furthermore, there was little variation among $\mathrm{Cd}$ measurements from subsamples of leaves collected from the same plants of two different genotypes (Coefficient of Variation $=0.018$ and 0.019 , respectively, for the two genotypes). Therefore, the variation observed between ramets from the 40 replicates appears to reflect true sample-to-sample variation among the replicates rather than lack of precision in the $\mathrm{Cd}$ measurements themselves. The total dry weight and $\mathrm{Cd}$ contents of leaves were uncorrelated ( $\mathrm{r}=0.012$; Figure 2.4.C.), suggesting that these traits varied independently in this experiment.

\section{QTL identification}

QTL were mapped for 16 phenotypes with a minimum LOD score of 2.5. Four of these QTL were identified in control conditions and 12 under Cd conditions. QTL were located on LG III and XVI (Figure 2.5; Table 2.3). The phenotypic variation explained by QTL ranged from $5.9 \%$ to $11.6 \%$ and averaged $8.2 \%$ across all traits. Excluding co-localizing QTL (+/- 1 LOD) and accounting for correlations among phenotypic traits (Table 2.4; Figure S.2.2), these 16 QTL correspond to four independent positions within the genome (Table 2.3), and ranged in size from approximately 15 to $30 \mathrm{cM}$ (Figure 2.5 ).

Three QTL for dry weight and its components under control conditions were co-located on LG III along with three QTL for Cd effects on dry weight, collectively referred to as locus cd1 (Table 2.3). Two clusters of QTL were mapped to LG XVI at two discrete positions, the first of which (cd3) contained QTL for leaf dry weight under control conditions and Cd effects on total dry weight and its components (Table 2.3). For both cd1 and cd3, the allelic effects for dry weight measures under control conditions were in the same direction as those for QTL for Cd effects. However, the relative effect of the allele originating from $P$. trichocarpa was in opposite directions for these two loci decreasing $\mathrm{Cd}$ tolerance at $\mathrm{cd} 1$ and enhancing $\mathrm{Cd}$ tolerance at $\mathrm{cd} 3$. 
The second cluster (cd2) on LG XVI contained QTL for total dry weight and its components under Cd conditions, as well as three QTL for Cd effects. In contrast, to the other two loci, the allelic effects were opposite for dry weight measures and Cd effects. In this case, the allele from P. trichocarpa conferred reduced Cd tolerance on average. Finally, an apparently independent locus on LG XVI (cd4) explained $11 \%$ of the variation in leaf Cd concentration under Cd conditions (Table 2.3).

\section{Candidate gene identification}

The Cd response QTL intervals encompassed 1571 predicted genes from v2.0 of the Populus trichocarpa genome annotation. In addition, across all genotypes and treatments there were 1748 different genes that showed up-regulation, and 672 genes that showed downregulation in response to Cd treatment (Figures S.2.4, S.2.5). Nine of these differentially expressed genes were also present in the Cd response QTL intervals (Table 2.6). Candidate genes that had no detected level of expression in the microarray study but present in the QTL intervals were also identified (Table 2.7). 
Table 2.1. Summary statistics and heritability estimates for total dry weight and other measured traits along with their variance components.

\begin{tabular}{|c|c|c|c|c|c|c|c|}
\hline CONTROL & Mean $(\mathrm{g})$ & $\mathrm{SD}^{\mathrm{a}}$ & Range & $\mathrm{SE}^{\mathrm{b}}$ & $\mathrm{V}_{\mathrm{G}}^{\mathrm{c}}$ & $\mathrm{V}_{\mathrm{p}}^{\mathrm{d}}$ & $\mathrm{H}^{2}{ }_{\mathrm{BS}}^{\mathrm{e}}$ \\
\hline Total dry weight $\mathrm{C}$ & 6.35 & 4.11 & 24.98 & 0.19 & 0.170 & 0.471 & 0.361 \\
\hline Leaf dry weight $\mathrm{C}$ & 3.57 & 2.28 & 13.05 & 0.10 & 0.160 & 0.499 & 0.321 \\
\hline Root dry weight $C$ & 1.14 & 0.88 & 7.34 & 0.04 & 0.201 & 0.581 & 0.346 \\
\hline Stem dry weight $\mathrm{C}$ & 1.63 & 1.16 & 7.39 & 0.05 & 0.233 & 0.597 & 0.390 \\
\hline Root volume $\mathrm{C}$ & 1.62 & 0.94 & 6.00 & 0.04 & 0.045 & 0.235 & 0.191 \\
\hline \multicolumn{8}{|l|}{$\underline{\text { CADMIUM }}$} \\
\hline Total dry weight $\mathrm{Cd}$ & 2.52 & 1.63 & 8.24 & 0.07 & 0.153 & 0.450 & 0.340 \\
\hline Leaf dry weight $\mathrm{Cd}$ & 1.46 & 1.01 & 5.23 & 0.04 & 0.147 & 0.533 & 0.276 \\
\hline Root dry weight Cd & 0.45 & 0.33 & 2.51 & 0.01 & 0.179 & 0.558 & 0.322 \\
\hline Stem dry weight Cd & 0.60 & 0.43 & 2.70 & 0.02 & 0.153 & 0.529 & 0.288 \\
\hline Root volume Cd & 0.97 & 0.64 & 9.00 & 0.02 & 0.024 & 0.218 & 0.110 \\
\hline $\mathrm{Cd} \mathrm{mg/g}$ & 0.34 & 0.27 & 1.51 & 0.01 & 0.108 & 0.859 & 0.126 \\
\hline \multicolumn{8}{|l|}{ "astandard deviation, } \\
\hline \multicolumn{8}{|l|}{ bstandard error, } \\
\hline \multicolumn{8}{|l|}{ 'genetic variance, } \\
\hline \multicolumn{8}{|c|}{${ }^{\mathrm{d}}$ phenotypic variance $\left(\mathrm{V}_{\mathrm{G}}+\mathrm{V}_{\varepsilon}\right)$} \\
\hline${ }^{\mathrm{e}}$ broa & & & & & & & \\
\hline
\end{tabular}


Table 2.2. Results of ANOVA for traits measured in the greenhouse hydroponic study that showed significant differences between Cd and control conditions.

\begin{tabular}{lrrrrrrrrrrrr}
\hline & \multicolumn{2}{c}{ Total dry weight } & \multicolumn{2}{c}{ Leaf dry weight } & \multicolumn{2}{c}{ Root dry weight } & \multicolumn{2}{c}{ Stem dry weight } & \multicolumn{2}{c}{ Root volume } \\
Trait & F & $P$ & F & $P$ & F & $P$ & F & $P$ & F & $P$ \\
\hline Genotype & 1.97 & $<.0001$ & 1.86 & $<.0001$ & 1.76 & $<.0001$ & 1.97 & $<.0001$ & 1.61 & $<.0001$ \\
Treatment & 589.94 & $<.0001$ & 525.75 & $<.0001$ & 335.03 & $<.0001$ & 555.28 & $<.0001$ & 215.37 & $<.0001$ \\
Genotype x Treatment & 1.49 & 0.0002 & 1.41 & 0.0009 & 1.28 & 0.0124 & 1.53 & $<.0001$ & 1.34 & 0.0044 \\
Rooted length of cutting & 10.08 & 0.0016 & 5.99 & 0.0147 & 16.76 & $<.0001$ & 7.71 & 0.0057 & 13.92 & 0.0002 \\
Cutting dry weight & 139.78 & $<.0001$ & 130.92 & $<.0001$ & 56.23 & $<.0001$ & 146.18 & $<.0001$ & 51.94 & $<.0001$ \\
PAR & 6.87 & 0.0091 & 4.85 & 0.0281 & 4.30 & 0.0388 & 9.18 & 0.0026 & 0.70 & 0.4027 \\
\hline
\end{tabular}


Table 2.3. Linkage group (LG), QTL positions, Logarithm of Odds ratio (LOD) scores, Percent Variation Explained (PVE), and direction of effect of each QTL are given under the control (C), Cadmium treated (Cd) conditions.

\begin{tabular}{|c|c|c|c|c|c|c|c|c|c|}
\hline Locus & Trait & $\begin{array}{l}\text { Linkage } \\
\text { Group }\end{array}$ & Position & LOD & PVE & Left marker & Right marker & T Effects ${ }^{\mathrm{a}}$ & D Effects ${ }^{\mathrm{b}}$ \\
\hline cd1 & Total dry weight C-Cd & III & 109.267 & 3.33 & 8.9 & *CCCGA_8 & *CACAC_218 & -0.047 & 0.043 \\
\hline cd1 & Root volume C-Cd & III & 110.267 & 3.04 & 9 & *CCCGA_8 & *CACAC_218 & -0.025 & 0.022 \\
\hline cd1 & Leaf dry weight C-Cd & III & 111.267 & 3.06 & 7.7 & *CCCGA_8 & *CACAC_218 & -0.046 & 0.039 \\
\hline cd1 & Total dry weight $\mathrm{C}$ & III & 111.676 & 2.51 & 6.1 & *CCCGA_8 & *CACAC_218 & -0.025 & 0.022 \\
\hline cd1 & Root volume C & III & 114.726 & 2.5 & 6.8 & *CCCGA_1 & *CCCAC_22 & -0.014 & 0.013 \\
\hline $\mathrm{cd} 1$ & Root dry weight $C$ & III & 110.267 & 2.66 & 6.6 & *CCCGA_8 & *CACAC_218 & -0.021 & 0.022 \\
\hline $\mathrm{cd} 2$ & Root dry weight C-Cd & XVI & 22.784 & 2.99 & 7.4 & G_3141 & *CCCCT_202R & 0.045 & -0.030 \\
\hline $\mathrm{cd} 2$ & Total dry weight C-Cd & XVI & 26.609 & 2.81 & 6.8 & *CCCCT_202R & *TCCGT_8R & 0.047 & -0.033 \\
\hline $\mathrm{cd} 2$ & Leaf dry weight C-Cd & XVI & 26.609 & 4.26 & 10 & *CCCCT_202R & *TCCGT_8R & 0.056 & -0.042 \\
\hline $\mathrm{cd} 2$ & Total dry weight $\mathrm{Cd}$ & XVI & 26.609 & 3.14 & 7.8 & *CCCCT_202R & *TCCGT_8R & -0.029 & 0.021 \\
\hline $\mathrm{cd} 2$ & Root dry weight $\mathrm{Cd}$ & XVI & 26.609 & 2.99 & 7.3 & *CCCCT_202R & *TCCGT_8R & -0.027 & 0.017 \\
\hline $\mathrm{cd} 2$ & Leaf dry weight Cd & XVI & 26.609 & 4.6 & 11.6 & *CCCCT_202R & *TCCGT_8R & -0.037 & 0.028 \\
\hline $\mathrm{cd} 3$ & Leaf dry weight $C$ & XVI & 56.812 & 2.9 & 5.9 & *CCCCT_246R & *CTCAG_356R & 0.033 & -0.016 \\
\hline $\mathrm{cd} 3$ & Total dry weight C-Cd & XVI & 56.812 & 3.61 & 7.4 & *CCCCT_246R & *CTCAG_356R & 0.059 & -0.028 \\
\hline $\mathrm{cd} 3$ & Leaf dry weight C-Cd & XVI & 56.812 & 5.41 & 11 & *CCCCT_246R & *CTCAG_356R & 0.072 & -0.036 \\
\hline $\operatorname{cd} 4$ & Leaf dry weight $\mathrm{Cd}$ & XVI & 68.558 & 4.61 & 11.3 & *CGCCA_308R & *CTCTC_100R & -0.040 & 0.025 \\
\hline
\end{tabular}

${ }^{\mathrm{a}}$ The relative effect of the allele originating from P. trichocarpa $;{ }^{\mathrm{b}}$ The relative effect of the allele originating from P. deltoides; ${ }^{\mathrm{c}}$ Difference in BLUP between control and Cd conditions (Cd effect). 
Table 2.4. Genetic (above diagonal) and phenotypic correlations among the variables measured.

\begin{tabular}{|c|c|c|c|c|c|c|c|c|c|c|c|c|c|c|c|}
\hline $\begin{array}{l}\text { Traits all } \\
\text { correlations }\end{array}$ & $\begin{array}{r}\text { Total } \\
\text { dry } \\
\text { weight } \\
\mathrm{C}\end{array}$ & $\begin{array}{r}\text { Root } \\
\text { dry } \\
\text { weight } \\
\mathrm{C}\end{array}$ & $\begin{array}{r}\text { Leaf } \\
\text { dry } \\
\text { weight } \\
C\end{array}$ & $\begin{array}{r}\text { Stem } \\
\text { dry } \\
\text { weight } \\
\mathrm{C}\end{array}$ & $\begin{array}{r}\text { Root } \\
\text { volume } \\
\mathrm{C}\end{array}$ & $\begin{array}{r}\text { Total } \\
\text { dry } \\
\text { weight } \\
\text { Cd }\end{array}$ & $\begin{array}{r}\text { Root } \\
\text { dry } \\
\text { weight } \\
\text { Cd }\end{array}$ & $\begin{array}{r}\text { Leaf } \\
\text { dry } \\
\text { weight } \\
\mathrm{Cd}\end{array}$ & $\begin{array}{r}\text { Stem } \\
\text { dry } \\
\text { weight } \\
\text { Cd }\end{array}$ & $\begin{array}{r}\text { Root } \\
\text { volume } \\
\text { Cd }\end{array}$ & $\begin{array}{r}\text { Total } \\
\text { dry } \\
\text { weight } \\
\text { C-Cd }\end{array}$ & $\begin{array}{r}\text { Root } \\
\text { dry } \\
\text { weight } \\
\text { C-Cd }\end{array}$ & $\begin{array}{r}\text { Leaf } \\
\text { dry } \\
\text { weight } \\
\mathrm{C}-\mathrm{Cd}\end{array}$ & $\begin{array}{r}\text { Stem } \\
\text { dry } \\
\text { weight } \\
\text { C-Cd }\end{array}$ & $\begin{array}{r}\text { Root } \\
\text { volume } \\
\text { C-Cd }\end{array}$ \\
\hline $\begin{array}{l}\text { Total dry } \\
\text { weight C }\end{array}$ & 1 & 0.8838 & 0.9765 & 0.9463 & 0.7703 & 0.268 & 0.2562 & 0.2242 & 0.2822 & 0.1859 & 0.9197 & 0.7918 & 0.8783 & 0.8825 & 0.5893 \\
\hline $\begin{array}{l}\text { Root dry } \\
\text { weight C }\end{array}$ & 0.9022 & 1 & 0.796 & 0.8016 & 0.7862 & 0.2106 & 0.2084 & 0.1769 & 0.2149 & 0.1401 & 0.8235 & 0.9271 & 0.7186 & 0.757 & 0.6323 \\
\hline $\begin{array}{l}\text { Leaf dry } \\
\text { weight C }\end{array}$ & 0.973 & 0.8317 & 1 & 0.8841 & 0.7102 & 0.2648 & 0.2556 & 0.2259 & 0.2669 & 0.1816 & 0.8968 & 0.7036 & 0.901 & 0.8232 & 0.537 \\
\hline $\begin{array}{l}\text { Stem dry } \\
\text { weight C }\end{array}$ & 0.9431 & 0.8152 & 0.8895 & 1 & 0.7313 & 0.2674 & 0.2454 & 0.2148 & 0.3103 & 0.1941 & 0.8646 & 0.7131 & 0.7899 & 0.9278 & 0.5485 \\
\hline $\begin{array}{l}\text { Root volume } \\
\text { C }\end{array}$ & 0.6294 & 0.626 & 0.6059 & 0.5817 & 1 & 0.2165 & 0.205 & 0.1793 & 0.2338 & 0.1961 & 0.7043 & 0.7131 & 0.6315 & 0.6758 & 0.7931 \\
\hline $\begin{array}{l}\text { Total dry } \\
\text { weight Cd }\end{array}$ & -0.3557 & -0.3091 & -0.2795 & -0.2959 & -0.0793 & 1 & 0.8005 & 0.961 & 0.8843 & 0.5168 & -0.1319 & -0.0947 & -0.1627 & -0.0663 & -0.1229 \\
\hline $\begin{array}{l}\text { Root dry } \\
\text { weight Cd }\end{array}$ & -0.2765 & -0.3656 & -0.1976 & -0.2234 & -0.0563 & 0.8157 & 1 & 0.655 & 0.6965 & 0.4847 & -0.0628 & -0.1733 & -0.0356 & -0.0157 & -0.1135 \\
\hline $\begin{array}{l}\text { Leaf dry } \\
\text { weight Cd }\end{array}$ & -0.3188 & -0.2572 & -0.3007 & -0.2286 & -0.0624 & 0.9129 & 0.6886 & 1 & 0.7598 & 0.4666 & -0.161 & -0.0729 & -0.219 & -0.0727 & -0.1258 \\
\hline $\begin{array}{l}\text { Stem dry } \\
\text { weight Cd }\end{array}$ & -0.3146 & -0.2638 & -0.2208 & -0.356 & -0.0569 & 0.8559 & 0.721 & 0.689 & 1 & 0.4719 & -0.0701 & -0.0505 & -0.071 & -0.0667 & -0.0792 \\
\hline $\begin{array}{l}\text { Root volume } \\
\text { Cd }\end{array}$ & -0.079 & -0.1164 & -0.0457 & -0.0305 & -0.1963 & 0.4798 & 0.4724 & 0.4145 & 0.46 & 1 & -0.0194 & -0.0446 & -0.0259 & 0.0186 & -0.4417 \\
\hline $\begin{array}{l}\text { Total dry } \\
\text { weight C-Cd }\end{array}$ & 0.8291 & 0.7409 & 0.7669 & 0.7582 & 0.4363 & -0.8175 & -0.6584 & -0.7426 & -0.706 & -0.3353 & 1 & 0.8533 & 0.9699 & 0.935 & 0.6565 \\
\hline $\begin{array}{l}\text { Root dry } \\
\text { weight C-Cd }\end{array}$ & 0.7198 & 0.8329 & 0.6294 & 0.6347 & 0.4196 & -0.6752 & -0.8196 & -0.5678 & -0.591 & -0.3515 & 0.8475 & 1 & 0.7372 & 0.7683 & 0.6802 \\
\hline Leaf dry & 0.7977 & 0.6723 & 0.803 & 0.69 & 0.412 & -0.7424 & -0.5519 & -0.8099 & -0.5664 & -0.2869 & 0.9358 & 0.742 & 1 & 0.8569 & 0.5939 \\
\hline
\end{tabular}


weight C-Cd

\begin{tabular}{lcccccccccccccccccccc}
$\begin{array}{l}\text { Stem dry } \\
\text { weight C-Cd }\end{array}$ & 0.7824 & 0.6716 & 0.6941 & 0.8424 & 0.405 & -0.682 & -0.558 & -0.5429 & -0.8034 & -0.2839 & 0.8902 & 0.7452 & 0.7662 & 1 & 0.6068 \\
$\begin{array}{l}\text { Root volume } \\
\text { C-Cd }\end{array}$ & 0.474 & 0.4948 & 0.4376 & 0.4119 & 0.796 & -0.3495 & -0.3295 & -0.2978 & -0.3221 & -0.7498 & 0.5016 & 0.5003 & 0.4553 & 0.4488 & 1 \\
\hline
\end{tabular}


Table 2.5 Paired correlations and their 'p' values estimated by the REML method.

\begin{tabular}{llcc}
\hline Variable 1 & Variable 2 & Correlation 'p'value \\
\hline Total dry weight & Cd mg/g & 0.111 & 0.0877 \\
Rooted length & Cd mg/g & 0.094 & 0.1490 \\
Rooted length & Total dry weight & 0.137 & $0.0342^{*}$ \\
Cutting dry weight Cd mg/g & -0.199 & $0.0021^{*}$ \\
Cutting dry weight & Total dry weight & 0.518 & $<.0001^{*}$ \\
Cutting dry weight $^{\text {Rooted length }}$ & -0.016 & 0.8006 \\
PAR & Cd mg/g & 0.226 & $0.0005^{*}$ \\
PAR & Total dry weight & 0.043 & 0.5098 \\
PAR & Rooted length & 0.112 & 0.0853 \\
PAR & Cutting dry weight & -0.050 & 0.4414 \\
\hline
\end{tabular}

${ }^{a}$ PAR $=$ Photosynthetically Active Radiation. $*$ Denotes significant effects. 
Table 2.6. Cd tolerance candidate genes in QTL intervals that also showed altered expression levels in the microarray experiment. Corresponding Arabidopsis genes were identified based on best reciprocal blast hits and the putative functions were derived from the TAIR 9 annotation. Fold Change is the ratio of normalized expression levels under Cd versus control conditions. ns, Not significant with false discovery rate of 0.05 .

\begin{tabular}{|c|c|c|c|c|c|c|c|c|}
\hline Populus Gene & $\begin{array}{l}\text { Arabidopsis } \\
\text { Gene }\end{array}$ & $\begin{array}{l}\text { QTL } \\
\text { LG }\end{array}$ & $\begin{array}{l}\text { Gene } \\
\text { Symbol }\end{array}$ & $\begin{array}{l}\text { Fold } \\
\text { Change }\end{array}$ & Pfp & Clone & $\begin{array}{l}\text { Time } \\
\text { (h) }\end{array}$ & Putative Function \\
\hline gw1.XVI.2928.1 & AT1G70280.2 & XVI & None & 12.3 & $3 \mathrm{E}-04$ & Both & 24 & $\begin{array}{l}\text { NHL repeat-containing membrane } \\
\text { protein }\end{array}$ \\
\hline fgenesh4_pg.C_LG_III001134 & AT3G59140.1 & III & MRP14 & 4.7 & 0.003 & 183 & 72 & $\begin{array}{l}\text { Multidrug Resistance-Associated } \\
\text { Protein; ATP:-type transporter }\end{array}$ \\
\hline gw1.XVI.2910.1 & AT2G28305.1 & XVI & $L O G 1$ & 3.3 & 0.013 & 182 & 72 & $\begin{array}{l}\text { Unknown function, expressed } \\
\text { during } 4 \text { leaf senescence stage }\end{array}$ \\
\hline eugene3.00031003 & AT4G11450.1 & III & $F 25 E 4.70$ & 3.1 & 0.021 & 183 & 24,72 & $\begin{array}{l}\text { Unknown function, expressed } \\
\text { during leaf senescence }\end{array}$ \\
\hline estExt_fgenesh4_pg.C_LG_III1085 & AT4G23496.1 & III & SP1L5 & 0.32 & 0.016 & 182 & 72 & $\begin{array}{l}\text { Unknown function; Potentially } \\
\text { involved in anisotropic cell } \\
\text { expansion }\end{array}$ \\
\hline estExt_fgenesh4_pg.C_LG_III1187 & AT4G24015.1 & III & None & 0.27 & 0.041 & 182 & 24 & Zinc Finger/Unknown function \\
\hline fgenesh4_pg.C_LG_III001060 & No Hits & III & None & 0.27 & 0.028 & 182 & 24 & None \\
\hline gw1.XVI.2786.1 & AT5G03150.1 & XVI & $J K D$ & 0.24 & 0.017 & 182 & 24,72 & $\begin{array}{l}\text { Zinc Finger Transcription Factor; } \\
\text { root development, regulation of cell } \\
\text { division, cell differentiation, } \\
\text { meristem growth }\end{array}$ \\
\hline fgenesh4_pm.C_LG_XVI000330 & AT2G37220.1 & XVI & F3G5.1 & 0.13 & 0.001 & 182 & 24 & $\begin{array}{l}\text { Chloroplast RNA binding protein, } \\
\text { response to ABA stimulus, response } \\
\text { to cold }\end{array}$ \\
\hline
\end{tabular}


Table 2.7. Candidate genes identified from the QTL intervals with no detected change in expression in response to Cd treatment.

\begin{tabular}{lllll}
\hline Populus Gene & Arabidopsis & & \\
& Gene & QTL LG & Gene symbol & Annotation \\
\hline estExt_fgenesh4_pm.C_LG_III0405 & AT4G23100.1 & III & GSH1, CAD2 & Glutamate-cysteine ligase \\
estExt_Genewise1_v1.C_LG_III2138 & AT1G63440.1 & III & HMA5 & Heavy metal ATPase \\
fgenesh4_pm.C_LG_III000450 & AT5G41610.1 & III & CHX18 & Monovalent cation:proton antiporter \\
estExt_fgenesh4_pg.C_LG_III1026 & AT5G41210.1 & III & GST10 & Glutathione S-transferase \\
fgenesh4_kg.C_LG_III000037 & AT4G11600.1 & III & GPX & Glutathione peroxidase \\
\hline
\end{tabular}



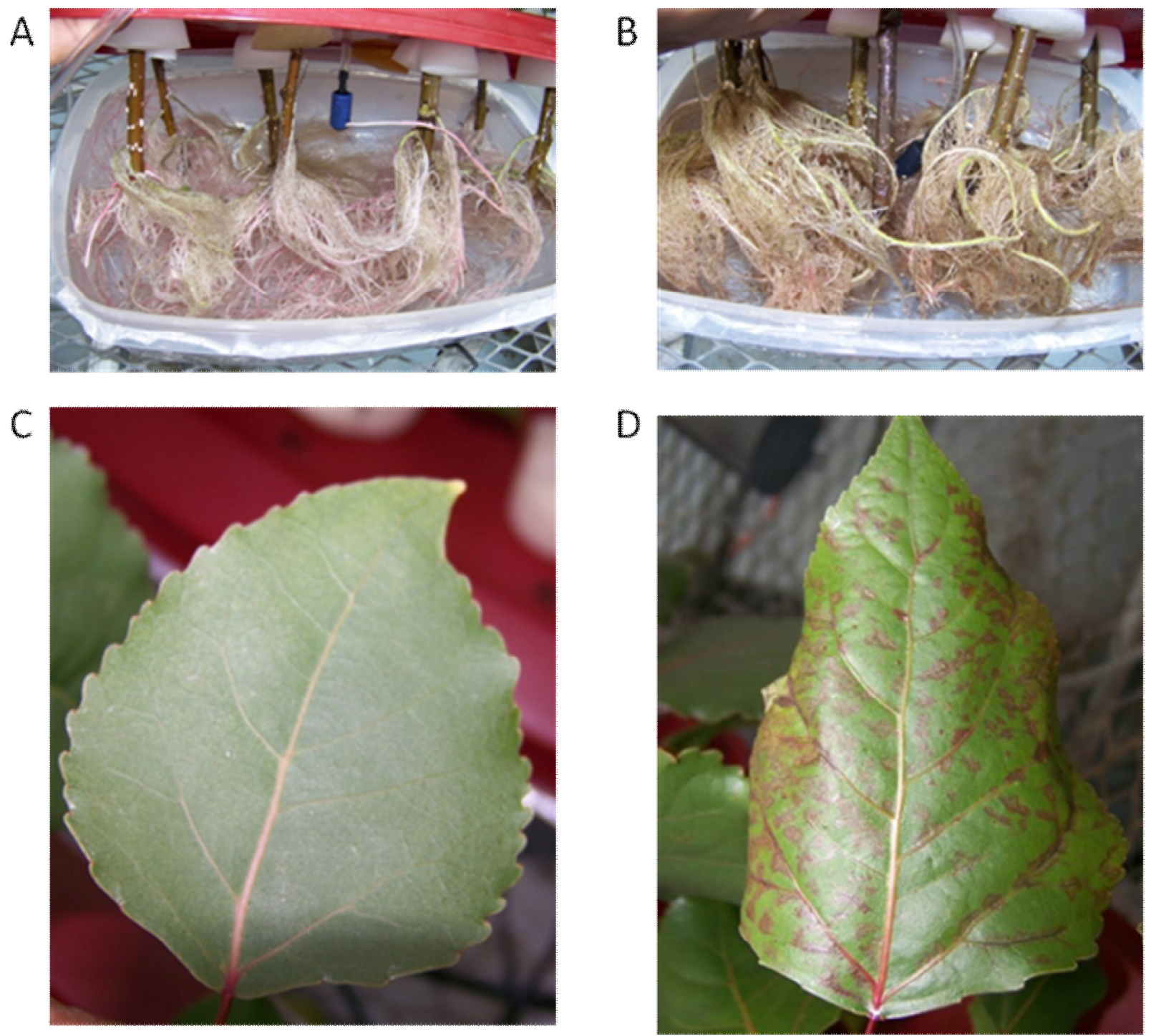

Figure 2.1. Morphological effects of $\mathrm{Cd}$ treatment in a hydroponic experiment. A) Control roots B) Cd treated roots C) Control leaf D) Cd treated leaf. 

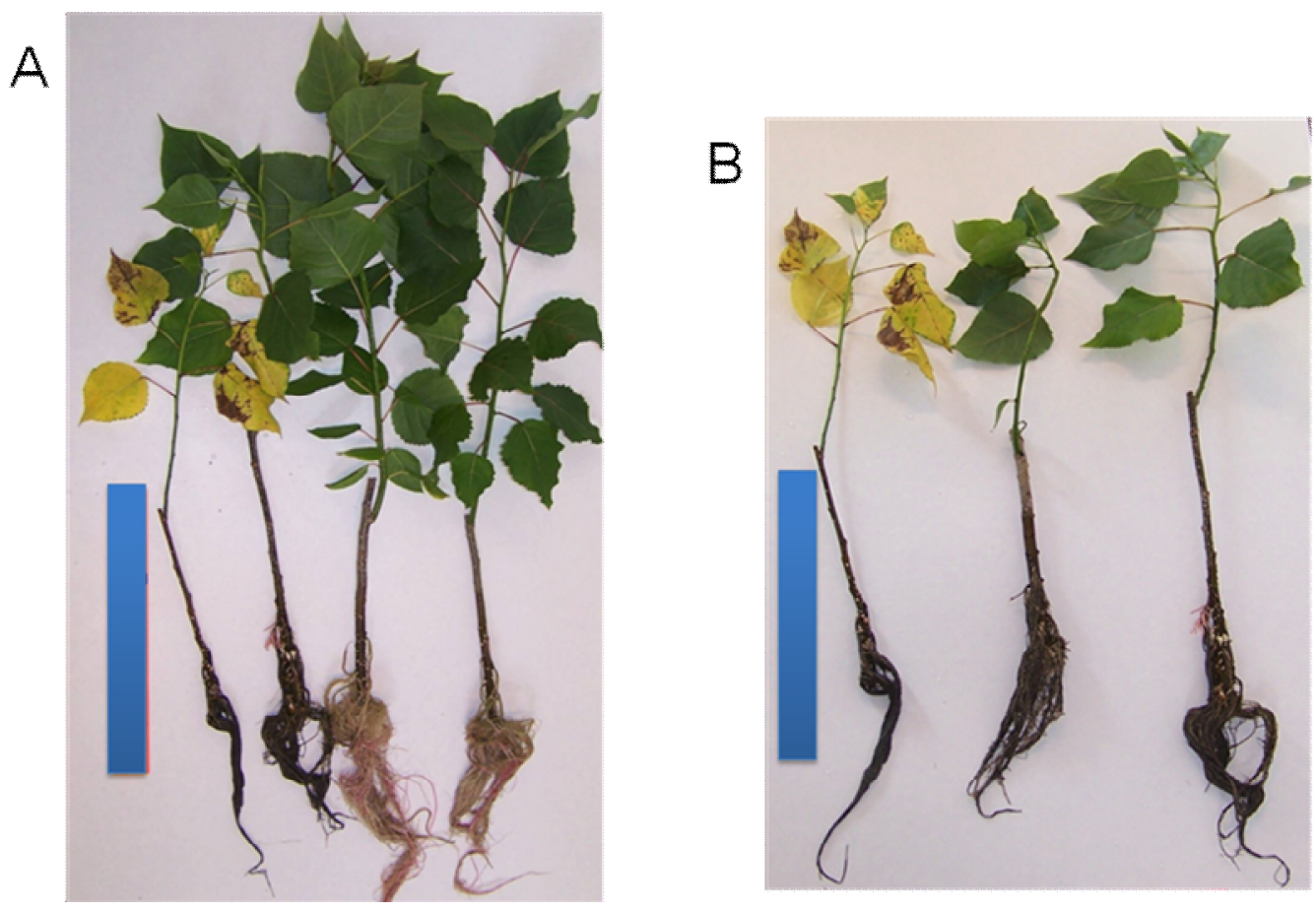

Figure 2.2. A) Genotypic variation in visible effects of $\mathrm{Cd}$ treatment. A) Differences between control (right two plants) and Cd (left two plants) treatments; B) Variation among genotypes under $\mathrm{Cd}$ conditions. Blue bar is $30.5 \mathrm{~cm}$. 


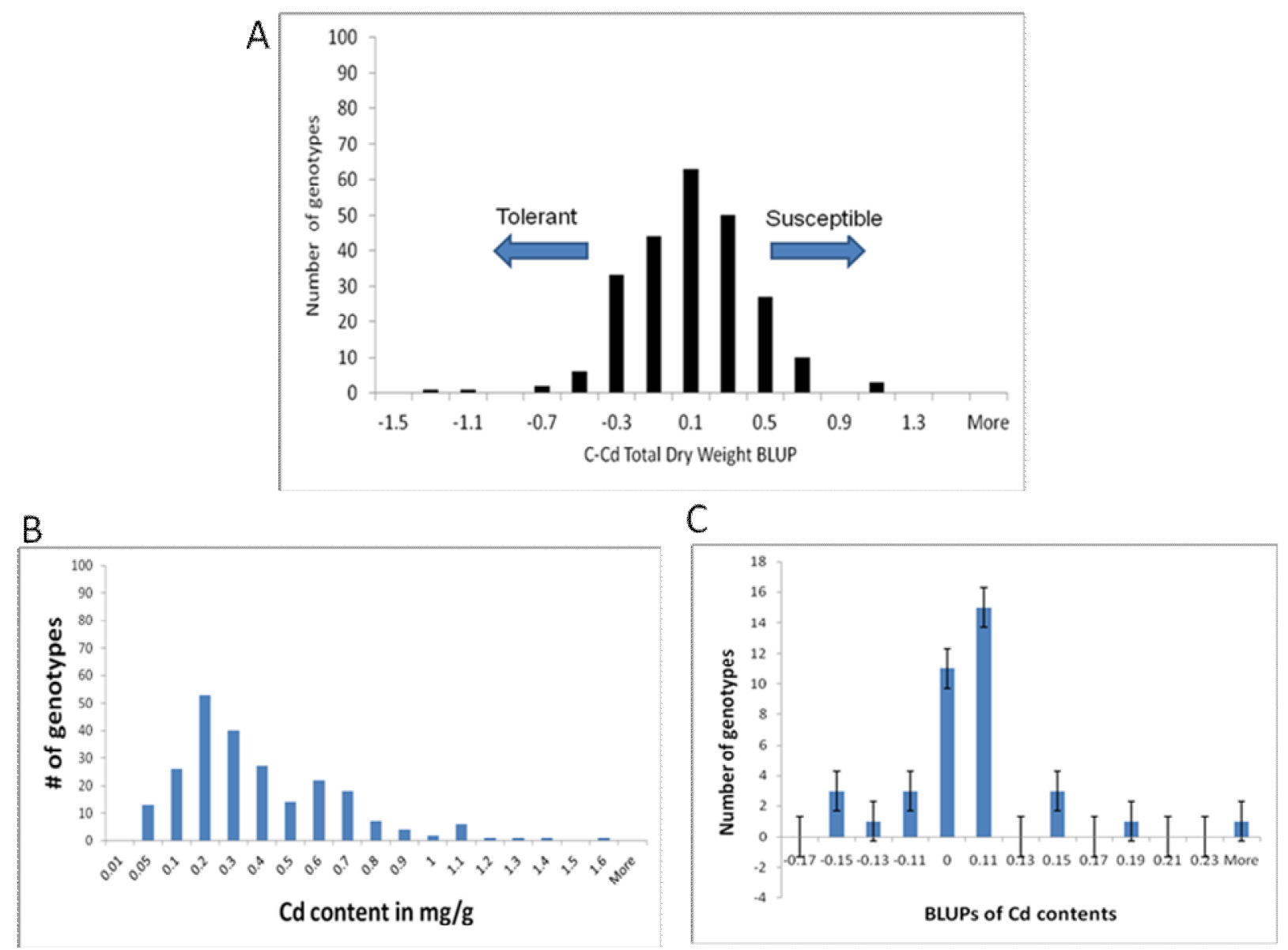

Figure 2.3. A) Distributions of the difference in BLUPs of total dry weight between control (C) and Cadmium $(\mathrm{Cd})$ treatments. Genotypes from the left portion of the curve are relatively tolerant of Cd treatment B). Distributions of BLUPs of Cd contents among 240 genotypes and C). BLUPs of Cd contents among 40 genotypes with replication. 

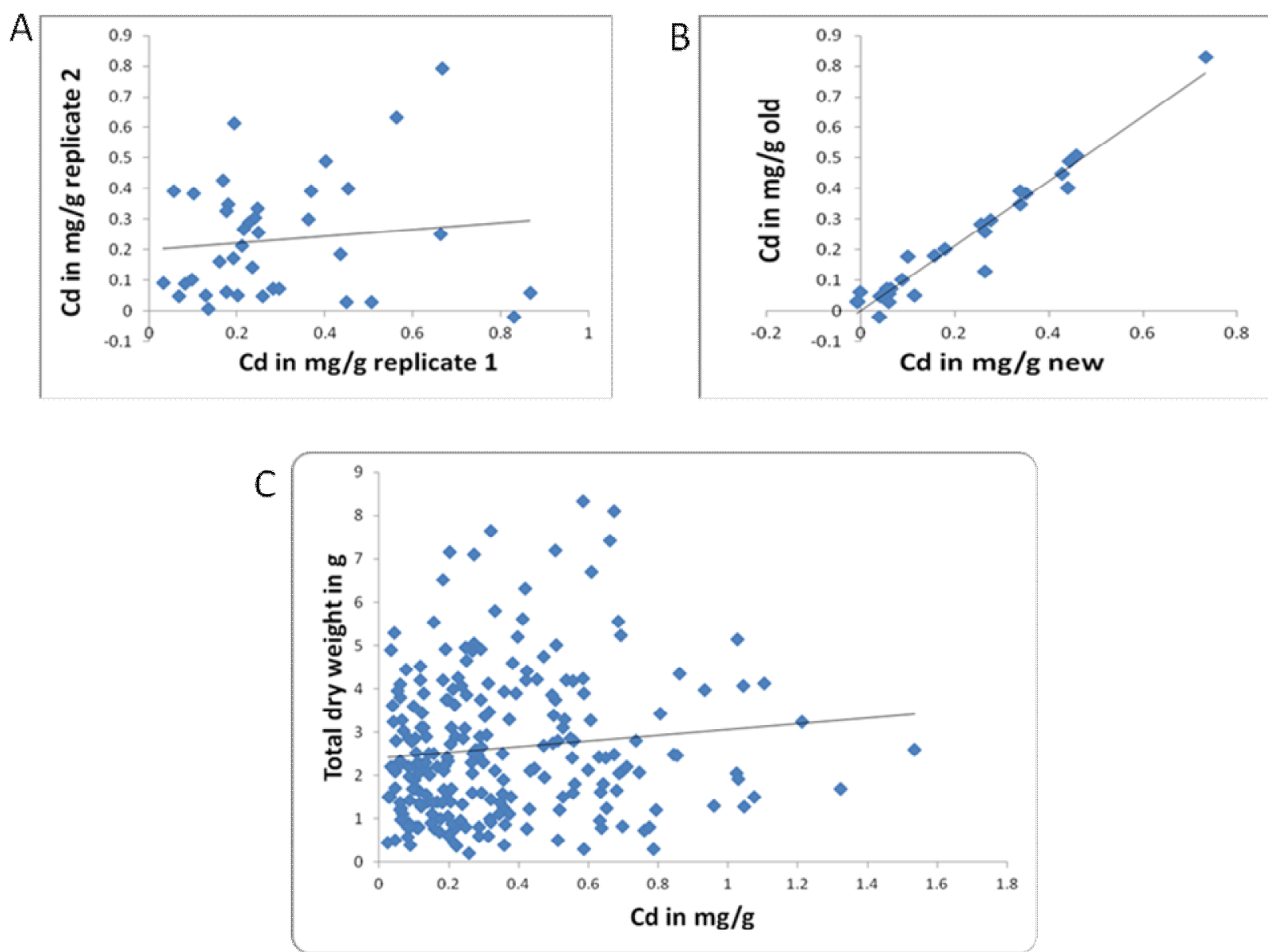

Figure 2.4 A). Dipiction of variation within the genotypes B). Correlation between independent digestions for the same samples and C) Correlation between $\mathrm{Cd}$ contents and total dry weights among the pedigree. 

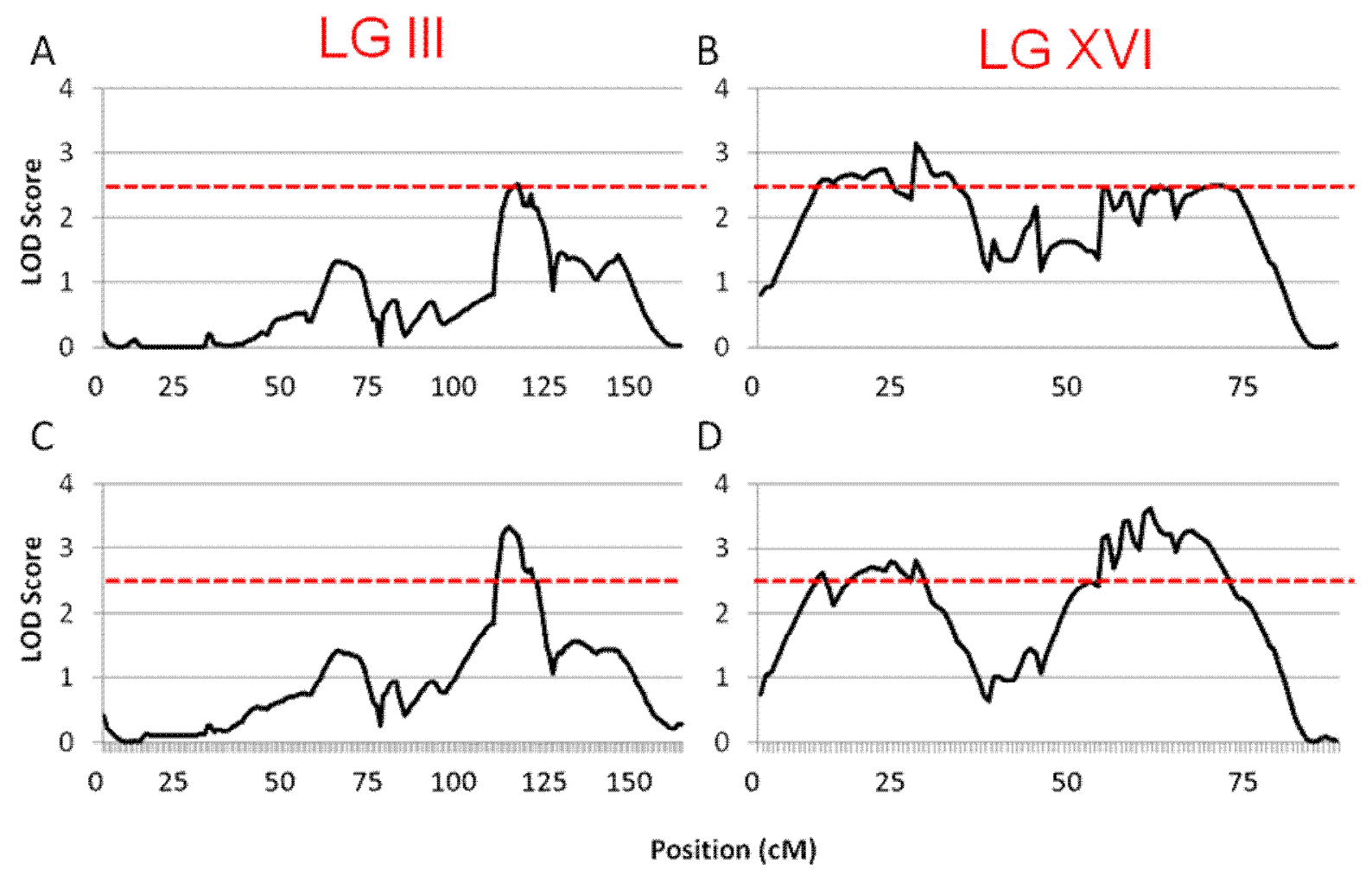

Figure 2.5. LOD scores from the QTL analysis. A) Total dry weight Control: Linkage Group III, B) Total dry weight Cd: Linkage Group XVI, C) Total dry weight Control-Cd: Linkage group III, and D) Total dry weight Control-Cd: Linkage group XVI. 


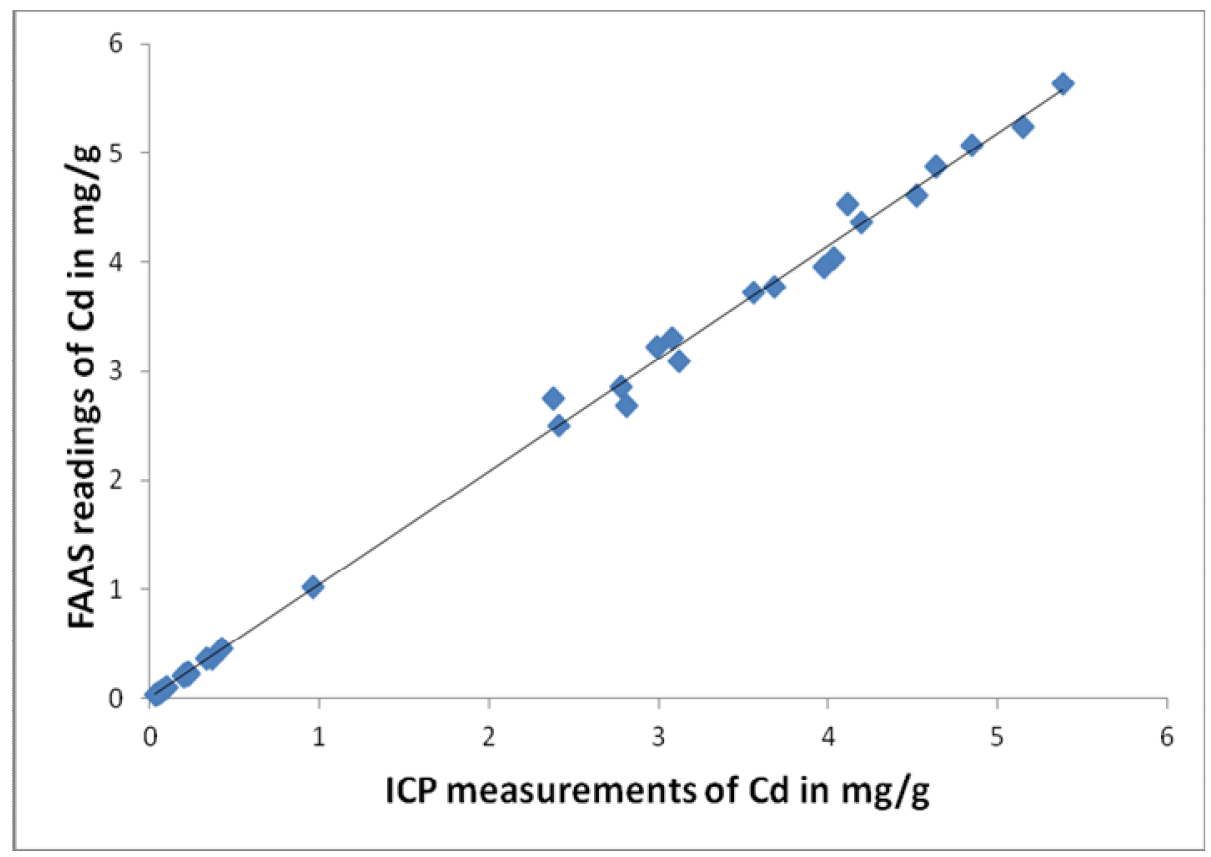

Supplementary Figure S.2.1. Correlation between ICP-OES and FAAS analyses of leaf Cd. 


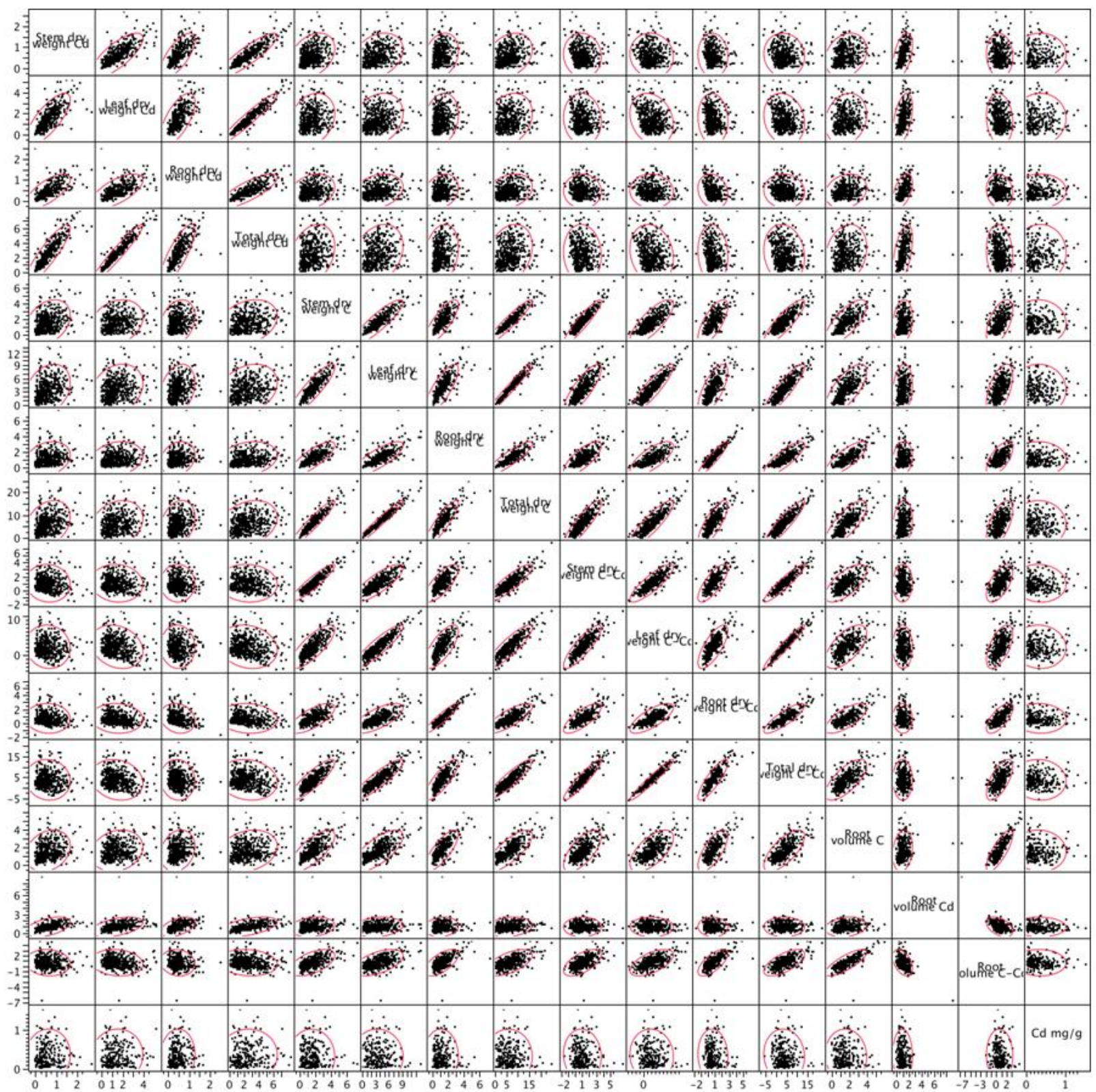

Supplementary Figure S.2.2. Matrix of dot plots showing pairwise relationships among all measured traits. 


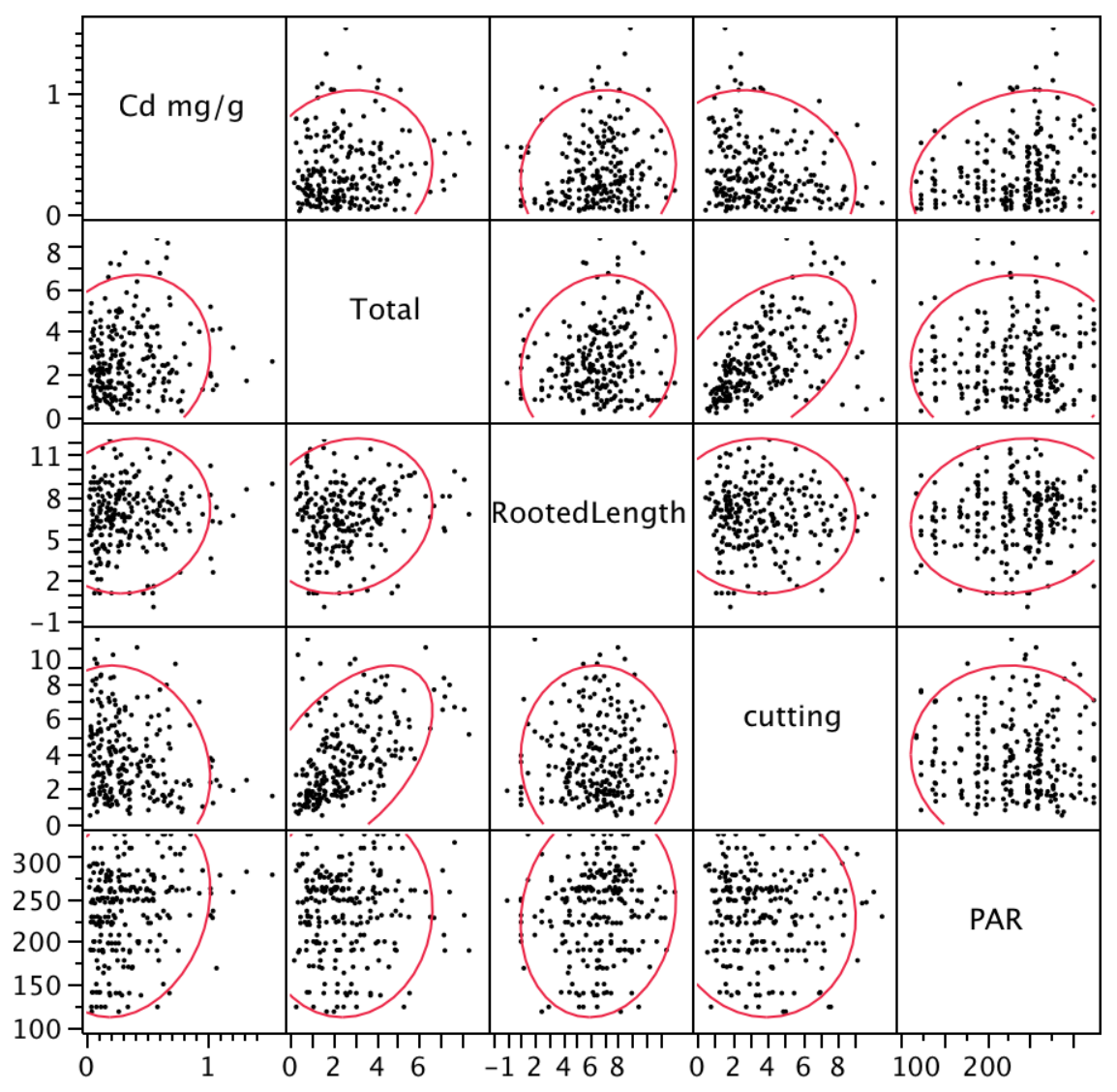

Supplementary Figure S.2.3. Matrix of dot plots showing pairwise relationships among all measured traits with PAR. 


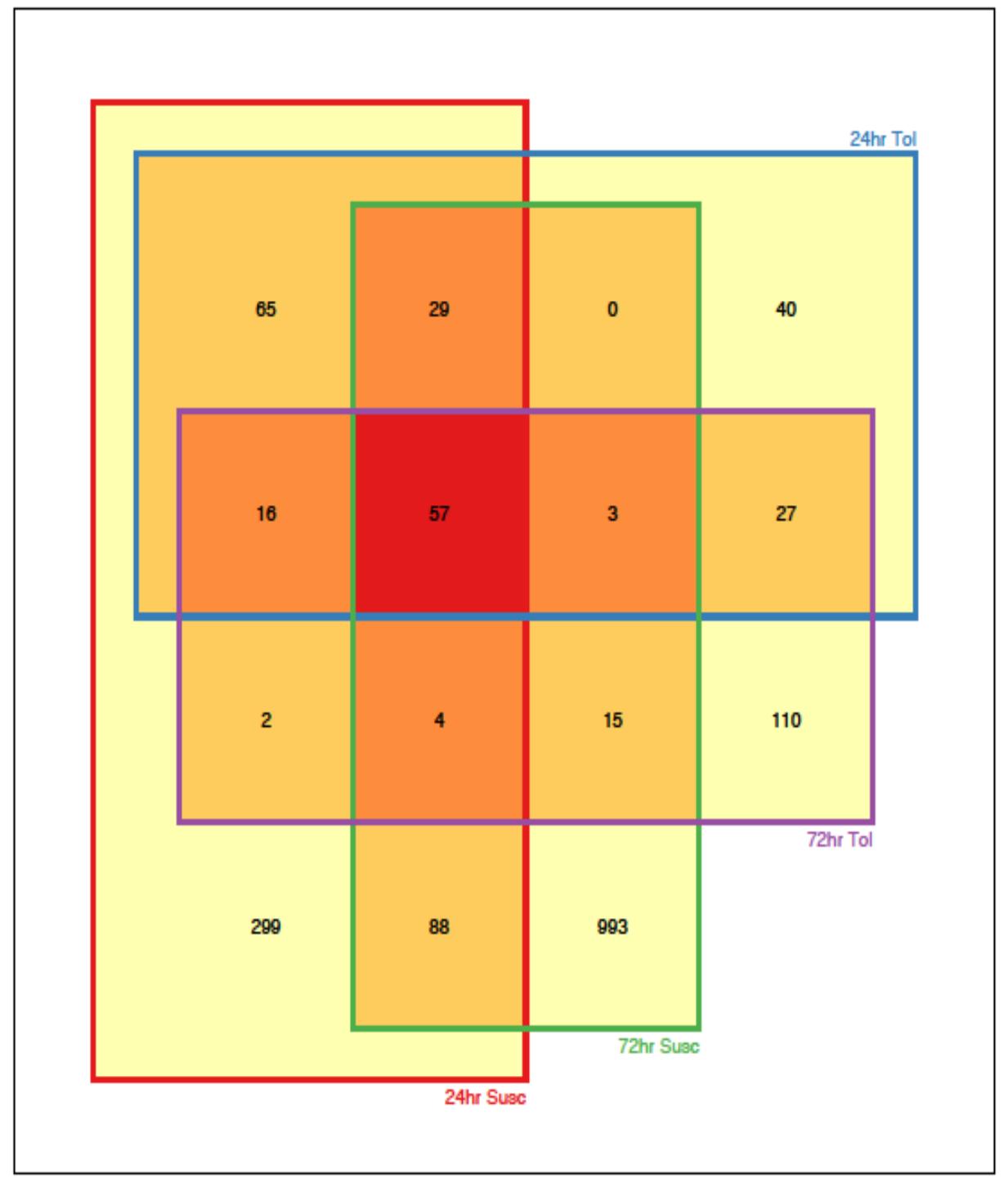

Supplementary Figure S.2.4. Venn diagram of number of up-regulated genes from microarray experiment for two genotypes after 24 and 72 hours. Tol, Cd-tolerant genotype (clone 1-183); Susc, Cd-susceptible genotype (clone 182). 


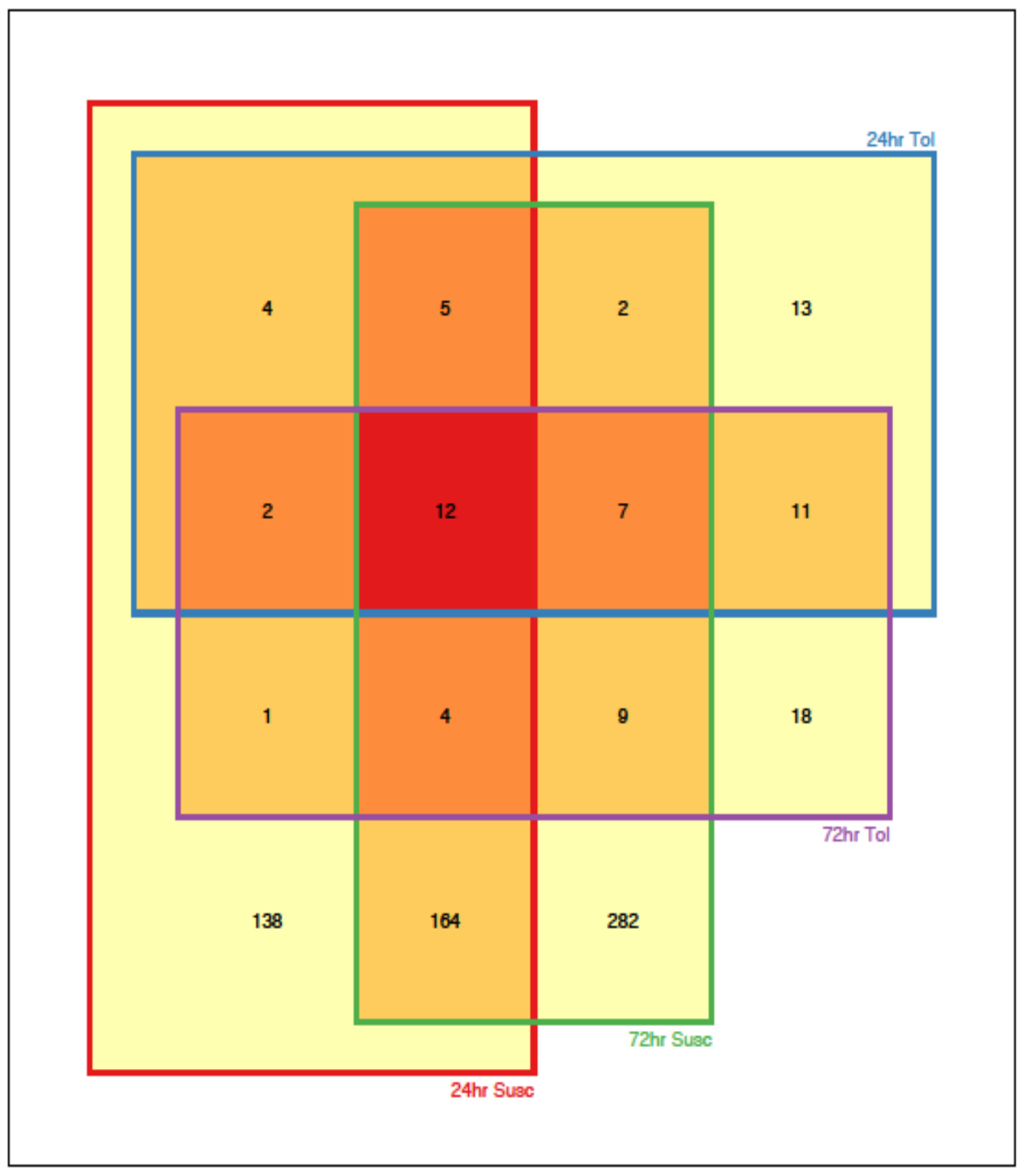

Supplementary Figure S.2.5. Venn diagram of number of down-regulated genes from microarray experiment for two genotypes after 24 and 72 hours. Codes are as in Fig. S2. 


\section{Discussion}

We observed substantial phenotypic variation in Cd effects on plant biomass and leaf $\mathrm{Cd}$ accumulation in Family 52-124, a pseudo-backcross pedigree derived from $P$. trichocarpa $\mathrm{x}$ deltoides hybrids. The effects of genotype, $\mathrm{Cd}$ treatment and their interactions were significant for all response variables measured in this study, including total dry weight, root dry weight, leaf dry weight, stem dry weight, and root volume. Substantial variation in Cd tolerance is commonly observed within and among species. For example, Pietrini et al., (2010) used $50 \mu \mathrm{M}$ of Cd (i.e., twice as high as in our experiment) to compare responses of multiple hybrid Populus clones involving six species. They observed significant variation among clones in the effects of Cd on biomass accumulation, photosynthetic responses, $\mathrm{Cd}$ content of plant parts, and concentration of photosynthetic pigments. Interestingly, the variation in $\mathrm{Cd}$ responses observed among full siblings in our inter-specific cross is of similar magnitude to the variation observed among highly diverse clones that were exposed to a higher concentration of $\mathrm{Cd}$. This illustrates the tremendous phenotypic variation captured by our crossing design and experimental conditions. The Cdtolerant and Cd-susceptible genotypes identified in this study are a useful resource for future experiments targeted at physiological and molecular dissection of Cd tolerance.

\section{Heritability estimates}

Our broad-sense heritability estimate for total dry weight was somewhat lower than those for growth and yield traits measured for Populus in recent field studies (Dillen et al., 2009; Marron et al., 2006; Marron et al., 2010; Rae et al., 2008), though certainly within the range of estimates in earlier studies (Riemenschneider et al., 1996). The broad-sense heritabilities calculated for total dry weight and its components under control conditions were not substantially different from the heritabilities calculated for these traits under Cd exposure. Root 
volume had the lowest heritabilities under both conditions, whereas root dry weight had heritabilities that were comparable to those for other dry weight components. This discrepancy may reflect difficulties in accurately measuring root volume through water displacement.

\section{Leaf Cd analysis}

Significant variation was observed for leaf Cd contents among the 240 genotypes analyzed. Heritability of this trait was low. Significant biological variation was observed between the replicates of a genotype for Cd content. PAR had significant positive correlation with Cd content (Table 2.5). It was hypothesized that PAR was one of the reasons for significant biological variation observed in $\mathrm{Cd}$ contents and also for the significant phenotypic variation observed among 240 genotypes. When the correlations of Cd contents were analyzed with different covariates by REML, PAR had the highest, significant positive coefficient with Cd content (0.22) (Table 2.5 and Supplemental Figure S.2.3). Higher PAR might have resulted in higher transpiration rates in some ramets, thereby increasing uptake of nutrient-Cd solution, which eventually resulted in higher Cd contents. In the study by (Pietrini et al., 2010) significant variation was observed for leaf as well as root Cd contents among the Populus clones subjected to $50 \mathrm{M} \mathrm{CdSO}_{4}$ exposure in hydroponics for three weeks. Variation in the leaf $\mathrm{Cd}$ content was observed when different Populus clones were grown on a metal contaminated site (Migeon et al., 2009). In another study by Laureysens et al., (2004) significant variation was observed for Cd accumulation among the Populus clones grown on a waste disposal site. In a study conducted in pots with different levels of metals, by using Populus clones, significant variation was observed for leaf Cd contents (Dos Santos Utmazian and Wenzel, 2007). In another hydroponic study by (Pilipovic et al., 2005) variation in the leaf Cd contents was observed when Populus clones were treated with Cd. Populus clones showed significant variability whereas willow clones showed no 
variability in leaf $\mathrm{Cd}$ accumulation (Zacchini et al., 2009). Large biomass and higher leaf Cd contents were reported among Populus clones in response to Cd treatment (Utmazian et al., 2007). In vitro screening of Populus clones resulted in significant variability among the clones for leaf Cd accumulation (Di Lonardo et al., 2011). The variation observed in leaf Cd contents among the genotypes in this study and all the studies discussed above suggested the potential for enhancing the phytoextraction component of phytoremediation.

\section{$Q T L$}

Although we detected 16 QTL in this study, these occurred at only four different chromosomal locations. Co-localization of QTL for total dry weight and dry weight components was not surprising, given that these traits were highly intercorrelated and were co-segregating in the pedigree. However, it is potentially more interesting and informative that dry weight under control and Cd conditions mapped to different QTL, and had opposing relationships to the Cd response QTL (C-Cd dry weight). Dry weight under control conditions was positively correlated with Cd effect and allelic effects were in the same direction for these traits when they were colocated, suggesting that these QTL were driven by the size of plants under control conditions (i.e., large plants showed more sensitivity to the $\mathrm{Cd}$ treatment). In contrast, dry weight under $\mathrm{Cd}$ conditions was negatively correlated with Cd effect, and allelic effects were opposite for these traits at co-located QTL, suggesting that Cd tolerance at this locus was associated with growth in the presence of $\mathrm{Cd}$ irrespective of performance under control conditions. The correlations among collocated traits could be the result of underlying genes with pleiotropic effects, positive selection, and/or linkage disequilibrium due to genes that are tightly linked (Novaes et al., 2009; Wullschleger et al., 2005). 
QTL for different traits may also be co-located even when they are not correlated (Wu et al., 1997; Zhang et al., 2006). For example, in this study leaf dry weight Cd and leaf dry weight C-Cd were mapped to the same position on LG XVI, but were not significantly correlated. The same was observed between root dry weight $\mathrm{Cd}$ and root dry weight $\mathrm{C}-\mathrm{Cd}$ and between total dry weight $\mathrm{Cd}$ and total dry weight C-Cd (Tables 2.3 and 2.4). This could be due to a single gene or a regulatory element having pleiotropic effects on these traits and/or different genes within the QTL interval that might be independently controlling these traits, as one QTL encompasses hundreds of candidate genes (Novaes et al., 2009; Wullschleger et al., 2005). Identification of different QTLs on different linkage groups under control and Cd conditions for total dry weight and root dry weight suggested that the genes governing those traits were differentially controlled (Rae et al., 2006), and that the control exerted by these QTLs or genomic regions was dependent on Cd availability. Finally, it is important to note that QTL identified in this study account for a relatively small proportion of the total variation in $\mathrm{Cd}$ responses. Furthermore, since the population used for the current study was relatively small, QTL effects were probably overestimated (Beavis and Paterson, 1998), so, much work remains to identify further mechanisms of Cd tolerance in Populus.

Identification of the underlying QTLs for Cd contents should shed some light on candidate genes for $\mathrm{Cd}$ accumulation. It would be interesting to see whether the QTLs underlying $\mathrm{Cd}$ tolerance and $\mathrm{Cd}$ accumulation coincide, even though the correlations between these traits were not significant. Bert et al., (2003) reported that $\mathrm{Cd}$ accumulation as a complex trait and that $\mathrm{Cd}$ tolerance and $\mathrm{Cd}$ accumulation segregate independently in Arabidopsis hallleri. In contrast, $\mathrm{Cd}$ accumulation and tolerance were reported be segregating together Thlaspi caerulescens populations (Escarre et al., 2000; Lombi et al., 2000). There is lack of clear 
evidence regarding the genetic control of these two traits. Potential candidate genes could be identified from a comparative study of the Cd tolerant and $\mathrm{Cd}$ accumulating plants and the colocated QTLs.

\section{Candidate genes from QTL and microarray analyses}

Transcriptional responses to experimental stimuli are one possible indicator of gene function. We therefore used microarray analyses to gain further insights into the potential roles of the many candidate genes within the QTL intervals. Of the 1571 genes contained within the Cd response QTL intervals, only 12 showed differential expression under Cd treatment. Among these were homologs of AT3G59140.1 (also known as Arabidopsis thaliana MULTIDRUG RESISTANCE-ASSOCIATED PROTEIN 14), which were significantly overexpressed in the Cd tolerant genotype (1-183) relative to the control after $72 \mathrm{~h}$ of treatment. Two closely-related sequences matching this gene occur in the Cd tolerance QTL on LG III, presumably the result of a recent tandem duplication. This gene belongs to the MRP (multidrug resistance-associated protein) subfamily of the superfamily of ATP Binding Cassette (ABC) transporters, which has been implicated in Cd sequestration (Klein et al., 2006). ABC transporters facilitate the translocation of chelates including glutathione with $\mathrm{Cd}$ and $\mathrm{Pb}$ by ATP-driven processes (Klein et al., 2003; Kolukisaoglu et al., 2002; Lu et al., 1998; Martinoia et al., 2002; Tommasini et al., 1998). Interestingly, expression of AtMRPs 3, 4, 6, 7 and 14 were upregulated by Cd in Arabidopsis (Bovet et al., 2003; Kim et al., 2007; Kolukisaoglu et al., 2002). Wojas et al. (2009) demonstrated the role of AtMRP7 in Cd tolerance and vacuolar sequestration in tobacco. Many yeast mutant complementation studies have demonstrated the role of AtMRPs in Cd tolerance, and these MRPs could be used as targets of genetic engineering to increase Cd tolerance and 
accumulation (Wojas et al., 2009). This MRP is therefore an excellent candidate for further functional characterization in Populus.

The remaining genes with differential expression in the QTL intervals have no known role in Cd homeostasis or transport. Four of these genes showed significant up-regulation, and five showed down-regulation (Table 2.7). Six of these have no known function for their closest homologs in model plant species. Interestingly, the gene that was most strongly up-regulated (12.3 fold) in response to 24 -h Cd treatment in both genotypes encodes a putative membrane protein. The predicted protein sequence contains an NHL-repeat domain which is a 6-bladed propeller structure characteristic of a large number of proteins across all major kingdoms (Chaudhuri et al., 2008), including 35 predicted proteins in Populus and 30 in Arabidopsis. For example, the beta propeller is a prominent feature of receptor proteins like TolB, which is involved in antibiotic translocation in E. coli (Kleanthous, 2010) and of phosphate-chelating phytases found in a wide range of bacteria and fungi (Lung et al., 2005). The vast majority of plant proteins containing this domain have no known function, though some may be involved in alkaloid biosynthesis (Ma et al., 2006). Although no known connection with Cd tolerance has been demonstrated, it is intriguing that this protein is localized in cell membranes and is known to function in pore formation in microbes. Functional characterization could well lead to the identification of a novel metal tolerance mechanism in Populus and other plants.

\section{Candidate genes from the QTL intervals}

It is quite possible that genes responsible for interspecific differences in Cd tolerance would not show transcriptional responses that would be detectable in our experiments. In fact, some candidate genes with potential roles in Cd tolerance were present in the QTL intervals, but did not show differential expression in the microarray experiment. These include CAD2 
(CADMIUM SENSITIVE 2), HMA5 (HEAVY METAL ATPase5), CHX18 (cation/hydrogen exchanger 18), GST10 (Glutathione S-Transferase1), and GPX6 (Glutathione peroxidase 6) (Table 2.7).

Phytochelatins (PCs) are one of the major chelators produced by plants upon exposure to heavy metals. These peptides chelate heavy metals and facilitate their sequestration in vacuoles, thus limiting heavy metal toxicity (Koprivova et al., 2002). Phytochelatins are synthesized from glutathione by phytochelatin synthase in the presence of heavy metal ions (Grill et al., 1986; Rauser, 1999). Phytochelatins are induced most strongly by Cd, and plants without phytochelatins showed hypersensitivity toward Cd (Howden et al., 1995b) and other heavy metals. The $\mathrm{Cd}-\mathrm{PC}$ complexes are stored primarily in the root vacuoles, though translocation to shoots also occurs (Kim et al., 2007; Saathoff et al., 2011). The transporter responsible for vacuolar sequestration of $\mathrm{Cd}-\mathrm{PC}$ complexes has yet to be definitively identified in plants, but ABC-transporters like the MRPs have been implicated in plants (Klein et al., 2006; Wojas et al., 2009) and yeast (Mendoza-Cozatl et al., 2010). CADMIUM SENSITIVE 2 is a $\gamma$ glutamylcysteine synthetase, which is involved in glutathione biosynthesis, a precursor for phytochelatins (Howden et al., 1995a). In Arabidopsis, cad2-1 seedlings were more sensitive to Cd than wild-type plants, presumably because the mutants were unable to synthesize phytochelatins (Howden et al., 1995a; Howden et al., 1995b). In this study, the presence of CAD2 in the Cd tolerance QTL on LG III suggests a role for this gene in Cd tolerance in Populus.

Populus contains three homologs of HMA5 (Heavy Metal ATPase5) (Migeon et al., 2010), including the one present within the LG III QTL. Some members of this family have been shown to transport $\mathrm{Cd}$ and enhance $\mathrm{Cd}$ tolerance when overexpressed. For example, HMA 1 
through 4 transport $\mathrm{Zn} / \mathrm{Cd} / \mathrm{Pb} / \mathrm{Co}$ in Arabidopsis and other plants (Cobbett et al., 2003). AtHMA4 enhanced $\mathrm{Cd}$ and $\mathrm{Zn}$ tolerance, transport, accumulation, and root-shoot partitioning when overexpressed in tobacco (Siemianowski et al., 2011). Furthermore, over-expression of HMA3 enhanced Cd accumulation and tolerance in rice, (Oryza sativa) (Miyadate et al., 2010). Although HMA5 is not known to transport Cd (Andres-Colas et al., 2006), it is possible that the specificities of these transporters are different in Populus, especially since the expression profiles of the putative homologs differ markedly between Populus and Arabidopsis (Migeon et al., 2010). This gene is therefore a viable candidate for functional characterization for $\mathrm{Cd}$ transport in Populus.

Another gene from the QTL interval on LG III has homology to CHX18, a cation transporter that belongs to a group of vacuolar membrane proteins in the cation exchanger (CAX) subfamily of proteins. These transport cations utilizing an H+/ATPase pump that generates proton gradients across the vacuolar membrane, and are involved in calcium transport and metal homeostasis (Hirschi et al., 2000; Mei et al., 2009; Migeon et al., 2010). CAXs have a broad range of metal substrates in plants, including significant roles in transporting Cd in roots and shoots (Korenkov et al., 2009). Overexpression of CAX genes enhances Cd tolerance and accumulation in Arabidopsis (Hirschi et al., 2000; Mei et al., 2009; Migeon et al., 2010), tobacco (Korenkov et al., 2007) and petunia (Wu et al., 2011).

A third gene from the QTL interval on LG III has homology to GST10, which belongs to the theta group of the superfamily of glutathione S-transferases (GSTs). GSTs are broadly important in protection against and detoxification of harmful xenobiotics, including heavy metals (Brentner et al., 2008; Dixon et al., 2005). GPX6 (glutathione peroxidase), together with reduced glutathione, reduces hydrogen peroxide and other organic peroxides to water. AtGPX6 was 
upregulated under Cd exposure in Arabidopsis (Sarry et al., 2006), and is strongly induced under a wide range of abiotic stresses (Milla et al., 2003). Thus, homologs of AtGSTT1 and AtGPX6 might contribute to Cd tolerance in Populus through glutathione-mediated oxidative stress tolerance. 


\section{Conclusions}

This study is the first to map QTL loci for Cd tolerance in the commercially and ecologically important genus Populus. This is an important initial step toward enhancing $\mathrm{Cd}$ tolerance in this genus for phytoremediation applications, either through future marker-assisted selection strategies, or through genetic engineering. We refined the list of potential candidate genes from the QTL intervals using whole genome microarray analysis. This revealed putative metal transporters and genes of unknown function that can now be further characterized for their role in Cd transport and vacuolar sequestration. Further work should be geared toward establishing finer-scale associations for these genes by assaying polymorphisms in association populations within $P$. trichocarpa and $P$. deltoides, and by assaying informative candidate polymorphisms that differentiate these species. Furthermore, expression data should be gathered for a larger number of genotypes, and QTLs should be validated in different genetic and environmental backgrounds under both greenhouse and field conditions. Ultimately, this research could lead to the development of heavy metal tolerant and/or hyperaccumulating Populus clones for reclaiming and remediating the extensive marginal lands contaminated with heavy metals. 


\section{Acknowledgements}

We greatly appreciate logistical and intellectual input from Carina Barth, Alex Lastinger, Chase Kempinski, Ryan Imperio, Jonathan Cumming, Dorothy Vesper, and Louis McDonald. Portions of this work were supported by the Department of Energy Bioenergy Science Center under Contract Number DE-AC05-00OR22725, and support from the Eberly College of Arts and Sciences at West Virginia University and the WVU Research Corporation. This was a key project for Jiangsu Universities (10KJA180018). 


\section{References}

Almeida, A.A.F.D., Valle, R.L.R., Mielke, M.S. Gomes, F.B.P. 2007. Tolerance and prospection of phytoremediator woody species of $\mathrm{Cd}, \mathrm{Pb}, \mathrm{Cu}$ and $\mathrm{Cr}$. Brazilian Journal of Plant Physiology 19:83-98.

Andres-Colas, N., Sancenon, V., Rodriguez-Navarro, S., Mayo, S., Thiele, D.J., Ecker, J.R., Puig, S., Penarrubia, L. 2006. The Arabidopsis heavy metal P-type ATPase HMA5 interacts with metallochaperones and functions in copper detoxification of roots. Plant Journal 45:225-236.

Beavis, W.D., A.D. Paterson. 1998. QTL Analyses: power, precision, and accuracy in molecular dissection of complex traits. CRC Press, Boca Raton, FL:145-162.

Bert, V., Meerts, P., Saumitou-Laprade, P., Salis, P., Gruber, W., Verbruggen, N. 2003. Genetic basis of Cd tolerance and hyperaccumulation in Arabidopsis halleri. Plant and Soil 249:9-18.

Bolstad, B.M., Irizarry, R.A., Gautier, L., Wu, Z. 2005. Preprocessing high-density oligonucleotide arrays in bioinformatics and computational biology solutions using $\mathrm{R}$ and Bioconductor. Springer, New York:13-32.

Bovet, L., T. Eggmann, M. Meylan-Bettex, J. Polier, P. Kammer, E. Marin, U. Feller and E. Martinoia. 2003. Transcript levels of AtMRPs after cadmium treatment: induction of AtMRP3. Plant Cell Environment 26:371-381.

Breitling, R., Armengaud, P., Amtmann, A., Herzvk, P. 2004. Rank products: a simple, yet powerful, new method to detect differentially regulated genes in replicated microarray experiments. FEBS Lett. 573:83-92. 
Brentner, L.B., Mukherji, S.T., Merchie, K.M., Yoon, J.M., Schnoor, J.L., Van Aken, B. 2008. Expression of glutathione S-transferases in poplar trees (Populus trichocarpa) exposed to 2,4,6-trinitrotoluene (TNT). Chemosphere 73:657-662.

Burken, J.G., J.L. Schnoor. 1997. Uptake and metabolism of atrazine by poplar trees. Environmental Science \& Technology 31:1399-1406.

Chaudhuri, I., Soding, J., Lupas, A.N. 2008. Evolution of the beta-propeller fold. ProteinsStructure Function and Bioinformatics 71:795-803.

Cobbett, C.S., Hussain, D., Haydon, M.J. 2003. Structural and functional relationships between type 1(B) heavy metal-transporting P-type ATPases in Arabidopsis. New Phytologist 159:315-321.

Coles, N.D., McMullen, M.D., Balint-Kurti, P.J., Pratt, R.C., Holland, J.B. 2010. Genetic control of photoperiod sensitivity in maize revealed by joint multiple population analysis. Genetics 184:799-U301.

Cunningham, S.D., Ow, D.W. 1996. Promises and prospects of phytoremediation. Plant Physiology 110:715-719.

Di Baccio, D., Tognetti, R., Minnocci, A., Sebastiani, L. 2009. Responses of the Populus $x$ euramericana clone I-214 to excess zinc: Carbon assimilation, structural modifications, metal distribution and cellular localization. Environmental and Experimental Botany 67:153-163.

Dillen, S.Y., Marron, N., Sabatti, M., Ceulemans, R., Bastien, C. 2009. Relationships among productivity determinants in two hybrid poplar families grown during three years at two contrasting sites. Tree Physiology 29:975-987. 
Di Lonardo, S., Capuana, M., Arnetoli, M., Gabbrielli, R., Gonnelli, C. 2011. Exploring the metal phytoremediation potential of three Populus alba L. clones using an in vitro screening. Environmental Science and Pollution Research 18, 82-90.

Dixon, D.P., Lapthorn, A.J., Edwards, R. 2005. Synthesis and analysis of chimeric maize glutathione transferases. Plant Science 168:873-881.

Eapen, S., D'Souza, S.F. 2005. Prospects of genetic engineering of plants for phytoremediation of toxic metals. Biotechnology Advances 23:97-114.

Escarre, J., Lefebvre, C., Gruber, W., Leblanc, M., Lepart, J., Riviere, Y., Delay, B. 2000. Zinc and cadmium hyperaccumulation by Thlaspi caerulescens from metalliferous and nonmetalliferous sites in the Mediterranean area: implications for phytoremediation. New Phytologist 145:429-437.

Fodor, F., Gaspar, L., Morales, F., Gogorcena, Y., Lucena, J.J., Cseh, E., Kropfl, K., Abadia, J., Sarvari, E. 2005. Effects of two iron sources on iron and cadmium allocation in poplar (Populus alba) plants exposed to cadmium. Tree Physiology 25:1173-1180.

Grill, E., Gekeler, W., Winnacker, E.L., Zenk, H.H. 1986. Homo-phytochelatins are heavy metal-binding peptides of homo-glutathione containing Fabales. FEBS Lett. 205:47-50.

Hirschi, K.D., Korenkov, V.D., Wilganowski, N.L., Wagner, G.J. 2000. Expression of Arabidopsis CAX2 in tobacco. Altered metal accumulation and increased manganese tolerance. Plant Physiology 124:125-133.

Howden, R., Andersen, C.R., Goldsbrough, P.B., Cobbett, C.S. 1995a. A cadmium-sensitive, glutathione-deficient mutant of Arabidopsis thaliana. Plant Physiology 107:1067-1073. 
Howden, R., Goldsbrough, P.B., Andersen, C.R., Cobbett, C.S. 1995b. Cadmium-sensitive, cad1 mutants of Arabidopsis thaliana are phytochelatin deficient. Plant Physiology 107:10591066.

Jones, J.B.J., Case, V.W. 1990. Sampling handling and analyzing plant tissue samples. Westerman, R. L. (Ed.). Soil Science Society of America Book Series, No. 3. Soil Testing and Plant Analysis, Third Edition. Xxvii+784p. Soil Science Society of America, Inc.: Madison, Wisconsin, USA. Illus. Maps, 389-428.

Kim, D.Y., Bovet, L., Maeshima, M., Martinoia, E., Lee, Y. 2007. The ABC transporter AtPDR8 is a cadmium extrusion pump conferring heavy metal resistance. Plant Journal 50:207218.

Kleanthous, C. 2010. Swimming against the tide: progress and challenges in our understanding of colicin translocation. Nature Reviews Microbiology 8:843-848.

Klein, M., Burla, B., Martinoia, E. 2006. The multidrug resistance-associated protein (MRP/ABCC) subfamily of ATP-binding cassette transporters in plants. FEBS Lett. 580:1112-1122.

Klein, M., Perfus-Barbeoch, L., Frelet, A., Gaedeke, N., Reinhardt, D., Mueller-Roeber, B., Martinoia, E., Forestier, C. 2003. The plant multidrug resistance ABC transporter AtMRP5 is involved in guard cell hormonal signalling and water use. Plant Journal $33: 119-129$.

Kolukisaoglu, H.U., Bovet, L., Klein, M., Eggmann, T., Geisler, M., Wanke, D., Martinoia, E., Schulz, B. 2002. Family business: the multidrug-resistance related protein (MRP) ABC transporter genes in Arabidopsis thaliana. Planta 216:107-119. 
Koprivova, A., Kopriva, S., Jager, D., Will, B., Jouanin, L., Rennenberg, H. 2002. Evaluation of transgenic poplars over-expressing enzymes of glutathione synthesis for phytoremediation of cadmium. Plant Biology 4:664-670.

Korenkov, V., Hirschi, K., Crutchfield, J.D., Wagner, G.J. 2007. Enhancing tonoplast Cd/H antiport activity increases $\mathrm{Cd}, \mathrm{Zn}$, and $\mathrm{Mn}$ tolerance, and impacts root/shoot $\mathrm{Cd}$ partitioning in Nicotiana tabacum L. Planta 226:1379-1387.

Korenkov, V., King, B., Hirschi, K., Wagner, G.J. 2009. Root-selective expression of AtCAX4 and AtCAX2 results in reduced lamina cadmium in field-grown Nicotiana tabacum L. Plant Biotechnology Journal 7:219-226.

Laureysens, I., Blust, R., De Temmerman, L., Lemmens, C., Ceulemans, R. 2004. Clonal variation in heavy metal accumulation and biomass production in a poplar coppice culture: I. Seasonal variation in leaf, wood and bark concentrations. Environmental Pollution 131, 485-494.

Lombi, E., Zhao, F.J., Dunham, S.J., McGrath, S.P. 2000. Cadmium accumulation in populations of Thlaspi caerulescens and Thlaspi goesingense. New Phytologist 145, 11-20.

Lu, Y.P., Li, Z.S., Drozdowicz, Y.M., Hortensteiner, S., Martinoia, E., Rea, P.A. 1998. AtMRP2, an Arabidopsis ATP binding cassette transporter able to transport glutathione Sconjugates and chlorophyll catabolites: Functional comparisons with AtMRP1. Plant Cell $10: 267-282$.

Lung, S.C., Chan, W.L., Yip, W., Wang, L.J., Yeung, E.C., Lim, B.L. 2005. Secretion of betapropeller phytase from tobacco and Arabidopsis roots enhances phosphorus utilization. Plant Science 169:341-349. 
Ma, X., Panjikar, S., Koepke, J., Loris, E., Stöckigt, J. 2006. The Structure of Rauvolfia serpentina strictosidine synthase is a novel six-bladed $\beta$-propeller fold in plant proteins. Plant Cell 18:907-920.

Marron, N., Bastien, C., Sabatti, M., Taylor, G., Ceulemans, R. 2006. Plasticity of growth and sylleptic branchiness in two poplar families grown at three sites across Europe. Tree Physiology 26:935-946.

Marron, N., Ricciotti, L., Bastien, C., Beritognolo, I., Gaudet, M., Paolucci, I., Fabbrini, F., Salani, F., Dillen, S.Y., Ceulemans, R., Pinel, M.P.C., Taylor, G., Scarascia-Mugnozza, G., Sabatti, M. 2010. Plasticity of growth and biomass production of an intraspecific Populus alba family grown at three sites across Europe during three growing seasons. Canadian Journal of Forest Research 40:1887-1903.

Martinoia, E., Klein, M., Geisler, M., Bovet, L., Forestier, C., Kolukisaoglu, U., Muller-Rober, B., Schulz, B. 2002. Multifunctionality of plant ABC transporters - more than just detoxifiers. Planta 214:345-355.

Mei, H., Cheng, N.H., Zhao, J., Park, S., Escareno, R.A., Pittman, J.K. Hirschi, K.D. 2009. Root development under metal stress in Arabidopsis thaliana requires the $\mathrm{H}+/$ cation antiporter CAX4. New Phytologist 183:95-105.

Mendoza-Cozatl, D.G., Zhai, Z.Y., Jobe, T.O., Akmakjian, G.Z., Song, W.Y., Limbo, O., Russell, M.R., Kozlovskyy, V.I., Martinoia, E., Vatamaniuk, O.K., Russell, P., Schroeder, J.I. 2010. Tonoplast-localized Abc2 transporter mediates phytochelatin accumulation in vacuoles and confers cadmium tolerance. Journal of Biological Chemistry 285:40416-40426. 
Migeon, A., Blaudez, D., Wilkins, O., Montanini, B., Campbell, M.M., Richaud, P., Thomine, S. Chalot, M. 2010. Genome-wide analysis of plant metal transporters, with an emphasis on poplar. Cellular and Molecular Life Sciences 67:3763-3784.

Migeon, A., Richaud, P., Guinet, F., Chalot, M., Blaudez, D. 2009. Metal accumulation by woody species on contaminated sites in the North of France. Water Air Soil Pollution 204:89-101.

Milla, M.A.R., Maurer, A., Huete, A.R., Gustafson, J.P. 2003. Glutathione peroxidase genes in Arabidopsis are ubiquitous and regulated by abiotic stresses through diverse signaling pathways. Plant Journal 36:602-615.

Milone, M.T., Sgherri, C., Clijsters, H., Navari-Izzo, F. 2003. Antioxidative responses of wheat treated with realistic concentration of cadmium. Environmental and Experimental Botany $50: 265-276$.

Miyadate, H., Adachi, S., Hiraizumi, A., Tezuka, K., Nakazawa, N., Kawamoto, T., Katou, K., Kodama, I., Sakurai, K., Takahashi, H., Satoh-Nagasawa, N., Watanabe, A., Fujimura, T., Akagi, H. 2010. OsHMA3, a P-1B-type of ATPase affects root-to-shoot cadmium translocation in rice by mediating efflux into vacuoles. New Phytologist 189:190-199.

Newman, L.A., Strand, S.E., Choe, N., Duffy, J., Ekuan, G., Ruszaj, M., Shurtleff, B.B., Wilmoth, J., Heilman, P., Gordon, M.P.1997. Uptake and biotransformation of trichloroethylene by hybrid poplars. Environmental Science \& Technology 31:10621067.

Novaes, E., Osorio, L., Drost, D.R., Miles, B.L., Boaventura-Novaes, C.R.D., Benedict, C., Dervinis, C., Yu, Q., Sykes, R., Davis, M., Martin, T.A., Peter, G.F., Kirst, M. 2009. 
Quantitative genetic analysis of biomass and wood chemistry of Populus under different nitrogen levels. New Phytologist 182:878-890.

Ouariti, O., Boussama, N., Zarrouk, M., Cherif, A., Ghorbal, M.H. 1997. Cadmium- and copperinduced changes in tomato membrane lipids. Phytochemistry. 45:1343-1350.

Pietrini, F., Zacchini, M., Iori, V., Pietrosanti, L., Bianconi, D., Massacci, A. 2010. Screening of poplar clones for cadmium phytoremediation using photosynthesis, biomass and cadmium content analyses. International Journal of Phytoremediation 12:105-120.

Pilipovic, A., Nikolic, N., Orlovic, S., Petrovic, N., Krstic, B. 2005. Cadmium phytoextraction potential of poplar clones (Populus spp.). Journal of Biosciences 60:247-251.

Pilon-Smits, E.A.H., de Souza, M.P., Lytle, C.M., Shang, C., Lugo, T., Terry, N.1998. Selenium volatilization and assimilation by hybrid poplar (Populus tremula $x$ P. alba). Journal of Experimental Botany 49:1889-1892.

Rae, A.M., Ferris, R., Tallis, M.J., Taylor, G. 2006. Elucidating genomic regions determining enhanced leaf growth and delayed senescence in elevated $\mathrm{CO}_{2}$. Plant Cell Environment 29:1730-1741.

Rae, A.M., Pinel, M.P.C., Bastien, C., Sabatti, M., Street, N.R., Tucker, J., Dixon, C., Marron, N., Dillen, S.Y., Taylor, G. 2008. QTL for yield in bioenergy Populus: identifying GxE interactions from growth at three contrasting sites. Tree Genetics and Genomes. 4:97112.

Rauser, W.E. 1999. Structure and function of metal chelators produced by plants - The case for organic acids, amino acids, phytin, and metallothioneins. Cell Biochemistry and Biophysics 31:19-48. 
Riemenschneider, D.E., Stelzer, H.E., Foster, G.S. 1996. Quantitative genetics of poplars and poplar hybrids. In Biology of Populus and its implications for management and conservation. NRC Researchl Press, Ottawa, ON:159-181.

Robinson, B.H., Mills, T.M., Petit, D., Fung, L.E., Green, S.R., Clothier, B.E. 2000. Natural and induced cadmium-accumulation in poplar and willow: Implications for phytoremediation. Plant Soil 227:301-306.

Rockwood, D.L., Naidu, C.V., Carter, D.R., Rahmani, M., Spriggs, T.A., Lin, C., Alker, G.R., Isebrands, J.G., Segrest, S.A. 2004. Short-rotation woody crops and phytoremediation: Opportunities for agroforestry? Agroforestry Systems 61-2:51-63.

Rodriguez-Serrano, M., Romero-Puertas, M.C., Pazmino, D.M., Testillano, P.S., Risueno, M.C., Del Rio, L.A., Sandalio, L.M. 2009. Cellular response of pea plants to cadmium toxicity: cross talk between reactive oxygen species, nitric oxide, and calcium. Plant Physiology 150:229-243.

Saathoff, A.J., Ahner, B., Spanswick, R.M., Walker, L.P. 2011. Detection of phytochelatin in the xylem sap of Brassica napus. Environmental Engineering Science 28:103-111.

Sandalio, L.M., Dalurzo, H.C., Gomez, M., Romero-Puertas, M.C., Del Rio, L.A. 2001. Cadmium-induced changes in the growth and oxidative metabolism of pea plants. Journal of Experimental Botany 52:2115-2126. Sarry, J.E., L. Kuhn, C. Ducruix, A. Lafaye, C. Junot, V. Hugouvieux, A. Jourdain, O. Bastien, J.B. Fievet, D. Vailhen, B. Amekraz, C. Moulin, E. Ezan, J. Garin and J. Bourguignon. 2006. The early responses of Arabidopsis thaliana cells to cadmium exposure explored by protein and metabolite profiling analyses. Proteomics. 6:2180-2198. 
Shao, G.S., Chen, M.X., Wang, D.Y., Xu, C.M., Mou, R.X., Cao, Z.Y., Zhang, X.F. 2008. Using iron fertilizer to control $\mathrm{Cd}$ accumulation in rice plants: A new promising technology. Science in China Series C-Life Sciences 51:245-253.

Shapiro, S.S., Wilk, M.B. 1965. An analysis of variance test for normality (complete samples). Biometrika. 52:591-611.

Siddique, K.H.M., Tennant, D. Perry, M.W., Belford, R.K. 1990. Water-use and water-use efficiency of old and modern wheat cultivars in a mediterranean-type environment. Australian Journal of Agricultural Research 41:431-447.

Siedlecka, A., Krupa, Z. 1999. Cd/Fe interaction in higher plants - its consequences for the photosynthetic apparatus. Photosynthetica 36:321-331.

Siemianowski, O., Mills, R.F., Williams, L.E., Antosiewicz, D.M. 2011. Expression of the P-1Btype ATPase AtHMA4 in tobacco modifies $\mathrm{Zn}$ and $\mathrm{Cd}$ root to shoot partitioning and metal tolerance. Plant Biotechnology Journal 9:64-74.

Smeets, K., A. Cuypers, A. Lambrechts, B. Semane, P. Hoet, A. Van Laere and J. Vangronsveld. 2005. Induction of oxidative stress and antioxidative mechanisms in Phaseolus vulgaris after Cd application. Plant Physiology and Biochemistry 43:437-444.

Solti, A., Gaspar, L., Meszaros, I., Szigeti, Z., Levai, L., Sarvari, E. 2008. Impact of iron supply on the kinetics of recovery of photosynthesis in Cd-stressed poplar (Populus glauca). Annals of Botany 102:771-782.

Tommasini, R., Vogt, E., Fromenteau, M., Hortensteiner, S., Matile, P., Amrhein, N., Martinoia, E. 1998. An ABC-transporter of Arabidopsis thaliana has both glutathione-conjugate and chlorophyll catabolite transport activity. Plant Journal 13:773-780. 
Tuskan, G.A., Gunter, L.E., Yang, Z.M.K., Yin, T.M., Sewell, M.M., DiFazio, S.P. 2004. Characterization of microsatellites revealed by genomic sequencing of Populus trichocarpa. Canadian Journal of Forest Research 34:85-93.

Utmazian, M.N.D., Wieshammer, G., Vega, R., Wenzel, W.W. 2007. Hydroponic screening for metal resistance and accumulation of cadmium and zinc in twenty clones of willows and poplars. Environmental Pollution 148, 155-165.

Van Ooijen, J. 2004. MapQTL 5, software for the mapping of quantitativetrait loci in experimental populations., Kyazma B.V. Wageningen, Netherlands.

Van Ooijen, J., Voorrips, R.E . 2001. JoinMap 3.0, Software for the calculation of genetic linkage maps. In Plant Research International, Wageningen, Netherlands.

Vanassche, F., Clijsters, H. 1990. Effects of metals on enzyme-activity in plants. Plant Cell Environment 13:195-206.

Wojas, S., Hennig, J., Plaza, S., Geisler, M., Siemianowski, O., Sklodowska, A., Ruszczynska, A., Bulska, E., Antosiewicz, D.M. 2009. Ectopic expression of Arabidopsis ABC transporter MRP7 modifies cadmium root-to-shoot transport and accumulation. Environment Pollution 157:2781-2789.

Wu, Q., Shigaki, T., Williams, K.A., Han, J.S., Kim, C.K., Hirschi, K.D., Park, S. 2011. Expression of an Arabidopsis $\mathrm{Ca}_{2}{ }^{+} / \mathrm{H}^{+}$antiporter CAX1 variant in petunia enhances cadmium tolerance and accumulation. Journal of Plant Physiology 168:167-173.

Wu, R., Bradshaw, H.D., Stettler, R.F. 1997. Molecular genetics of growth and development in Populus (Salicaceae). Mapping quantitative trait loci affecting leaf variation. American Journal of Botany 84:143-153. 
Wullschleger, S., Yin, T.M., DiFazio, S.P., Tschaplinski, T.J., Gunter, L.E. Davis, M.F., Tuskan, G.A. 2005. Phenotypic variation in growth and biomass distribution for two advancedgeneration pedigrees of hybrid poplar. Canadian Journal of Forest Research 35:17791789.

Yin, T.M., DiFazio, S.P., Gunter, L.E.,Jawdy, S.S., Boerjan, W., Tuskan, G.A. 2004. Genetic and physical mapping of Melampsora rust resistance genes in Populus and characterization of linkage disequilibrium and flanking genomic sequence. New Phytologist 164:95-105.

Yin, T.M., Zhang, X.Y., Gunter, L.E., Li, S.X., Wullschleger, S.D., Huang, M.R., Tuskan, G.A. 2009. Microsatellite primer resource for Populus developed from the mapped sequence scaffolds of the Nisqually-1 genome. New Phytologist 181:498-503.

Zacchini, M., Pietrini, F., Scarascia, G., Mugnozza, Iori, V., Pietrosanti, L., Massacci, A. 2009. Metal tolerance, accumulation and translocation in Populus and willow clones treated with cadmium in hydroponics. Water, Air, and Soil Pollution 197:23-24.

Zhang, D., Zhang, Z., Yang, K. 2006. QTL analysis of growth and wood chemical content traits in an interspecific backcross family of white poplar (Populus tomentosa $\mathrm{x}$ P. bolleana) $\mathrm{x}$ P. tomentosa. Canadian Journal of Forest Research 36:2015-2023. 


\title{
CHAPTER III
}

\section{QUANTITATIVE TRAIT LOCI FOR GROWTH, BIOMASS AND PHENOLOGY TRAITS IN POPULUS UNDER GREENHOUSE AND FIELD CONDITIONS}

\author{
Authors \\ Brahma Reddy Induri, Wellington Muchero, Gancho T. Slavov, Tong-Ming Yin, Xinye Zhang, \\ Gerald A. Tuskan, Stephen P. DiFazio
}

\section{Authors' contribution}

Brahma Reddy Induri wrote the manuscript and performed the greenhouse experiments and Cd assays. Wellington Muchero and Gerald Tuskan contributed toward QTL mapping, QTL analysis and provided text describing those methods. Tongming Yin and XinYe Zhang contributed towards mapping. Gancho Slavov contributed to the statistical analysis. Stephen DiFazio directed the project and contributed toward the writing. 


\begin{abstract}
A pseudo-backcross pedigree of Populus trichocarpa and P. deltoides (Family 52-124) was examined under greenhouse and field conditions to quantify the phenotypic variation and to identify the genetic basis of growth, biomass distribution and phenology traits. Broad-sense heritability $\left(H^{2}{ }_{\text {BS }}\right)$ values ranged from 0.18 to 0.39 in the greenhouse, and from 0.33 to 0.68 and 0.50 to 0.78 in Years 1 and 2 in the field, respectively. The lower heritabilities in the greenhouse might be due to competition among genotypes, which were grown at tight spacing in relatively small hydroponic containers. Quantitative trait locus (QTL) analysis revealed a total of 15 QTLs under greenhouse conditions at a logarithm of odds (LOD) ratio $\geq 2.5$, accounting for an average of $6.1 \%$ of phenotypic variation per QTL. We also detected 62 QTLs in the first growing season and 52 QTLs in the second growing season under field conditions (LOD $\geq 3.0$ ), accounting for $4.4 \%$ and $5.1 \%$ of the phenotypic variation on average, respectively. Many biomass traits were intercorrelated and consequently shared QTL positions within the greenhouse and field studies. There was some correspondence between QTL measured in the two years of the field study, but little correspondence with QTL detected in other studies with this and other Populus pedigrees, indicating substantial genotype $\mathrm{x}$ environment interactions for these traits. There was also a weak relationship between biomass and phenology traits based on correlations and colocation of QTL. Allometric analyses suggested changes in biomass distribution with increase in age, from the first to second growing season. The findings reported here provide further insights into mechanisms of genetic control of growth, phenology, and crown architecture, and will therefore contribute toward the development of Populus as an important model system and as a crop for production of fuel, fiber, wood, and phytoremediation.
\end{abstract}




\section{Introduction}

Breeding for high biomass has long been a major goal in forest tree improvement. Hybrid Populus breeding programs have been focused in part on developing renewable feedstocks for biofuel production (Marron et al., 2010 b). Populus is one of the fastest growing temperate trees and can sequester more carbon over a longer period of time compared to annual crops, and is also ecologically important, often playing the role of a foundation species in different ecosystems (Whitham et al., 2008). Populus is regarded as one of the best suited species for short rotation coppicing (Laureysens et al., 2003). In fact, Populus is already being grown in intensively managed plantations and its biomass is used as a source of wood fiber and as an energy source (Scarascia Mugnozza et al., 1997). Exploration of new methods to enhance commercial Populus biomass production and elucidation of the effects of genetics and environment on biomass production are of immediate importance to make short rotation forestry an economically viable option (Marron et al., 2010 b; Updegraff et al., 2004).

Allometry describes the relationships of one plant component to another in morphology, physiology and anatomy, and it also reveals any major shifts in biomass distribution to various plant growth components including height, diameter and number of sylleptic branches at different growth stages. These relationships among traits can be studied by using an allometric power equation (McMahon, 1973; Schmidt-Nielsen, 1984). The pattern of carbon allocation and partitioning to roots and shoots determines the competitive ability of a genotype in a particular environment (Aerts et al., 1991; Wullschleger et al., 2005). Despite its importance, there have been a very few studies that have investigated allometric relationships in Populus (Wullschleger et al., 2005; Marron et al., 2010 a; Karim and Hawkins, 1999; Dillen et al., 2007; Dillen et al., 2009). Although the exact mechanisms are not understood, a genetic basis was expected for these 
changes in size in different organisms (Oldham et al., 2000). The genetic basis of aboveground and belowground biomass distribution has been examined in various Populus studies (Scarascia Mugnozza et al., 1997; Karim and Hawkins, 1999; Dickson et al., 1998; Pregitzer et al., 1990; Heilman et al., 1994). Five Populus clones upon exposure to elevated $\mathrm{CO}_{2}$ and $\mathrm{O}_{3}$ demonstrated significant differences in their carbon allocation patterns to the above-ground and below-ground plant parts within and among genotypes (Dickson et al., 1998). In another study, four P. trichocarpa x P. deltoides Populus clones were studied for growth and biomass traits for four years and they exhibited significant clonal variation in their biomass and biomass allocation patterns to leaf and root components in different seasons of growth (Scarascia Mugnozza et al., 1997). Another study using two Populus genotypes with differing phenology and morphology demonstrated significant variation in biomass distribution to roots and shoots (Pregitzer et al., 1990; Isebrands and Nelson, 1983). It is difficult to draw robust inferences on biomass distribution from these studies because most of them used a small number of genotypes (Wullschleger et al., 2005). As a result there is an urgent need to not only study phenotypic variation in total and fractional biomass distribution but also to elucidate its genetic basis, using a large number of genotypes (Poorter and Nagel, 2000).

Genotype by environment ( $\mathrm{G} \times \mathrm{E})$ interactions determine the robustness and repeatability of genotypic control across different environments (Marron et al., 2010 a). The presence of a G x E interaction implies that the effects of genotypes and environment are not statistically additive (Lynch et al., 1998) such that the same genotypes respond differently in different environments. Estimation of the performance of a genotype is difficult with the presence of a $\mathrm{G} x \mathrm{E}$ interaction in changing environments (Marron et al., 2010 a) as it is difficult to deconvolute the main effects of genotype and environment unless trials are replicated across environments. It is therefore 
important to measure quantitative trait locus (QTL) in multiple environments and years to determine the robustness of the associations, which will inform the range of scenarios in which these loci are relevant. Many studies in Populus have employed interspecific hybridization and QTL analysis to elucidate the genetic basis of quantitative traits (Wu, 1998; Bradshaw and Stettler, 1995). Such studies, coupled with the availability of Populus whole genome sequence (Tuskan et al., 2004) facilitate not only the understanding of the genetic basis of complex traits but also the identification of candidate genes for quantitative characters including total and fractional biomass distribution (Wullschleger et al., 2005; Ingvarsson, 2005; Grattapaglia et al., 2009).

Some studies have identified QTL for biomass related traits in Populus including bud burst and bud set (Bradshaw and Stettler, 1995; Frewen et al., 2000), branching (Bradshaw and Stettler, 1995), osmotic potential (Tschaplinski et al., 2006), growth and biomass (Wullschleger et al., 2005), rooting capacity (Zhang et al., 2009), yield in bio-energy plantations (Rae et al., 2008; Rae et al., 2009; Wu et al., 1998), leaf biomass productivity traits (Bunn et al., 2004), and sylleptic branch number and stem volume (Zhang et al., 2006). The present study is one of the first to explore growth and biomass distribution in Populus using a large number of genotypes under greenhouse and field conditions. The main objectives of the current study are (1) characterization of the extent of genetic and phenotypic variation in different growth, biomass distribution, and phenology traits in a pseudo-backcross Populus pedigree under field and greenhouse hydroponic conditions; (2) estimation of allometric relationships among individual plant biomass components under field and greenhouse hydroponic conditions; (3) identification of QTLs, and thereby the genetic basis for growth and fractional distribution of biomass under 
greenhouse and field conditions; and (4) comparison of QTLs across greenhouse and field conditions and among years in the field. 


\section{Material and Methods}

\section{Mapping population used for greenhouse and field studies}

An interspecific mapping population was developed at the University of Minnesota Natural Resources Research Institute by hybridization of $P$. trichocarpa clone 93-968 from western Washington and P. deltoides clone ILL-101 from Southern Illinois. The resulting F1 hybrid, 52225, was in turn backcrossed to $P$. deltoides clone D-124 from Minnesota. The resulting full-sib progeny from the 'pseudo-backcross' pedigree (family 52-124) were used for the current study. Greenhouse hydroponic study

This manuscript describes QTL for untreated cuttings from a larger experiment to map QTL for Cd-tolerance (Induri et al., 2012). Cuttings of approximately $15 \mathrm{~cm}$ length and $1 \mathrm{~cm}$ diameter were pre-rooted in a non-randomized design with four adjacent cuttings per clone. Rooting dates were recorded on all genotypes at 2 to 3 day intervals. Groups of 8 rooted cuttings were transferred to containers with $20 \mathrm{~L}$ Johnson's solution of $0.1 \mathrm{X}$ strength in a completely randomized design with 2 ramets per genotype and 504 total cuttings (63 containers; Figure 3.1a). Observations were made on root volume (by water displacement), shoot length (from the base of the shoot to the base of the apical bud), cutting diameter, shoot diameter $(2.5 \mathrm{~cm}$ from the base of the shoot), photosynthetically active radiation (PAR), root collar diameter (right above the origin point of the uppermost root), and rooted length of each cutting (length of cutting occupied by roots) at 30 and 50 days after transfer to experimental containers. At the conclusion of the experiment, roots and shoots were harvested separately into paper bags and dried in an oven at $60{ }^{\circ} \mathrm{C}$ for 6 days. Dry weights were recorded for leaves, roots, and shoots. Cutting dry weights were also recorded and were used as a covariate in the data analysis. 


\section{Field study}

Cuttings for 755 genotypes from Family 52-124 were procured from the University of Minnesota and the University of Florida and were rooted and grown in conetainers from March to April of 2006 in the Department of Biology greenhouse at West Virginia University. A plantation was established in a field that had previously been used for hay production at the West Virginia University Agronomy Farm (GPS coordinates from Google Earth: latitude: 39³9'37"N and longitude: $\left.79^{\circ} 54^{\prime} 19^{\prime \prime} \mathrm{W}\right)$. The field was prepared by disking and tilling during May and June of 2007 and was sprayed with glyphosate shortly before planting. Trees were planted in July 2007 at $2 \mathrm{~m}$ x $2 \mathrm{~m}$, with two ramets per genotype in an interlocking block design during early July of 2007. A moisture gradient was apparent in north-south and east-west directions in the field due to a moderate elevational gradient that roughly corresponded to rows and columns. The plantation was drip irrigated as needed and was surrounded by an electric fence to prevent incursion by deer (Figure 3.1b). The plantation was thinned in December 2008 by removing every other tree in a diamond pattern. All remaining trees were harvested in January of 2010.

\section{Growth and phenology traits in the field study}

Phenotypes were measured on all trees ( 742 genotypes with $\geq 2$ replicates) in December 2008 and on the trees remaining after thinning (170 genotypes with $\geq 2$ replicates and 360 genotypes unreplicated) in January, 2010. It should be noted that height and diameter observations were taken on standing trees in 2008 whereas these observations were taken on harvested trees in January 2010. Height $(\mathrm{cm})$ was recorded from base of the stem to the tree apex. Stem diameter $(\mathrm{mm})$ was recorded at $20 \mathrm{~cm}$ above the tree base. Internode length $(\mathrm{cm})$ was measured for five consecutive internodes in the zone where consecutive internode lengths varied the least (typically 15-20 nodes below the tree apex). Number of nodes without branches 
(counting from the tree apex) was recorded. Apical dominance was measured as the distance from the base of the highest branch to the tree apex. Number of sylleptic branches was recorded for the 2008 and 2009 growing seasons. Stem volume was calculated assuming a conical stem shape (Marron et al., 2006).

Bud set of the terminal leader was scored during weekly surveys between August 1 and September 18 of 2008 as the first date on which a closed bud was observed (Figure S.3.1). Bud flush was recorded on the date when the first fully unfolded leaf was observed (Howe et al., 2000) at the beginning of the 2008 and 2009 growing seasons based on biweekly surveys. Julian dates were used for the statistical analyses of bud flush and bud set.

\section{Statistical Analysis}

Both greenhouse and field data were analyzed by analysis of variance using a mixed model based on Type IV sum of squares using SAS JMP, version 8.0. The data were tested for normality for each trait separately using the Shapiro-Wilk test (Shapiro and Wilk, 1965) and transformations were performed wherever necessary to correct for heteroscedasticity. Differences between means were considered significant for $P<0.05$ and highly significant for $P$ $<0.01$ by using a reverse selection procedure.

The transformed data for all the greenhouse traits was analyzed by fitting a mixed model using Restricted Maximum Likelihood and a reverse selection procedure. The full model for greenhouse traits was:

$$
Y=\text { Genotype }+ \text { Rooted length of each cutting }+ \text { Cutting dry weight }+P A R+\text { Error }
$$

The full model for field traits was:

$$
Y=\text { Genotype }+ \text { Row }+ \text { Column }+ \text { Row }^{2}+\text { Column }^{2}+\text { Error }
$$


where, Genotype was the only random effect in the model and the remaining variables were fixed effects. The row and column positions were squared and included in the model to account for a nonlinear gradient (White et al., 2007), presumably due to soil moisture. Variance components of genotype and environment were estimated using REML (Howe et al., 2000) and broad sense heritabilities were calculated from these variance components. The response of each genotype for all the traits was estimated using Best Linear Unbiased Predictors (BLUPs) (Coles et al., 2010), which provided input data for QTL analysis.

The response variables for the greenhouse study were total dry weight, root dry weight, leaf dry weight, stem dry weight, root volume, shoot length, shoot diameter (mm), leaf number, internodes and rooting dates. Fractional biomass distributions including the ratios of total biomass to its individual components, root volume, height, diameter, leaf number and internodes were also estimated. The response variables for the field study were height year 1 , height year 2 , diameter, sylleptic branch number, apical dominance, average internode length, stem volume, nodes without branches, bud flush and bud set. Height:diameter ratios were calculated for both years separately. Height, diameter and internode length were compared across greenhouse and field conditions. Finally, greenhouse rooting data was compared with the phenology data from the field. A list of traits and abbreviations is provided in Tables 3.1 and 3.2.

\section{Construction of linkage map}

A SNP genetic map with 3,559 markers previously described in Slavov et al., (2012) was used in this study. The SNP were selected based on 32X Illumina sequences of the $P$.

trichocarpa and P. deltoides parents of this pedigree (clones 93-968, ILL-101, and D-124). SNP loci were selected that were homozygous in all three parents and different between species, thereby maximizing the chances of informative segregation in the backcross. An Illumina 
Infinium ${ }^{\circledR}$ assay was devised for each locus using polymorphism information for flanking sequences. SNP were selected to maximize coverage of the genome and also to enhance assembly of sequence scaffolds that were not previously mapped. The map was constructed based on SNP segregating among 692 individuals from the 52-124 pedigree. SNPs were named according to the scaffold carrying the SNP and the physical position of each locus. The map was comprised of 19 linkage groups corresponding to the haploid number of chromosomes in Populus and encompassed 3,054 cM in length with a genome-wide average marker distance of $0.86 \mathrm{cM}$. Individual linkage groups ranged in size from 98.7 to $379.2 \mathrm{cM}$ and genome coverage was estimated at $91 \%$.

\section{QTL analysis}

The Multiple-QTL Model (MQM) mapping package in MapQTL 6.0 (Van Ooijen, 2009) was used to identify QTL intervals using Best Linear Unbiased Predictors (BLUPs) determined as described above as input data. Logarithm Of Odds (LOD) significance thresholds were calculated empirically for each trait and experiment using 1000 permutations at the 0.05 significance level (Churchill and Doerge, 1994). QTL were declared significant when they met the genome-wide significance threshold in at least two independent measurements for each trait. 


\section{Results}

There was substantial phenotypic variation for all traits measured in the greenhouse (Table 3.2, Figure 3.2) and in each year of the field study (Table 3.3, Figure 3.3). Backcross offspring showed transgressive segregation, exceeding the extremes of parental traits and even those of the $F_{1}$ for all traits measured in the field study (Table 3.3, Figure 3.3). Parental trees were not included in the greenhouse study due to inadequate rooting.

Broad-sense heritability $\left(\mathrm{H}^{2}\right)$ of greenhouse traits ranged from 0.18 to 0.39 (Table 3.2) and was generally lower than that of field traits, which ranged from 0.33 to 0.68 in Year 1 and 0.50 to 0.78 in Year 2 (Table 3.4). Stem dry weight and abscissed leaf number showed highest heritability $\left(\mathrm{H}^{2}=0.39\right)$ whereas shoot diameter showed the lowest heritability $\left(\mathrm{H}^{2}=0.18\right)$ under greenhouse conditions. All dry weight components showed comparable heritability estimates under greenhouse conditions. In the field study, shoot diameter again showed lowest heritabilities in Year $1\left(\mathrm{H}^{2}=0.23\right)$ whereas sylleptic branch number showed the lowest heritability $\left(\mathrm{H}^{2}=0.35\right)$ in Year 2 . There was a considerable difference in the heritability estimates for shoot diameter and shoot length in Year 1 (0.23 and 0.55 respectively) and the difference narrowed in Year 2 (0.42 and 0.47 respectively). Bud flush showed highest heritabilities in Year $1\left(\mathrm{H}^{2}=0.64\right)$ and Year $2\left(\mathrm{H}^{2}=0.71\right)$ of the field trial respectively, whereas bud set showed a heritability of 0.57 in the only season (2008) it was recorded and was lower than the bud flush heritability reported in both seasons. Bud flush heritability was relatively higher in the second growing season $\left(\mathrm{H}^{2}=0.71\right)$ than the first growing season $\left(\mathrm{H}^{2}=0.64\right)($ Table $3.4)$.

Correlations among growth and biomass traits in greenhouse and field studies 
In the greenhouse study, all measured growth and biomass traits except rooting dates showed significant phenotypic and genetic correlations (Table 3.5). Total dry weight showed the highest correlations with its components including root dry weight, stem dry weight and leaf dry weight. Growth traits including shoot length, shoot diameter, leaf number, number of nodes, root volume and stem volume showed significant correlations among themselves and also with the biomass traits. Rooting dates showed no correlations with either growth or biomass traits (Table $3.5)$.

In the field study, there were significant positive phenotypic and genetic correlations between height and diameter in $2008(\mathrm{r}=0.82)$ and $2009(\mathrm{r}=0.76)$ (Figure 3.4A, 3.4B; Table 3.6). Apical dominance and height showed a weak correlation of 0.18 in 2008 whereas they showed a strong positive correlation of 0.51 in 2009 (Figure 3.4C, 3.4D; Table 3.6). It was interesting to observe strong correlation between total height in 2008 and 2009 (Figure 3.5A), whereas there was no correlation between height growth during the 2008 and 2009 field seasons (Figure 3.5B). Shoot length and shoot diameter of the greenhouse study showed significant positive correlations with height growth, apical dominance and bud flush of 2009 season of the field study, but no correlations were observed among these traits in 2008 (Table 3.7). Most of the greenhouse traits showed no correlations with 2008 field study traits.

\section{Correlations with Phenology}

There was poor correlation between rooting in the greenhouse and bud flush and bud set in 2008. However, there was a significant correlation of 0.29 between rooting and 2009 bud flush (Table 3.7). Similarly, there was no correlation between height and bud flush of 2008 ( $r=0.03$, Table 3.6; Figure 3.6A) whereas there was a significant positive correlation between height and bud set of $2008(r=0.46$; Table 3.6; Figure 3.6B). Bud flush of 2008 had a positive genetic 
correlation with bud flush of 2009 ( $r=0.29$; Figure 3.6C) and the heritabilities were very high across both seasons for these traits. No correlation $(r=0.06)$ was observed between bud flush and bud set in 2008 (Table 3.6; Figure 3.6D). Finally, sylleptic branching had significant positive correlations with bud set but not with bud flush of both the growing seasons (Table 3.6).

\section{QTL in Greenhouse study}

A total of 15 QTLs were identified for the traits including total dry weight, root dry weight, stem dry weight, leaf dry weight, shoot length, shoot diameter, root volume, stem volume, leaf number, number of nodes and rooting dates in the greenhouse hydroponic study, at a LOD ratio of $\geq 2.5$ (Table 3.8). The QTL for total dry weight and its components including root dry weight, stem dry weight and leaf dry weight were localized to positions $122.4 \mathrm{cM}$ and $152.3 \mathrm{cM}$ on linkage group III. Leaf number and shoot diameter were mapped to positions 19.8 , 33.3 and 54.1 cM on linkage group XIX. No QTLs were detected for shoot length whereas three QTLs were detected for shoot diameter on LG XIX and XV at LOD ratio of $\geq 2.5$. Two QTLs were identified for shoot length:shoot diameter ratio on LG I (at position $89.5 \mathrm{cM}$ ) and LG XVIII (at position $45.9 \mathrm{cM}$ ). The QTL detected for shoot diameter at position $19.8 \mathrm{cM}$ on LG XIX had the highest LOD score value among all the greenhouse traits studied. Two QTLs were detected for leaf scar number on LG X at position 151.92 and LG VI at position $143.68 \mathrm{cM}$ and a single QTL was detected for number of nodes on LG V at position $184.3 \mathrm{cM}$. The percent variation explained by each of the QTL ranged from 5.4\% to $8.5 \%$ averaging $6.1 \%$ across all the traits.

These QTLs were localized to six independent positions within the genome after accounting for co-localization (e.g., Figure 3.6) and correlations among phenotypic traits. Total dry weight and its components were intercorrelated (Table 3.5) and co-localized to linkage group III, although at two different positions (Table 3.8). In contrast, growth traits including shoot 
length and shoot diameter showed significant phenotypic and genetic correlations with biomass traits (Table 3.5) but their QTLs were not co-localized (Table 3.8). No QTLs were co-localized for traits that did not show significant correlations in the greenhouse study.

\section{Field study QTL}

In the first growing season, 62 QTLs were detected at a LOD of $\geq 3.0$ for the 14 traits studied. The percent variation explained by each QTL ranged from $2.1 \%$ to $9.7 \%$ and averaged 4.4\% across all QTLs (Table 3.9). In the second growing season for all the 13 traits studied, 52 QTLs were detected at a LOD of $\geq 3.0$. The percent variation explained by each QTL ranged from $3.1 \%$ to $13.6 \%$ and averaged $5.1 \%$ across all QTLs. Across both growing seasons, plant height had common QTLs on linkage groups IV, VI, IX, and XI with the QTLs on IV and VI being localized to the same positions in both years. Height, height growth, stem volume, diameter, nodes without branches and bud flush had QTLs that were shared between the growing seasons 2008 and 2009 (Table 3.9). Several QTLs were co-localized and correlated in both growing seasons of the field-study (Table 3.6 and 3.9). Some traits, including bud flush 09 and Sylleptic branching 08 were co-localized to LG V at position $84.74 \mathrm{cM}$ but not inter-correlated (Tables 3.7 and 3.9). One of the QTLs for bud flush and apical dominance in 2009 was colocalized to LG VI at a position of $72 \mathrm{Cm}$ but these are not inter-correlated.

\section{Phenology}

Six QTLs were detected for bud flush in 2008 whereas in 2009 only five QTLs were detected. Bud flush QTL which occurred on linkage groups II, VI and XI were consistent across years, suggesting the importance of these loci in their genetic control of bud flush. Four QTLs were detected for bud set. Although bud flush and bud set QTLs were both detected on linkage groups VI and XI, their positions are not overlapping (Table 3.9). In 2008, bud flush QTL on LG 
II had the highest percent variation explained (PVE 8.4\%) and bud set QTL on LG VI had the highest PVE of $8.7 \%$. Percent variation explained by bud flush in both field seasons was similar (Table 3.9).

\section{Comparison of QTL locations across greenhouse and field studies}

No QTLs were detected for shoot length and stem volume under greenhouse conditions whereas more than 5 QTLs were identified for these traits under field conditions across both years. Shoot diameter had completely different QTLs under greenhouse (LG XIX and XV) and field conditions (LG I, IV, VI). Under field conditions, shoot diameter QTLs were located to the same positions on linkage groups IV and VI in 2008 and 2009 whereas in 2009 it had an additional QTL on LG I. QTL for number of leaf nodes in the greenhouse and nodes without branches in the field were localized to the same positions on LG V in 2009 but not in 2008 (Table 3.8 and Table 3.9). Height to diameter ratio had one QTL localized to the same position on linkage group XVIII under greenhouse conditions and 2009 of the field study whereas in 2008 all QTLs were localized to LG IV (Table 3.9). 
Table 3.1. List of traits measured in the field trial.

\begin{tabular}{ll}
\hline Field Trait & Description \\
\hline Hgt 08 & Height at the end of 2008, mm \\
Hg1 08 & Height growth until 2008, mm \\
Hg2 08 & Height growth in 2008, mm \\
Dia 08 & Diameter of stem in 2008, mm \\
Adl 08 & Apical dominance in 2008, mm \\
SB 08 & Sylleptic branch number in 2008 \\
NWB 08 & Nodes without branches in 2008 \\
INL 08 & Internode length in 2008, mm \\
BF 08 & Bud flush in 2008 \\
BS 08 & Bud set in 2008 \\
BF 09 & Bud flush in 2009 \\
Hgt 09 & Height at the end of 2009, mm \\
Hg3 09 & Height growth in 2009, mm \\
Adl 09 & Apical dominance in 2009, mm \\
Dia 09 & Diameter of stem in 2009, mm \\
SB 09 & Sylleptic branch number in 2009 \\
NWB 09 & Nodes without branches in 2009 \\
INL 09 & Internode length in 2009, mm \\
\hline
\end{tabular}


Table 3.2. Clonal means, variance components, and heritabilities for all measured traits in the greenhouse hydroponic study. Values in parentheses are standard deviations.

\begin{tabular}{|c|c|c|c|c|c|}
\hline Greenhouse trait & Mean (SD) & Range & $\mathrm{Vg}$ & $\mathrm{Vp}$ & $\mathrm{H}^{2} \mathrm{BS}$ \\
\hline Stem dry weight, $\mathrm{g}$ & $1.63(1.17)$ & 7.39 & 0.23 & 0.6 & 0.39 \\
\hline Leaf dry weight, g & $3.56(2.29)$ & 13.05 & 0.16 & 0.5 & 0.32 \\
\hline Root Dry Weight, $\mathrm{g}$ & $1.14(0.89)$ & 7.34 & 0.2 & 0.58 & 0.35 \\
\hline Total Dry weight, g & $6.32(4.14)$ & 24.98 & 0.17 & 0.47 & 0.36 \\
\hline Root volume & $1.63(0.95)$ & 5.8 & 0.05 & 0.23 & 0.23 \\
\hline Number of Leaves & $19.71(6.91)$ & 67 & 0.04 & 0.1 & 0.36 \\
\hline Shoot Length, cm & $42.80(12.03)$ & 76.9 & 0.04 & 0.11 & 0.37 \\
\hline Shoot diameter, $\mathrm{cm}$ & $0.48(0.14)$ & 0.99 & 0 & 0.01 & 0.18 \\
\hline Number of Leaf Scars & $4.40(2.95)$ & 16 & 0.16 & 0.41 & 0.39 \\
\hline Number of Nodes & $23.68(6.43)$ & 67 & 12.25 & 32.92 & 0.37 \\
\hline Stem volume, $\mathrm{cm}^{3}$ & $61.85(77.77)$ & 741.15 & 1.16 & 3.11 & 0.37 \\
\hline Rooting date, Julian & $144.65(3.02)$ & 12 & 2.89 & 9.17 & 0.31 \\
\hline Root/Leaf+Shoot, g & $0.23(0.14)$ & 1.64 & & & \\
\hline Root/Leaf, g & $0.34(0.21)$ & 2.17 & & & \\
\hline Leaf/Total dry weight, g & $0.57(0.07)$ & 0.62 & & & \\
\hline Stem/Total dry weight, $g$ & $0.25(0.06)$ & 0.51 & & & \\
\hline Root/Total dry weight, g & $0.18(0.07)$ & 0.60 & & & \\
\hline Leaf+Shoot/Total dry weight, $\mathrm{g}$ & $0.82(0.07)$ & 0.60 & & & \\
\hline Root volume/Total dry weight, $\mathrm{g}$ & $0.33(0.30)$ & 4.22 & & & \\
\hline Leaf no/Total dry weight, $\mathrm{g}$ & $4.97(5.65)$ & 73.98 & & & \\
\hline Shoot Length/Total dry weight, g & $9.78(7.44)$ & 91.28 & & & \\
\hline Shot diameter/Total dry weight, $\mathrm{g}$ & $0.13(0.28)$ & 5.55 & & & \\
\hline Shoot length/Diameter, $\mathrm{cm}$ & $91.17(19.28)$ & 1776.93 & & & \\
\hline Shoot Length/nodes number & $1.89(0.39)$ & 2.53 & & & \\
\hline Nodes number / Shoot Length & $0.56(0.15)$ & 1.18 & & & \\
\hline
\end{tabular}

$\mathrm{Vg}=$ genetic variance, $\mathrm{Vp}=$ phenotypic variance, $\mathrm{H}^{2}{ }_{\text {BS }}=$ broad-sense heritability 
Table 3.3. Mean and standard deviation (SD) estimates for all the measured traits at the end of 2008 and 2009 in the field.

\begin{tabular}{|c|c|c|c|c|c|c|c|c|}
\hline \multirow[b]{2}{*}{ Field Trait } & \multicolumn{4}{|c|}{2008} & \multicolumn{4}{|c|}{2009} \\
\hline & $52-124$ & $\mathrm{~T}^{\mathrm{a}}$ & $\mathrm{D}^{\mathrm{b}}$ & $\mathrm{TD}^{\mathrm{c}}$ & $52-124$ & $\mathrm{~T}$ & $\mathrm{D}$ & TD \\
\hline Height, cm & $324.33(73.41)$ & $432.33(36.22)$ & $297.66(47.48)$ & $425(21.2)$ & $502.44(93.91)$ & 631 & $512.2(23.48)$ & 641 \\
\hline Height growth, cm & $261.75(60.46)$ & $367.66(40.50)$ & $239.33(42.30)$ & $333(18.38)$ & $212.95(56.87)$ & 259 & $228.8(23.29)$ & 263 \\
\hline Diameter, $\mathrm{cm}$ & $3.54(1.38)$ & $52.66(4.16)$ & $28.5(7.39)$ & $68.5(13.43)$ & $6.1(1.49)$ & 76 & $50.2(6.68)$ & 92 \\
\hline Apical Dominance, $\mathrm{cm}$ & $170.88(73.17)$ & $136.33(4.50)$ & $148.33(42.76)$ & $216(111.72)$ & $179.93(66.16)$ & 272 & $205.6(53.04)$ & 274 \\
\hline Sylleptic branches \# & $6.39(8.36)$ & $41(4.58)$ & $4.33(4.27)$ & $10(9.89)$ & $2.51(4.05)$ & 0 & $1(1.41)$ & 0 \\
\hline Bud Flush & $108.56(2.94)$ & $110(0)$ & $110(2.12)$ & $110(0.71)$ & $113.42(2.82)$ & $112(1.73)$ & $115.5(1.22)$ & 111 \\
\hline Bud Set & $243.64(8.05)$ & $262(0)$ & $249.6(5.50)$ & $248.5(9.19)$ & & & & \\
\hline Height/Diameter, cm & $90.94(43.08)$ & $8.21(0.31)$ & $10.77(1.66)$ & $6.29(0.92)$ & $84.73(14.06)$ & 8.30 & $10.31(1.07)$ & 6.96 \\
\hline Stem volume, $\mathrm{m}^{3}$ & $28.94(44.73)$ & $11071(6203)$ & $693(657)$ & 16964 (10303) & $557.15(797.11)$ & $23310(11515)$ & 143703 & 228035 \\
\hline Nodes without branches & $45.48(17.73)$ & $30.5(14.85)$ & 21 & 24 & $43.37(13.21)$ & 42 & $50.2(19.56)$ & 48 \\
\hline Internode length, $\mathrm{cm}$ & $22.8(4.8)$ & $33(8.49)$ & 26 & 31 & $51.89(10.4)$ & 83.8 & $48.76(13.37)$ & 63.2 \\
\hline
\end{tabular}

T - Populus trichocarpa, genotype 93-968, female grandparent

D - Populus deltoides, genotypes - ILL-101(male grandparent) and D-124 (male parent)

TD - Female parental genotype - 52-225, F1 hybrid of Populus trichocarpa (93-968) x Populus deltoides (ILL-101) 
Table 3.4. Heritability estimates for field traits measured in 2008 and 2009 growing seasons.

\begin{tabular}{l|rrr|rrr}
\hline & \multicolumn{3}{|c|}{2008} & \multicolumn{3}{c}{2009} \\
\hline Field Trait & \multicolumn{1}{c}{$\mathrm{Vg}$} & \multicolumn{1}{c}{$\mathrm{Vp}$} & $\mathrm{H}^{2}{ }_{\text {BS }}$ & $\mathrm{Vg}$ & $\mathrm{Vp}$ & $\mathrm{H}^{2}{ }_{\text {BS }}$ \\
\hline Height, cm & 2272.50 & 4155.30 & 0.55 & 3670.10 & 7767.11 & 0.47 \\
Height 1, cm & 290.32 & 556.91 & 0.52 & & & \\
Height 2, cm & 1245.80 & 2719.20 & 0.46 & 1576.20 & 3009.15 & 0.52 \\
Diameter, cm & 0.44 & 1.91 & 0.23 & 0.82 & 1.97 & 0.42 \\
Apical dominance, cm & 1948.20 & 5327.2 & 0.37 & 1896.91 & 4257.02 & 0.45 \\
Sylleptic branch number & 0.46 & 0.88 & 0.53 & 0.26 & 0.74 & 0.35 \\
Bud flush & 5.48 & 8.62 & 0.64 & 5.61 & 7.90 & 0.71 \\
Bud set & 35.51 & 62.10 & 0.57 & & & \\
Nodes without branches & 88.35 & 296.30 & 0.30 & 65.43 & 171.76 & 0.38 \\
Average internode length, cm & 6.77 & 21.01 & 0.32 & 52.45 & 106.98 & 0.49 \\
Stem volume, $\mathrm{cm}^{3}$ & 1.31 & 2.52 & 0.52 & 0.78 & 1.79 & 0.44 \\
\hline
\end{tabular}

$\mathrm{Vg}=$ genetic variance, $\mathrm{Vp}=$ phenotypic variance, $\mathrm{H}^{2}{ }_{\mathrm{BS}}=$ broad-sense heritability . 
Table 3.5. Phenotypic (below diagonal) and genetic correlations (above diagonal) among greenhouse traits estimated by REML method. All the correlations were significant except with rooting dates.

\begin{tabular}{|c|c|c|c|c|c|c|c|c|c|c|c|}
\hline Trait & $\begin{array}{c}\text { Total } \\
\text { dry } \\
\text { weight, } \\
\text { g }\end{array}$ & $\begin{array}{c}\text { Root } \\
\text { dry } \\
\text { weight, } \\
\text { g }\end{array}$ & $\begin{array}{c}\text { Leaf } \\
\text { dry } \\
\text { weight, } \\
\text { g }\end{array}$ & $\begin{array}{c}\text { Stem } \\
\text { dry } \\
\text { weight, } \\
\text { g }\end{array}$ & $\begin{array}{c}\text { Root } \\
\text { volume }\end{array}$ & $\begin{array}{c}\text { Leaf } \\
\text { number }\end{array}$ & $\begin{array}{c}\text { Shoot } \\
\text { length, } \\
\mathrm{cm}\end{array}$ & $\begin{array}{c}\text { Shoot } \\
\text { diameter, } \\
\mathrm{cm}\end{array}$ & $\begin{array}{l}\text { No. of } \\
\text { nodes }\end{array}$ & $\begin{array}{c}\text { Stem } \\
\text { volume, } \\
\mathrm{cm}^{3}\end{array}$ & $\begin{array}{c}\text { Rooting } \\
\text { dates }\end{array}$ \\
\hline Total dry weight, $g$ & & 0.92 & 0.98 & 0.95 & 0.74 & 0.62 & 0.83 & 0.67 & 0.52 & 0.82 & 0.04 \\
\hline Root dry weight, g & 0.89 & & 0.86 & 0.84 & 0.78 & 0.56 & 0.72 & 0.63 & 0.50 & 0.72 & 0.07 \\
\hline Leaf dry weight, $g$ & 0.98 & 0.80 & & 0.92 & 0.70 & 0.61 & 0.80 & 0.64 & 0.49 & 0.79 & 0.04 \\
\hline Stem dry weight, $\mathrm{g}$ & 0.95 & 0.80 & 0.89 & & 0.69 & 0.60 & 0.88 & 0.66 & 0.52 & 0.88 & 0.03 \\
\hline Root volume & 0.79 & 0.81 & 0.72 & 0.75 & & 0.57 & 0.61 & 0.64 & 0.52 & 0.60 & 0.09 \\
\hline Leaf number & 0.51 & 0.47 & 0.49 & 0.48 & 0.52 & & 0.58 & 0.57 & 0.76 & 0.58 & 0.09 \\
\hline Shoot length, cm & 0.78 & 0.65 & 0.75 & 0.79 & 0.65 & 0.48 & & 0.58 & 0.46 & 1.00 & 0.05 \\
\hline Shoot diameter, $\mathrm{cm}$ & 0.74 & 0.62 & 0.71 & 0.76 & 0.70 & 0.55 & 0.72 & & 0.53 & 0.57 & 0.03 \\
\hline No. of nodes & 0.56 & 0.50 & 0.53 & 0.56 & 0.58 & 0.90 & 0.59 & 0.65 & & 0.46 & -0.02 \\
\hline Stem volume, $\mathrm{cm}^{3}$ & 0.75 & 0.65 & 0.70 & 0.80 & 0.61 & 0.36 & 0.78 & 0.58 & 0.44 & & 0.05 \\
\hline
\end{tabular}


Table 3.6. Phenotypic (below diagonal) and genetic (above diagonal) correlations among shared genotypes of growing seasons 2008 and 2009 estimated by REML method (Correlations of $>|0.5|$ are in bold).

\begin{tabular}{|c|c|c|c|c|c|c|c|c|c|c|c|c|c|c|}
\hline Trait & $\begin{array}{r}\text { Hgt } \\
08\end{array}$ & Hg2 08 & Dia 08 & Adl 08 & SB 08 & BF 08 & BS 08 & BF 09 & Hgt 09 & $\mathrm{Hg} 309$ & Adl 09 & Dia 09 & $\begin{array}{r}\text { NWB } \\
09\end{array}$ & INL 09 \\
\hline Hgt 08 & & 0.95 & 0.65 & 0.33 & 0.27 & 0.04 & 0.52 & -0.05 & 0.72 & 0.05 & -0.03 & 0.37 & 0.25 & -0.05 \\
\hline Hg2 08 & 0.95 & & 0.59 & 0.34 & 0.28 & 0.01 & 0.44 & 0.02 & 0.68 & 0.11 & 0.07 & 0.30 & 0.15 & 0.01 \\
\hline Dia 08 & 0.82 & 0.78 & & 0.09 & 0.26 & 0.07 & 0.27 & -0.09 & 0.49 & 0.01 & 0.14 & 0.16 & -0.01 & 0.19 \\
\hline Adl 08 & 0.18 & 0.16 & -0.01 & & -0.42 & 0.08 & 0.11 & -0.02 & 0.11 & -0.09 & 0.03 & -0.17 & -0.12 & -0.07 \\
\hline SB 08 & 0.41 & 0.44 & 0.47 & -0.46 & & -0.10 & 0.22 & -0.05 & 0.33 & 0.10 & 0.02 & 0.29 & 0.08 & 0.12 \\
\hline BS 08 & 0.46 & 0.39 & 0.26 & 0.09 & 0.20 & 0.06 & & -0.02 & 0.42 & 0.12 & -0.07 & 0.18 & 0.03 & 0.09 \\
\hline BF 09 & 0.01 & 0.02 & 0.03 & 0.02 & -0.03 & 0.54 & 0.00 & & -0.18 & 0.66 & -0.20 & -0.05 & -0.13 & 0.55 \\
\hline Hgt 09 & 0.78 & 0.74 & 0.68 & 0.04 & 0.42 & -0.01 & 0.39 & -0.07 & & 0.16 & 0.05 & 0.40 & 0.33 & -0.04 \\
\hline Hg3 09 & 0.10 & 0.09 & 0.13 & -0.13 & 0.18 & -0.05 & 0.08 & -0.11 & 0.66 & & 0.37 & -0.26 & -0.39 & 0.60 \\
\hline Adl 09 & 0.12 & 0.12 & 0.09 & 0.10 & -0.08 & 0.06 & 0.12 & 0.01 & 0.51 & 0.69 & & -0.64 & -0.66 & 0.36 \\
\hline Dia 09 & 0.80 & 0.76 & 0.86 & 0.01 & 0.47 & -0.01 & 0.27 & 0.02 & 0.76 & 0.27 & 0.16 & & 0.82 & -0.59 \\
\hline INL 09 & 0.18 & 0.21 & 0.19 & 0.01 & 0.12 & -0.03 & -0.08 & 0.01 & 0.39 & 0.45 & 0.40 & 0.25 & 0.07 & \\
\hline
\end{tabular}


Table 3.7. Genetic correlations between selected traits measured in the greenhouse and those measured in the field.

\begin{tabular}{|c|c|c|c|c|c|c|c|c|c|c|c|c|c|c|c|c|}
\hline Trait & $\begin{array}{l}\mathrm{Hg} \\
08\end{array}$ & $\begin{array}{l}\text { Adl } \\
08\end{array}$ & $\begin{array}{l}\text { Dia } \\
08\end{array}$ & $\begin{array}{l}\mathrm{BF} \\
08\end{array}$ & $\begin{array}{l}\text { BS } \\
08\end{array}$ & $\begin{array}{l}\text { SB } \\
08\end{array}$ & $\begin{array}{l}\text { NWB } \\
08\end{array}$ & $\begin{array}{l}\text { Stem } \\
\text { Vol } \\
08\end{array}$ & $\begin{array}{l}\text { Hgt } \\
09\end{array}$ & $\begin{array}{l}\text { Hgt3 } \\
09\end{array}$ & Adl 09 & $\begin{array}{l}\text { Dia } \\
09\end{array}$ & $\begin{array}{l}\text { NWB } \\
09\end{array}$ & $\begin{array}{l}\text { SB } \\
09\end{array}$ & $\begin{array}{l}\mathrm{BF} \\
09\end{array}$ & $\begin{array}{l}\text { Stem } \\
\text { Vol } \\
09\end{array}$ \\
\hline Total dry wt & -0.08 & -0.09 & 0.05 & 0.07 & -0.19 & 0.05 & -0.10 & 0.06 & 0.12 & 0.27 & 0.26 & -0.32 & -0.16 & -0.23 & 0.27 & -0.32 \\
\hline $\begin{array}{l}\text { Koot } \\
\text { volume }\end{array}$ & 0.01 & -0.13 & 0.06 & 0.00 & -0.11 & 0.18 & -0.16 & 0.01 & 0.00 & 0.21 & 0.19 & -0.06 & 0.07 & -0.10 & 0.14 & -0.09 \\
\hline $\begin{array}{l}\text { Shoot length } \\
\text { Shoot }\end{array}$ & -0.04 & -0.09 & 0.05 & -0.03 & -0.13 & 0.04 & -0.19 & 0.00 & 0.08 & 0.49 & 0.25 & -0.20 & -0.04 & 0.04 & 0.48 & -0.15 \\
\hline Dia & 0.07 & -0.03 & 0.10 & -0.02 & -0.12 & 0.15 & -0.11 & -0.03 & 0.05 & 0.27 & 0.13 & -0.10 & 0.06 & 0.06 & 0.25 & -0.06 \\
\hline $\begin{array}{l}\text { Rooting } \\
\text { date }\end{array}$ & -0.01 & 0.03 & -0.08 & 0.02 & -0.07 & 0.02 & 0.01 & -0.09 & 0.05 & 0.00 & -0.25 & 0.16 & 0.10 & 0.08 & 0.29 & 0.09 \\
\hline $\begin{array}{l}\text { Stem } \\
\text { volume }\end{array}$ & -0.04 & -0.09 & 0.05 & -0.03 & -0.13 & 0.04 & -0.19 & 0.00 & $\begin{array}{r}- \\
0.07\end{array}$ & 0.50 & 0.24 & -0.20 & -0.03 & 0.05 & 0.49 & -0.14 \\
\hline $\begin{array}{l}\text { No. of } \\
\text { nodes }\end{array}$ & 0.08 & -0.18 & 0.13 & -0.02 & -0.03 & 0.21 & -0.11 & 0.23 & 0.14 & 0.30 & 0.48 & -0.30 & -0.16 & -0.14 & -0.03 & -0.19 \\
\hline
\end{tabular}


Table 3.8. QTLs identified for traits measured in the greenhouse study.

\begin{tabular}{lrrlrrrrr}
\hline Trait & Group & Position & Locus & LOD & mu_ac $\{00\}$ & mu_bd $\{00\}$ & Variance & PVE \\
\hline TotalDryWeight & III & 152.3 & scaffold_3_16851717 & 2.64 & 0.061091 & -0.08324 & 0.084995 & 5.7 \\
RootDryWeight & III & 122.478 & scaffold_3_14318461 & 2.5 & 0.073528 & -0.07959 & 0.101916 & 5.4 \\
LeafDryWeight & III & 152.3 & scaffold_3_16851717 & 2.72 & 0.0562 & -0.07874 & 0.071885 & 5.9 \\
LeafStemDryWeight & III & 152.3 & scaffold_3_16851717 & 2.8 & 0.062729 & -0.08616 & 0.084829 & 6.1 \\
Leaf number & XIX & 54.186 & scaffold_19_12422289 & 2.91 & 0.030627 & -0.04136 & 0.018999 & 6.4 \\
Shoot diameter & XIX & 19.806 & scaffold_19_5105586 & 3.99 & 0.008026 & -0.0075 & 0.000644 & 8.5 \\
& XIX & 33.368 & scaffold_19_9728106 & 2.75 & 0.006631 & -0.00633 & 0.000662 & 6 \\
Leaf scar number & XV & 38.717 & scaffold_15_4994116 & 2.55 & -0.0691 & 0.06798 & 0.072453 & 6 \\
& X & 151.927 & scaffold_10_18548092 & 2.54 & 0.089935 & -0.04969 & 0.072464 & 6 \\
Root/Total dry weight & VI & 143.684 & scaffold_6_20157326 & 2.65 & 0.006165 & -0.00459 & 0.000471 & 5.8 \\
& VI & 143.684 & scaffold_6_20157326 & 2.71 & 0.00384 & -0.00285 & 0.000178 & 5.9 \\
Shoot length/Shoot diameter & III & 141.784 & scaffold_3_16087018 & 2.83 & 0.380513 & -0.37807 & 2.19789 & 6.1 \\
& I & 89.561 & scaffold_1_6501526 & 2.6 & 0.365827 & -0.3622 & 2.20923 & 5.7 \\
Number of nodes & XVIII & 45.939 & scaffold_18_325052 & 2.91 & 0.246306 & -0.41434 & 1.59344 & 6.3 \\
& V & 184.437 & scaffold_5_23503568 & 2.53 & 0.503554 & -0.6767 & 5.542 & 5.9 \\
\hline
\end{tabular}


Table 3.9. QTLs identified for traits measured in the field study in both growing seasons.

\begin{tabular}{|c|c|c|c|c|c|c|c|c|}
\hline Trait & Group & Position & Locus & LOD & mu_ac $\{00\}$ & mu_bd $\{00\}$ & Variance & PVE \\
\hline \multirow[t]{6}{*}{ Height 08} & IV & 5.097 & scaffold_4_539917 & 8.86 & -12.4838 & 7.21805 & 1397.11 & 6 \\
\hline & VI & 170.543 & scaffold_6_22731802 & 11.45 & 10.9703 & -10.3438 & 1372.18 & 7.6 \\
\hline & IX & 36.294 & scaffold_9_5575904 & 4.68 & -6.1561 & 7.66471 & 1438.24 & 3.2 \\
\hline & $\mathrm{X}$ & 128.917 & scaffold_10_16314664 & 5.63 & 8.95735 & -6.29537 & 1428.73 & 3.8 \\
\hline & $\mathrm{XI}$ & 27.816 & scaffold_11_4270068 & 10.6 & -9.65271 & 10.8943 & 1380.33 & 7.1 \\
\hline & XVII & 103.138 & scaffold_17_2127487 & 3.28 & -4.83744 & 6.8266 & 1452.27 & 2.3 \\
\hline \multirow[t]{6}{*}{ Height 12008} & VI & 167.788 & scaffold_6_22478252 & 14.71 & 4.52118 & -3.98709 & 168.212 & 9.7 \\
\hline & VI & 138.759 & scaffold_6_19467988 & 12.08 & 4.39226 & -3.37623 & 171.308 & 8.1 \\
\hline & VIII & 85.323 & scaffold_8_6983625 & 5.87 & 3.72855 & -1.90747 & 178.857 & 4 \\
\hline & $\mathrm{X}$ & 137.43 & scaffold_10_17119908 & 7.76 & 3.9005 & -2.43972 & 176.528 & 5.2 \\
\hline & XI & 28.725 & scaffold_11_4391888 & 8.75 & -3.0119 & 3.62018 & 175.319 & 5.9 \\
\hline & XVII & 50.95 & scaffold_17_10534691 & 3.33 & -1.63984 & 2.51484 & 182.043 & 2.3 \\
\hline \multirow[t]{6}{*}{ Height 22008} & I & 287.688 & scaffold_1_32522298 & 3.91 & -4.49619 & 4.23294 & 690.695 & 2.7 \\
\hline & IV & 5.097 & scaffold_4_539917 & 9.49 & -9.07566 & 5.00129 & 664.463 & 6.4 \\
\hline & VI & 170.543 & scaffold_6_22731802 & 6.24 & 5.54396 & -5.42779 & 679.623 & 4.2 \\
\hline & IX & 37.105 & scaffold_9_5626994 & 4.29 & -4.20565 & 4.94805 & 688.884 & 2.9 \\
\hline & $\mathrm{X}$ & 128.917 & scaffold_10_16314664 & 3.7 & 4.92252 & -3.65717 & 691.674 & 2.5 \\
\hline & XI & 27.816 & scaffold_11_4270068 & 7.5 & -5.7644 & 6.24692 & 673.693 & 5.1 \\
\hline \multirow[t]{4}{*}{ ADL 2008} & VI & 93.217 & scaffold_6_9191531 & 3.6 & 5.75624 & -4.07339 & 940.702 & 2.5 \\
\hline & VIII & 92.892 & scaffold_8_7564001 & 4 & -5.94868 & 4.52761 & 938.125 & 2.7 \\
\hline & XII & 88.155 & scaffold_12_10815212 & 4.96 & 5.61847 & -5.84526 & 931.868 & 3.4 \\
\hline & XIV & 70.526 & scaffold_14_6437075 & 8.78 & 7.72848 & -7.38385 & 907.476 & 5.9 \\
\hline \multirow[t]{2}{*}{ Diameter 2008} & IV & 5.097 & scaffold_4_539917 & 7.17 & -0.07944 & 0.088421 & 0.127069 & 4.8 \\
\hline & VI & 174.227 & scaffold_6_23030368 & 5.27 & 0.100331 & -0.03753 & 0.128738 & 3.6 \\
\hline INL_Average_08 & XIV & 144.07 & scaffold_14_16355453 & 3.52 & -0.30099 & 0.287576 & 2.26806 & 3.7 \\
\hline SB_2008 & IV & 12.993 & scaffold_4_841806 & 4.05 & -0.13994 & 0.072707 & 0.264128 & 3.6 \\
\hline
\end{tabular}




\begin{tabular}{|c|c|c|c|c|c|c|c|c|}
\hline & $\mathrm{V}$ & 84.744 & scaffold_5_8368828 & 3.57 & 0.098261 & -0.08867 & 0.265278 & 3.2 \\
\hline & $\mathrm{V}$ & 134.183 & scaffold_5_19064721 & 4.72 & 0.101012 & -0.11439 & 0.26253 & 4.2 \\
\hline & VIII & 93.333 & scaffold_8_7639312 & 6.88 & 0.150769 & -0.10892 & 0.25744 & 6 \\
\hline & XI & 39.056 & scaffold_11_5313640 & 3.62 & -0.08636 & 0.101889 & 0.265168 & 3.2 \\
\hline \multirow[t]{3}{*}{ NWB_2008 } & VI & 194.608 & scaffold_6_24869186 & 3.03 & 1.04447 & -0.84172 & 29.5028 & 2.9 \\
\hline & VIII & 125.204 & scaffold_8_10399900 & 3.19 & -0.95654 & 0.984878 & 29.4582 & 3.1 \\
\hline & XIV & 70.526 & scaffold_14_6437075 & 7.27 & 1.43941 & -1.46042 & 28.3033 & 6.9 \\
\hline \multirow[t]{9}{*}{ StemVolume_08 } & I & 288.385 & scaffold_1_35185480 & 3.13 & -0.12865 & 0.137588 & 0.803634 & 2.2 \\
\hline & IV & 5.097 & scaffold_4_539917 & 11.98 & -0.33645 & 0.199423 & 0.755741 & 8 \\
\hline & VI & 125.882 & scaffold_6_17149154 & 4.78 & 0.187804 & -0.14094 & 0.794476 & 3.3 \\
\hline & VI & 170.543 & scaffold_6_22731802 & 10.44 & 0.251122 & -0.22835 & 0.76385 & 7 \\
\hline & IX & 36.294 & scaffold_9_5575904 & 3.15 & -0.11399 & 0.153531 & 0.80352 & 2.2 \\
\hline & $X$ & 131.207 & scaffold_10_16522436 & 4.51 & 0.195742 & -0.12646 & 0.795961 & 3.1 \\
\hline & XI & 6.866 & scaffold_11_1001189 & 8.2 & -0.21456 & 0.212588 & 0.775836 & 5.5 \\
\hline & XVII & 103.138 & scaffold_17_2127487 & 3.73 & -0.11745 & 0.174586 & 0.800335 & 2.6 \\
\hline & XI & 32.982 & scaffold_11_4596463 & 6.39 & -0.17371 & 0.203955 & 0.785687 & 4.3 \\
\hline \multirow[t]{5}{*}{ Height08_Diameter08 } & IV & 4.106 & scaffold_4_413415 & 8.18 & 0.012609 & -0.00762 & 0.001604 & 5.5 \\
\hline & IV & 14.655 & scaffold_4_1012241 & 6.96 & 0.011311 & -0.00725 & 0.001617 & 4.7 \\
\hline & IV & 16.281 & scaffold_4_1136937 & 5.94 & 0.010469 & -0.00672 & 0.001629 & 4 \\
\hline & IV & 26.219 & scaffold_4_2141909 & 4.88 & 0.009165 & -0.00632 & 0.001641 & 3.3 \\
\hline & IV & 37.637 & scaffold_4_3083849 & 3.04 & 0.006595 & -0.00548 & 0.001662 & 2.1 \\
\hline \multirow[t]{2}{*}{ Height_2_Diameter08 } & I & 19.943 & scaffold_1_4955139 & 3.58 & -0.0073 & 0.006922 & 0.002 & 2.5 \\
\hline & IV & 5.097 & scaffold_4_539917 & 5.52 & 0.01128 & -0.00709 & 0.001973 & 3.8 \\
\hline \multirow[t]{3}{*}{ SB08_Height_2 } & $\mathrm{V}$ & 84.744 & scaffold_5_8368828 & 3.06 & 0.092839 & -0.08285 & 0.274388 & 2.7 \\
\hline & V & 134.183 & scaffold_5_19064721 & 4.17 & 0.096878 & -0.10882 & 0.271632 & 3.7 \\
\hline & VIII & 93.333 & scaffold_8_7639312 & 7.5 & 0.15948 & -0.11519 & 0.263561 & 6.6 \\
\hline \multirow[t]{5}{*}{ Height_2009 } & I & 282.516 & scaffold_1_33177048 & 4.05 & -9.47752 & 9.58832 & 2081.61 & 4.2 \\
\hline & IV & 14.655 & scaffold_4_1012241 & 7.53 & -16.5644 & 10.0882 & 2006.75 & 7.6 \\
\hline & VI & 170.543 & scaffold_6_22731802 & 5.53 & 11.2733 & -10.9064 & 2049.48 & 5.7 \\
\hline & IX & 67.7 & scaffold_9_8279027 & 6.3 & -10.2941 & 13.4856 & 2033.02 & 6.4 \\
\hline & XI & 0 & scaffold_21_497649 & 4.6 & -10.0985 & 10.1893 & 2069.59 & 4.7 \\
\hline
\end{tabular}




\begin{tabular}{|c|c|c|c|c|c|c|c|c|}
\hline \multirow[t]{5}{*}{ Height_3_2009 } & I & 181.85 & scaffold_938_3145 & 3.42 & -7.05738 & 5.14313 & 963.52 & 3.5 \\
\hline & IV & 55.632 & scaffold_4_5102638 & 3.92 & -6.60328 & 6.16863 & 958.496 & 4 \\
\hline & IV & 109.523 & scaffold_325_19478 & 5.56 & -8.15728 & 7.03828 & 942.088 & 5.7 \\
\hline & IX & 89.174 & scaffold_9_10082291 & 6.02 & -6.62042 & 9.16188 & 937.393 & 6.2 \\
\hline & XIX & 25.865 & scaffold_19_5993152 & 3.47 & 6.50063 & -5.4804 & 963.026 & 3.6 \\
\hline \multirow[t]{6}{*}{ ADL_2009 } & I & 183.564 & scaffold_1_23137681 & 6.14 & -7.43715 & 9.62648 & 1082 & 6.3 \\
\hline & I & 271.48 & scaffold_140_37688 & 4.19 & -6.63733 & 7.49234 & 1104.42 & 4.3 \\
\hline & IV & 109.523 & scaffold_325_19478 & 3.17 & -6.58307 & 5.84169 & 1116.35 & 3.3 \\
\hline & V & 198.414 & scaffold_5_24593616 & 4.73 & -6.77641 & 8.23049 & 1098.13 & 4.9 \\
\hline & VI & 72.119 & scaffold_6_6832007 & 3.61 & 7.26364 & -5.86994 & 1111.29 & 3.7 \\
\hline & IX & 89.174 & scaffold_9_10082291 & 3.21 & -5.13363 & 7.34274 & 1115.89 & 3.3 \\
\hline \multirow[t]{3}{*}{ Diameter_09 } & I & 282.976 & scaffold_1_33071595 & 3.53 & -0.15219 & 0.142121 & 0.568755 & 3.7 \\
\hline & IV & 15.408 & scaffold_4_1035770 & 13.89 & -0.37238 & 0.216432 & 0.509842 & 13.6 \\
\hline & VI & 170.543 & scaffold_6_22731802 & 5.39 & 0.181068 & -0.18033 & 0.557729 & 5.5 \\
\hline SB_2009 & IX & 86.651 & scaffold_9_10004054 & 3.5 & 0.068048 & -0.0834 & 0.066394 & 7.9 \\
\hline \multirow[t]{6}{*}{ NWB_2009 } & I & 183.564 & scaffold_1_23137681 & 4.03 & -1.12756 & 1.49312 & 38.9034 & 4.2 \\
\hline & IV & 144.732 & scaffold_1702_2558 & 3.81 & -1.41686 & 1.15881 & 38.9948 & 4 \\
\hline & V & 183.323 & scaffold_5_23438659 & 3.23 & -0.99382 & 1.36019 & 39.2351 & 3.4 \\
\hline & VI & 118.261 & scaffold_6_12847732 & 3.08 & 1.27957 & -1.01408 & 39.2974 & 3.2 \\
\hline & VI & 193.621 & scaffold_6_24683679 & 9.16 & 2.08266 & -1.80576 & 36.8333 & 9.3 \\
\hline & IX & 89.174 & scaffold_9_10082291 & 4.12 & -1.09784 & 1.56216 & 38.8641 & 4.3 \\
\hline \multirow[t]{4}{*}{ INL_AVG_2009 } & I & 271.48 & scaffold_140_37688 & 3.27 & -1.10682 & 1.22734 & 38.8129 & 3.4 \\
\hline & IV & 80.025 & scaffold_4_7989212 & 4.83 & -1.52631 & 1.32036 & 38.1757 & 5 \\
\hline & IV & 49.104 & scaffold_4_4314064 & 3.02 & -1.1946 & 1.06623 & 38.9126 & 3.1 \\
\hline & VI & 194.721 & scaffold_6_24769044 & 4.26 & -1.30381 & 1.35664 & 38.4066 & 4.4 \\
\hline \multirow[t]{6}{*}{ StemVolume09 } & I & 282.516 & scaffold_1_33177048 & 4.13 & -0.11783 & 0.127885 & 0.371504 & 3.9 \\
\hline & IV & 14.655 & scaffold_4_1012241 & 9.59 & -0.23815 & 0.145529 & 0.352406 & 8.8 \\
\hline & VI & 170.543 & scaffold_6_22731802 & 6.01 & 0.149612 & -0.14562 & 0.364815 & 5.6 \\
\hline & VI & 174.551 & scaffold_6_23095856 & 3.64 & 0.120093 & -0.11103 & 0.373244 & 3.5 \\
\hline & IX & 64.973 & scaffold_9_8062670 & 4.38 & -0.10795 & 0.146873 & 0.37058 & 4.1 \\
\hline & $\mathrm{X}$ & 137.43 & scaffold_10_17119908 & 3.32 & 0.138169 & -0.08668 & 0.374399 & 3.2 \\
\hline
\end{tabular}




\begin{tabular}{|c|c|c|c|c|c|c|c|c|}
\hline & $\mathrm{XI}$ & 6.866 & scaffold_11_1001189 & 5.18 & -0.1412 & 0.134011 & 0.367733 & 4.9 \\
\hline \multirow[t]{4}{*}{ Height09_Diameter09 } & IV & 4.106 & scaffold_4_413415 & 5.79 & 2.06476 & -1.1014 & 39.4368 & 5.4 \\
\hline & VIII & 135.75 & scaffold_8_11454391 & 4.46 & -1.56814 & 1.12125 & 39.944 & 4.2 \\
\hline & IX & 37.105 & scaffold_9_5626994 & 3.65 & -1.12313 & 1.28764 & 40.2598 & 3.5 \\
\hline & XVIII & 39.954 & scaffold_18_992938 & 4.44 & 1.12325 & -1.55706 & 39.9534 & 4.2 \\
\hline \multirow[t]{3}{*}{ SB09_Height_3 } & $\mathrm{V}$ & 183.323 & scaffold_5_23438659 & 4 & 0.094182 & -0.15488 & 0.175913 & 7.8 \\
\hline & VI & 188.849 & scaffold_6_24260292 & 3.38 & -0.13781 & 0.090763 & 0.178075 & 6.7 \\
\hline & IX & 93.908 & scaffold_9_10462781 & 4.16 & 0.10801 & -0.14202 & 0.175324 & 8.1 \\
\hline Height_3_Diameter09 & VIII & 135.75 & scaffold_8_11454391 & 4.17 & -0.98338 & 0.703588 & 16.7837 & 4 \\
\hline \multirow[t]{3}{*}{ SB_09_Height_09 } & $\mathrm{V}$ & 183.323 & scaffold_5_23438659 & 3.2 & 0.066591 & -0.10665 & 0.107426 & 6.3 \\
\hline & VI & 188.849 & scaffold_6_24260292 & 3.96 & -0.11315 & 0.077602 & 0.10576 & 7.7 \\
\hline & IX & 93.908 & scaffold_9_10462781 & 3.69 & 0.080885 & -0.10165 & 0.10636 & 7.2 \\
\hline \multirow[t]{6}{*}{ Bud flush 2008} & II & 38.102 & scaffold_2_5202086 & 12.76 & 0.652289 & -0.51542 & 3.66859 & 8.4 \\
\hline & III & 81 & scaffold_3_10635121 & 4.15 & 0.307358 & -0.36683 & 3.89213 & 2.8 \\
\hline & VI & 54.714 & scaffold_6_5114896 & 6.07 & 0.433755 & -0.37717 & 3.84123 & 4.1 \\
\hline & VI & 93.77 & scaffold_6_9237051 & 4.48 & 0.38736 & -0.31418 & 3.88312 & 3 \\
\hline & XI & 89.739 & scaffold_11_14473403 & 4.82 & 0.333877 & -0.39266 & 3.87378 & 3.3 \\
\hline & $\mathrm{XV}$ & 114.235 & scaffold_15_13816694 & 4.68 & -0.43828 & 0.289442 & 3.87806 & 3.2 \\
\hline \multirow[t]{4}{*}{ Bud set 2008} & VI & 167.513 & scaffold_6_22536804 & 12.53 & 1.51405 & -1.36257 & 21.6349 & 8.7 \\
\hline & IX & 36.294 & scaffold_9_5575904 & 3.79 & -0.6827 & 0.928099 & 23.058 & 2.7 \\
\hline & $X$ & 133.923 & scaffold_10_16760641 & 8.69 & 1.48674 & -0.95847 & 22.2478 & 6.1 \\
\hline & XI & 23.072 & scaffold_11_3651079 & 6.87 & -1.01565 & 1.1353 & 22.5469 & 4.9 \\
\hline \multirow[t]{5}{*}{ Bud flush 2009} & II & 7.943 & scaffold_2_2534655 & 3.85 & 0.455254 & -0.42298 & 4.62901 & 4 \\
\hline & V & 81.1 & scaffold_5_8062017 & 4.57 & -0.49298 & 0.461702 & 4.59415 & 4.7 \\
\hline & VI & 63.34 & scaffold_6_5742508 & 3.91 & 0.462762 & -0.42215 & 4.62619 & 4.1 \\
\hline & VII & 96.69 & scaffold_7_2740574 & 3.69 & 0.519462 & -0.35457 & 4.63698 & 3.8 \\
\hline & XI & 91.64 & scaffold_11_14742983 & 3.69 & 0.393131 & -0.47139 & 4.63658 & 3.8 \\
\hline
\end{tabular}




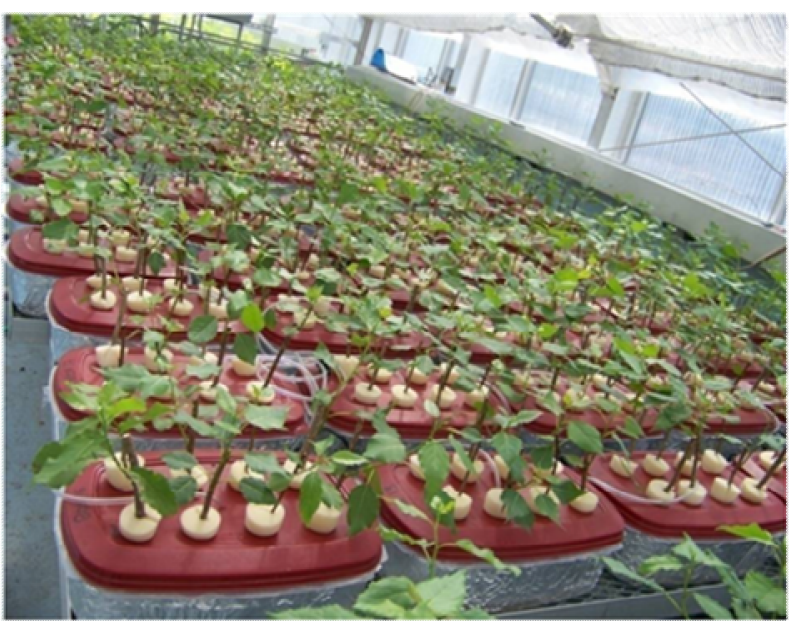

A

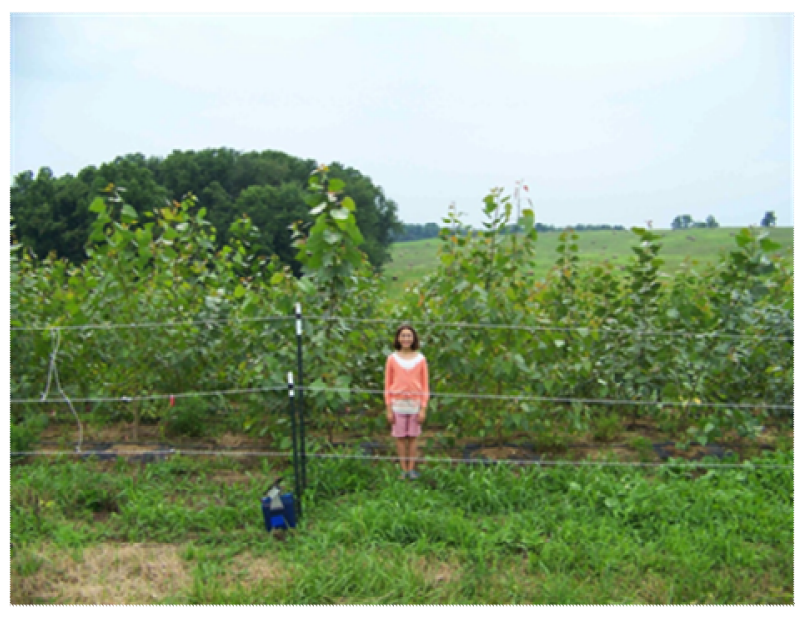

B

Figure 3.1. Overview of A) Greenhouse hydroponic study and B) Field trial on July 28, 2008, one year after establishment. 

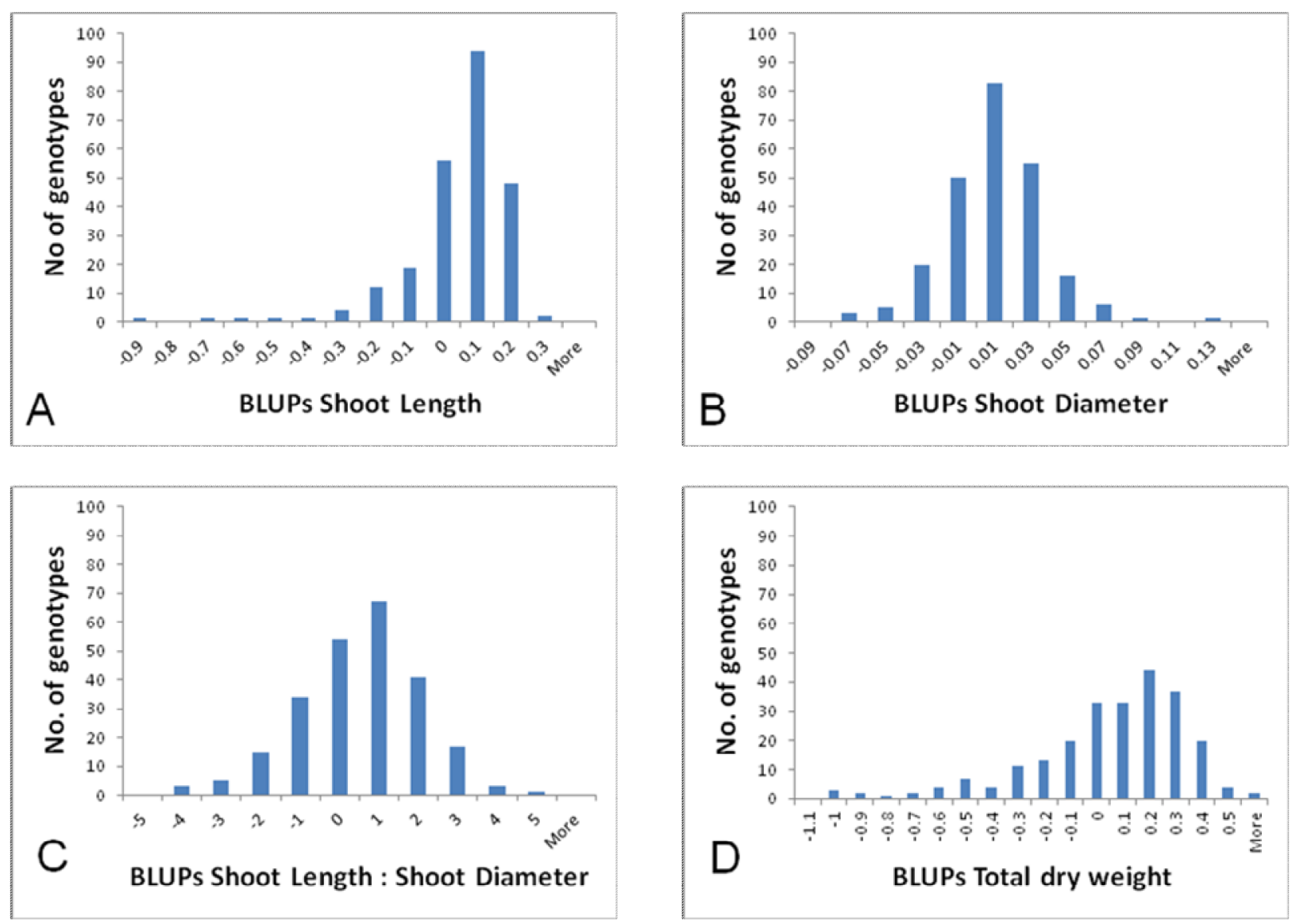

Figure 3.2. Distributions of BLUPs for A) Shoot length, B) Shoot diameter C) Shoot length/Shoot diameter and D) Total dry weight in the greenhouse study. 

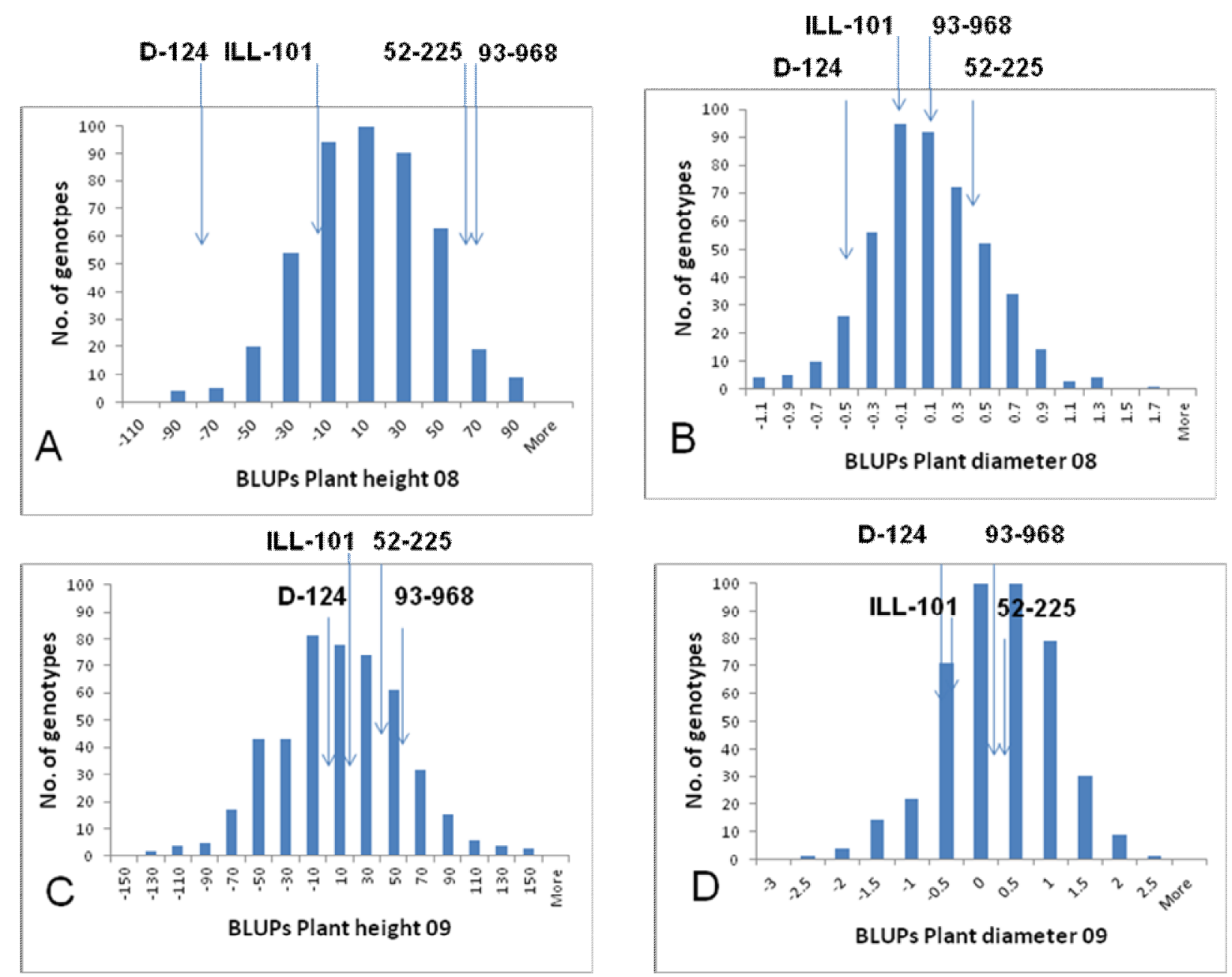

Figure 3.3. Transgressive segregation in 52-124 Family demonstrated by the distributions of BLUPs for A) Plant height 2008, B) Plant diameter 2008 C) Plant height 2009, D) Plant diameter 2009 in the field study. 

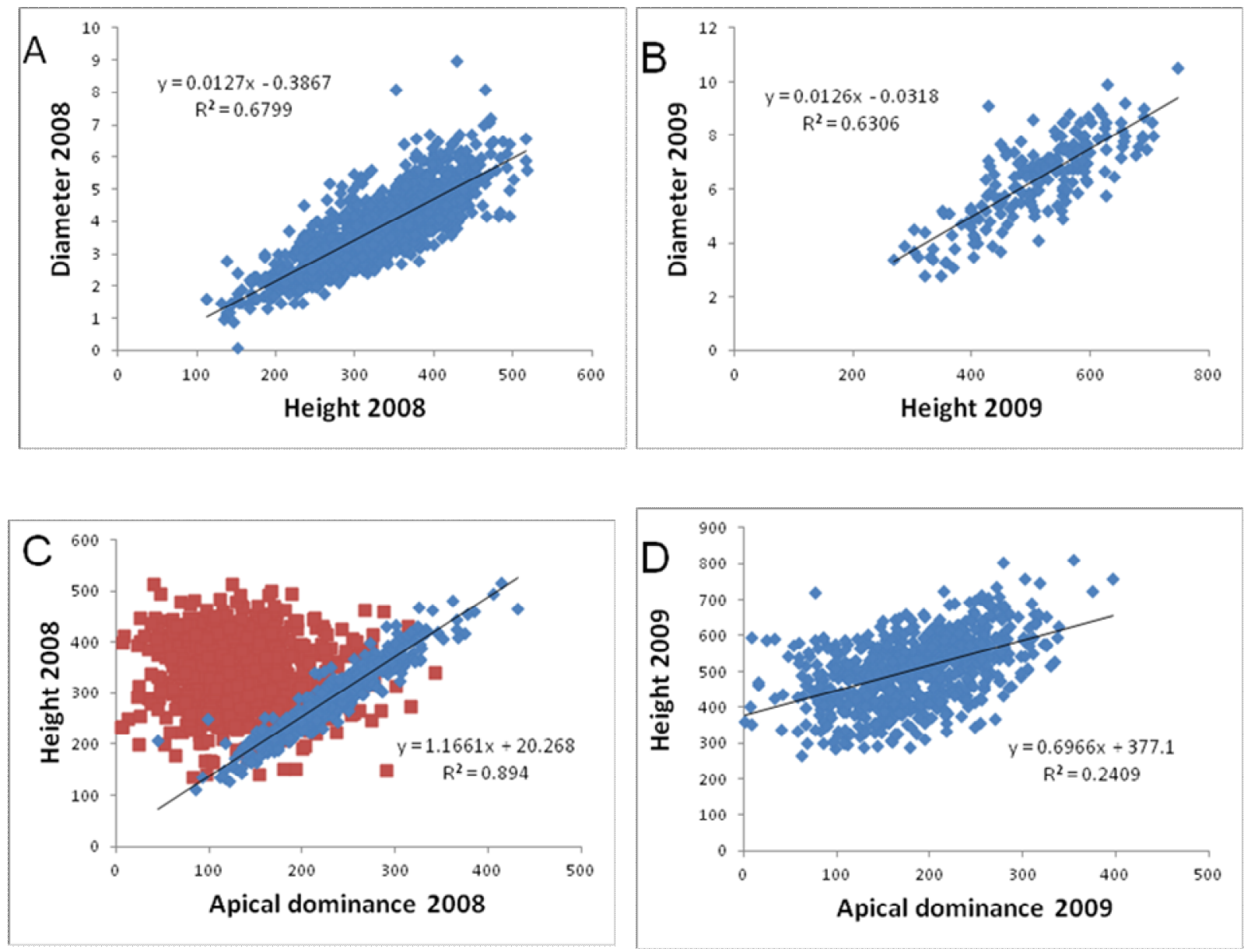

Fig 4

Figure 3.4. Scatter plots showing correlations among the measured growth traits within the same year in the field study. 

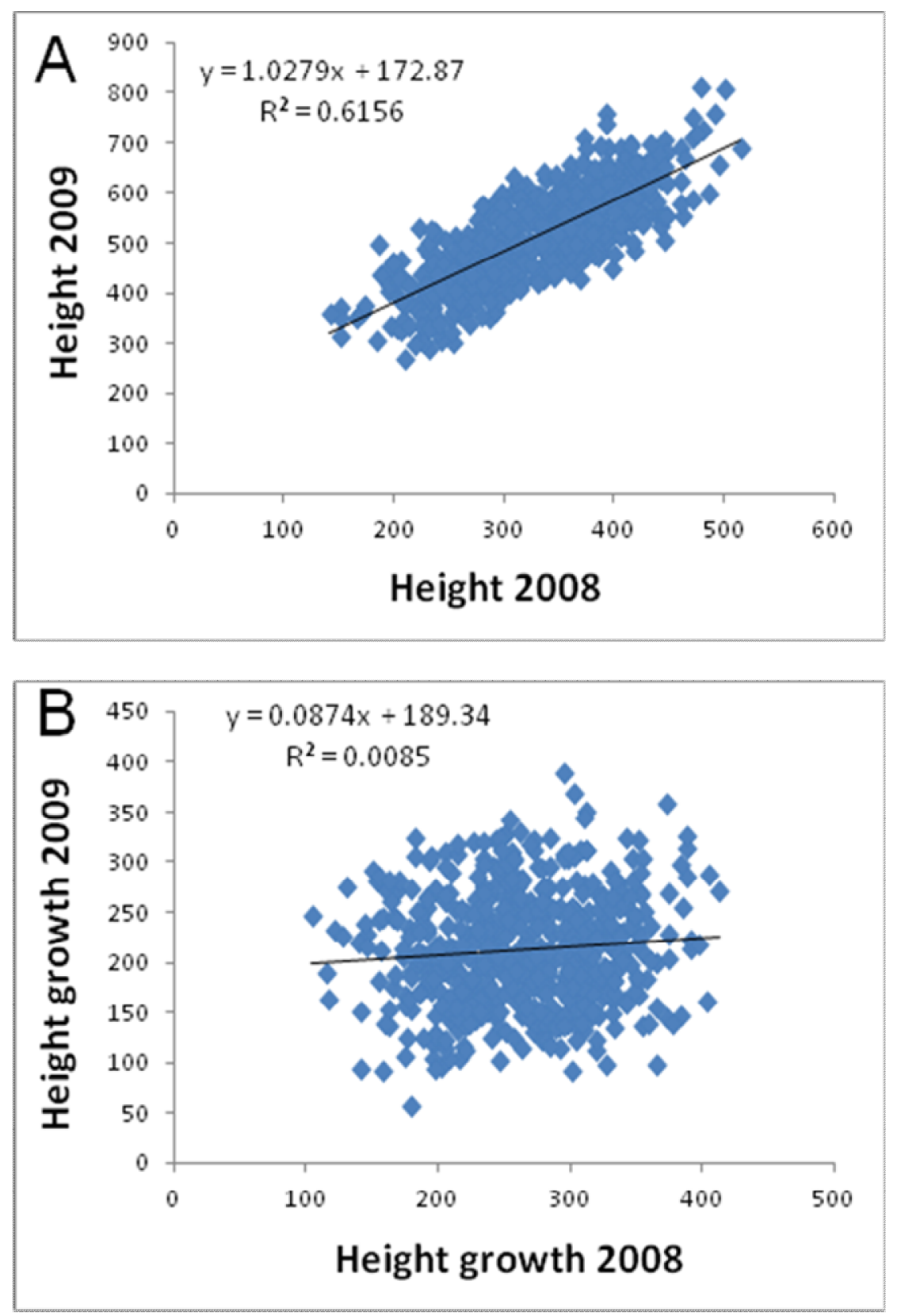

Figure 3.5. Scatter plots showing correlations among the measured traits across different years in the field study. 

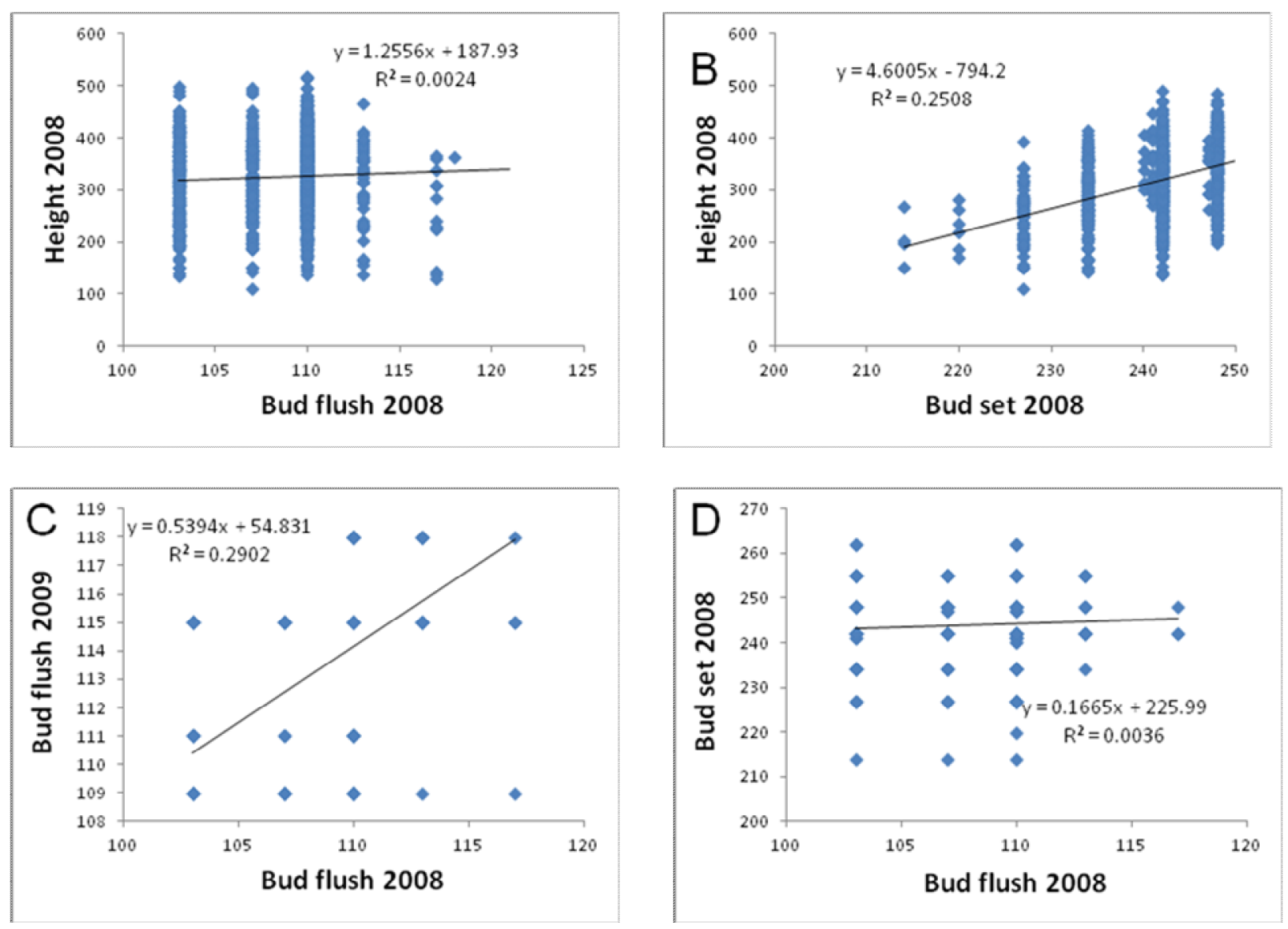

Figure 3.6. Scatter plots showing correlations among the measured phenology traits and relationships to height in the field study. 


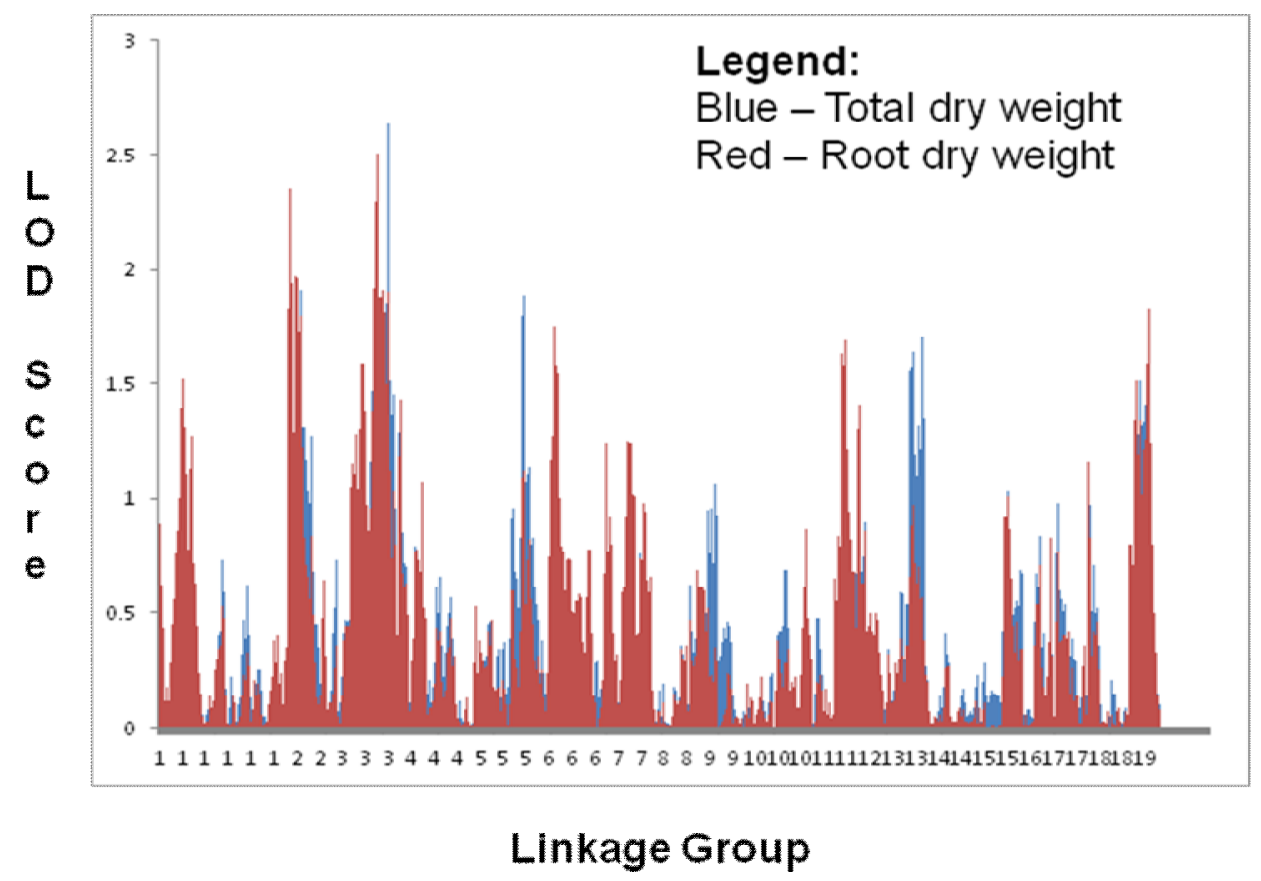

Figure 3.7. Co-localization of QTLs as demonstrated by superimposition of QTL peaks observed for total dry weight (blue colored) and root dry weight (red colored) at a LOD threshold of 3.0. 


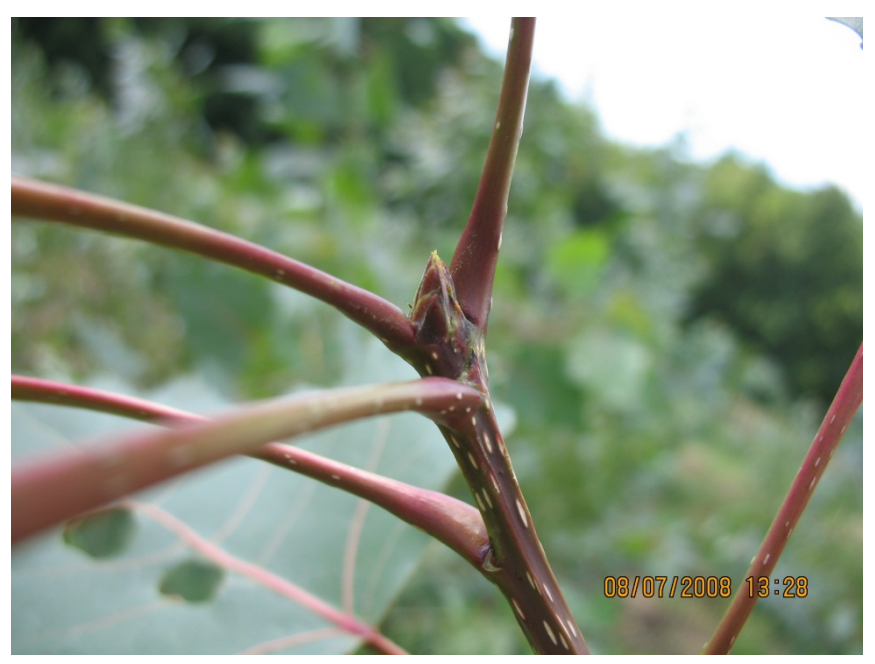

Figure S 3.1. Appearance of a terminal vegetative bud in the family 52-124 trial shortly after bud set. 


\section{Discussion}

\section{Phenotypic variation across environments and growing seasons}

Extensive variation was observed in Family 52-124 for all studied traits under both greenhouse and field conditions. Considerable differences were observed among the genotypes in their performance across environments, as indicated by the poor correspondence between performance in the greenhouse and field, and also across years as shown by the poor correspondence in productivity between 2008 and 2009 (Figure 3.5B).

It is apparent from Figure 3.3 that transgressive segregation was observed in the progeny, because the phenotypes observed in the progeny were beyond the range of the parental phenotypes. This is commonly observed in Populus hybrids. For example, transgressive segregation was observed in Populus family 331, an $\mathrm{F}_{2}$ inbred family that uses the same $P$. trichocarpa parent as family 52-124 (Rae et al., 2008). Similarly, most drought response traits exhibit transgressive segregation in family 331 (Street et al., 2006). In an unrelated Populus pedigree, all studied traits including growth and wood chemical content showed transgressive segregation (Zhang et al., 2006). However, in another Populus pedigree, there was negative transgressive segregation for rooting traits, in which the backcross hybrids had values less than the parental trait values (Zhang et al., 2009).

\section{Heritabilities}

All traits in both study environments showed moderate to high heritabilities for growth and biomass traits, as has been observed in other studies in Populus (Marron et al., 2010 b; Dillen et al., 2007; Marron et al., 2006). Surprisingly, heritability estimates were generally higher in the field study compared to the greenhouse study. This suggests that environmental effects were stronger in the greenhouse than in the field. One possible reason is that the intensity 
of the artificial lights was not uniform across the experiment, as reflected by PAR measurements on each of the containers used in the study (data not shown). Although PAR was used as a covariate in the model, this did not account for all of the variation contributing to differential performance of ramets within a genotype. Furthermore, competition between genotypes was likely more severe in the greenhouse experiment due to close spacing of the plants, thereby accentuating environmental effects. In contrast, there was little obvious interaction among ramets in the field study due to adequate spacing in the first growing season, and thinning prior to the second growing season. Finally, because the greenhouse experiment was much shorter duration than the field study, it is likely that the effects of variation among vegetative cuttings had a stronger effect in the former.

The heritability estimates were comparatively higher in the second growing season relative to the first growing season. The differences between years could be due to differential establishment effects in 2008 and also local micro-environmental conditions, which may have varied between years (Marron et al., 2010 a). The hypothesis of establishment and production phases in Populus (Stanton, 2001) may partially explain why different genotypes perform differentially across years, as demonstrated by several Populus species and hybrids (Afas et al., 2008). C-effects, the variation that results due to the physiological preconditioning of the cuttings of different genotypes during propagation, could also explain some of the above discrepancies in the correlations in the first growing season compared to the second growing season (Dillen et al., 2009; Lerner, 1958). Another possible cause of the differences could be the larger population size in the pre-thinning population measured in 2008, although there is no inherent reason to believe that this would lead to lower heritability of the measured traits, as the 
sample size was quite large in both years (742 replicated genotypes in 2008 and 170 replicated genotypes in 2009).

\section{Phenology}

Bud set and bud flush were under strong genetic control in this field study across both the growing seasons, as has been observed in other replicated clonal field trials in hybrid Populus (Marron et al., 2010 b). Spring bud flush appears to be under very strong genetic control in Populus with up to $98 \%$ of the phenotypic variation attributable to genetic control (Marron et al., 2010 b; Bradshaw and Stettler, 1995; Frewen et al., 2000). Different populations of $P$. trichocarpa trees showed bud set heritabilities of 0.71 and 0.81 in previous experiments (Howe et al., 2000). In fact, bud phenology traits often have the among highest heritabilities among all measured traits in forest trees, indicating that these traits are less affected by the microenvironmental changes and show relatively low genotype $\mathrm{x}$ environment interaction on a local scale (Howe et al., 2000).

\section{Correlations}

Bud flush and bud set are important adaptive traits that could determine the length of the growing season (Howe et al., 2000). Temperature plays a major role in determining bud flush timing whereas bud set timing is affected by a multitude of factors and their interactions including short days, cold days, soil moisture and soil nutrient status (Howe et al., 2000). Length of the growing season is influenced by the timing of bud flush and bud set. Specifically, the amount of biomass produced will be proportional to the length of the growing season, assuming minimal frost damage. Growing season length in turn is determined by vegetative phenology. In general, bud set but not bud flush determines the duration of growing season (Dillen et al., 2009) and thus has more direct relationship to biomass produced by plants. The timing of bud flush and 
bud set helps the plants avoid unfavorable growth conditions (Dillen et al., 2009). Delayed bud set was found to be genetically associated with increased height growth in some Populus studies (Riemenschneider et al., 1992; Rohde et al., 2011) but not others (Marron et al., 2010 b). We also detected very poor phenotypic and genetic correlations between growth traits and bud flush, but we detected significant positive phenotypic and genetic correlations between growth traits and bud set (Table 3.6).

We also detected no relationship between bud flush and bud set dates. This is in contrast to other studies, which have found both positive (Howe et al., 2000; Eriksson et al., 1978; Rehfeldt, 1992 b) and negative (Marron et al., 2010 b) correlations between these traits in Populus and other trees. Similar to the current study, bud flush and bud set were poorly correlated $(\mathrm{r}=-0.12)$ in a Populus study of family 822 , which also uses clone $93-968$ as the $P$. trichocarpa parent (Frewen et al., 2000). However, QTLs for bud flush and bud set were localized to completely to different positions in our study, whereas some bud flush and bud set QTL have been colocalized in previous studies (Frewen et al., 2000). Bud flush and bud set can show strong correlations under growth chamber conditions, but this can be attributed to the photoperiodic component of the response rather than to the complex interplay of photoperiod and temperature that typifies a natural setting (Howe et al., 2000). The poor correlation between bud flush and bud set under field conditions could be explained by a lack of control over temperature at the beginning and end of the season, which might differentially affect bud set and bud flush of different genotypes.

QTLS

The current study focused on identifying the genomic regions governing growth, biomass and phenology traits across two experiments and also whether these genomic regions were 
consistent across years. The number of QTLs identified in this study for the studied traits suggested the polygenic control and complex nature of these traits, as has been observed previously (Marron et al., 2010 b; Wullschleger et al., 2005; Bradshaw and Stettler, 1995; Rae et al., 2008; Rae et al., 2009; Novaes et al., 2009). Co-locating QTLs were observed for a majority of growth and biomass traits. In the greenhouse study, several QTLs were co-located (Figure 3.6) and correlated suggesting the pleiotropic nature of these QTLs (Marron et al., 2010 b). The QTLs governing total dry weight and its dry weight components were all co-located and were highly correlated, suggesting that they represent the same genetic mechanisms and are driven by allometric relationships among biomass components.

Sylleptic branching increases the leaf area index by increasing light interception area of the plant, thus eventually influencing the growth and productivity of hybrid Populus clones (Ceulemans et al., 1990). Sylleptic branching shows plasticity and the degree of syllepsis could vary greatly from genotype to genotype (Dillen et al., 2007; Wu et al., 1998). Sylleptic branching contributes to stem growth and shows remarkable genetic variation than other growth traits when growth conditions are not limiting (Dillen et al., 2007). Sylleptic branching is under moderate to strong genetic control and has been included in Populus ideotype breeding (Rae et $a l .$, 2004). Sylleptic branching was found to be positively associated with radial growth and biomass productivity in Populus (Marron et al., 2010 b; Wu et al., 1998; Marron et al., 2006; Rae et al., 2004). However, a weaker genetic correlation between syllepsis and growth traits has also been observed in previous studies (Rae et al., 2008). In the current study, sylleptic branching had moderate heritability (0.35 to 0.53$)$ and significant positive correlations with height, height growth and diameter. The correlation between height and apical dominance of 2008 was very low and depended on number of sylleptic branches. Two groups of genotypes 
could be observed in the color coded figure (Fig 4C) with genotypes in red having sylleptic branches and the genotypes in blue without any sylleptic branches. This supports the importance of this trait in predicting the growth and biomass productivity of Populus clones.

\section{Relation between biomass QTLs and phenology QTLS}

The QTLs governing height across both growing seasons were localized to the same positions on linkage groups IV, VI, IX and XI suggesting that the genetic control of this trait did not change with increase of plant age. Even though these traits were poorly correlated, it was interesting to note that the height growth QTLs identified in 2008 and 2009 were localized to LG I, IV and IX albeit to different positions. Although there are a few other QTLs governing plant height on other linkage groups, these QTLs suggested the importance of these linkage groups in the genetic control of this trait. Diameter also had QTLs localized to the same positions on linkage groups IV and VI across both growing seasons, indicating that genetic control of these traits was consistent over time. The trend of constant QTLs across years provides an opportunity to genetically manipulate these traits in genetic improvement trials and other related research investigations including biofuel research and carbon sequestration. For traits including sylleptic branching, bud flush and others, the QTLs changed across years suggesting that the genetic control of these traits changes as the plants mature.

\section{Comparisons between current study and previously reported QTLS}

Some QTL reported in the current study were also detected in the past in other families of T x D hybrids of Populus. Plant height and plant diameter had a QTL on linkage group IV under field conditions in the current study and also in other studies of Populus family 331, which shares one of the grandparents, 93-968 (Rae et al., 2007). Similarly, the QTL for plant height in the current field study was localized to the same linkage group VI in another field study of 
Populus family 331 (Rae et al., 2008). Finally, it was interesting to note that QTLs for stem volume were detected on linkage groups I, IV, VI, IX, X and XVII in the current study and also in family 331 (Rae et al., 2007). Furthermore, the QTL for plant height under field conditions were localized to the common linkage groups of $\mathrm{X}$ and $\mathrm{XI}$ in the current study and yet another related field study of family 331 (Wu et al., 1998). Interestingly, there was virtually no overlap with the major pleiotropic biomass QTL detected in a greenhouse study with family 52-124 previously (Novaes et al., 2009), providing further evidence of poor transferability between greenhouse and field studies.

The QTL for sylleptic branch number were localized to linkage groups IV, V and VIII in the current study and also in another related field study of family 331 (Rae et al., 2008). The QTLs detected for sylleptic branch number on LG IX and XI were detected only in this study and not in the past studies.

Four of the bud flush QTLs identified in this study on linkage groups II, III, VI and XI were also detected in another study of Populus family 331 (Bradshaw and Stettler, 1995). Bud flush QTLs on linkage groups VI, VII and XI were also shared across the current study and with another Populus study of family 822, which also shares a grandparent with family 52-124 (Frewen et al., 2000). Two bud flush QTLs detected on LG II and LG III were also identified by past bud flush QTL studies although the Populus families were different (Marron et al., $2010 \mathrm{~b}$; Bradshaw and Stettler, 1995). The bud flush QTLs detected on LG VI and XI in the current study were also localized to the same linkage groups in other studies involving families 331 and 822 (Bradshaw and Stettler, 1995; Frewen et al., 2000). Bud set QTLs on linkage groups VI and $\mathrm{X}$ also were located to the same linkage groups in family 822 (Frewen et al., 2000). 


\section{Conclusions}

We identified QTLs for growth, biomass and phenology traits under greenhouse and field conditions in the interspecific pseudo-backcross family 52-124 of Populus. This was one of the first studies to use an outcrossed tree pedigree of this size to identify the underlying genomic regions for phenotypes under field and greenhouse conditions and across multiple years. Shared growth, biomass and phenology QTLs across years, families, pedigrees and environments suggested the robustness of some of these QTLs in governing these traits. Phenology traits were highly heritable and QTLs were highly consistent across studies and families, demonstrating the appropriateness of these traits for in-depth genetic and molecular studies, and their value as targets for breeding and selection. Genetic manipulation of these traits with consistent QTLs provides opportunities to modify the growth and biomass allocation patterns in Populus thereby facilitating breeding for genotypes improved in paper, pulp, above/below ground carbon sequestration and biofuels applications. Further research on identifying the candidate genes from these consistent QTLs will enhance understanding of the mechanisms underlying the genetic control of these traits. Nevertheless, QTL studies do have certain limitations. Although many QTL were identified in this study, multiple and repeated experiments are required to test the repeatability of these QTLs across families, pedigrees, environments and genetic backgrounds. Furthermore, the identified QTL intervals encompass hundreds of genes and further research will be required to unearth the actual genes controlling the traits. 


\section{Acknowledgements}

We thank Carina Barth, Jonathan Cumming, Mindie Lipphardt, Hao Ma, Danielle Ellis, Dhiraj Naik, Shalaka Desai, Andrew Nelson, Alex Lastinger, Ernie Smith, Chase Kempinski, Ryan

Imperio, Lee Gunter, Sara Jawdy, Nancy Engle, and others too numerous to name for their help during establishment, maintenance, data collection, and harvesting of the field and greenhouse studies. This work was supported by funding from the BioEnergy Science Center, a U.S. DOE Bioenergy Research Center supported by the Office of Biological and Environmental Research in the DOE Office of Science. 


\section{References}

Aerts, R., Boot, R.G.A., Aart, P.J.M.V.D. 1991. The relation between above- and belowground biomass allocation patterns and competitive ability. Oecologia 87:551-559.

Afas, N.A., Marron, N., Van Dongen, S., Laureysens, I., Ceulemans, R. 2008. Dynamics of biomass production in a poplar coppice culture over three rotations (11 years). Forest Ecology and Management 255:1883-1891.

Bradshaw, H.D., Stettler, R.F. 1995. Molecular genetics of growth and development in Populus for mapping QTLs with large effects on growth, form, and phenology traits in a forest tree. Genetics 139:963-973.

Bunn, S.M., Rae, A.M., Herbert, C.S., Taylor, G. 2004. Leaf-level productivity traits in Populus grown in short rotation coppice for biomass energy. Forestry 77:307-323.

Ceulemans, R., Stettler, R.F., Hinckley, T.M., Isebrands, J.G., Heilman, P.E. 1990. Crown architecture of Populus clones as determined by branch orientation and branch characteriistics. Tree Physiology 7:157-167.

Coles, N.D., McMullen, M.D., Balint-Kurti, P.J., Pratt, R.C., Holland, J.B. 2010. Genetic control of photoperiod sensitivity in maize revealed by joint multiple population analysis. Genetics 184:799-U301.

Dickson, R.E., Coleman, M.D., Riemenschneider, D.E., Isebrands, J.G., Hogan, G.D., Karnosky, D.F. 1998. Growth of five hybrid poplar genotypes exposed to interacting elevated $\mathrm{CO}_{2}$ and $\mathrm{O}_{3}{ }^{-}$. Canadian Journal of Forest Research 28:1706-1716.

Dillen, S.Y., Marron, N., Bastien, C., Ricciotti, L., Salani, F., Sabatti, M., Pinel, M.P.C., Rae, A.M., Taylor, G., Ceulemans, R. 2007. Effects of environment and progeny on biomass estimations of five hybrid poplar families grown at three contrasting sites across Europe. 
Forest Ecology and Management 252:12-23.

Dillen, S.Y., Storme, V., Marron, N., Bastien, C., Neyrinck, S., Steenackers, M., Ceulemans, R., Boerjan, W. 2009. Genomic regions involved in productivity of two interspecific poplar families in Europe. 1. Stem height, circumference and volume.Tree Genetics \& Genomes 5:375-376.

Eriksson, G., Ekberg, I., Dormling, I., Matérn, B., Wettstein, D. 1978. Inheritance of bud-set and bud-flushing in Picea abies. TAG Theoretical and Applied Genetics 52:3-19.

Frewen, B.E., Chen, T.H.H., Howe, G.T., Davis, J., Rohde, A., Boerjan, W., Bradshaw, H.D. 2000. Quantitative trait loci and candidate gene mapping of bud set and bud flush in Populus. Genetics 154:837-845.

Heilman, P.E., Ekuan, G., Fogle, D. 1994. Above ground and belowground biomass and fine roots of 4 year old hybrids of Populus trichocarpa x Populus deltoides and parental species in short rotation culture. Canadian Journal of Forest Research 24:1186-1192.

Howe, G.T., Saruul, P., Davis, J., Chen, T.H.H. 2000. Quantitative genetics of bud phenology, frost damage, and winter survival in an F-2 family of hybrid poplars. Theoretical and Applied Genetics 101:632-642.

Induri, B.R., Ellis, D.R., Slavov, G.T., Yin, T., Zhang, X., Muchero, W., Tuskan, G.A., DiFazio, S.P. 2012. Identification of quantitative trait loci and candidate genes for cadmium tolerance in Populus. Tree Physiology 32:626-638.

Isebrands, J.G., Nelson, N.D. 1983. Distribution of (C-14) labeled photosynthates within intensively cultured Populus clones during the establishment year. Physiologia Plantarum 59:9-18.

Karim, S.A., Hawkins, B.J. 1999. Variation in response to nutrition in a three-generation 
pedigree of Populus. Canadian Journal of Forest Research 29:1743-1750.

Laureysens, I., Deraedt, W., Indeherberge, T., Ceulemans, R. 2003. Population dynamics in a 6year old coppice culture of poplar. Clonal differences in stool mortality, shoot dynamics and shoot diameter distribution in relation to biomass production. Biomass \& Bioenergy 24:81-95.

Lerner, I.M. 1958. The genetic basis of selection. Wiley, New York, 298.

Lynch, M., Walsh, B., Lynch, M., Walsh, B. 1998. Genetics and analysis of quantitative traits. 980.

Marron, N., Bastien, C., Sabatti, M., Taylor, G., Ceulemans, R. 2006. Plasticity of growth and sylleptic branchiness in two poplar families grown at three sites across Europe. Tree Physiology 26:935-946.

Marron, N., Ricciotti, L., Bastien, C., Beritognolo, I., Gaudet, M., Paolucci, I., Fabbrini, F., Salani, F., Dillen, S.Y., Ceulemans, R., Pinel, M.P.C., Taylor, G., Scarascia-Mugnozza, G., Sabatti, M. 2010 a. Plasticity of growth and biomass production of an intraspecific Populus alba family grown at three sites across Europe during three growing seasons. Canadian Journal of Forest Research 40:1887-1903.

Marron, N., Storme, V., Dillen, S.Y., Bastien, C., Ricciotti, L., Salani, F., Sabatti, M., Rae, A.M., Ceulemans, R., Boerjan, W. 2010 b. Genomic regions involved in productivity of two interspecific poplar families in Europe. 2. Biomass production and its relationships with tree architecture and phenology. Tree Genetics \& Genomes 6:533-554.

McMahon, T. 1973. Size and shape in biology. Science 179.

Novaes, E., Osorio, L., Drost, D.R., Miles, B.L., Boaventura-Novaes, C.R.D., Benedict, C., Dervinis, C., Yu, Q., Sykes, R., Davis, M., Martin, T.A., Peter, G.F., Kirst, M. 2009. 
Quantitative genetic analysis of biomass and wood chemistry of Populus under different nitrogen levels. New Phytologist 182:878-890.

Oldham, S., Bohni, R., Stocker, H., Brogiolo, W., Hafen, E. 2000. Genetic control of size in Drosophila. Philosophical Transactions of the Royal Society of London Series BBiological Sciences 355:945-952.

Poorter, H., Nagel, O. 2000. The role of biomass allocation in the growth response of plants to different levels of light, $\mathrm{CO} 2$, nutrients and water: a quantitative review. Australian Journal of Plant Physiology 27:1191-1191.

Pregitzer, K.S., Dickmann, D.I., Hendrick, R., Nguyen, P.V. 1990. Whole-tree carbon and nitrogen partitioning in young hybrid poplars. Tree Physiology 7:79-93.

Rae, A.M., Pinel, M.P.C., Bastien, C., Sabatti, M., Street, N.R., Tucker, J., Dixon, C., Marron, N., Dillen, S.Y., Taylor, G. 2008. QTL for yield in bioenergy Populus: identifying GxE interactions from growth at three contrasting sites. Tree Genetics \& Genomes 4:97-112.

Rae, A.M., Robinson, K.M., Street, N.R., Taylor, G. 2004. Morphological and physiological traits influencing biomass productivity in short-rotation coppice poplar. Canadian Journal of Forest Research 34:1488-1498.

Rae, A.M., Street, N.R., Robinson, K.M., Harris, N., Taylor, G. 2009. Five QTL hotspots for yield in short rotation coppice bioenergy poplar: The Poplar Biomass Loci. BMC Plant Biology:9.

Rae, A.M., Tricker, P.J., Bunn, S.M., Taylor, G. 2007. Adaptation of tree growth to elevated CO2: quantitative trait loci for biomass in Populus. New Phytologist 175:59-69.

Rehfeldt, G.E. 1992 b. Early selection in Pinus ponderosa: compromises between growth potential and growth rhythm in developing breeding strategies. Forest Science 38:661- 
677.

Riemenschneider, D.E., McMahon, B.G., Ostry, M.E. 1992. Use of selection indices to increase tree height and to control damaging agents in 2-year-old balsam poplar. Canadian Journal of Forest Research 22:561-567.

Rohde, A., Bastien, C., Boerjan, W. 2011. Temperature signals contribute to the timing of photoperiodic growth cessation and bud set in poplar. Tree Physiology 31:472-482.

Scarascia Mugnozza, G.E., Ceulemans, R., Heilman,P.E., Isebrands, J.G., Stettler, R.F., Hinckley, T.M. 1997. Production physiology and morphology of Populus species and their hybrids grown under short rotation .II. Biomass components and harvest index of hybrid and parental species clones. Canadian Journal of Forest Research 27:285-294.

Schmidt-Nielsen, K. 1984. Scaling why is animal size so important? Cambridge University Press: New York, N.Y., USA; London, England, 241.

Shapiro, S.S., Wilk, M.B. 1965. An analysis of variance test for normality (complete samples). Biometrika 52:591-611.

Stanton, B.J. 2001. Clonal variation in basal area growth patterns during stand development in hybrid poplar. Canadian Journal of Forest Research 31:2059-2066.

Street, N.R., Skogstrom, O., Sjodin, A., Tucker, J., Rodriguez-Acosta, M., Nilsson, P., Jansson, S., Taylor, G. 2006. The genetics and genomics of the drought response in Populus. Plant Journal 48:321-341.

Tschaplinski, T.J., Tuskan, G.A., Sewell, M.M., Gebre,G.M., Donald, E.T.I., Pendleyi, C. 2006. Phenotypic variation and quantitative trait locus identification for osmotic potential in an interspecific hybrid inbred F-2 poplar pedigree grown in contrasting environments. Tree Physiology 26:595-604. 
Tuskan, G.A., DiFazio, S.P., Teichmann, T. 2004. Poplar genomics is getting popular: The impact of the poplar genome project on tree research. Plant Biology 6:2-4.

Updegraff, K., Baughman, M.J., Taff, S.J. 2004. Environmental benefits of cropland conversion to hybrid poplar: economic and policy considerations. Biomass \& Bioenergy 27:411428.

White, T.L., Adams, W.T., Neale, D.B. 2007. Forest Genetics: CABI Pub.

Wu, R., Bradshaw, H.D., Stettler, R.F. 1998. Developmental quantitative genetics of growth in Populus. Theoretical and Applied Genetics 97:1110-1119.

Wu, R.L. 1998. Genetic mapping of QTLs affecting tree growth and architecture in Populus: implication for ideotype breeding. Theoretical and Applied Genetics 96:447-457.

Wullschleger, S., Yin, T.M., DiFazio, S.P., Tschaplinski, T.J., Gunter, L.E., Davis, M.F., Tuskan, G.A. 2005. Phenotypic variation in growth and biomass distribution for two advanced-generation pedigrees of hybrid poplar. Canadian Journal of Forest Research $35: 1779-1789$.

Zhang, B., Tong, C., Yin, T., Zhang, X., Zhuge, Q., Huang, M., Wang, M., Wu, R. 2009. Detection of quantitative trait loci influencing growth trajectories of adventitious roots in Populus using functional mapping. Tree Genetics \& Genomes, 5.

Zhang, D., Zhang, Z., Yang, K. 2006. QTL analysis of growth and wood chemical content traits in an interspecific backcross family of white poplar (Populus tomentosa x P. bolleana) $\mathrm{x}$ P. tomentosa. Canadian Journal of Forest Research 36:2015-2023. 


\title{
CHAPTER IV
}

\section{INFLUENCE OF Fe ON Cd TOXICITY ON GROWTH AND BIOMASS TRAITS OF Cd TOLERANT AND Cd SUSCEPTIBLE GENOTYPES OF POPULUS}

\author{
Authors \\ Brahma Reddy Induri, Danielle R. Ellis, Gancho T. Slavov, Stephen P. DiFazio
}

\section{Authors' contribution}

Brahma Reddy Induri wrote the manuscript and performed the greenhouse experiments and Cd assays. Danielle Ellis and Gancho Slavov contributed towards statistical analysis. Stephen DiFazio directed the project and contributed toward the writing. 


\begin{abstract}
Cadmium (Cd) affects a wide range of physiological processes in plants, and disturbance of plant mineral homeostasis, especially of iron $(\mathrm{Fe})$, is an important symptom of $\mathrm{Cd}$ toxicity. $\mathrm{Fe}$ is an essential micronutrient used for plant growth and metabolism. In this study, $\mathrm{Cd}$ and $\mathrm{Fe}$ interaction was demonstrated in Populus by changing the external $\mathrm{Cd}$ and $\mathrm{Fe}$ status of a hydroponic nutrient medium. Two Populus clones with differential responses to Cd were examined for Cd tolerance at Fe deficient $(0 \mu \mathrm{M})$ and high Fe $(100 \mu \mathrm{M})$ levels. There were significant differences between genotypes within different treatment combinations for total dry weight, leaf dry weight, shoot dry weight and root dry weight. Cd toxicity was more severe on the Cd-susceptible genotype than the Cd-tolerant genotype under both Fe conditions. Furthermore, the symptoms of Cd toxicity were reduced under high Fe conditions for both genotypes for all the growth and biomass traits studied, although the effect was stronger for the Cd-tolerant genotype. The effects of $\mathrm{Cd}-\mathrm{Fe}$ interaction were more pronounced on the $\mathrm{Cd}$ susceptible genotype 182, compared to the Cd tolerant genotype 1-183. Examining Cd uptake, translocation and distribution patterns in the leaf, shoot and root tissues should reveal further insights on Cd-Fe interaction mechanisms in Populus.
\end{abstract}




\section{Introduction}

Cadmium (Cd) is a widespread toxic heavy metal pollutant that poses a serious threat to human health (Shao et al., 2007). Cd enters food chain from contaminated soils thorugh plant uptake. In plants, symptoms of Cd toxicity include leaf roll, chlorosis and reductions in root and shoot growth, even at minute concentrations (Milone et al., 2003; Almeida et al., 2007). Cd disrupts the structure of many proteins by acting on sulphydryl groups (Vanassche and Clijsters, 1990) and is reported to change the permeability of membranes by altering lipid composition (Ouariti et al., 1997). Apart from affecting the ion and water balance of plants, Cd has been shown to cause reduced plant growth by affecting various physiological processes including photosynthesis, respiration, nitrate assimilation, metabolite accumulation and enzyme activity (Sanità di Toppi and Gabbrielli, 1999; Smeets et al., 2005; Solti et al., 2008; Das et al., 1997; Sanita Di Toppi et al., 1998). Cd decreases the photosynthetic activity of plants by disturbing chloroplast ultrastructure (Sandalio et al., 2001) and altering stomatal closure. Cd has also been shown to affect the electron transport system, interact with antioxidative defense systems and induce lipid peroxidation (Smeets et al., 2005; Rodriguez-Serrano et al., 2009). Cd interferes with the uptake, distribution and metabolism of other mineral nutrients in plants (Shao et al., 2007; RodriguezSerrano et al., 2009; Liu et al., 2003), most notably Fe (Solti et al., 2008; Sandalio et al., 2001; Fodor et al., 2005; Siedlecka and Krupa, 1999; Zhang et al., 2002; Wallace et al., 1992).

Although abundant in the Earth's crust, the essential micronutrient Fe is mostly unavailable for uptake by plants as it is mostly in insoluble ferric form, especially in alkaline and neutral soils and the Fe status of the plant environment determines one of the two strategies that plants use for Fe uptake (Shao et al., 2007). All higher plants except the grasses utilize strategy I to assimilate iron. This involves reducing the ferric form to ferrous form before uptake by a 
plasma-membrane bound redox system (Schmidt, 2003). In grasses, a complex involving phytosiderophores, the plant-borne high affinity Fe (III) chelators, is formed with ferric iron before it is translocated by a transporter specific to this complex (Shao et al., 2007). The specific Fe transporters used in strategy I can also transport Cd (Lombi et al., 2002; Thomine et al., 2000; Rogers et al., 2000).

$\mathrm{Cd}$ may compete with other divalent ions including $\mathrm{Ca}, \mathrm{Zn}$ and $\mathrm{Fe}$ for binding sites in the root apoplast and transporters at the plasma membrane (Fodor et al., 2005; Clemens, 2001). Cd accumulates in roots in large quantities and inhibits root to shoot Fe translocation (MendozaCozatl et al., 2008) resulting in higher Fe levels in cucumber (Fodor et al., 1996) and mungbean (Liu et al., 2000) roots. Cd treatment causes Fe deficiency in Populus (Solti et al., 2008; Fodor et al., 2005; Sarvari et al., 2001) and in other plants (Siedlecka and Krupa, 1999; Wallace et al., 1992; Siedlecka and Krupa, 1996). Cd can also inhibit Fe (III)-chelate reductase, the inducible enzyme under Fe deficient conditions in roots (Alcantara et al., 1994; Chang et al., 2003). Iron can also affect the intensity of $\mathrm{Cd}$ toxicity, with higher $\mathrm{Fe}$ mitigating $\mathrm{Cd}$ toxicity and $\mathrm{Fe}$ deficiency raising Cd toxicity levels (Morrissey and Guerinot, 2009). Such effects have been demonstrated in maize (Meda et al., 2007) and in soybean (Smith et al., 1985). Up-regulation of a high affinity Fe transporter under Fe deficiency increased Cd uptake and sensitivity (BessonBard et al., 2009; Nakanishi et al., 2006). Also, Cd accumulation decreased by 5 fold upon knocking out the Fe transporter, IRT1 in Arabidopsis compared to the wild-type (Vert et al., 2002), demonstrating the role of this iron transporter in Cd uptake. Although Fe is required for growth and metabolism of plants, it can also be toxic to plants at high levels (Siedlecka and Krupa, 1996; Kabata Pendias, 1992). Under excess Fe levels, Fe was toxic to the bean plants and 
also increased the toxic effects of $\mathrm{Cd}$ whereas under moderate $\mathrm{Fe}$ levels Fe reduced $\mathrm{Cd}$ translocation to leaves by immobilizing the Cd on the roots (Siedlecka and Krupa, 1996).

We are currently investigating mechanisms of Cd tolerance in the model tree genus Populus. We have conducted a whole-genome microarray (Ellis et al., Unpublished) using two genotypes with extreme responses for Cd tolerance in a greenhouse hydroponic study conducted to detect QTL for Cd tolerance (Induri et al., 2012). We identified several Fe homeostasis genes that were up-regulated in this study suggesting that the genotypic differences in Cd tolerance were partially due to differences in Fe homeostasis (Ellis et al., Unpublished). More specifically, we hypothesized that the up-regulation of Fe homeostasis genes in the susceptible genotype might have resulted in increased $\mathrm{Cd}$ uptake, thereby resulting in greater toxicity.

Here, we seek to directly test this interaction by conducting a hydroponic study with a $\mathrm{Cd}$ tolerant and a Cd susceptible genotype of Populus exposed to different levels of $\mathrm{Cd}$ ( 0 and 25 $\mu \mathrm{M})$ and $\mathrm{Fe}(0$ and $100 \mu \mathrm{M})$. It was hypothesized that $\mathrm{Cd}$ stress under Fe deficiency conditions would decrease the growth and biomass of plants, especially in the susceptible genotype. It was further hypothesized that higher Fe concentration in the hydroponic nutrient medium would reduce $\mathrm{Cd}$ toxicity in Populus with the reduction being stronger in the $\mathrm{Cd}$ susceptible genotype. 


\section{Material and Methods}

\section{Plant material}

Two genotypes, a Cd tolerant genotype (1-183) and a Cd susceptible genotype (182) were selected from a Cd tolerance screening study of 252 genotypes from the 52-124 Family of Populus conducted by Induri et al. (2012). Dormant cuttings were collected from West Virginia University Agronomy Farm prior to bud break and were stored at $4^{\circ} \mathrm{C}$ for 5 weeks to meet chilling requirements. This facilitated uniform rooting of the cuttings, and enabled selection of plants that were of approximately uniform in size at the beginning of the experiment.

\section{Greenhouse hydroponic experiment}

Cuttings of approximately $15 \mathrm{~cm}$ length and $1 \mathrm{~cm}$ diameter were dipped in 1:10 dilution of the commercial liquid rooting hormone solution (Dip N Grow 1\% IBA, $0.5 \%$ NAA) for 15 seconds, surrounded by foam stoppers and plugged into $3 \mathrm{~cm}$ holes at $8 \mathrm{~cm}$ spacing in the lids of polyethylene boxes. Approximately $5 \mathrm{~cm}$ of the base of the cuttings was submerged incontinuously aerated 0.1X Johnson's solution (Siddique et al., 1990). The nutrient solution was composed of $400 \mu \mathrm{M} \mathrm{NH} \mathrm{NO}_{3}, 400 \mu \mathrm{M} \mathrm{KNO} 3,200 \mu \mathrm{M} \mathrm{Ca}\left(\mathrm{NO}_{3}\right)_{2} \cdot 4 \mathrm{H}_{2} \mathrm{O}, 100 \mu \mathrm{M}$ $\mathrm{MgSO}_{4} \cdot 7 \mathrm{H}_{2} \mathrm{O}, 50 \mu \mathrm{M} \mathrm{K}_{2} \mathrm{HPO}_{4}, 20 \mu \mathrm{M} \mathrm{KCl}, 25 \mu \mathrm{M} \mathrm{H}_{3} \mathrm{BO}_{3}, 0.5 \mu \mathrm{M} \mathrm{Na}_{2} \mathrm{MoO}_{4} \cdot 2 \mathrm{H}_{2} \mathrm{O}, 2 \mu \mathrm{M}$ $\mathrm{MnSO}_{4} \cdot 4 \mathrm{H}_{2} \mathrm{O}, 0.5 \mu \mathrm{M} \mathrm{CuSO}_{4} \cdot 5 \mathrm{H}_{2} \mathrm{O}, 2 \mu \mathrm{M} \mathrm{ZnSO}_{4} \cdot 7 \mathrm{H}_{2} \mathrm{O}, 0.5 \mu \mathrm{M} \mathrm{CoCl}_{2} 20 \mu \mathrm{M}$ Fe-Na EDTA. One primary shoot was maintained per cutting (Figure 4.1). For greenhouse growth conditions and other details of hydroponic methods, see Induri et al. (2012).

This study had two levels of $\mathrm{Cd}(0$ and $25 \mu \mathrm{M})$ and 2 levels of Fe (0 and $100 \mu \mathrm{M})$. Once the cuttings developed roots and shoots, they were transplanted to smaller polyethylene boxes arranged in a randomized block design (Table 4.1 and Figure 4.1). The experiment contained 16 polyethylene containers of size $24 \mathrm{~cm} \times 12 \mathrm{~cm}$ x $38 \mathrm{~cm}$. Each container had four plants of a single 
genotype at $9 \mathrm{~cm}$ spacing and contained 7L of the $0.1 \mathrm{X}$ Johnson's solution described above. The solutions were changed every third day throughout the experiment to maintain nutrient and oxygen levels and to avoid algal growth. An aliquot of hydroponic solution samples was collected from each box in all the treatment combinations just prior to changing solutions to determine the available $\mathrm{Cd}$ concentration. These solution samples were filtered using Whatmann number 44 filter paper. Cd contents were determined by ICP-OES (Inductively Coupled Plasma - Optical Emission Spectra) at the Virginia University Plant analysis lab.

\section{Harvesting followed by Cd and Fe treatments}

Treatments were applied after 35 days of growth. Cd treatments consisted of $25 \mu \mathrm{M}$ $\mathrm{CdCl}_{2}$. Fe was supplied as $100 \mu \mathrm{M} \mathrm{Fe}-\mathrm{Na}$ EDTA. Iron starvation was imposed by excluding $\mathrm{Fe}$ from the micronutrient solution described above. The $\mathrm{Cd}$ and $\mathrm{Fe}$ concentrations for this experiment were selected based on a pilot experiment that revealed substantial phenotypic variation in this family without excessive mortality at these selected concentrations. Fresh Cd and Fe were added each time solutions were changed. The plants were exposed to $\mathrm{Fe}$ and $\mathrm{Cd}$ treatments for a period of 14 days before harvest.

Observations were taken before and after treatment on plant height (from the base of the shoot to the base of the apical bud $)$, cutting diameter, shoot diameter $(2.5 \mathrm{~cm}$ from the base of the shoot), leaf number, number of leaf scars, photosynthetically active radiation, (PAR), root collar diameter (just above the origin point of the uppermost root), and rooted length of each cutting (place occupied by the roots throughout the length of a cutting). Plants were also rated twice on a scale of 1 to 4 (with $0=$ no damage, $1=<25 \%$ damage, $2=25-50 \%$ damage, $3=50-75 \%$ damage and $4=75-100 \%$ damage or dead plant) and the average rating was used for statistical analyses. Roots and shoots were harvested separately into paper bags and dried in an oven at 60 
${ }^{\circ} \mathrm{C}$ for 6 days. Dry weights were recorded for leaves, roots, and shoots separately and total dry weights were calculated by adding all these components. Cutting dry weights were also recorded and were used as a covariate in the data analysis.

\section{Minteq- species composition analyses}

As the measurements of total dissolved ions of $\mathrm{Fe}, \mathrm{Cd}$ and EDTA will not provide the exact amount of these ions accessible for plant uptake, speciation analyses of Cd, Fe and EDTA were performed using a geochemical speciation program, Visual MINTEQ (Vasyukova et al., 2012; Gustafsson, 1999; Allison et al., 1991). Analyses were performed to estimate the total free ions of $\mathrm{Fe}^{++}, \mathrm{Fe}^{+++}$and $\mathrm{Cd}^{++}$ions in the hydrponic solution and also to determine if the total ions are present as free or as complexed species with other ions at different $\mathrm{pH}$ ranges and at different concentrations of $\mathrm{Cd}, \mathrm{Fe}$ and EDTA.

\section{Statistical analysis}

Data was analyzed by mixed-model analysis of variance (ANOVA) based on type IV sum of squares using SAS JMP, version 10.0. Response variables were plant height difference (i.e., height after treatment - height before treatment), leaf number difference, shoot diameter difference, average damage rating, total dry weight, root dry weight, leaf dry weight, shoot dry weight and rooted length of cutting. The data was tested for normality for each trait separately by Shapiro-Wilk test (Shapiro and Wilk, 1965) and no variables required transformation. Three-way nested ANOVA was used for analyzing growth traits but because of limited number of cuttings for each genotype, individual plants were considered as independent replicates for analysis of dry weights, which could be considered pseudo-replication (Hurlbert, 1984). However, the effect of box was not significant ( $p>0.05$, data not shown), so this approach is justified for analysis of dry weights. 


\section{Results}

\section{Cd content of hydroponic solutions}

According to geochemical speciation analyses, at the average hydroponic solution $\mathrm{pH}$ of 5.2, $99 \%$ of the Cd ions were free and $<1 \%$ was complexed with EDTA and other anions. At the same $\mathrm{pH}$, most of the Fe was chelated with EDTA.

Solution samples collected at the time of solution changes (after 3 days of exposure) contained $61 \%$ more $\mathrm{Cd}$ in the high Fe treatment compared to the low Fe treatments. There was no detectable $\mathrm{Cd}$ in solutions that did not have $\mathrm{Cd}$ added (Figure 4.10).

\section{Normalized Effects of Cd and Fe}

The effects of $\mathrm{Cd}$ and $\mathrm{Fe}$ were apparent when subtracting trait values before treatment application from those measured following treatment (Table 4.2; Figures 4.2 and 4.4). Under Fe starvation, Cd caused reduced growth and higher damage for both genotypes, though as expected the effects were stronger for the susceptible clone (number 182) (Table 4.2; Figures 4.2 and 4.4). This suggested that $\mathrm{Cd}$ effects were increased under Fe starvation. In contrast, the effect of Cd was greatly diminished under high Fe for both genotypes. All the main effects were significant in the ANOVA analysis except the Cd effect for shoot diameter difference (Table 4.4). Furthermore, the $\mathrm{Cd} x \mathrm{Fe}$ interaction was significant for leaf number difference and average damage rating but not for height difference and shoot diameter difference. Fe x Genotype was also significant for leaf number difference (Table 4.4). Cd x Fe x Genotype interaction was significant only for shoot diameter difference among all the growth and biomass traits studied (Table 4.4). 


\section{Biomass traits - Average trait values}

Similar trends were observed for rooted length (Figure 4.5) and the raw biomass measurements at the termination of the experiment. The two genotypes showed differences in total dry weight and its components including leaf dry weight, shoot dry weight and root dry weight at different treatment combinations (Table 4.3; Figures 4.6 to 4.9). The average trait values were lower under low Fe - high Cd conditions for total dry weight (Figure 4.6) compared to the other treatment combinations. The effect was particularly pronounced for leaf dry weight (Figure 4.7), although roots and shoots also showed substantial reductions under high $\mathrm{Cd}$ and low Fe.

The genotype main effect was not significant for any of the biomass traits, whereas the Cd effect was significant for all biomass traits (Table 4.4). The Fe effect was significant or at least exhibited trends towards significance for all biomass traits except rooted length. None of the interactions between $\mathrm{Cd}, \mathrm{Fe}$ and genotype were significant for the biomass traits except $\mathrm{Cd} \mathrm{x}$ Genotype interaction for root dry weight. 
Table 4.1. Lay-out of the Cd-Fe interaction experiment.

\begin{tabular}{lrlrrr}
\hline Genotype & Cd & Fe & Table \# & Row & Column \\
\hline 182 & 0 & $\mathrm{H}$ & 2 & 2 & 1 \\
182 & 0 & $\mathrm{H}$ & 3 & 3 & 1 \\
182 & 0 & $\mathrm{~L}$ & 1 & 5 & 1 \\
182 & 0 & $\mathrm{~L}$ & 2 & 1 & 1 \\
182 & 25 & $\mathrm{H}$ & 3 & 6 & 1 \\
182 & 25 & $\mathrm{H}$ & 3 & 4 & 2 \\
182 & 25 & $\mathrm{~L}$ & 2 & 3 & 1 \\
182 & 25 & $\mathrm{~L}$ & 3 & 2 & 2 \\
$1-183$ & 0 & $\mathrm{H}$ & 3 & 5 & 1 \\
$1-183$ & 0 & $\mathrm{H}$ & 1 & 3 & 2 \\
$1-183$ & 0 & $\mathrm{~L}$ & 2 & 5 & 1 \\
$1-183$ & 0 & $\mathrm{~L}$ & 1 & 3 & 1 \\
$1-183$ & 25 & $\mathrm{H}$ & 2 & 5 & 2 \\
$1-183$ & 25 & $\mathrm{H}$ & 2 & 2 & 2 \\
$1-183$ & 25 & $\mathrm{~L}$ & 3 & 2 & 1 \\
$1-183$ & 25 & $\mathrm{~L}$ & 2 & 4 & 2 \\
\hline
\end{tabular}


Table 4.2. Treatment effects averaged over ramets. Effects are calculated as the difference in trait values measured before treatments were imposed subtracted from the final trait values.

Numbers in parentheses are standard deviations.

\begin{tabular}{lrlllll}
\hline Clone & Cd & Fe & $\begin{array}{l}\text { Height } \\
\text { difference, mm }\end{array}$ & $\begin{array}{l}\text { Leaf number } \\
\text { difference }\end{array}$ & $\begin{array}{l}\text { Shoot diameter } \\
\text { difference, mm }\end{array}$ & $\begin{array}{l}\text { Damage } \\
\text { rating }\end{array}$ \\
\hline $1-183$ & 0 & H & $156.87(26.47)$ & $5.37(3.02)$ & $1.78(1.07)$ & $0.00(0.00)$ \\
$1-183$ & 0 & L & $173.87(48.92)$ & $6.00(2.20)$ & $0.82(1.38)$ & $0.00(0.00)$ \\
$1-183$ & 25 & H & $130.62(26.92)$ & $3.37(3.16)$ & $1.33(0.61)$ & $1.06(0.50)$ \\
$1-183$ & 25 & L & $97.75(61.81)$ & $2.12(3.36)$ & $1.46(0.73)$ & $2.50(0.53)$ \\
182 & 0 & H & $156.50(25.34)$ & $6.12(2.53)$ & $1.15(0.48)$ & $0.25(0.46)$ \\
182 & 0 & L & $132.00(46.42)$ & $4.25(1.98)$ & $0.93(0.49)$ & $1.18(1.28)$ \\
182 & 25 & H & $102.37(45.81)$ & $3.75(3.41)$ & $1.06(0.57)$ & $2.25(0.85)$ \\
182 & 25 & L & $55.12(42.31)$ & $-3.25(3.92)$ & $0.18(0.39)$ & $3.50(0.71)$ \\
\hline
\end{tabular}


Table 4.3. Leaf dry weight, Shoot dry weight, Root dry weight and Total dry weight averaged over ramets. Numbers in parentheses are standard deviations.

\begin{tabular}{lrllllll}
\hline Clone & Cd & Fe & $\begin{array}{l}\text { Leaf dry } \\
\text { weight,g }\end{array}$ & $\begin{array}{l}\text { Shoot dry } \\
\text { weight,g }\end{array}$ & $\begin{array}{l}\text { Root dry } \\
\text { weight,g }\end{array}$ & $\begin{array}{l}\text { Total } \\
\text { weight,g }\end{array}$ & $\begin{array}{l}\text { Rooted } \\
\text { length,mm }\end{array}$ \\
\hline $1-183$ & 0 & H & $5.33(0.78)$ & $1.70(0.16)$ & $2.17(0.43)$ & $9.21(1.27)$ & $62.00(31.16)$ \\
$1-183$ & 0 & L & $5.04(1.58)$ & $1.70(0.54)$ & $1.65(0.36)$ & $8.40(2.38)$ & $78.00(28.15)$ \\
$1-183$ & 25 & H & $5.70(2.48)$ & $1.60(0.57)$ & $1.97(0.78)$ & $9.28(3.80)$ & $56.00(16.83)$ \\
$1-183$ & 25 & L & $3.43(1.11)$ & $0.95(0.44)$ & $0.93(0.45)$ & $5.32(1.97)$ & $53.00(36.96)$ \\
182 & 0 & H & $5.73(2.60)$ & $1.60(0.80)$ & $2.47(1.07)$ & $9.80(4.45)$ & $72.25(15.65)$ \\
182 & 0 & L & $4.96(1.51)$ & $1.46(0.29)$ & $2.73(0.73)$ & $9.16(2.30)$ & $69.50(18.98)$ \\
182 & 25 & H & $4.00(1.63)$ & $0.98(0.38)$ & $1.01(0.38)$ & $5.99(2.22)$ & $57.00(14.58)$ \\
182 & 25 & L & $1.26(0.50)$ & $0.48(0.12)$ & $0.67(0.19)$ & $2.42(0.62)$ & $21.00(6.56)$ \\
\hline
\end{tabular}


Table 4.4. Summary of results of ANOVA analyses. 'p' values are from the 'F' test. Corresponding 'p' values for interaction terms are in parentheses. Significant 'p' values are in bold.

\begin{tabular}{llllll}
\hline Trait & Genotype & $\mathrm{Cd}$ & $\mathrm{Fe}$ & Significant interactions & $\mathrm{R}^{2}$ Adjusted \\
\hline Height difference & 0.0083 & $<.0001$ & 0.0380 & None & 0.42 \\
Leaf number difference & 0.0423 & $<.0001$ & $\mathbf{0 . 0 0 1 8}$ & Cd*Fe $(\mathbf{0 . 0 1 8 7}), \mathrm{Fe}^{*}$ Genotype $(\mathbf{0 . 0 0 6 1})$ & 0.49 \\
Shoot diameter difference & $\mathbf{0 . 0 1 1 7}$ & 0.4154 & $\mathbf{0 . 0 1 8 8}$ & Cd*Fe*Genotype $(\mathbf{0 . 0 3 1 8})$ & 0.16 \\
Average damage rating & $\mathbf{< . 0 0 0 1}$ & $<.0001$ & $\mathbf{< . 0 0 0 1}$ & Cd*Fe $(<\mathbf{0 . 0 0 0 1}), \mathrm{Cd}^{*}$ Fe*Genotype $(0.0073)$ & 0.91 \\
Total dry weight & 0.2264 & $\mathbf{0 . 0 0 2 0}$ & $\mathbf{0 . 0 3 0 3}$ & None & 0.34 \\
Leaf dry weight & 0.1616 & $\mathbf{0 . 0 1 2 5}$ & $\mathbf{0 . 0 2 1 6}$ & None & 0.27 \\
Shoot dry weight & 0.0470 & $\mathbf{0 . 0 0 1 5}$ & 0.0704 & None & 0.33 \\
Root dry weight & 0.8672 & $\mathbf{< . 0 0 0 1}$ & 0.0825 & Cd*Genotype $(\mathbf{0 . 0 0 8 0})$ & 0.51 \\
Rooted length & 0.3988 & $\mathbf{0 . 0 1 0 5}$ & 0.4568 & None & 0.16 \\
\hline
\end{tabular}



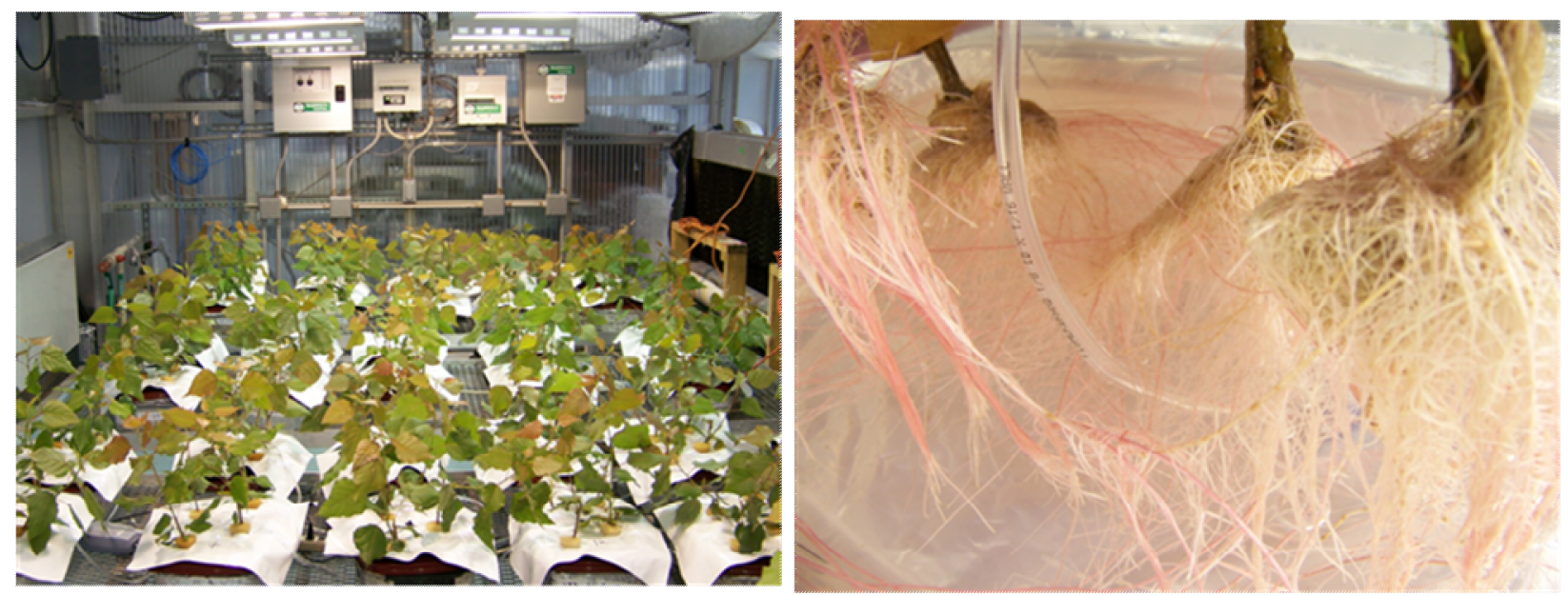

A

B

Figure 4.1. Cd-Fe experiment setup. A). Overview of hydroponic experiment prior to $\mathrm{Cd}, \mathrm{Fe}$ treatments. B). Control hydroponic roots before $\mathrm{Cd}$, Fe treatments 


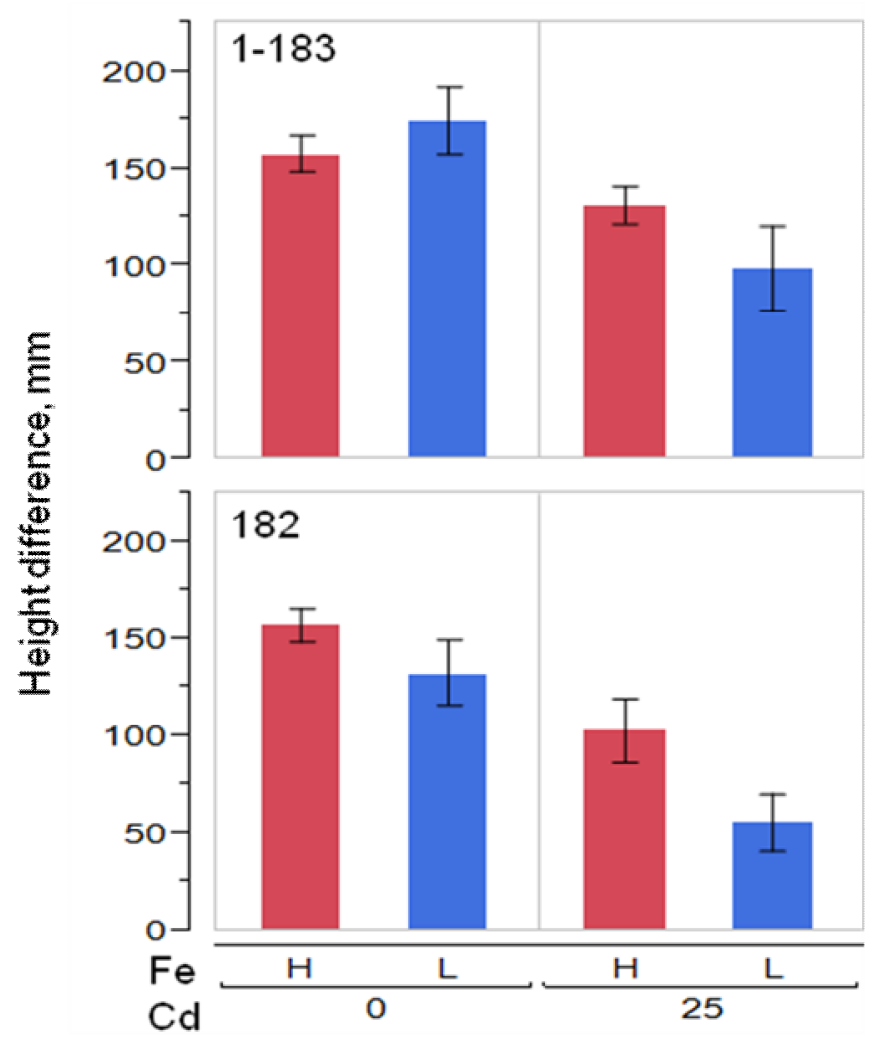

Figure 4.2. Effects of $\mathrm{Cd}$ and $\mathrm{Fe}$ on plant height, calculated as the difference in trait values measured before treatments were imposed subtracted from the final trait values. Error bars represent standard error in this and subsequent figures. 


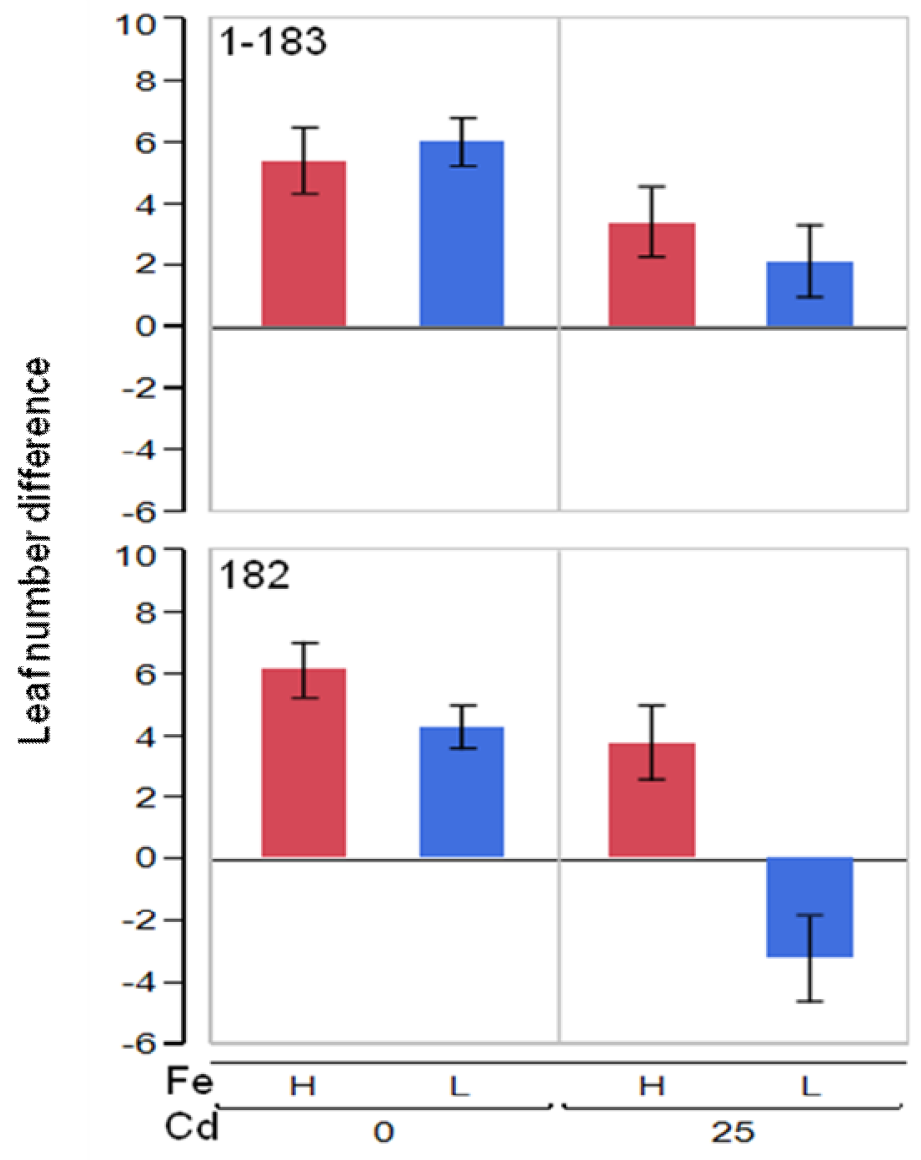

Figure 4.3. Effects of $\mathrm{Cd}$ and $\mathrm{Fe}$ on leaf number, calculated as the difference in trait values measured before treatments were imposed subtracted from the final trait values. 


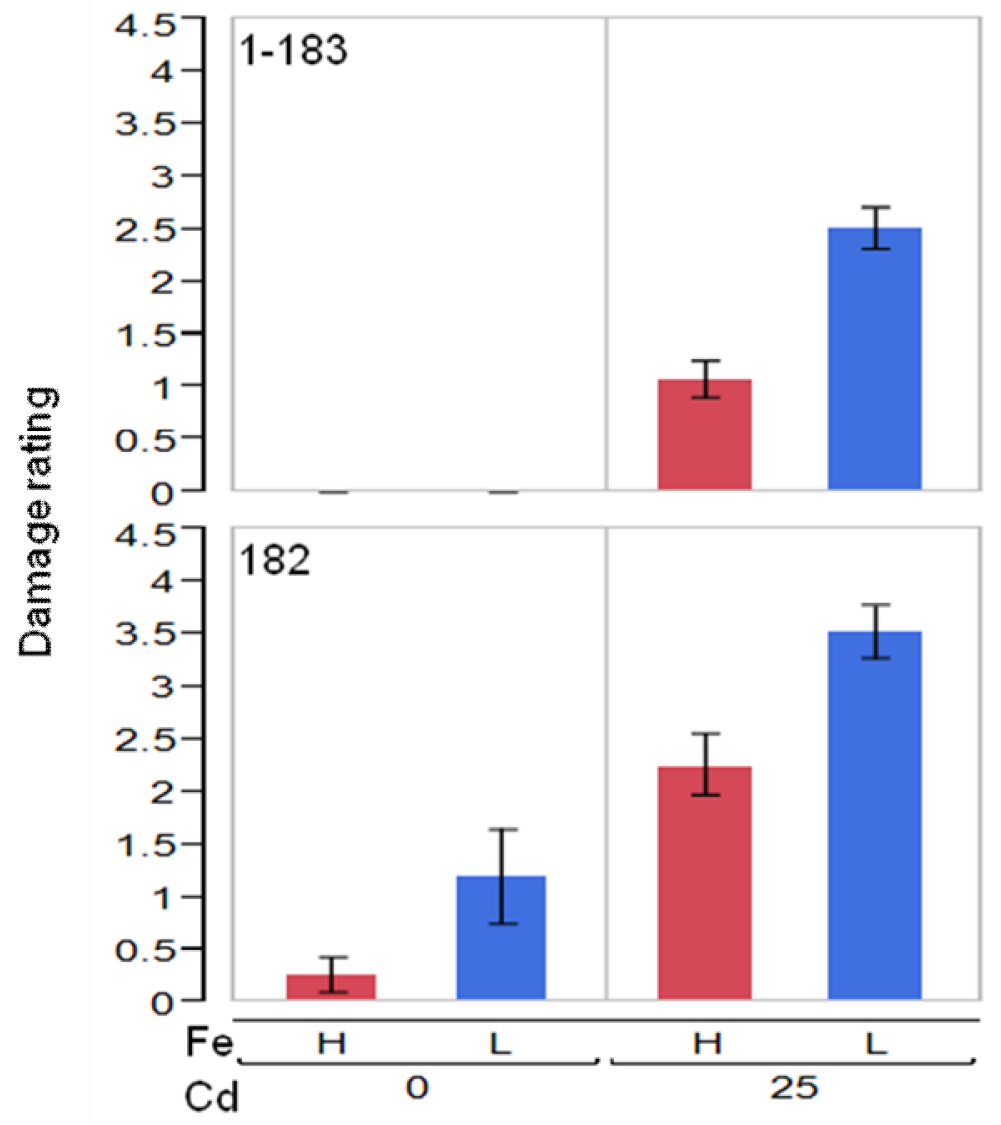

Figure 4.4. Average damage rating at different levels of $\mathrm{Cd}$ and $\mathrm{Fe}$. 


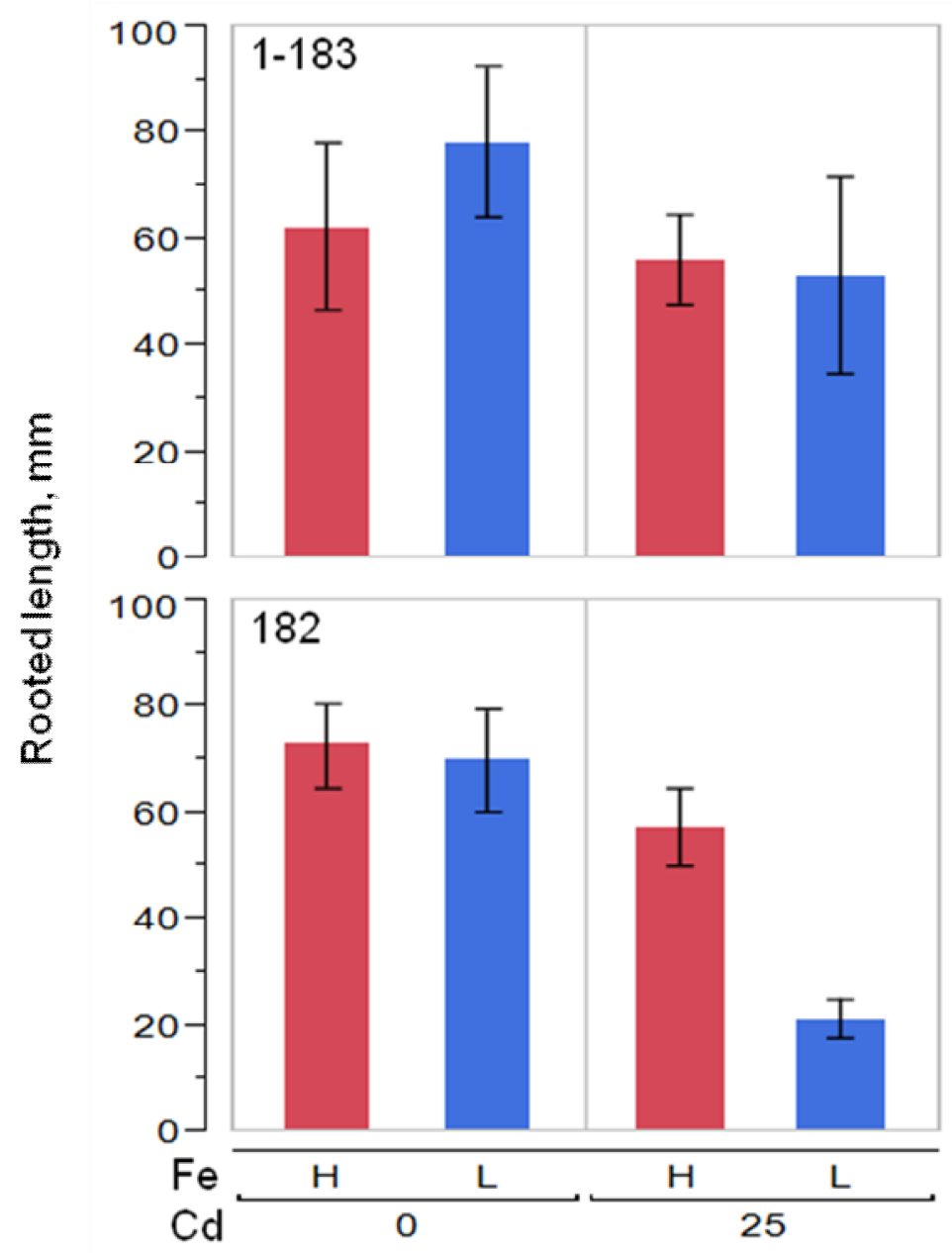

Figure 4.5. Rooted length observations at different levels of $\mathrm{Cd}$ and $\mathrm{Fe}$. 


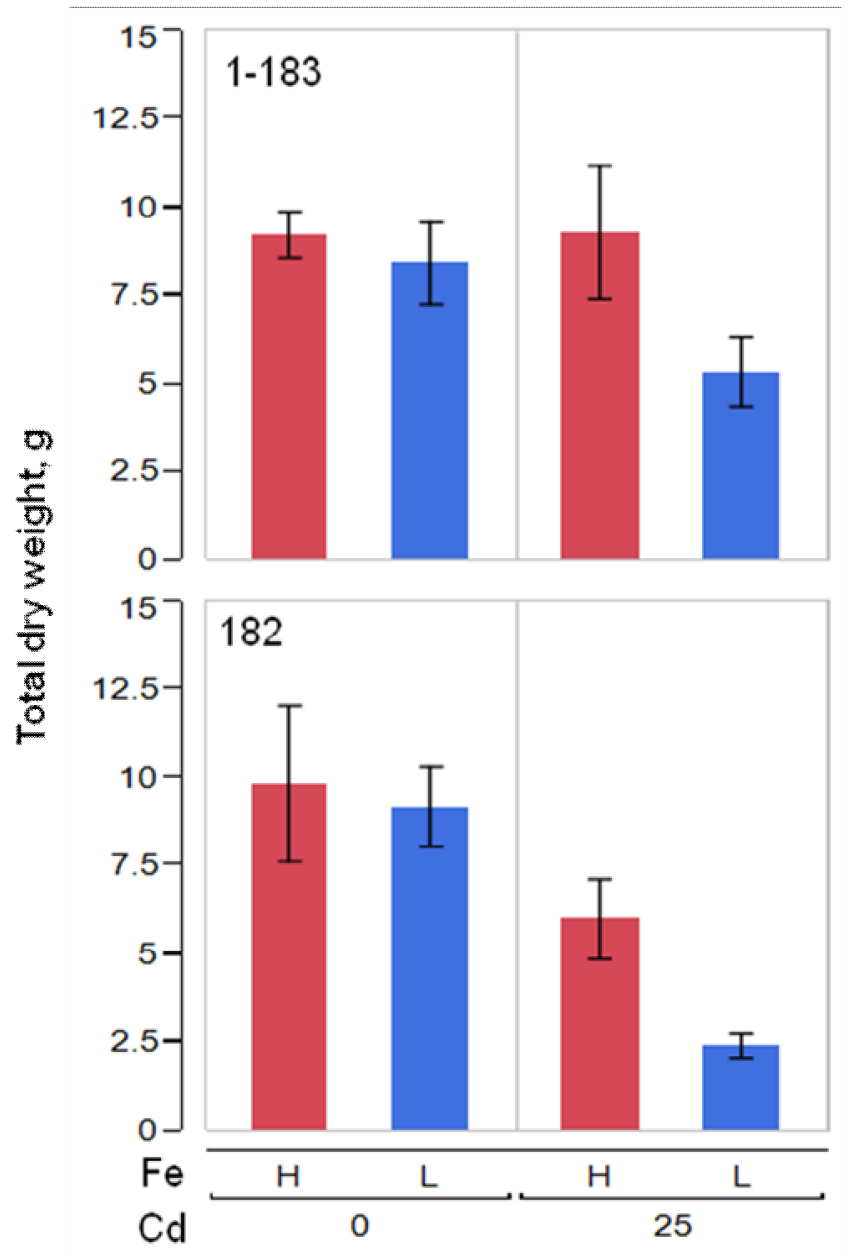

Figure 4.6. Total dry weight of plants at different levels of $\mathrm{Cd}$ and $\mathrm{Fe}$. 


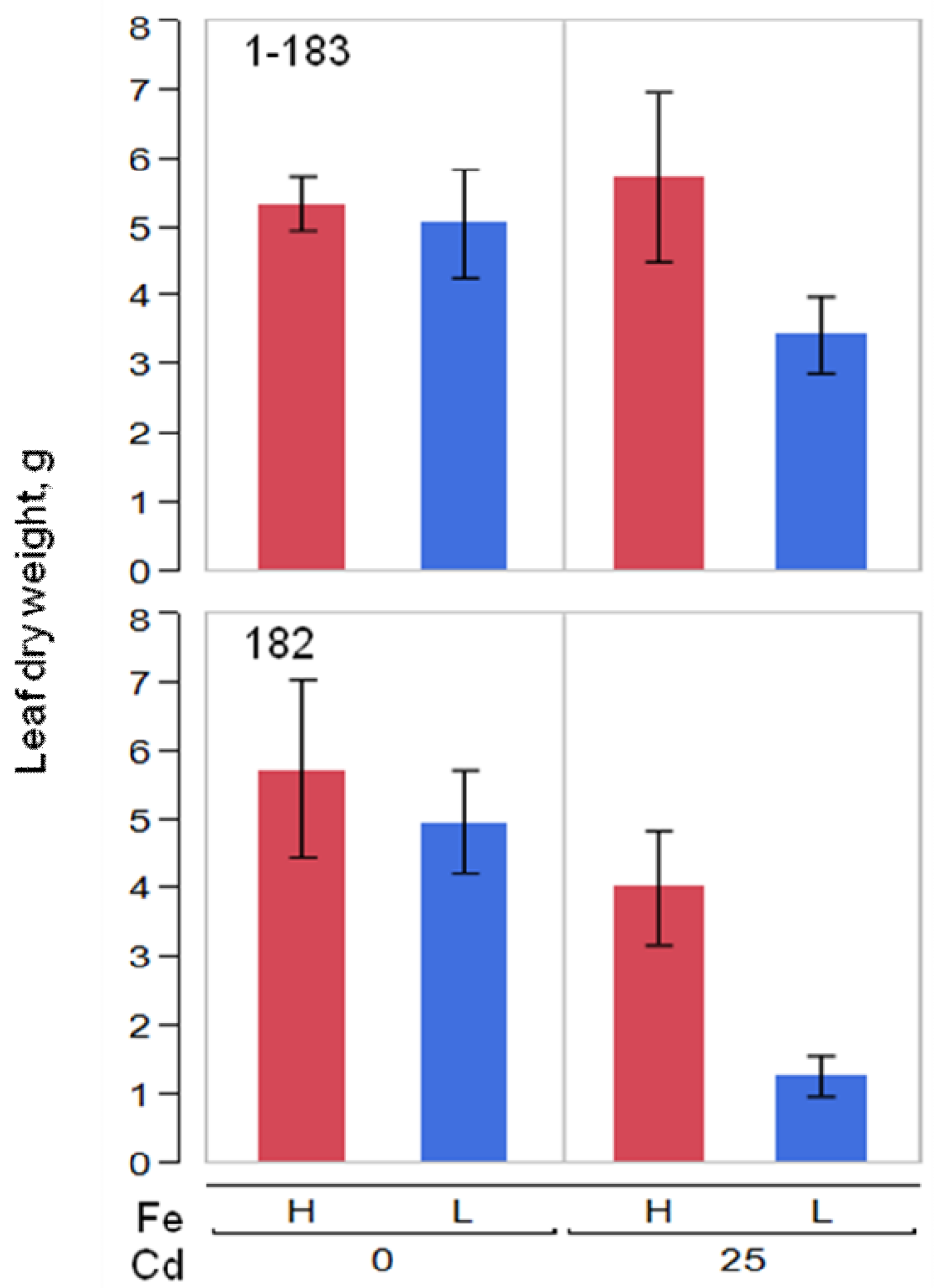

Figure 4.7. Leaf dry weight at different levels of $\mathrm{Cd}$ and Fe. 


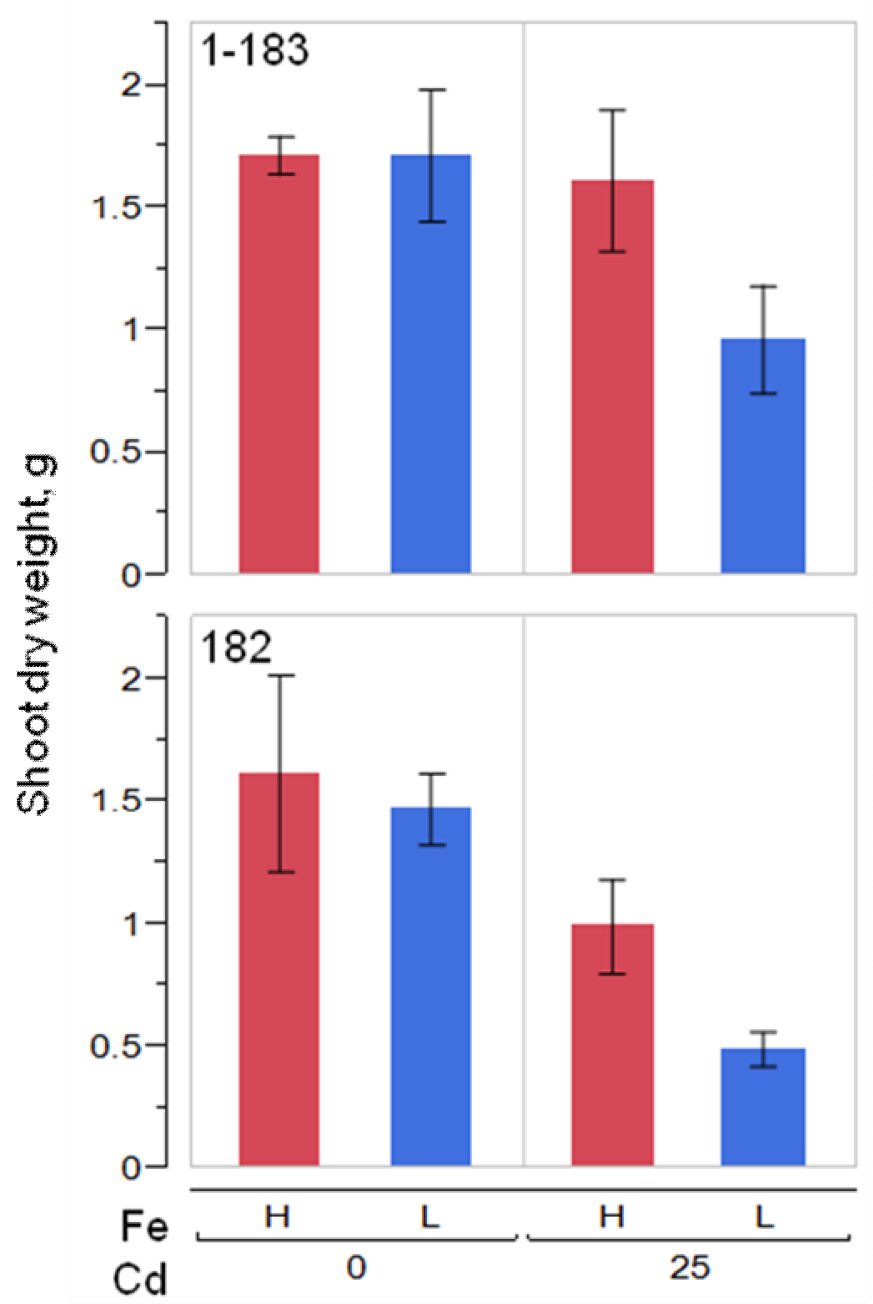

Figure 4.8. Shoot dry weight at different levels of $\mathrm{Cd}$ and Fe. 


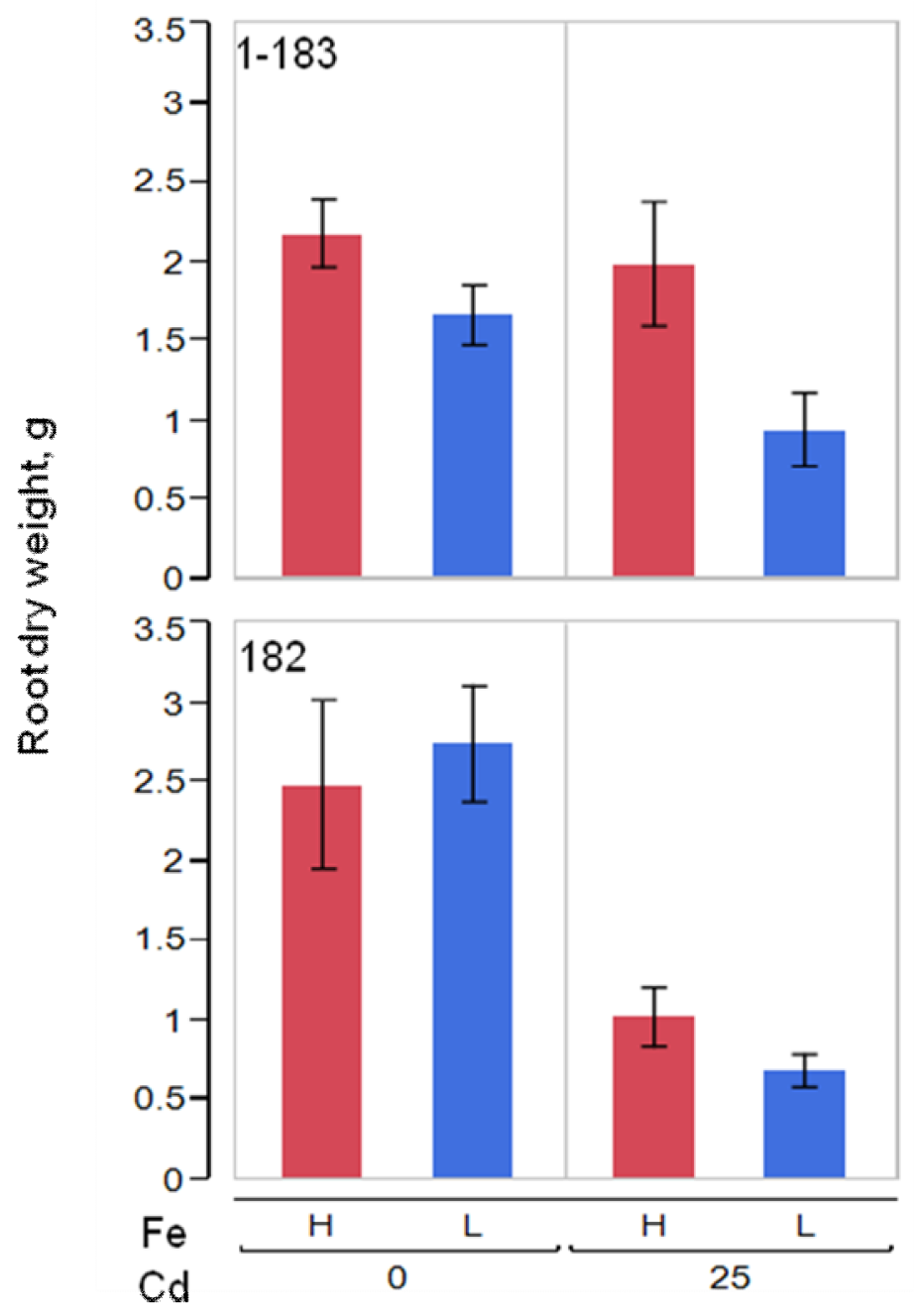

Figure 4.9. Root dry weight at different levels of $\mathrm{Cd}$ and $\mathrm{Fe}$. 


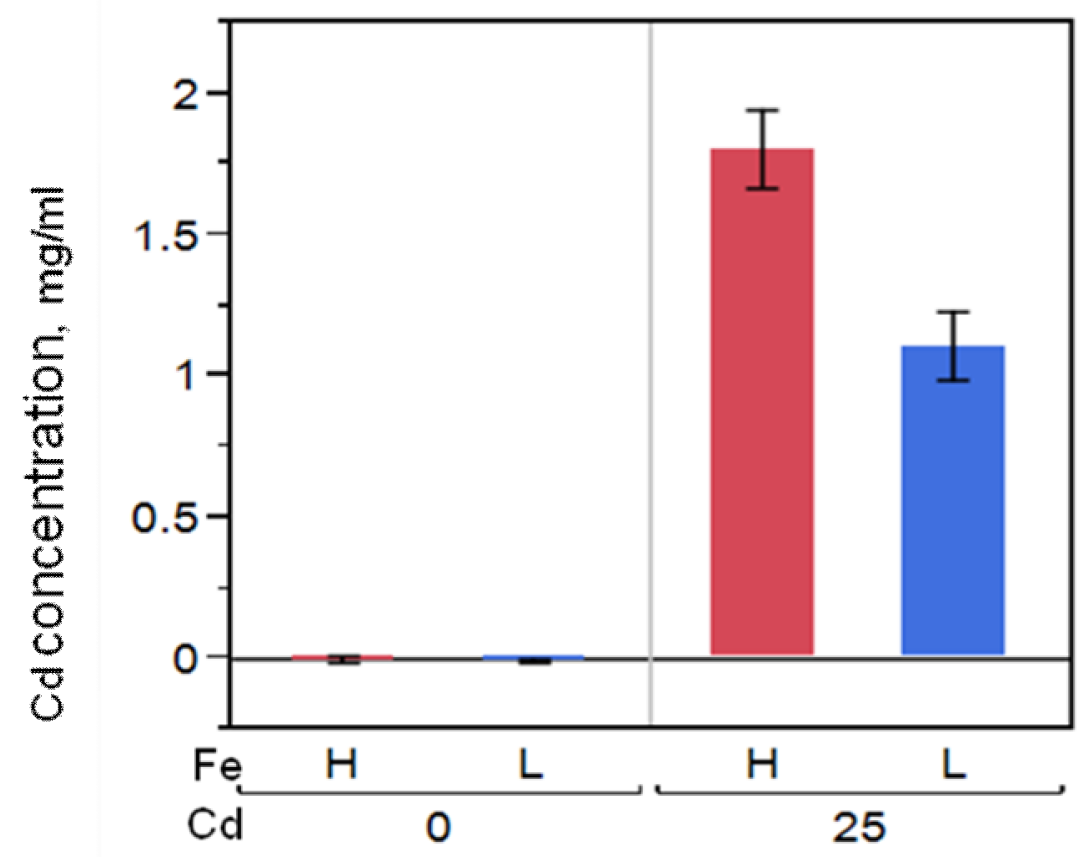

Figure 4.10. Average $\mathrm{Cd}$ content of solutions measured after 3 days for different treatment combinations. 


\section{Discussion}

The present study was aimed at examining the interaction between $\mathrm{Cd}$ and $\mathrm{Fe}$ by studying the effects of low $(0 \mu \mathrm{M})$ and high $\mathrm{Fe}(100 \mu \mathrm{M})$ levels in the presence and absence of Cd on growth and biomass traits of a Cd tolerant genotype (1-183) and a Cd susceptible genotype (182) identified in an earlier Cd screening study of Populus genotypes. This study demonstrated that the effects of $\mathrm{Cd}$ could be mitigated at elevated Fe concentrations, and that the effect differed for the susceptible and tolerant genotypes. This supports our hypothesis, derived from microarray analyses, that differential interactions of $\mathrm{Cd}$ and $\mathrm{Fe}$ occur in these two genotypes and are possibly related to their different levels of $\mathrm{Cd}$ tolerance.

\section{Cd and Fe starvation conditions}

Under $\mathrm{Cd}$ and Fe deficiency conditions, both genotypes showed no significant differences in the change in height and leaf number during the experiment. This is in contrast to a prior study that showed reduced leaf and root growth, chlorophyll content and photosynthetic rate in Populus plants under Cd stress and Fe starvation conditions (Fodor et al., 2005). However, under high Fe and Cd deficiency conditions, both genotypes showed increased, though not significant, growth (Table 4.2). This is consistent with the general trend as Fe is required for growth, photosynthesis and general plant metabolism (Solti et al., 2008). A similar trend was observed for total dry weight and its components including root dry weight, leaf dry weight and shoot dry weight (Table 4.3).

One of the symptoms of Cd toxicity is Fe deficiency (Wallace et al., 1992). This is expected to result in reduced photosynthesis and therefore reduced growth (Sarvari et al., 2001). Cd has previously been shown to reduce Populus leaf growth under Fe deficient conditions (Fodor et al., 2005). A significant reduction in Cd toxicity has also been observed in rice plants 
at high Fe concentrations, and genotypic variation in this effect was apparent (Shao et al., 2007). Reduced Cd accumulation has also been observed in grains, shoot, leaves and roots when EDTA $\cdot \mathrm{Na}_{2} \mathrm{Fe}$ was added to rice plants (Shao et al., 2008). Cd toxicity was also enhanced under Fe deficiency conditions in common bean, and root and leaf $\mathrm{Cd}$ accumulation were enhanced (Siedlecka and Krupa, 1996). Finally, a significant reduction of total dry weight and leaf chlorophyll content was observed when tobacco seedlings were exposed to $100 \mu \mathrm{M} \mathrm{Cd}$ but not at $20 \mu \mathrm{M}$ Cd (Yoshihara et al., 2006). Moreover, Yoshihara et al. (2006) observed that the tobacco seedlings appeared similar when they were treated separately with $100 \mu \mathrm{M} \mathrm{Cd}$ and Fe deficiency.

There were no significant interactions detected between Fe and $\mathrm{Cd}$ detected for the biomass traits in the present study. However, the main effects were significant for most biomass traits. The failure to detect the interaction may be due to the differential responses of the genotypes, which were accounted for with the genotypic main effects. It may also simply be a case of lack of power to detect the effect.

\section{Decreased Cd effects and Fe effects under high Fe level}

Under high Fe, plant height and biomass were similar for the low and high Cd treatments, suggesting that the toxic effects of $\mathrm{Cd}$ were mitigated by the high Fe levels. Contrary to our findings, Fe toxicity was observed in bean plants at $1 \mathrm{mmol} \mathrm{Fe}$ concentrations (Siedlecka and Krupa, 1996) but the current study showed somewhat enhanced growth in both genotypes, suggesting that interaction between $\mathrm{Cd}$ and Fe could be antagonistic or synergistic depending upon on their levels. Analysis of $\mathrm{Cd}$ levels in the hydroponic solutions suggested that $\mathrm{Cd}$ uptake depended on the level of $\mathrm{Fe}$, with low Fe containers showing increased $\mathrm{Cd}$ uptake and high $\mathrm{Fe}$ containers showing reduced $\mathrm{Cd}$ uptake. Increased root to shoot $\mathrm{Cd}$ translocation might have 
occurred in the susceptible genotype compared to the tolerant genotype leading to more Cd toxic effects on it compared to the tolerant genotype.

$\mathrm{Cd}-\mathrm{Fe}$ interaction was stronger on the susceptible genotype compared to the tolerant. The mechanism(s) of Cd-Fe interaction are not clearly understood. In future studies it will be important to explore not only the $\mathrm{Cd}$ and $\mathrm{Fe}$ uptake and distribution patterns but also $\mathrm{Cd}$ immobilization mechanisms in the roots through phytochelatins or non-protein amino acids and/ other chelators (Siedlecka and Krupa, 1999). 


\section{Acknowledgements}

Help from Casey Michalski, Eryn Daugherty and Rachel McCormick in recording observations and during solution changes is greatly appreciated. Louis McDonald and Dorothy Vesper provided invaluable logistical support. 


\section{References}

Alcantara, E., Romera, F.J., Canete, M., Delaguardia, M.D. 1994. Effects of heavy metals on both induction and function of root Fe (III) reductase in Fe deficient cucumber (Cucumis sativus L.) plants. Journal of Experimental Botany 45:1893-1898.

Almeida, A.A.F.de., Valle, R.R., Mielke, M.S., Gomes, F.P. 2007. Tolerance and prospection of phytoremediator woody species of $\mathrm{Cd}, \mathrm{Pb}, \mathrm{Cu}$ and $\mathrm{Cr}$. Brazilian Journal of Plant Physiology 19:83-98.

Allison, J.D., Brown, D.S., Novo-Gradac, K.J., 1991. MINTEQA2/PRODEFA2, A Geochemical Assessment Model for Environmental Systems: Version 3.0. User's Manual. EPA/600/3-91/021.

Besson-Bard, A., Gravot, A., Richaud, P., Auroy, P., Duc, C., Gaymard, F., Taconnat, L., Renou, J.P., Pugin, A., Wendehenne, D. 2009. Nitric oxide contributes to cadmium toxicity in Arabidopsis by promoting cadmium accumulation in roots and by ppregulating genes related to iron uptake. Plant Physiology 149:1302-1315.

Chang, Y.C., Zouari, M., Gogorcena, Y., Lucena, J.J., Abadia, J. 2003. Effects of cadmium and lead on ferric chelate reductase activities in sugar beet roots. Plant Physiology and Biochemistry 41:999-1005.

Clemens, S. 2001. Molecular mechanisms of plant metal tolerance and homeostasis. Planta $212: 475-486$.

Das, P., Samantaray, S., Rout, G.R. 1997. Studies on cadmium toxicity in plants: A review. Environmental Pollution 98:29-36.

Fodor, F., Gaspar, L., Morales, F., Gogorcena, Y., Lucena, J.J., Cseh, E., Kropfl, K., Abadia, J., Sarvari, E. 2005. Effects of two iron sources on iron and cadmium allocation in poplar 
(Populus alba) plants exposed to cadmium. Tree Physiology 25:1173-1180.

Fodor, F., Sarvari, E., Lang, F.R., Szigeti, Z., Cseh, E. 1996. Effects of Pb and Cd on cucumber depending on the Fe-complex in the culture solution. Journal of Plant Physiology 148:434-439.

Gustafsson, J. WinHumicV for Win95/98/NT, 1999. <http://amov.ce.kth.se/people/ gustafjp/winhumicv.htm>. A Windows Version of MINTEQA2 Website, Gustafsson, J.; <http://www.lwr.kth.se/English/OurSoftware/vminteq/index.htm>.

Hurlbert, S.H. 1984. Psuedoreplication and the design of ecological field experiments. Ecological Monographs 54:187-211.

Induri, B.R., Ellis, D.R., Slavov, G.T., Yin, T., Zhang, X., Muchero, W., Tuskan, G.A., DiFazio, S.P. 2012. Identification of quantitative trait loci and candidate genes for cadmium tolerance in Populus. Tree Physiology 32:626-638.

Kabata Pendias, A., Pendias, H. 1992. Trace Elements in Soils and Plants. Boca Raton, FL: CRC Press.

Liu, J., Reid, R.J., Smith, F.A. 2000. The mechanism of cobalt toxicity in mung beans. Physiologia Plantarum 110:104-110.

Liu, J.G., Liang, J.S., Li, K.Q., Zhang, Z.J., Yu, B.Y., Lu, X.L., Yang, J.C., Zhu, Q.S. 2003. Correlations between cadmium and mineral nutrients in absorption and accumulation in various genotypes of rice under cadmium stress. Chemosphere 52:1467-1473.

Lombi, E., Tearall, K.L., Howarth, J.R., Zhao, F.J., Hawkesford, M.J., McGrath, S.P. 2002. Influence of iron status on cadmium and zinc uptake by different ecotypes of the hyperaccumulator Thlaspi caerulescens. Plant Physiology 128:1359-1367.

Meda, A.R., Scheuermann, E.B., Prechsl, U.E., Erenoglu, B., Schaaf, G., Hayen, H., Weber, G., 
von Wiren, N. 2007. Iron acquisition by phytosiderophores contributes to cadmium tolerance. Plant Physiology 143:1761-1773.

Mendoza-Cozatl, D.G., Butko, E., Springer, F., Torpey, J.W., Komives, E.A., Kehr, J., Schroeder, J.I. 2008. Identification of high levels of phytochelatins, glutathione and cadmium in the phloem sap of Brassica napus. A role for thiol-peptides in the longdistance transport of cadmium and the effect of cadmium on iron translocation. Plant Journal 54:249-259.

Milone, M.T., Sgherri, C., Clijsters, H., Navari-Izzo, F. 2003. Antioxidative responses of wheat treated with realistic concentration of cadmium. Environmental and Experimental Botany 50:265-276.

Morrissey, J., Guerinot, M.L. 2009. Iron uptake and transport in plants: The good, the dad, and the ionome. Chemical Reviews 109:4553-4567.

Nakanishi, H., Ogawa, I., Ishimaru, Y., Mori, S., Nishizawa, N.K. 2006. Iron deficiency enhances cadmium uptake and translocation mediated by the $\mathrm{Fe}_{2}{ }^{+}$transporters OsIRT1 and OsIRT2 in rice. Soil Science and Plant Nutrition 52:464-469.

Ouariti, O., Boussama, N., Zarrouk, M., Cherif, A., Ghorbal, M.H. 1997. Cadmium- and copper-induced changes in tomato membrane lipids. Phytochemistry 45:1343-1350.

Rodriguez-Serrano, M., Romero-Puertas, M.C., Pazmino, D.M., Testillano, P.S., Risueno, M.C., del Rio, L.A., Sandalio, L.M. 2009. Cellular response of pea plants to cadmium toxicity: cross talk between reactive oxygen species, nitric oxide, and calcium. Plant Physiology 150:229-243.

Rogers, E.E., Eide, D.J., Guerinot, M.L. 2000. Altered selectivity in an Arabidopsis metal transporter. Proceedings of the National Academy of Sciences of the United States of 
America 97:12356-12360.

Sandalio, L.M., Dalurzo, H.C., Gomez, M., Romero-Puertas, M.C., Del Rio, L.A. 2001. Cadmium-induced changes in the growth and oxidative metabolism of pea plants. Journal of Experimental Botany 52:2115-2126.

Sanità Di Toppi, L., Gabbrielli, R. 1999. Response to cadmium in higher plants. Environmental and Experimental Botany 41:105-130.

Sanita Di Toppi, L., Lambardi, M., Pazzagli, L., Cappugi, G., Durante, M., Gabbrielli, R. 1998. Response to cadmium in carrot in vitro plants and cell suspension cultures. Plant Science 137:119-129.

Sarvari, E., Szigeti, Z., Fodor, F., Cseh, E., Varga, A., Zaray, G., Veres, S., Meszaros, I. 2001. Relationship of iron deficiency and the altered thylakoid development in $\mathrm{Cd}$ treated poplar plants. Photosynthesis Research 69:31-32.

Schmidt, W. 2003. Iron solutions: acquisition strategies and signaling pathways in plants. Trends in Plant Science 8:188-193.

Shao, G.S., Chen, M.X., Wang, D.Y., Xu, C.M., Mou, R.X., Cao, Z.Y., Zhang, X.F. 2008. Using iron fertilizer to control $\mathrm{Cd}$ accumulation in rice plants: A new promising technology. Science in China Series C-Life Sciences 51:245-253.

Shao, G.S., Chen, M.X., Wang, W.X., Mon, R.X., Zhang, G.P. 2007. Iron nutrition affects cadmium accumulation and toxicity in rice plants. Plant Growth Regulation 53:33-42.

Shapiro, S.S., Wilk, M.B. 1965. An Analysis of variance test for normality (complete samples). Biometrika 52:591-611.

Siddique, K.H.M., Tennant, D., Perry, M.W., Belford, R.K. 1990. Water use and water use efficiency of old and modern wheat cultivars in a mediterranean type environment. 
Australian Journal of Agricultural Research 4: 431-447.

Siedlecka, A., Krupa, Z. 1996. Interaction between cadmium and iron. Accumulation and distribution of metals and changes in growth parameters of Phaseolus vulgaris. L seedlings. Acta Societatis Botanicorum Poloniae 65:277-282.

Siedlecka, A., Krupa, Z. 1999. Cd/Fe interaction in higher plants - its consequences for the photosynthetic apparatus. Photosynthetica 36:321-331.

Smeets, K., Cuypers, A., Lambrechts, A., Semane, B., Hoet, P., Van Laere, A., Vangronsveld, J. 2005. Induction of oxidative stress and antioxidative mechanisms in Phaseolus vulgaris after Cd application. Plant Physiology and Biochemistry 43:437-444.

Smith, G.C., Brennan, E.G., Greenhalgh, B.J. 1985. Cadmium sensitivity of soybean related to efficiency in iron utilization. Environmental and Experimental Botany 25:99-106.

Solti, A., Gaspar, L., Meszaros, I., Szigeti, Z., Levai, L., Sarvari, E. 2008. Impact of iron supply on the kinetics of recovery of photosynthesis in Cd-stressed poplar (Populus glauca). Annals of Botany 102:771-782.

Thomine, S., Wang, R.C., Ward, J.M., Crawford, N.M., Schroeder, J.I. 2000. Cadmium and iron transport by members of a plant metal transporter family in Arabidopsis with homology to NRAMP genes. Proceedings of the National Academy of Sciences of the United States of America 97:4991-4996.

Vanassche, F., Clijsters, H. 1990. Effects of metals on enzyme activity in plants. Plant Cell and Environment 13:195-206.

Vasyukova, E., Pokrovsky, O.S., Viers, J., Dupre, B. 2012. New operational method of testing colloid complexation with metals in natural waters. Applied Geochemistry 27, 12261237. 
Vert, G., Grotz, N., Dedaldechamp, F., Gaymard, F., Guerinot, M.L., Briat, J.F., Curie, C. 2002. IRT1, an Arabidopsis transporter essential for iron uptake from the soil and for plant growth. Plant Cell 14:1223-1233.

Wallace, A., Wallace, G.A., Cha, J.W. 1992. Some modifications in trace metal toxicities and deficiencies in plants resulting from interactions with other elements and chelating agents - the special case of iron. Journal of Plant Nutrition 15:1589-1598.

Yoshihara, T., Hodoshima, H., Miyano, Y., Shoji, K., Shimada, H., Goto, F. 2006. Cadmium inducible Fe deficiency responses observed from macro and molecular views in tobacco plants. Plant Cell Reports 25:365-373.

Zhang, G., Fukami, M., Sekimoto, H. 2002. Influence of cadmium on mineral concentrations and yield components in wheat genotypes differing in Cd tolerance at seedling stage. Field Crops Research 77:93-98. 


\section{CHAPTER V}

\section{GENERAL CONCLUSIONS}


Heavy metals released from industrial activity can affect microbial activity and soil fertility and thereby plant growth through several direct and indirect effects (Gu et al., 2007; Durand et al., 2011). Cd is not beneficial to living organisms except for a few marine diatoms (Lane and Morel, 2000). Cd also enters the food chain and can cause various disorders in humans, including lung and prostate cancer and leukemia. The traditional methods of remediation are expensive and ineffective, and disturb the natural topography of the soil. Phytoremediation, the use of plants to remove these pollutants, is an emerging technology that is not only cost-effective but also environmentally friendly. Phytoremediation is 10 times cheaper than the traditional engineering methods (Pilon-Smits, 2005). The plants store the metal in their harvestable plant parts and the metal can be extracted and recycled after harvest. Metal hyperaccumulators typically have short stature and low biomass, which makes them ineffective in metal uptake and storing in harvestable plant parts. There is a need to develop hyperaccumulators of heavy metals. The present study was one of the initial steps in that direction.

In Chapter II, a first of its kind in Populus, I examined phenotypic and genetic variation among full siblings from an interspecific pseudobackcross family, and identified QTL and candidate genes for $\mathrm{Cd}$ tolerance. Extensive phenotypic variation in $\mathrm{Cd}$ tolerance was observed among the genotypes, measured as changes in dry weight. Cd tolerant and $\mathrm{Cd}$ susceptible genotypes were identified which could be a valuable source for future selection and breeding programs targeted at physiological dissection of heavy metal tolerance. Heritabilities were low to moderate, suggesting the variation observed among these genotypes was due to genetic variation. QTL identified in control and Cd conditions were localized to different linkage groups which suggested that QTL location was determined by availability of Cd. A total of 16 QTLs were identified for Cd tolerance located on four different chromosomes. These QTL could aid future 
investigations of phytoremediation and metal tolerance studies through marker assisted selection of superior genotypes.

Candidate genes identified from the underlying Cd QTL intervals were refined using a microarray study that identified genes that were up- and down-regulated in response to Cd. Some of these genes had previously been reported to have roles in heavy metal transport and/or tolerance. These included a chelator specific gene CAD2, $\gamma$-glutamylcysteine synthetase, which was involved in glutathione biosynthesis, a precursor for phytochelatins (Howden et al., 1995), a cation transporter $\mathrm{CHX} 18$, that belongs to a group of vacuolar membrane proteins in the cation exchanger (CAX) subfamily (Mei et al., 2009), a detoxifier GST10, which belongs to the theta group of the superfamily of glutathione S-transferases, GSTs (Brentner et al., 2008) and HMA5 (Heavy Metal ATPase5) involved in heavy metal transport and tolerance (Migeon et al., 2010). This suggested to us that Cd tolerance might have resulted from a combination of tolerance mechanisms rather than a single method of tolerance. Several other genes in the QTL intervals showed transcriptional responses, but were not previously known to be involved in Cd tolerance. One of these, the Arabidopsis thaliana multidrug resistance-associated protein 14 from the superfamily of ATP Binding Cassette $(\mathrm{ABC})$ transporters was one of the most strongly upregulated genes in the $\mathrm{Cd}$ tolerant genotype. Another, encoding a putative membrane protein containing an NHL-repeat domain, was the strongest up-regulated gene in both the genotypes after 24 hours of Cd treatment. Functional characterization of these candidate genes could unravel novel mechanisms of Cd tolerance in Populus and other plants (Induri et al., 2012). These results lay the groundwork for further research in genetic engineering and association genetics to develop Cd tolerant hyperaccumulators that could potentially be used to remediate the extensive marginalized soils polluted with heavy metals, especially $\mathrm{Cd}$. 
For my Chapter III, I compared the QTLs of growth, biomass and phenology traits of the 52-124 Populus pedigree grown under greenhouse and field conditions and across years. Extensive phenotypic variation and transgressive segregation observed in both greenhouse and field trials respectively, suggested heterosis in the pseudo-backcross progeny, which could be used as a source to select better parents for future breeding and hybridization programs. Heritabilities of greenhouse traits were in general lower than those of field traits because of the non-uniform greenhouse conditions and also because of tight spacing between greenhouse plants within a container. Within field traits, heritabilities of 2009 were higher than those of 2008 because of the establishment effect in 2008 plants. Higher heritabilities in general reflected the amount of variation that was attributable to genetic variation and the scope for genetic studies. Heritabilities were highest for bud flush and bud set traits, which suggested that these traits were under the highest genetic control among all the traits studied. High heritabilities, high genetic variation, heterosis and transgressive segregation could be a good source of germplasm for future tree breeding programs in selection of superior hybrid Populus genotypes (Marron et al., 2006).

Detection of 15, 62 and 52 QTLs in greenhouse, 2008 and 2009 seasons respectively, suggested that these traits were genetically controlled by multiple QTL on different linkage groups. Identifying QTLs among correlated and co-localized traits will aid in understanding the genetic relationships among these traits and pave the way for coordinated control of these traits through breeding and genetic engineering. Some of the QTLs were co-localized and intercorrelated, suggesting allometric relationships and/or common genetic mechanisms among these traits. QTL makers could be used to select genotypes with robust growth and biomass traits (Kim et al., 2004). 
Phenotypic plasticity observed in these studies suggested the ability of Populus genotypes in showing varied phenotypes in different environments. Ideally, it would be desirable to have the QTLs from greenhouse traits to be located to the same genomic positions as those under field conditions to avoid extensive field trials for corroborating the results of greenhouse experiments. However, this was only true for a small number of traits, including number of nodes and height to diameter ratio. This suggests that genetic control of these traits did not change across environments and suggested low genotype $\mathrm{x}$ environment interaction. Future studies should be directed to validate these findings across environments. Non-significant correlations between phenology and biomass traits need further detailed studies to validate this finding.

QTLs were tested across years to investigate if the genomic regions governing growth, biomass, and phenology traits change as the plant ages. Traits that are stable across years make better targets for genetic modification in tree improvement programs. Some QTLs for traits including plant height and diameter in the field study were localized to the same positions across years whereas for some traits including sylleptic branching, QTLs changed across years.

Investigating the genes contained within the QTL intervals for these traits should shed more light on the actual genetic mechanisms involved in controlling these traits. Employing genetical genomics approaches (Street et al., 2006; Morreel et al., 2006; Dillen et al., 2009) and association genetics (Neale and Savolainen, 2004; Ingvarsson, 2005) should refine the list of candidate genes for these traits. However, because the intervals are so large, there are hundreds of candidate genes for each QTL, so identification of viable candidates is beyond the scope of this study. 
As demonstrated in Chapter II, it was not surprising that the microarray study showed significant up-regulation of Fe related genes in the $\mathrm{Cd}$ susceptible genotype but not in the $\mathrm{Cd}$ tolerant genotype. Past and current literature showed that $\mathrm{Cd}$ could disturb Fe metal homeostasis in plants (Besson-Bard et al., 2009; Siedlecka and Krupa, 1996). Cd-Fe interaction has been demonstrated in past studies of Populus and other plants (Siedlecka and Krupa, 1996; Solti et al., 2008; Sharma et al., 2004; Shao et al., 2007). Considering this, for my Chapter IV, one Cd tolerant and one Cd susceptible genotype were selected from the Cd QTL hydroponic screening study and the effects of this interaction were examined for growth and biomass traits between these two genotypes. The results of this interaction experiment demonstrated that Cd toxicity increased under Fe deficiency conditions, especially in the Cd susceptible genotype. Both genotypes showed positive response under high $\mathrm{Fe}$ under $\mathrm{Cd}$ stress conditions but high $\mathrm{Fe}$ mitigated Cd toxicity effects more in the susceptible genotype than the tolerant genotype. High Fe mitigated the $\mathrm{Cd}$ toxicity effects possibly through reduced $\mathrm{Cd}$ translocation from roots to shoots. In one such Cd and zinc interaction study (Durand et al., 2011), Cd translocation from roots to shoots appeared to be the limiting factor of Cd toxicity and they suggested that some proteins might be interacting with the metals in the medium thus maintaining metal homeostasis and decreasing their translocation to shoots. Investigating $\mathrm{Cd}$ and $\mathrm{Fe}$ uptake, translocation and distribution patterns should reveal further insights into their mechanism of interaction. Fe nutrition status of the soil was changed to reduce Cd uptake and accumulation in rice (Shao et al., 2007). As Fe was also classified as a heavy-metal, very high Fe levels in the nutrient medium might have Fe toxicity effects as observed in bean plants (Siedlecka and Krupa, 1996). It should be safe to assume that the interaction of $\mathrm{Cd}$ with Fe or any other metal might depend on their concentrations in the nutrient medium rather than by themselves. 
High Fe reduced the Cd uptake and accumulation in rice by inhibiting the expression of the high-affinity iron transport system (Shao et al., 2007). Hyper-accumulators could be produced through enhanced expression of high-affinity iron transporters though genetic engineering thereby increasing the Cd uptake and accumulation (Shao et al., 2007). Similar transgenic techniques could be employed in Populus to develop Cd hyperaccumulators by overexpressing the Fe transporters. Heavily polluted soils including strip mines could be remediated using these Cd hyperaccumulators with great success, assuming mechanisms for Cd tolerance also exist. My work therefore has been successful in generating numerous hypotheses that are worth pursuing for the improvement of Populus as a crop for biofuels production and phytoremediation. 


\section{References}

Besson-Bard, A., Gravot, A., Richaud, P., Auroy, P., Duc, C., Gaymard, F., Taconnat, L., Renou, J.P., Pugin, A., Wendehenne, D. 2009. Nitric oxide contributes to cadmium toxicity in Arabidopsis by promoting cadmium accumulation in roots and by upregulating genes related to iron pptake. Plant Physiology 149:1302-1315.

Brentner, L.B., Mukherji, S.T., Merchie, K.M., Yoon, J.M., Schnoor, J.L., Van Aken, B. 2008. Expression of glutathione S-transferases in poplar trees (Populus trichocarpa) exposed to 2,4,6-trinitrotoluene (TNT). Chemosphere 73:657-662.

Dillen, S.Y., Storme, V., Marron, N., Bastien, C., Neyrinck, S., Steenackers, M., Ceulemans, R., Boerjan, W. 2009. Genomic regions involved in productivity of two interspecific poplar families in Europe. 1. Stem height, circumference and volume. Tree Genetics \& Genomes 5:375-376.

Durand, T.C., Baillif, P., Albric, P., Carpin, S., Label, P., Hausman, J.F., Morabito, D. 2011. Cadmium and Zinc are differentially distributed in Populus tremula $x$ P. alba exposed to metal excess. Plant Biosystems 145:397-405.

Gu, J., Qi, L., Jiang, W., Liu, D. 2007. Cadmium accumulation and its effects on growth and gas exchange in four Populus cultivars. Acta Biologica Cracoviensia Series Botanica 49:7-14.

Howden, R., Andersen, C.R., Goldsbrough, P.B., Cobbett, C.S. 1995. A cadmium sensitive, glutathione deficient mutant of Arabidopsis thaliana. Plant Physiology 107:1067-1073.

Induri, B.R., Ellis, D.R., Slavov, G.T., Yin, T., Zhang, X., Muchero, W., Tuskan, G.A., DiFazio, S.P. 2012. Identification of quantitative trait loci and candidate genes for cadmium tolerance in Populus. Tree Physiology 32:626-638. 
Ingvarsson, P.K. 2005. Nucleotide polymorphism and linkage disequilbrium within and among natural populations of European Aspen (Populus tremula L., Salicaceae). Genetics 169:945-953.

Kim, Y.Y., Kang, B.Y., Choi, H.S., Hong, Y.P., Yeo, J.K., Koo, Y.B. 2004. Identification of QTL (quantitative trait loci) associated with 2-year growth traits of full-sib progenies in Populus davidiana code based on composite interval mapping. Journal of Korean Forestry Society 93:251-264.

Lane, T.W., Morel, F.M.M. 2000. A biological function for cadmium in marine diatoms. Proceedings of the National Academy of Sciences 97:4627-4631.

Marron, N., Bastien, C., Sabatti, M., Taylor, G., Ceulemans, R. 2006. Plasticity of growth and sylleptic branchiness in two poplar families grown at three sites across Europe. Tree Physiology 26:935-946.

Mei, H., Cheng, N.H., Zhao, J., Park, S., Escareno, R.A., Pittman, J.K., Hirschi, K.D. 2009. Root development under metal stress in Arabidopsis thaliana requires the $\mathrm{H}^{+} /$cation antiporter CAX4. New Phytologist 183:95-105.

Migeon, A., Blaudez, D., Wilkins, O., Montanini, B., Campbell, M.M., Richaud, P., Thomine, S., Chalot, M. 2010. Genome-wide analysis of plant metal transporters, with an emphasis on poplar. Cellular and Molecular Life Sciences 67:3763-3784.

Morreel, K., Goeminne, G., Storme, V., Sterck, L., Ralph, J., Coppieters, W., Breyne, P., Steenackers, M., Georges, M., Messens, E., Boerjan, W. 2006. Genetical metabolomics of flavonoid biosynthesis in Populus: a case study. Plant Journal 47:224-237.

Neale, D.B., Savolainen, O. 2004. Association genetics of complex traits in conifers. Trends in Plant Science 9:325-330. 
Pilon-Smits, E. 2005. Phytoremediation. Annual Review of Plant Biology Palo Alto: Annual Reviews 56:15-39.

Shao, G.S., Chen, M.X., Wang, W.X., Mon, R.X., Zhang, G.P. 2007. Iron nutrition affects cadmium accumulation and toxicity in rice plants. Plant Growth Regulation 53:33-42.

Sharma, S.S., Kaul, S., Metwally, A., Goyal, K.C., Finkemeier, I., Dietz, K.J. 2004. Cadmium toxicity to barley (Hordeum vulgare) as affected by varying Fe nutritional status. Plant Science 166:1287-1295.

Siedlecka, A., Krupa, Z. 1996. Interaction between cadmium and iron. Accumulation and distribution of metals and changes in growth parameters of Phaseolus vulgaris $\mathrm{L}$ seedlings. Acta Societatis Botanicorum Poloniae 65:277-282.

Solti, A., Gaspar, L., Meszaros, I., Szigeti, Z., Levai, L., Sarvari, E. 2008. Impact of iron supply on the kinetics of recovery of photosynthesis in Cd-stressed poplar (Populus glauca). Annals of Botany 102:771-782.

Street, N.R., Skogstrom, O., Sjodin, A., Tucker, J., Rodriguez-Acosta, M., Nilsson, P., Jansson, S., Taylor, G. 2006. The genetics and genomics of the drought response in Populus. Plant Journal 48:321-341. 


\title{
CURRICULUM VITAE
}

\author{
BRAHMA REDDY INDURI \\ Department of Biology \\ West Virginia University \\ 53 Campus Drive LSB 5206 \\ Morgantown WV 26506-6057 \\ Phone: 304-276-9179 \\ Fax: 304-293-6363 \\ breddyinduri@gmail.com
}

\section{RESEARCH EXPERIENCE:}

Graduate Research Assistant

August 2006 - August 2007

Department of Biology, West Virginia University.

$>$ Extensive experience in establishing hydroponic experiments.

$>$ Extensive experience in field work including laying out the field, planting, thinning, irrigation, weeding, mulching, spraying pesticides and harvesting

PhD dissertation - Mechanisms of cadmium tolerance in Populus

August 2006 - Present

Department of Biology, West Virginia University.

$>$ Identified Quantitative Trait Loci (QTLs) and candidate genes Cd tolerance after screening 252 Populus genotypes for Cd tolerance.

$>$ Compared the QTLs of growth and biomass traits in the above hydroponic study with the QTLs of growth and biomass traits from a field study conducted over 2 years.

$>$ Studied the influence of Fe on $\mathrm{Cd}$ toxicity and Cd tolerance on growth and biomass traits of Cd tolerant and Cd susceptible genotypes of Populus.

MS thesis - Genetic diversity analysis and morphological characterization of landraces of pigeonpea [Cajanus cajan (L.)]

August 2003 - November 2005

Department of Botany, Mahathma Phule Krishi Vidyapeeth

$>$ Genetic diversity among 150 genotypes of Cajanus cajan (redgram) was assessed, grouped them into 16 genetic clusters and suggested better parents for future hybridization programs.

$>$ These genotypes were also characterized on the basis of morphological characters. 
B.S. - Agriculture Extension Worker, Andhra Pradesh, India

September 2002 - December 2002

$>$ Studied the agronomic practices and socio-economic status of the farmers and suggested sustainable agricultural practices.

\section{EDUCATION:}

\begin{tabular}{|l|l|l|l|}
\hline Degree & Duration & College/ University & Percentage \\
\hline PhD (Biology) & $\begin{array}{l}\text { Fall 2006 } \\
\text { present }\end{array}$ & $\begin{array}{l}\text { West Virginia University, } \\
\text { Morgantown, West Virginia, } \\
\text { United States of America }\end{array}$ & $\begin{array}{l}\text { Current GPA is } \\
\mathbf{3 . 9 0 / 4 . 0 0}\end{array}$ \\
\hline $\begin{array}{l}\text { M.S. (Cytogenetics } \\
\text { \& Plant Breeding) }\end{array}$ & Nov. 2005 & $\begin{array}{l}\text { Mahatma Phule Krishi Vidya } \\
\text { Peeth, Rahuri, Maharashtra, India }\end{array}$ & $\begin{array}{l}\text { Passed out in First } \\
\text { class with 84.6\% }\end{array}$ \\
\hline B.Sc (Agriculture) & Jul. 2003 & $\begin{array}{l}\text { Agricultural College , Bapatla, } \\
\text { Guntur Dist, Andhra Pradesh, } \\
\text { India }\end{array}$ & $\begin{array}{l}\text { Passed out in First } \\
\text { class with 85.9\% }\end{array}$ \\
\hline
\end{tabular}

\section{MANUSCRIPTS:}

Induri, B.R., Ellis, D.R., Slavov, G.T., Yin, T., Zhang, X., Muchero, W., Tuskan, G.A., DiFazio, S.P. 2012. Identification of quantitative trait loci and candidate genes for cadmium tolerance in Populus. Tree Physiology 32:626-638.

Induri, B.R., Slavov, G.T., Yin, T., Zhang, X., Muchero, W., Tuskan, G.A., DiFazio, S.P. 2012. Quantitative trait loci for growth, biomass and phenology traits in Populus under greenhouse and field conditions. Tree Genetics and Genomes (In preparation).

Dllis, D.R., Induri, B.R., Slavov, G.T., DiFazio, S.P. 2012. Transcriptional profiling of cadmium tolerant and susceptible genotypes of Populus under cadmium and iron exposure (In preparation).

\section{PRESENTATIONS:}

ESA Conference: Oral presentation on the research paper "Mechanisms of cadmium toxicity and tolerance in Populus" at the $95^{\text {th }}$ Ecological Society of America Annual Meeting held at Pittsburgh, PA, USA. Presented by S DiFazio. 


\section{ACADEMIC ACHIEVEMENTS:}

$>$ Secured first class and $1^{\text {st }}$ Rank with distinction in B.S (Agriculture) with $85.9 \%$.

$>$ Leah Williams Graduate Student Summer Scholarship in 2009, Department of Biology, West Virginia University

> Doctoral Student Research Scholarship in 2010, Department of Biology, West Virginia University

$>$ Doctoral Student Travel Grant in 2010, Department of Biology, West Virginia University

$>$ David Fairchild Blaydes Biology Doctoral Dissertation Scholarship, 2012, Eberly College of Arts and Sciences, West Virginia University.

\section{TEACHING EXPERIENCE:}

I taught the laboratory sections of the following courses at the Department of Biology, West Virginia University.

Bio 103 (Introductory Biology): Basis biological concepts including DNA structure, Seed germination were covered in this lab. This lab also covered fields of genetics, ecology, organismal biology. I taught this course for one semester.

Bio 115 (Principles of Biology): Basic principles of modern biology were covered in this introductory biology course. It also covered aspects including ecology and evolution, organismal biology, and cellular and molecular biology. I taught this course for two semesters.

Bio 117 (Introductory Physiology): Different biological principles encompassing the diversity of reproductive, developmental, functional, and integrative mechanisms in plants and animals were discussed in this course. I taught this course for two semesters.

Bio 219 (Living Cell): This course primarily dealt with the structure, function, and diversity of cells with an emphasis on gene expression and cellular phenotype including cell chemistry, energetics, and regulation of cell activities. I taught this course for two semesters.

Bio 321 (Total Science Experience Lab): Cap-stone biological research experience course incorporating diverse learning experiences that take place in the process of being a research scientist. In this course, students were asked to write grant proposals on two-way interaction studies; carry on their own experiments to test their hypotheses; analyze their results statistically; write a manuscript on their experiments, and present their results in a public forum. As a Graduate Teaching Assistant and as an advisor for 20 students in this course, I reviewed their grant proposals and manuscripts. I taught this lab for one semester.

\section{IMPORTANT COURSE WORK:}

\section{Genetics}

Fundamentals of genetics

Molecular genetics 
Biometrical genetics

Cytology - genetics - cytogenetics

Population and quantitative genetics

\section{Plant Breeding}

Fundamentals \& Advanced courses in Principles of Plant Breeding and Botany

Seed production and certification

Breeding for Field crops \& Crop Production

Molecular Biology

\section{Statistics}

Statistical methods

Design of experiments

Genetical statistics

Biometry (SAS-JMP)

Statistical genetics

\section{PROFESSIONAL ACTIVITIES:}

$>$ Biology Graduate Student Association (BGSA) Vice-President, West Virginia University, 4/2010 - 4/2011. Assisted the student body in organizing social, educational and service activities for graduate students of Biology Department.

LANGUAGES: Fluent in English, Hindi, Marathi and Telugu. 